\title{
GEOHIDROLOGÍA DE LA PLANICIE COSTERA DEL RÍO DE LA PLATA MEDIO, PARTIDO DE MAGDALENA
}

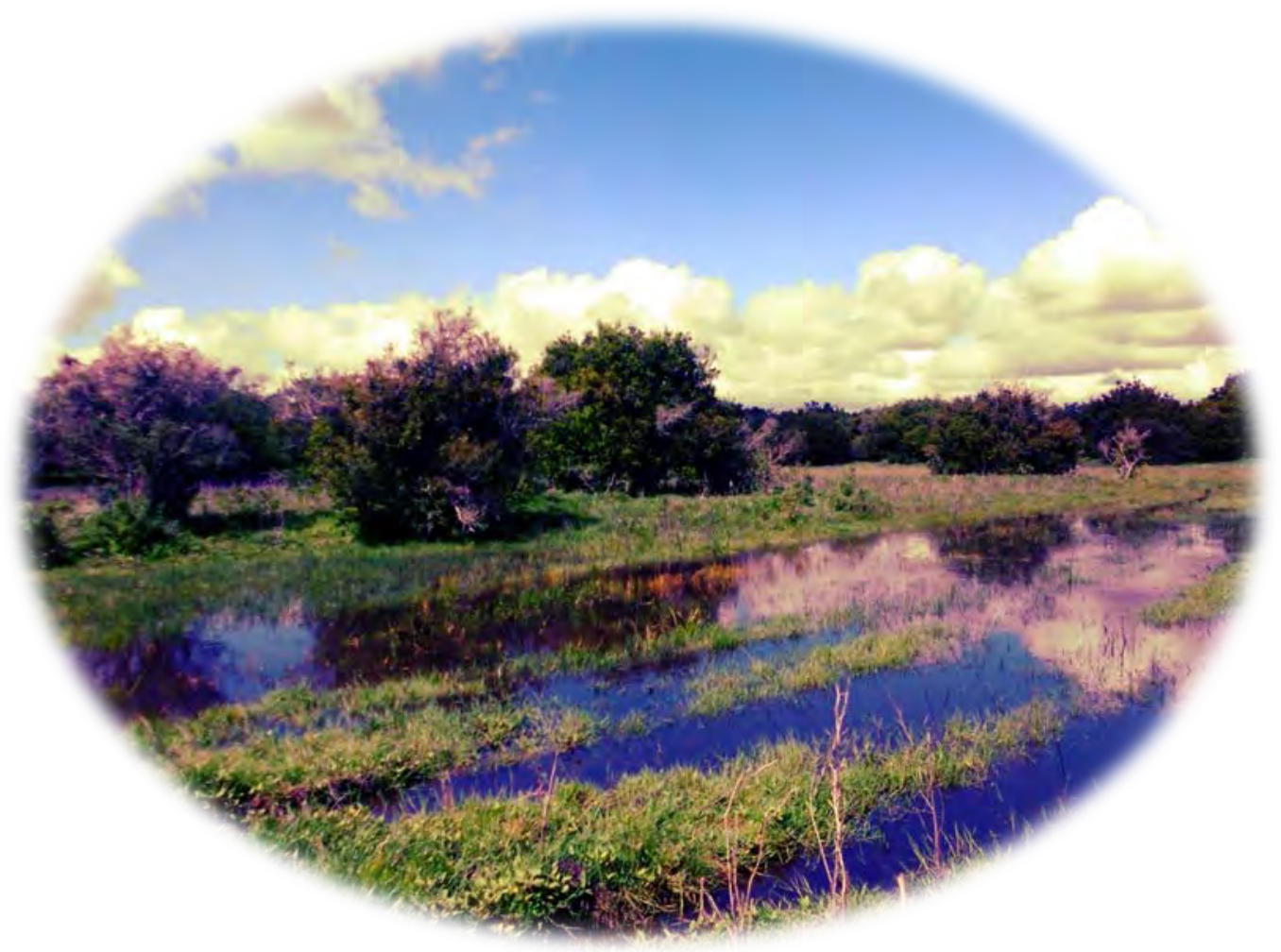

Lic. Marisol Melo

Directora: Dra. Eleonora Carol 


\section{A Gerson y Marco}




\section{AGRADECIMIENTOS}

En especial, a Eleonora Carol por su paciencia, dedicación y apoyo para llevar adelante este proyecto.

A Eduardo Kruse por acompañarme en la primera etapa de este trabajo.

A mis compañeros de trabajo, en especial a Francisco, Lucía, Federico y Esteban por las charlas laborales y las salidas de campo compartidas.

A Macarena Tejada por su amabilidad y docencia durante mi pasantía.

A mis compañeros del Instituto de Investigación en Paleobiología y Geología, especialmente a Alberto Caselli.

A cada una de las personas que nos permitieron el acceso a sus propiedades para poder realizar los trabajos de campo: a Marcela Holguín y Marcelo Montenegro del Establecimiento Juan Blanco, a Sebastián y Marcelo Arriaga de la Estancia Villa Villabona y el tambo, a Verónica Morvillo y Miguel Nisnovich de la Reserva Natural y Cultural El Saladero, a Julio de la Sociedad Rural de Magdalena y a los pobladores de Atalaya y Magdalena. A mi familia y a los amigos por la compañía incondicional en esta etapa.

A Gerson, por estar siempre....

A la Dra. Patricia Laurencena y a los Dres. Jorge Carrica y Luis Vives por sus observaciones y sugerencias en la evaluación de esta tesis, las cuales contribuyeron a mejorar la misma.

Esta tesis se desarrolló con la ayuda económica del Consejo Nacional de Investigaciones Científicas y Técnicas a través del programa de Becas Doctorales. 


\section{RESUMEN}

Las planicies costeras son áreas de abundantes recursos hídricos y ecosistemas de gran diversidad. Estos lugares constituyen ambientes geohidrológicos complejos vulnerables a los cambios naturales y antrópicos. Por lo tanto, el conocimiento del funcionamiento hidrológico de las planicies costeras es fundamental para gestionar sustentablemente el recurso hídrico.

La planicie costera del Río de la Plata es la unidad geomorfológica que caracteriza la costa noreste de la provincia de Buenos Aires, y constituye una planicie estrecha e irregular de rumbo noroeste-sureste que se extiende entre la línea de costa y la llanura loessica. Esta planicie comprende tres subambientes: antigua Ilanura intermareal, planicie con cordones de conchilla y marisma (desde el interior del continente hacia la costa). Sedimentos marinos depositados durante el Pleistoceno-Holoceno caracterizan esta unidad geomorfológica. La llanura loessica presenta un relieve suavemente ondulado formado por depósitos loessicos de edad Pleistocena.

Estudios previos en distintos sectores de la planicie costera del Río de la Plata caracterizaron el funcionamiento geohidrológico de esta unidad y evidenciaron modificaciones vinculadas a la actividad antrópica. Particularmente, en la zona litoral del partido de Magdalena, planicie costera del Río de la Plata medio, no se abordaron estudios de detalle sobre la geohidrología de este ambiente que sirvan de base para el uso sustentable del recurso hídrico. Estas circunstancias motivaron el desarrollo de la presente Tesis cuyo objetivo es comprender el funcionamiento geohidrológico de este sector de planicie costera y evaluar los cambios naturales y antrópicos en las distintas componentes del ciclo hidrológico. La Tesis está focalizada en el estudio del acuífero freático desde el punto de vista de su dinámica y química, y su relación con el agua superficial.

En un contexto geohidrológico regional, la planicie costera del Río de la Plata medio en Magdalena es un ambiente de circulación del agua subterránea que proviene de la llanura loessica (zona de recarga) y que descarga en el Río de la Plata. En esta unidad, el agua de las precipitaciones infiltra con poca evaporación y recarga localmente al acuífero freático. Además, el agua de las precipitaciones escurre hacia las zonas deprimidas (p. ej. arroyos y canales de marea) y se evapotranspira. El drenaje superficial en la zona litoral del partido de Magdalena está representado por las cuencas hidrográficas de los arroyos Buñirigo y Juan Blanco, los cuales son efluentes. La cuenca baja de ambos arroyos se ubica en la planicie costera mientras que los sectores de cuenca alta y media se localizan en la llanura loessica. En ambas cuencas se desarrollan principalmente actividades agropecuarias. La actividad industrial en la cuenca media y baja del arroyo Buñirigo modificó la dinámica y la calidad del agua del arroyo. 
El acuífero freático de la planicie costera de Magdalena exhibe variaciones dinámicas y químicas asociadas a las características propias de cada subambiente (antigua llanura intermareal, planicie con cordones de conchilla y marisma) y a los cambios naturales y antrópicos. Respecto a la dinámica del flujo subterráneo, la recarga por infiltración del agua de lluvia es un proceso que se reconoce en todos los subambientes pese a las diferencias de permeabilidad entre estos. En la antigua Ilanura intermareal los antiguos canales de marea interceptan al nivel freático constituyendo zonas de descarga subterránea local. En la planicie con cordones de conchilla, los cordones constituyen zonas de recarga directa preferencial del agua subterránea debido a su morfología positiva y la alta permeabilidad de sus sedimentos, formando lentes de agua dulce. El flujo subterráneo de estas lentes se mueve localmente desde la cresta hacia los bordes de los cordones, descargando en zonas de intercordón. La reducción de la morfología positiva de los cordones de conchilla a causa de las actividades antrópicas produce una disminución en la capacidad de acumular agua dulce que tienen estas geoformas. En cuanto a la química, la antigua llanura intermareal y la planicie con cordones de conchilla presentan una estratificación de las facies hidroquímicas en el acuífero freático. La estratificación hidroquímica estaría controlada por la composición original del agua meteórica, la velocidad del flujo subterráneo y las reacciones químicas producto de la interacción agua subterránea-sedimento. Particularmente, la dinámica y química del agua subterránea de la marisma está regulada por los flujos mareales provenientes del Río de la Plata. Entonces, la dinámica y química del agua subterránea de la marisma es la más variable de todos los subambientes de la planicie costera.

El análisis de nitrato y microorganismos en el acuífero freático demuestra que las zonas de recarga son las áreas más vulnerables al ingreso de contaminantes. La cría intensiva de ganado y los pozos sépticos podrían ser fuentes de aporte de estos contaminantes al acuífero freático, y constituir posibles focos de contaminación puntual.

Los datos originales aportados por este estudio geohidrológico constituyen una base para la gestión sustentable del agua de un sector de la planicie costera del Río de la Plata medio. 


\section{ABSTRACT}

Coastal plains are areas of abundant water resources and ecosystems of great diversity. They are complex geohydrological environments vulnerable to natural and anthropogenic changes. Therefore, the study of the hydrological functioning of these plains is fundamental for the sustainable management of the water resources.

The Río de la Plata coastal plain is the geomorphological unit that characterizes the northeast coast of Buenos Aires province, and constitutes a narrow and irregular NW-SE-trending plain lying between the coastline and the loessic plain. This coastal plain comprises three sub-environments: ancient intertidal plain, plain with shell ridges and marsh (from the interior of the continent toward the coastline). PleistoceneHolocene marine sediments characterize this geomorphological unit. The loessic plain presents a gently undulate topography and consists of Pleistocene loessic deposits.

Previous studies in different sectors of the Rio de la Plata coastal plain characterized the geohydrologic features of this unit and evidenced modifications associated with anthropic activity. Particularly, in the coast of Magdalena (coastal plain of the middle Río de la Plata) detailed geohydrological studies which provide the basis for sustainable management of water resource have not been performed yet. These circumstances led to the execution of this thesis, whose objective is to understand the geohydrological functioning of this sector of the plain and to evaluate the natural and anthropic changes of the hydrologic cycle components. The thesis is focused on the study of the phreatic aquifer from the point of view of its dynamics and chemistry and its relationship with surface water.

In a regional geohydrologic context, the coastal plain of the middle Río de la Plata in Magdalena is a circulation environment of the groundwater that recharge in the loessic plain and discharge in the Río de la Plata. In the coastal plain, rainwater infiltrates with poor evaporation recharging locally the phreatic aquifer. Moreover, rainwater flows toward depressions (e.g. creeks and tidal channels) where evapotranspiration occurs. In this area, surface runoff is represented by the hydrographic basins of the Buñirigo and Juan Blanco effluent creeks. The lower basin of both creeks is in the coastal plain whereas the higher and middle basins are in the loessic plain. Agriculture and livestock mainly develop in both basins. Industrial activity in the middle and lower basin of the Buñirigo creek modified dynamics and water quality of the stream.

The phreatic aquifer of the coastal plain of Magdalena exhibits variations in chemical composition and dynamics associated with both the characteristics of each sub-environment (ancient intertidal plain, plain with shell ridges and marsh) and the anthropic and natural changes. Regarding to groundwater dynamics, rainwater recharge is a process recognized in all sub-environments, despite permeability 
differences. In the ancient intertidal plain, ancient tidal channels intercept the water table forming zones of groundwater local discharge. In the plain with shell ridge, shell ridges constitute preferential recharge areas of groundwater because of their positive morphology and high permeability, forming freshwater lenses. Groundwater local flow in the shell ridges flows from the crest of the ridge towards the areas between ridges. The reduction of the positive morphology of the shell ridges because of anthropic activities produces a decrease in the capacity of accumulation of freshwater on these geoforms. Regarding groundwater chemistry, both the ancient intertidal plain and the plain with shell ridges show a hydrochemical facies stratification of the phreatic aquifer. The stratification would be controlled by the meteoric water composition, the groundwater velocity and the chemical reactions between the groundwater and sediments. Particularly, the chemical composition and dynamics of the marsh groundwater are controlled by tidal flows from the Río de la Plata. Thus, the chemical composition and dynamics of the marsh groundwater are the most variable of the coastal plain sub-environments.

The analysis of nitrate and microorganisms in phreatic aquifer demonstrates that recharge zones are the most vulnerable areas to the entry of pollutants. Feedlots and septick tanks might be the pollutants of groundwater, constituting occurrences of punctual contamination.

Original data provided from this geohydrological study are the basis for sustainably manage of water resources of a sector of the coastal plain of the middle Río de la Plata. 


\section{ÍNDICE}

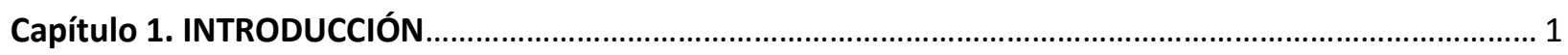

1.1. OBJETIVOS

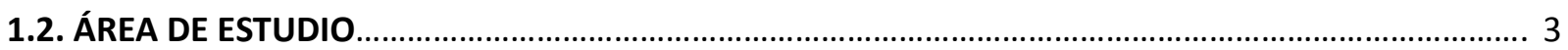

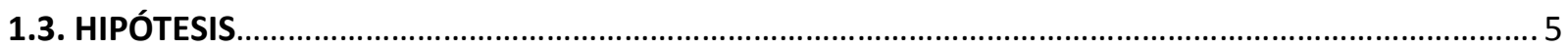

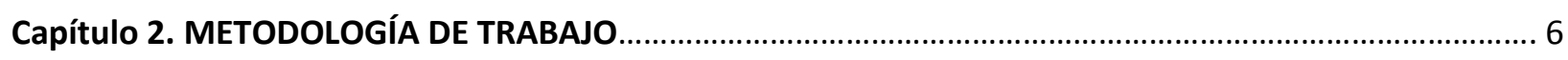

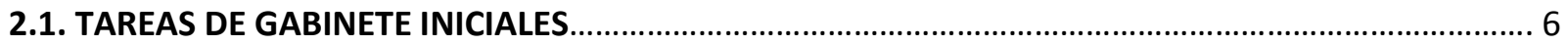

2.1.1. Recopilación de antecedentes bibliográficos y cartográficos del marco regional................... 6

2.1.2. Análisis y elaboración de datos a escala regional (noreste de la provincia de Buenos Aires) 6

2.1.3. Análisis y elaboración de datos en las cuencas de los arroyos Buñirigo y Juan Blanco...........7

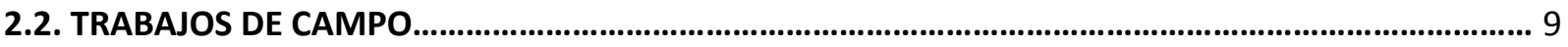

2.2.1. Relevamientos geohidrológicos en las cuencas de los arroyos Buñirigo y Juan Blanco.......... 9

2.2.2. Relevamientos geohidrológicos en el área de planicie costera............................................... 12

2.3. TAREAS DE GABINETE POSTERIORES A LOS TRABAJOS DE CAMPO ............................................... 14

2.3.1. Procesamiento de los datos geohidrológicos para las cuencas de los arroyos Buñirigo y Juan

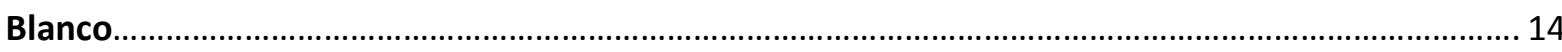

2.3.2. Procesamiento de los datos geohidrológicos para las transectas en el área de planicie

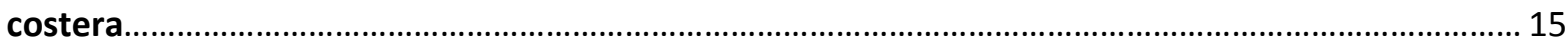

2.3.3. Formulación de modelos conceptuales...................................................................................... 16

Capítulo 3. GEOLOGÍA, GEOMORFOLOGÍA E HIDROGEOLOGÍA DEL NORESTE DE LA PROVINCIA DE BUENOS

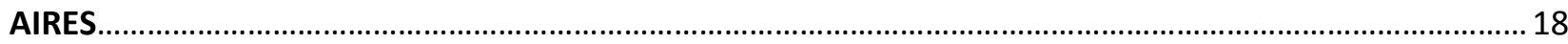

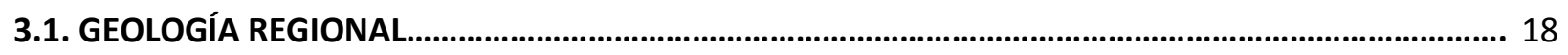

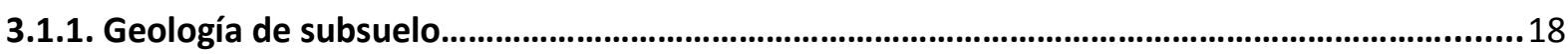

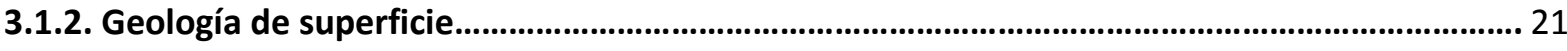

3.2. RASGOS GEOMORFOLÓGICOS Y EDÁFICOS........................................................................................... 24

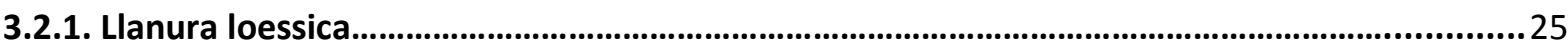

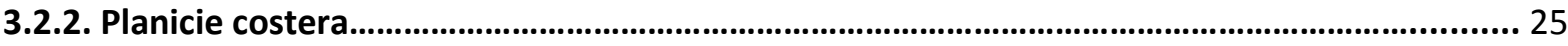

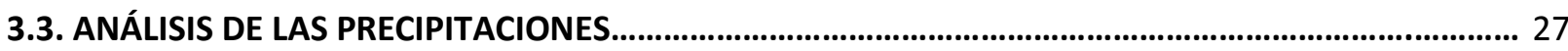


Capítulo 4. LAS CUENCAS DE LOS ARROYOS BUÑIRIGO Y JUAN BLANCO................................................ 36

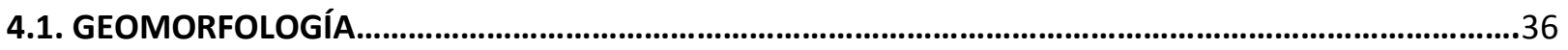

4.1.1. Cuenca alta y media de los arroyos Buñirigo y Juan Blanco.......................................................... 36

4.1.1.1. Llanura loessica............................................................................................................................... 36

4.1.2. Cuenca baja de los arroyos Buñirigo y Juan Blanco .......................................................................... 40

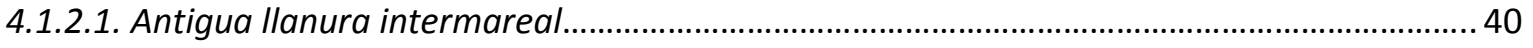

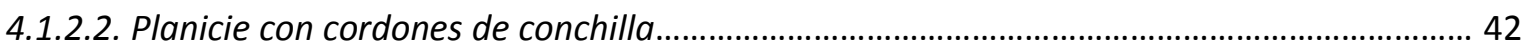

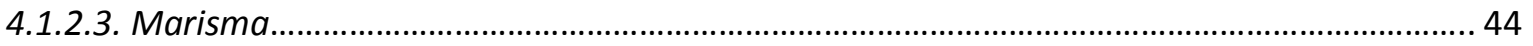

4.2. PRECIPITACIONES Y BALANCE HÍDRICO

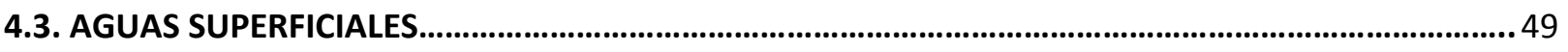

4.3.1. Hidrodinámica............................................................................................................................................. 49

4.3.2. Hidroquímica....................................................................................................................................... 52

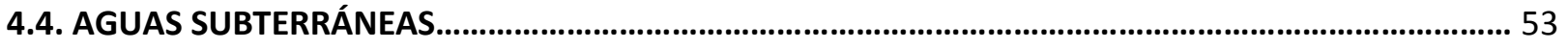

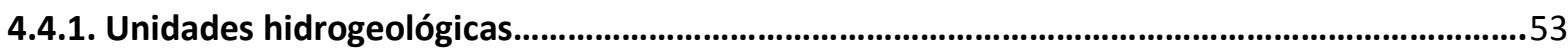

4.4.2. Características hidrodinámicas del acuífero freático................................................................... 55

4.4.3. Características hidroquímicas del acuífero freático................................................................... 59

Capítulo 5. HIDRODINÁMICA DE LA PLANICIE COSTERA DEL RÍO DE LA PLATA MEDIO EN EL LITORAL DEL

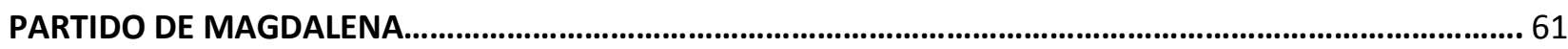

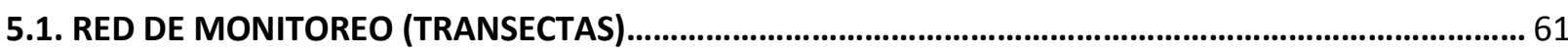

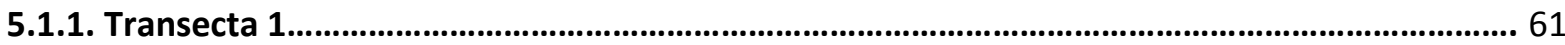

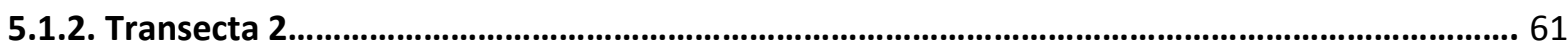

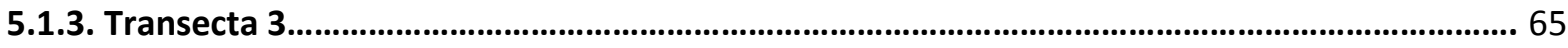

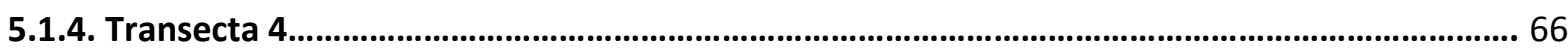

5.2. HIDRODINÁMICA DE LAS UNIDADES GEOMORFOLÓGICAS DE LA PLANICIE COSTERA..................... 66

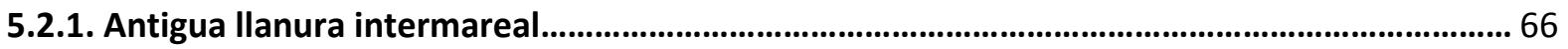

5.2.2. Planicie con cordones de conchilla..................................................................................................69 69

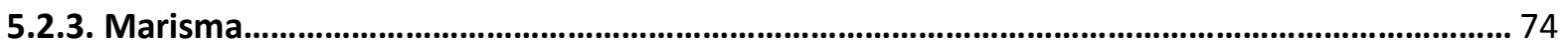


Capítulo 6. HIDROGEOQUÍMICA DE LA PLANICIE COSTERA DEL RÍO DE LA PLATA MEDIO EN EL LITORAL

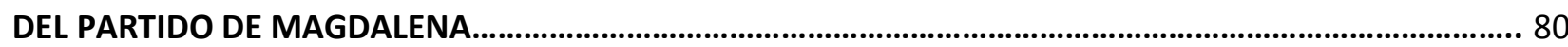

6.1. HIDROQUÍMICA DE LAS UNIDADES GEOMORFOLÓGICAS DE LA PLANICIE COSTERA..................... 80

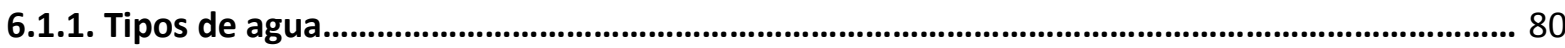

6.1.2. Identificación de procesos geoquímicos a partir de relaciones isotópicas e iónicas................. 88

Capítulo 7. MODELOS GEOHIDROLÓGICOS CONCEPTUALES...........................................................................99

7.1. FUNCIONAMIENTO GEOHIDROLÓGICO REGIONAL DE LA PLANICIE COSTERA..................................99

7.2. FUNCIONAMIENTO GEOHIDROLÓGICO DE LOS SUBAMBIENTES QUE COMPONEN LA PLANICIE

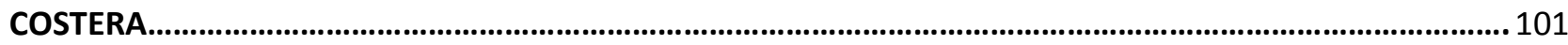

7.2.1. Antigua Ilanura intermareal..................................................................................................................... 101

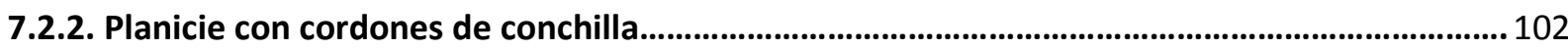

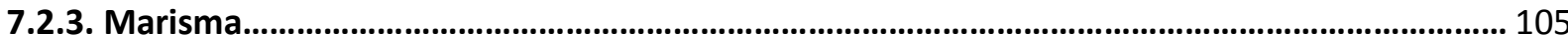

7.3. COMPARACIÓN DEL FUNCIONAMIENTO GEOHIDROLÓGICO DEL LITORAL DEL PARTIDO DE MAGDALENA EN EL CONTEXTO DE LA PLANICIE COSTERA DEL RÍO DE LA PLATA....................................... 105

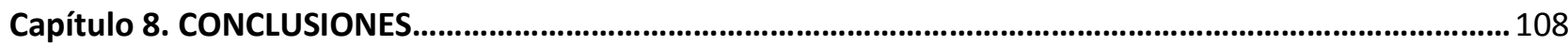

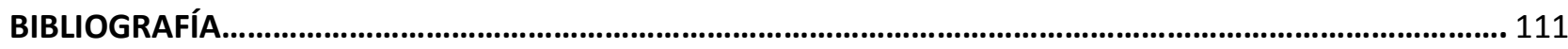

ANEXO I. Muestras de agua analizadas.........................................................................................................118

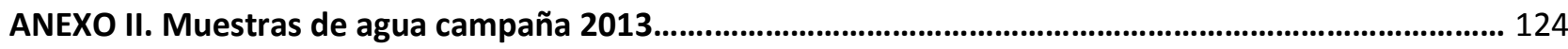

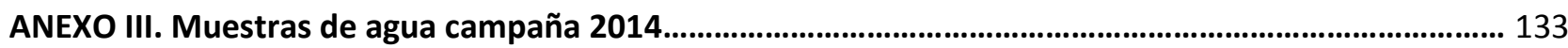




\section{Capítulo 1. INTRODUCCIÓN}

Las áreas costeras sustentan a gran parte de la población mundial y se estima que en la actualidad el $80 \%$ de ella vive a menos de 100 kilómetros de la costa (Arenas Granados, 2010). Asimismo, las áreas litorales contienen los ecosistemas de mayor diversidad y productividad, y sostienen una significativa parte de la actividad portuaria, el transporte, la agricultura, la acuicultura, la industria y el turismo mundiales (Odum, 1979). El creciente desarrollo socioeconómico que se produce en estas áreas determina que sean zonas vulnerables que requieran de estudios de detalle que aporten datos de utilidad para su manejo sustentable.

Dentro de las áreas costeras, las planicies costeras son uno de los ambientes geohidrológicos más complejos donde la dinámica y química del agua superficial y subterránea dependen de la influencia mareal, la geología, la geomorfología y, en aquellas con desarrollo poblacional, también de las actividades antrópicas (Ladouche y Weng, 2005; Montalto et al., 2006; Pousa et al., 2007; Carol et al., 2009, 2011; De Franco et al., 2009; Tosi et al., 2009; Zampella et al., 2010; Moussa et al., 2011; Teatini et al., 2011; Da Lio et al., 2013; Tosi et al., 2013). En este tipo de ambientes tanto los cambios naturales como los inducidos por el hombre pueden generar significativas modificaciones en el funcionamiento hidrológico y su conocimiento resulta una base indispensable para la gestión sustentable del recurso hídrico. Para lograr un uso racional del agua, evitar las posibilidades de contaminación, contribuir al enriquecimiento de las reservas hídricas y conservar los ecosistemas de una región, es necesario comprender el funcionamiento geohidrológico para evaluar los impactos naturales y antrópicos en el ciclo hidrológico.

La planicie costera del Río de la Plata es una unidad geomorfológica que se desarrolla en el litoral noreste y este de la provincia de Buenos Aires, a lo largo de aproximadamente 200 kilómetros de costa (Violante y Parker, 2000; Cavallotto et al., 2005) y limita hacia el sudoeste con la llanura loessica (Carol, 2015; Carol et al., 2017) (Fig. 1.1). Estudios realizados en los sectores de la planicie costera adyacentes a la Ciudad Autónoma de Buenos Aires, el Conurbano y La Plata mostraron que tanto los diversos usos del suelo (constitución de áreas densamente pobladas, polos industriales y petroquímicos, elevación en la cota del terreno para urbanización, creación de lagunas artificiales, alteración de la línea de costa) como la sobreexplotación del agua subterránea alteraron en gran medida el comportamiento hidrológico natural de este sistema (Kruse et al., 2003; Laurencena et al., 2010; Melo et al., 2012; Carol et al., 2013a; López et al., 2013; Santucci et al., 2016, 2017b). Asimismo, sectores menos poblados de la planicie costera también evidencian modificaciones del comportamiento hidrológico natural, principalmente a partir de la actividad minera no sustentable y el desarrollo de obras de ingeniería como las canalizaciones, rutas y terraplenes (Carol et al., 2012a, 2013c, 2015, 2016, 2017; Carol y Kruse, 2012; Cellone et al., 2016; Tanjal et al., 2017b). 


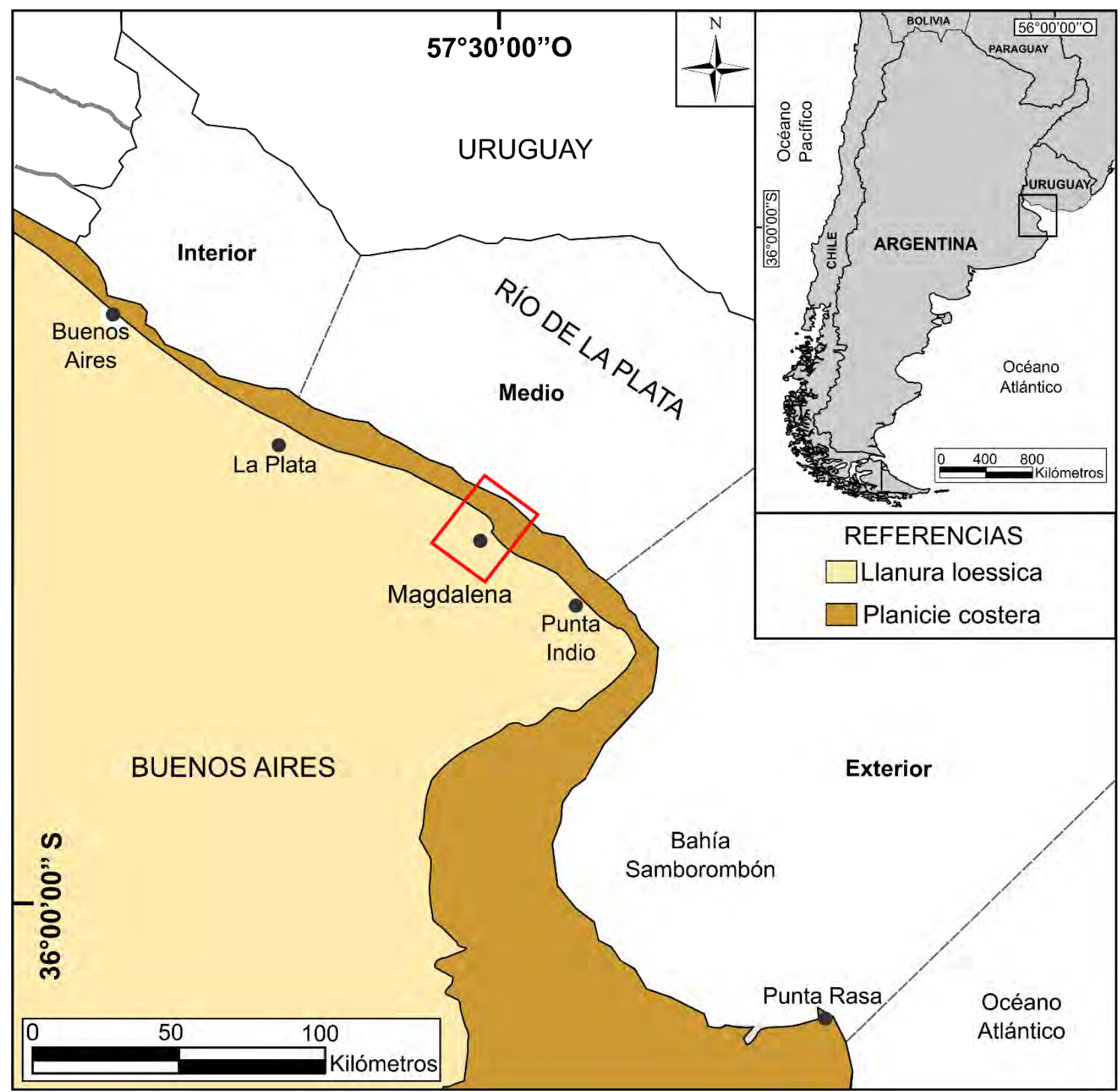

Figura 1.1. Mapa geomorfológico del noreste de la provincia de Buenos Aires y su ubicación en el contexto del extremo sur de Sudamérica. El recuadro rojo indica la ubicación del área de estudio.

Particularmente, en la planicie costera del Río de la Plata medio comprendida en el litoral del partido de Magdalena, no se abordaron estudios de detalle sobre la geohidrología de este ambiente. El principal antecedente de este sector corresponde a un trabajo regional efectuado para todo el noreste de la provincia de Buenos Aires por Sala (1972). Frente a esta situación, el presente estudio está focalizado en el conocimiento integral de la geohidrología de este sector de planicie costera del Río de la Plata medio y en el estudio del acuífero freático desde el punto de vista de su dinámica y química, y su relación con el agua superficial. La importancia de este estudio radica no sólo en caracterizar geohidrológicamente en detalle el 
sector sino también en aportar datos que permitan establecer un equilibrio entre el desarrollo socioeconómico sustentable, las necesidades de agua y la protección de estos ambientes costeros.

\subsection{OBJETIVOS}

El objetivo general del estudio es ampliar el conocimiento actual del ciclo hidrológico en la planicie costera del Río de la Plata. Particularmente, el estudio intenta contribuir a la comprensión del funcionamiento geohidrológico de la planicie costera del Río de la Plata medio en el sector litoral del partido de Magdalena y evaluar los cambios naturales y antrópicos que se reconocen en las distintas componentes del ciclo hidrológico de este sector.

Los objetivos específicos relacionados con los problemas en cuestión son:

* Determinar el comportamiento hidrodinámico e hidroquímico regional y local de las aguas subterráneas y establecer su interacción con las aguas superficiales.

* Definir el funcionamiento geohidrológico en áreas naturales y modificadas por la acción antrópica.

* Elaborar modelos conceptuales de la dinámica y química del agua y de la relación agua subterránea - agua superficial contemplando sus modificaciones como consecuencia de la acción antrópica.

\section{2. ÁREA DE ESTUDIO}

El área de estudio se ubica en el litoral del partido de Magdalena, provincia de Buenos Aires, y comprende principalmente el sector de la planicie costera del Río de la Plata medio correspondiente a las cuenca baja de los arroyos Buñirigo y Juan Blanco (Fig. 1.2). Para comprender de manera integral la geohidrología de la planicie costera también se estudió a escala regional la llanura loessica contigua, particularmente, los sectores de cuenca alta y media de los arroyos mencionados.

El litoral del partido de Magdalena presenta un desarrollo poblacional escaso y principalmente de carácter rural o turístico. Al respecto, en la planicie costera se asienta la localidad de Atalaya que es un pequeño poblado de 720 habitantes (Instituto Nacional De Estadística y Censos, 2010) cuyas principales actividades, en la actualidad, están vinculadas con el turismo, fundamentalmente, en los meses de verano. Sin embargo, a principios de 1900 se asentaba una importante fábrica de cemento la cual se abastecía de materia prima a partir de la explotación de cordones de conchilla de la planicie costera. Hoy en día sólo quedan residuos de la antigua fábrica y numerosas canteras abandonadas se reconocen como relicto de la actividad minera asociada. Además, en esta unidad geomorfológica se desarrollan dos pequeños balnearios 
con viviendas de uso turístico, así como una reserva natural en la margen izquierda del arroyo Buñirigo (Reserva Natural y Cultural El Saladero). El centro poblado más importante es la localidad de Magdalena que se encuentra en la llanura loessica lindante a la planicie costera. Magdalena es la localidad cabecera del partido homónimo y cuenta con una población de 11.093 habitantes (Instituto Nacional De Estadística y Censos, 2010).

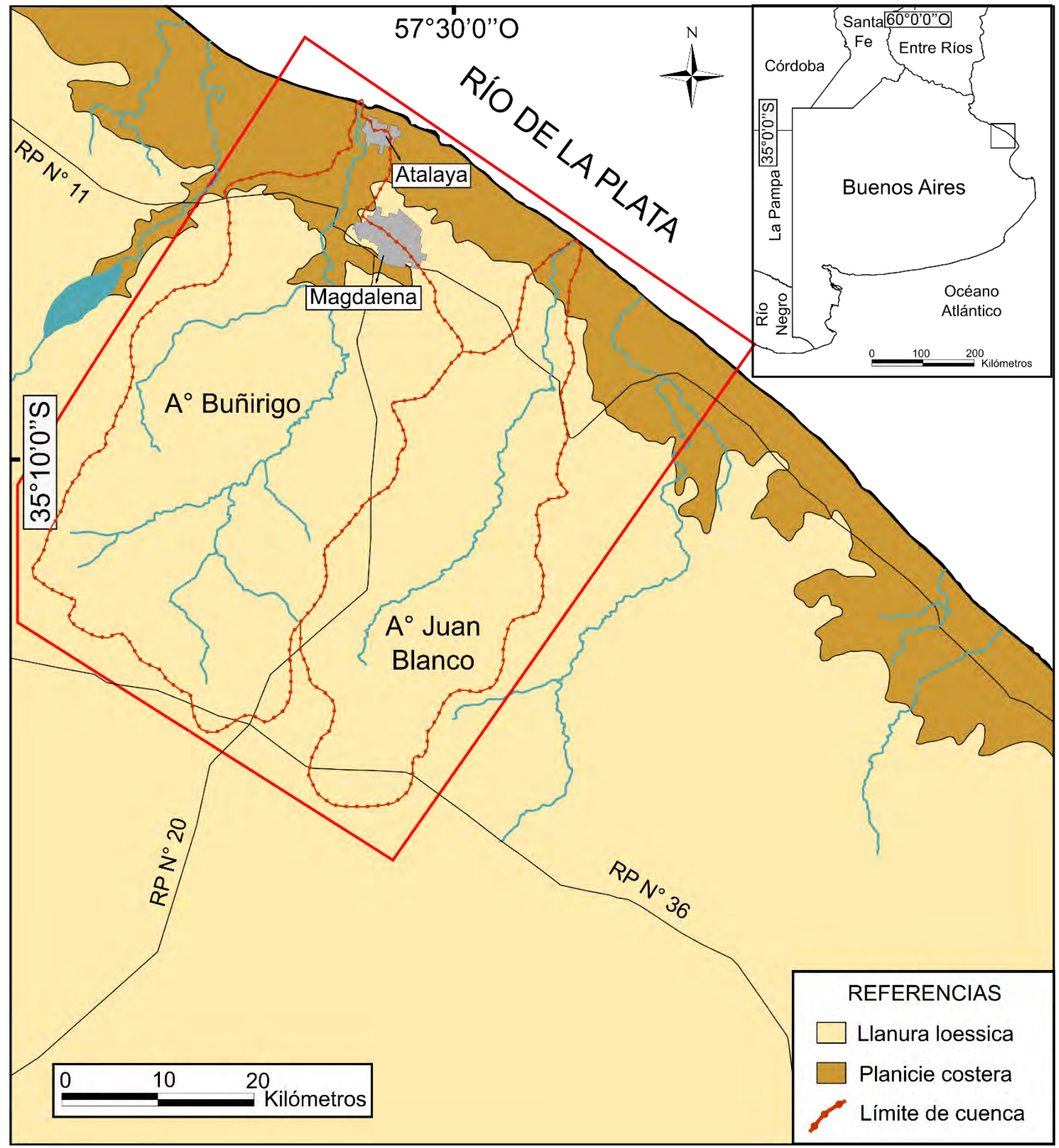

Figura 1.2. Mapa geomorfológico del litoral de Magdalena, sector de la planicie costera del Río de la Plata medio, y su ubicación respecto al noreste de la provincia de Buenos Aires. El mapa incluye la ubicación del área de estudio (polígono rojo) y los límites de las cuencas de los arroyos Buñirigo y Juan Blanco. 


\subsection{HIPÓTESIS}

Se postula como hipótesis que, en condiciones naturales, el funcionamiento geohidrológico de la planicie costera depende principalmente de las características geomorfológicas, geológicas y del balance hídrico local, sumándose a estos factores la influencia mareal en las zonas más costeras. En las áreas de planicie costera en las que se desarrollan actividades antrópicas los cambios inducidos por el hombre generan modificaciones en el funcionamiento geohidrológico que pueden alterar la dinámica y química del agua. 


\section{Capítulo 2. METODOLOGÍA DE TRABAJO}

La base metodológica fundamental que se propone emplear es la observación de los procesos que estuvieron o están sometidos los ambientes costeros comprendidos en el área de estudio. A partir del conocimiento básico del medio natural y modificado por las actividades antrópicas se planificó la medición de variables y la valoración de su influencia hidrológica en cada subambiente de la planicie costera. Con base en esta información se diseñó, a partir de modelos conceptuales, el funcionamiento geohidrológico de la planicie costera considerando las principales variables y los procesos más significativos.

El desarrollo de la tesis contempló una primera instancia de análisis global en un marco regional, y luego en sucesivas aproximaciones de mayor detalle. De esta manera se estudiaron inicialmente las características geohidrológicas regionales del noreste de la provincia de Buenos Aires, en donde se enmarca el área de estudio, y posteriormente se efectuó un estudio geohidrológico de las cuencas de drenaje de los arroyos Buñirigo y Juan Blanco debido a que la cuenca baja de ambos arroyos se ubica en el sector de planicie costera a estudiar. Por último, se trabajó en detalle la hidrología de las distintas unidades geomorfológicas dentro del área de planicie costera del Río de la Plata. Las actividades efectuadas constaron de (1) tareas de gabinete iniciales, (2) trabajos de campo y (3) tareas de gabinete posteriores a los trabajos de campo. En este capítulo se describen en detalle todas las labores realizadas durante estas etapas.

\subsection{TAREAS DE GABINETE INICIALES}

\subsubsection{Recopilación de antecedentes bibliográficos y cartográficos del marco regional}

Se seleccionaron los antecedentes bibliográficos y cartográficos publicados e inéditos (artículos en revistas científicas tanto nacionales como internacionales, libros, actas de congresos, hojas geológicas) referidos a las características geológicas, geomorfológicas e hidrológicas del sector noreste de la provincia de Buenos Aires. La compilación, valoración e interpretación de la información existente definió el contexto hidrogeológico regional donde se enmarca el área de estudio.

\subsubsection{Análisis y elaboración de datos a escala regional (noreste de la provincia de Buenos Aires)}

Con el fin de caracterizar a las unidades geológicas de subsuelo y superficie se trabajó a nivel de cuenca del río Salado, analizando las descripciones realizadas para el sector noreste de dicha cuenca. Para las unidades de subsuelo se realizaron dos secciones estratigráficas basadas en el trabajo de Yrigoyen (1975), 
mientras que para las unidades de superficie se realizó un mapa y un perfil geológico basado en el trabajo de Fucks et al. (2010).

El mapa con las principales unidades geomorfológicas fue confeccionado en función de la bibliografía antecedente, cartas topográficas a escala 1:50.000 del Instituto Geográfico Nacional e imágenes satelitales de alta resolución de Google Earth ${ }^{\mathrm{TM}}$. El mapa de dominios edáficos para las unidades geomorfológicas se elaboró según el trabajo de Salazar Lea Plaza y Moscatelli (1989). Por su parte, el mapa de las regiones hidrogeológicas de la provincia de Buenos Aires y la descripción de las unidades hidrogeológicas se realizó sobre la base del trabajo de González (2005).

La tendencia regional de las precipitaciones se interpretó según los datos históricos de tres estaciones meteorológicas cercanas al área de estudio: La Plata, Punta Indio y Dolores. La interpretación se realizó para un período de 84 años (1925 - 2009) a partir de datos procedentes del Servicio Meteorológico Nacional. Los datos fueron analizados estadísticamente y se elaboraron gráficos con las precipitaciones medias anuales y mensuales para esa serie de años.

Para determinar las disponibilidades de agua en el suelo, se realizó un balance hídrico seriado (Pascale y Damario, 1977) del periodo 2000 - 2009 para cada una de las estaciones meteorológicas (La Plata, Punta Indio y Dolores). Con el balance hídrico, basado en la metodología de Thornthwaite y Mather (1957), se calculó para cada uno de los años del periodo un balance y, a partir de dicha información, se establecieron las diferentes situaciones de déficits y excesos hídricos en cada año para caracterizar el régimen hidrológico regional en el que se enmarca el área de estudio. Los datos utilizados para la confección de cada uno de los balances corresponden a promedios mensuales de precipitación y evapotranspiración potencial mensual (ETP) la que fue calculada mediante el método de FAO Penman - Monteith (Allen et al. 1994, 2006). La reserva de agua útil máxima del suelo se estableció en un valor de $100 \mathrm{~mm}$ teniendo en cuenta las características del suelo de la región estudiada. Para el cálculo de la ETP mensual se utilizó el software ETO Calculator y los datos de entrada utilizados corresponden a las variables de temperatura máxima y mínima del aire, humedad relativa del aire, presión de vapor y velocidad del viento.

\subsubsection{Análisis y elaboración de datos en las cuencas de los arroyos Buñirigo y Juan Blanco}

Se elaboró cartografía geomorfológica, hidrológica y de suelos de las cuencas de los arroyos Buñirigo y Juan Blanco. Para esto se integraron en el Sistema de Información Geográfica libre QGIS (http://www.qgis.org):

*Cartas topográficas del Instituto Geográfico Nacional a escala 1:50.000 (Magdalena 3557-20-2, Vieytes 3557-20-4, Magdalena Este 3557-21-1 y Álvarez Jonte 3557-21-3) (Fig. 2.1). 
*Fotografías aéreas del año 1984 a escala 1:20.000 (Ministerio de Infraestructura y Servicios Públicos de la provincia de Buenos Aires).

*Cartas de suelos del Instituto Nacional de Tecnología Agropecuaria (INTA) a escala 1:50.000 (Magdalena 3557-20-2, Vieytes 3557-20-4, Magdalena Este 3557-21-1 y Álvarez Jonte 3557-21-3).

*Imágenes satelitales de libre acceso y resolución espacial media (LYSAT-8 y SENTINEL-2 http://lv.eosda.com) y alta (mosaico de imágenes satelitales de alta resolución de Google Earth ${ }^{\text {TM}}$; Fig. 2.2).

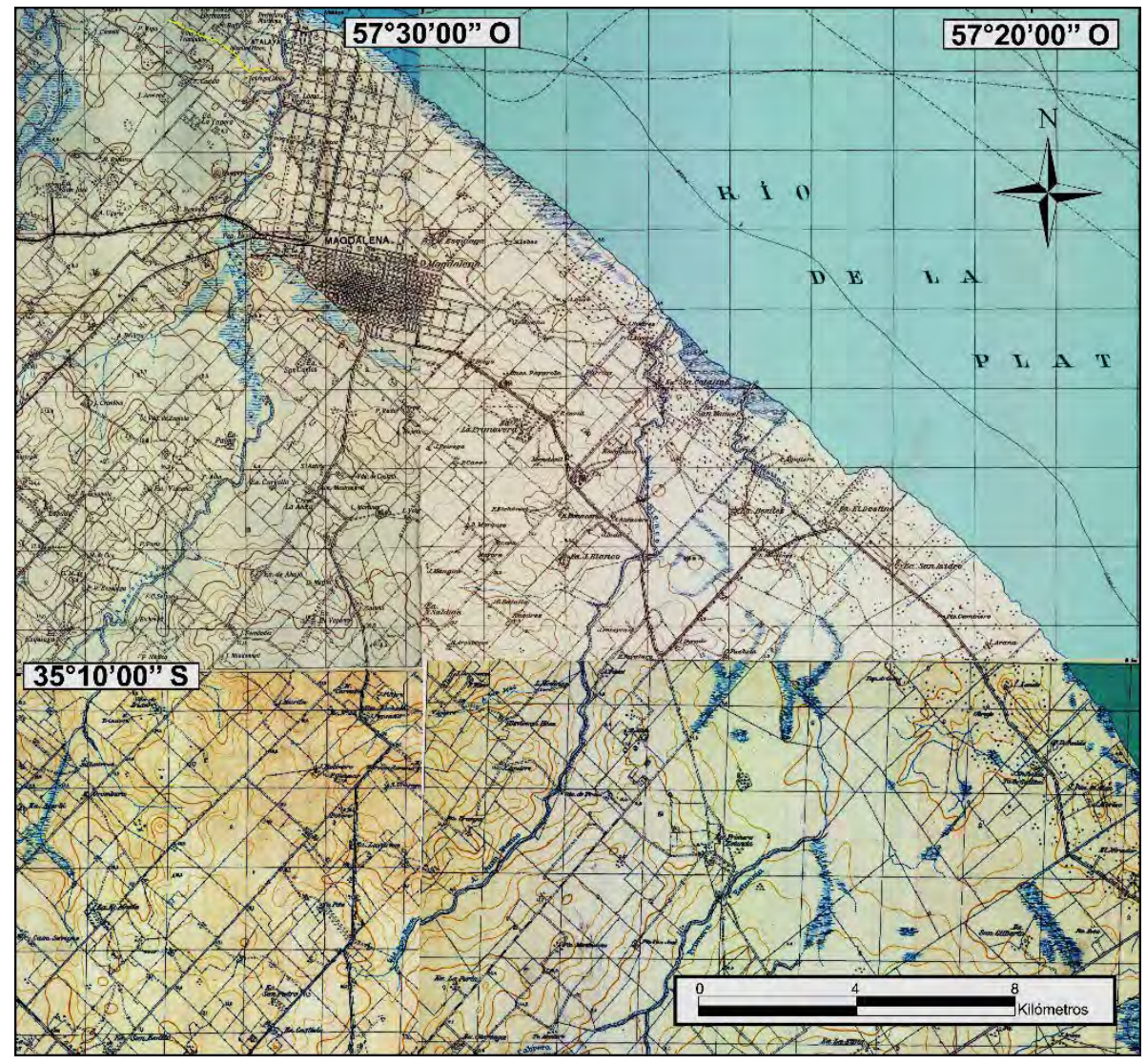

Figura 2.1. Extracto del mosaico a escala regional de las cartas topográficas utilizadas en la confección de los mapas preliminares.

El mapa geomorfológico se confeccionó en función de la interpretación de las cartas topográficas, fotografías aéreas e imágenes satelitales de alta resolución. Se identificaron las principales unidades geomorfológicas tanto de la llanura loessica como de la planicie costera del Río de la Plata. Con esta información de base también se elaboró el mapa hidrológico con las cuencas de los arroyos Buñirigo y Juan Blanco y se identificaron, además de los cursos principales, rasgos de drenajes menores como cañadas, canales y zonas de drenaje intermitente. Completa la cartografía, para esta escala de trabajo, el mapa de tipos de suelos el cual se elaboró a partir de la digitalización de las cartas de suelos del Instituto Nacional de Tecnología Agropecuaria. 
Todos los mapas anteriormente mencionados sirvieron como base para los relevamientos geohidrológicos efectuados en los trabajos de campo y para la definición y diseño de la red de monitoreo de agua superficial y subterránea a nivel de cuenca hidrográfica. En función de esto se realizó la caracterización hidrodinámica e hidroquímica a nivel de cuenca abarcando no sólo el área de planicie costera sino también el área de llanura loessica adyacente.

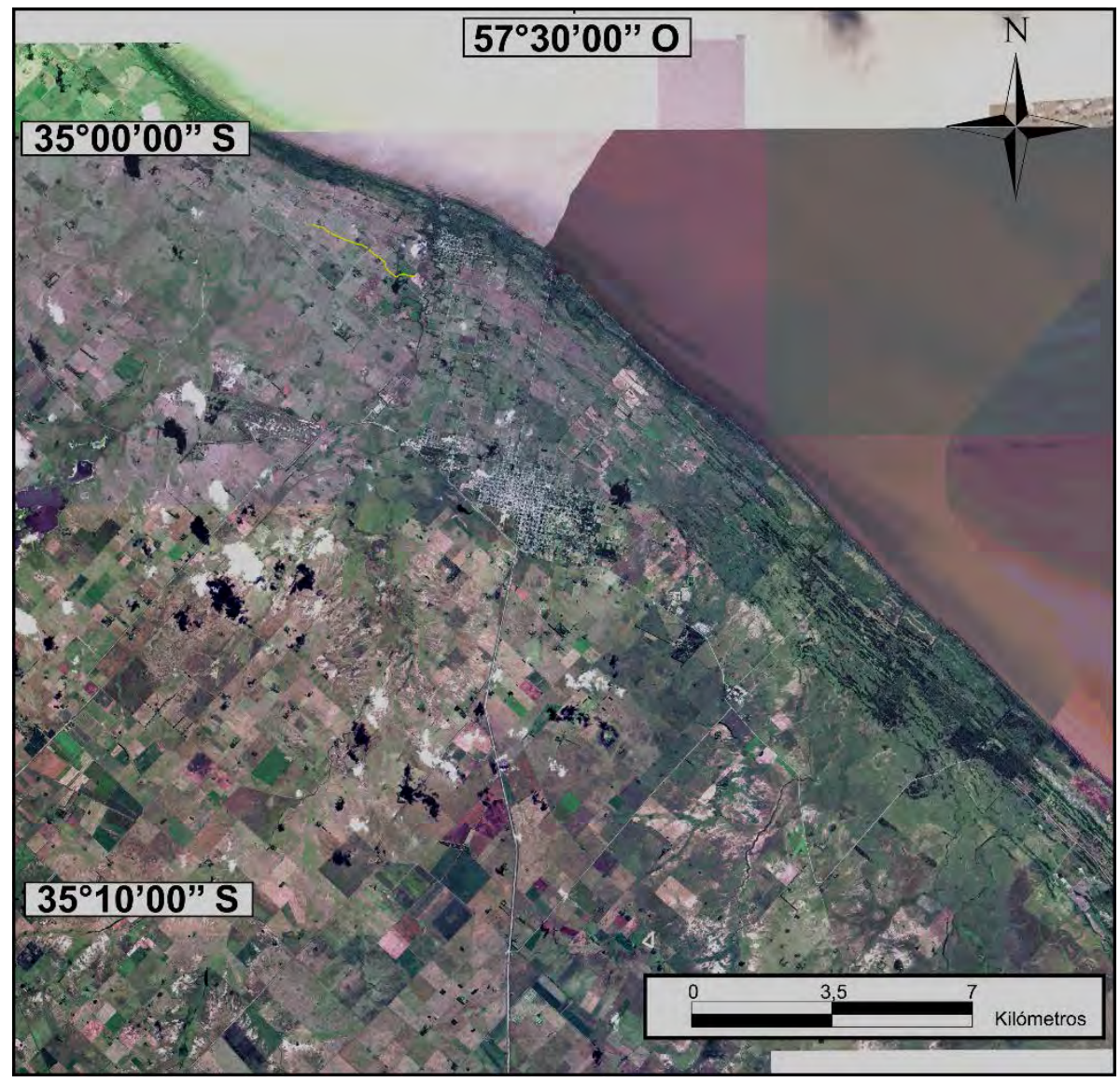

Figura 2.2. Extracto a escala regional de las imágenes de alta resolución de Google Earth ${ }^{\mathrm{TM}}$ utilizadas en la confección de los mapas preliminares.

\subsection{TRABAJOS DE CAMPO}

\subsubsection{Relevamientos geohidrológicos en las cuencas de los arroyos Buñirigo y Juan Blanco}

Con el apoyo de la cartografía de base, en los meses de marzo, abril y mayo de 2013, se realizó un reconocimiento del área de estudio. Durante el trabajo de campo se identificó la geomorfología y geología de las distintas unidades. Se relevaron puntos de medición y muestreo de agua subterránea (perforaciones domiciliarias y molinos de viento en la localidad de Magdalena y Atalaya) contemplando que la distribución de los mismos comprenda tanto el área de planicie costera del Río de la Plata como la zona de llanura loessica. 
En los sitios seleccionados, se hicieron mediciones de la profundidad de los niveles freáticos, conductividad eléctrica y temperatura del agua subterránea somera y se detallaron las particularidades de cada obra de captación. Además, se realizaron mediciones de conductividad eléctrica y temperatura del agua en los arroyos Buñirigo y Juan Blanco y en el Río de la Plata. Para la medición de la profundidad de los niveles freáticos se utilizó una sonda manual sonora de 10 metros de largo; la conductividad eléctrica y temperatura del agua se midieron con un equipo portátil marca Thermo Scientific Orion 3 Star (Fig. 2.3a).

En alguno de los sitios relevados, se tomaron muestras de agua subterránea y superficial para su posterior análisis en laboratorio. Para el muestreo de molinos y/o pozos con bombas, previo a la toma de la muestra, éstos fueron puestos en funcionamiento por un tiempo prolongado a fin de realizar la purga. El agua fue recogida en botellas de plástico rotuladas de 1 litro. La recolección y preservación de las muestras de agua fue realizada según los protocolos establecidos por la American Public Health Association (1998).

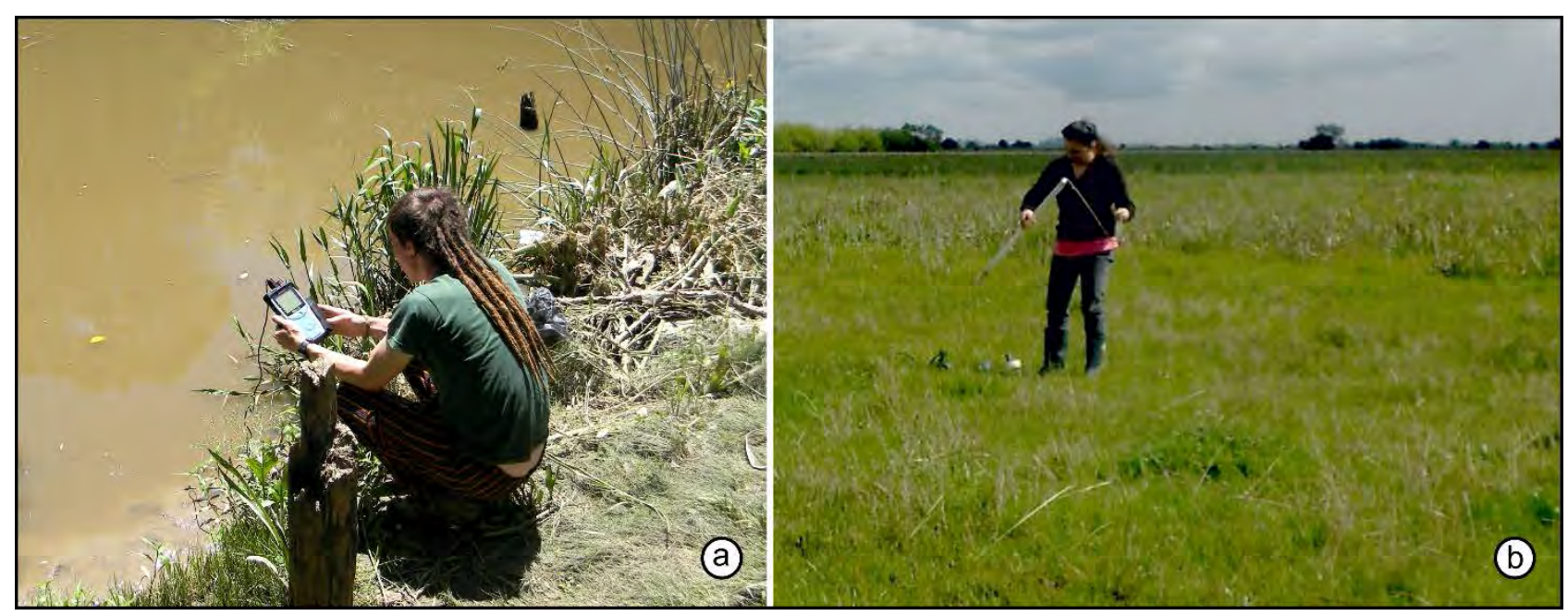

Figura 2.3. Trabajo de campo. (a) Medición de la conductividad eléctrica y temperatura del agua en la cuenca baja del arroyo Buñirigo con el equipo portátil. (b) Toma de una muestra de agua subterránea con un muestreador de tipo bailer en el Establecimiento Juan Blanco.

Las muestras recolectadas durante los trabajos de campo fueron enviadas al laboratorio para la determinación de $\mathrm{pH}$, sólidos totales disueltos (STD), iones mayoritarios (calcio, magnesio, sodio, potasio, bicarbonato, carbonato, sulfato, cloruro) y nitrato. Las determinaciones fueron realizadas por el Grupo de Estudios del Medio Ambiente (G.E.M.A SRL) de la ciudad de La Plata.

Las técnicas analíticas, el código de cada método y el límite de detección para la determinación de los parámetros físico-químicos y químicos se presentan en la tabla 2.1. 
Tabla 2.1. Técnicas analíticas, código de cada método y límite de detección empleados por el Grupo de Estudios del Medio Ambiente (G.E.M.A SRL) para la determinación de los parámetros físico- químicos y químicos del agua.

\begin{tabular}{|c|c|c|c|c|}
\hline DETERMINACIÓN & i & TÉCNICA & MÉTODO & $\begin{array}{c}\text { LÍMITE DE } \\
\text { ¿DETECCIÓN (mg/l) }\end{array}$ \\
\hline Alcalinidad & ! & Titulométrica & SM-2320B & i \\
\hline Carbonato & $\vdots$ & Método de cálculo & SM-2320B & i \\
\hline Bicarbonato & ¡ & Titulométrica & SM-2320B & i \\
\hline Dureza & i & Titulométrica EDTA & SM-2340C & i \\
\hline Calcio & i & Titulométrica EDTA & $i_{i}$ SM-3500-Ca-B & i \\
\hline Cloruro & $\begin{array}{l}\text { i } \\
\vdots \\
i\end{array}$ & $\begin{array}{l}\text { Argentométrica } \\
\text { Método de Mohr }\end{array}$ & SM-4500-Cl & i \\
\hline Magnesio & i & Método de cálculo & i SM-3500-Mg B & $i$ \\
\hline Sodio & ! & $\begin{array}{l}\text { Fotometría de } \\
\text { emisión de llama }\end{array}$ & SM-3500-Na-B & i \\
\hline Potasio & i & $\begin{array}{l}\text { Fotometría de } \\
\text { emisión de llama }\end{array}$ & 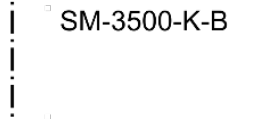 & $\begin{array}{l}\mathrm{i} \\
\mathrm{i} \\
\mathrm{i}\end{array}$ \\
\hline Sulfato & i & Nefelométrica & SM-4500-SO4-E & ! \\
\hline Nitrato & i & Electrodo selectivo & SM-4500-NO3 -D & i \\
\hline Sólidos totales disueltos & ! & $\begin{array}{l}\text { Gravimétrico } \\
\left(105^{\circ} \mathrm{C}\right)\end{array}$ & SM-2540-B & i \\
\hline
\end{tabular}

Para caracterizar la hidrodinámica de los arroyos Buñirigo y Juan Blanco se realizaron mediciones de caudal en la cuenca alta y baja de ambos arroyos con un molinete hidrométrico marca Siap (Fig. 2.4). Las mediciones se realizaron durante los meses de febrero y marzo de 2013 en el arroyo Buñirigo y durante el mes de noviembre de 2013 en el arroyo Juan Blanco. En cada punto de medición de caudal se determinó la sección del cauce con una cinta métrica; cada 10 centímetros se midió la profundidad del cauce con barras de acero graduadas cada 1 centímetro. Las mediciones de velocidad del agua se efectuaron por triplicado utilizándose luego para el cálculo final de caudal el valor promedio. 


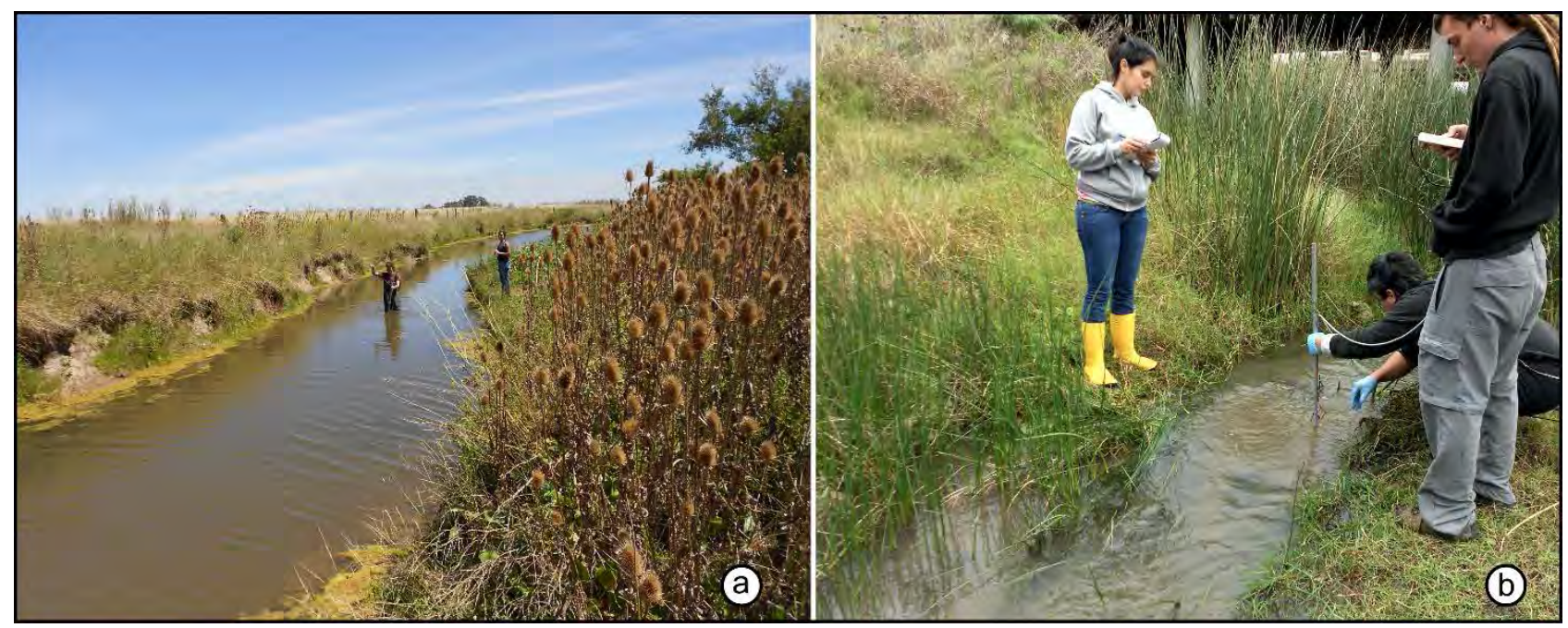

Figura 2.4. Trabajo de campo. Medición de caudal con el molinete hidrométrico en el arroyo Buñirigo. (a) Cuenca alta. (b) Cuenca baja.

\subsubsection{Relevamientos geohidrológicos en el área de planicie costera}

Para el análisis en detalle de la hidrodinámica e hidroquímica del agua superficial y subterránea somera se confeccionó una red de monitoreo a partir de cuatro transectas, perpendiculares a la línea de costa, en los principales subambientes de la planicie costera. Las áreas para las transectas se seleccionaron en base al análisis de la cartografía y datos geohidrológicos relevados en los trabajos de campo a nivel de cuenca de los arroyos Buñirigo y Juan Blanco. Las transectas se establecieron en cuatro sitios: Establecimiento Juan Blanco, Unidad Penitenciaria N ${ }^{\circ} 28$ del partido de Magdalena, Estancia Villa Villabona y Reserva Natural y Cultural El Saladero (Fig. 2.5).

En cada sitio seleccionado para el estudio en detalle se efectuaron relevamientos de campo para el reconocimiento de los rasgos geomorfológicos, geológicos e hidrológicos de cada subambiente de la planicie costera y para el diseño de la red de monitoreo de agua superficial y subterránea somera. Esta última, contempló tanto a perforaciones existentes como a pozos de exploración de agua subterránea somera construidos con un barreno manual. Los pozos se realizaron a 2 metros de profundidad, se entubaron con caño de PVC de 2 pulgadas y fueron diseñados con filtro continuo y prefiltro de grava silícea bien seleccionada. Durante la realización de las perforaciones se efectuó una descripción de las características litológicas de los sedimentos. 


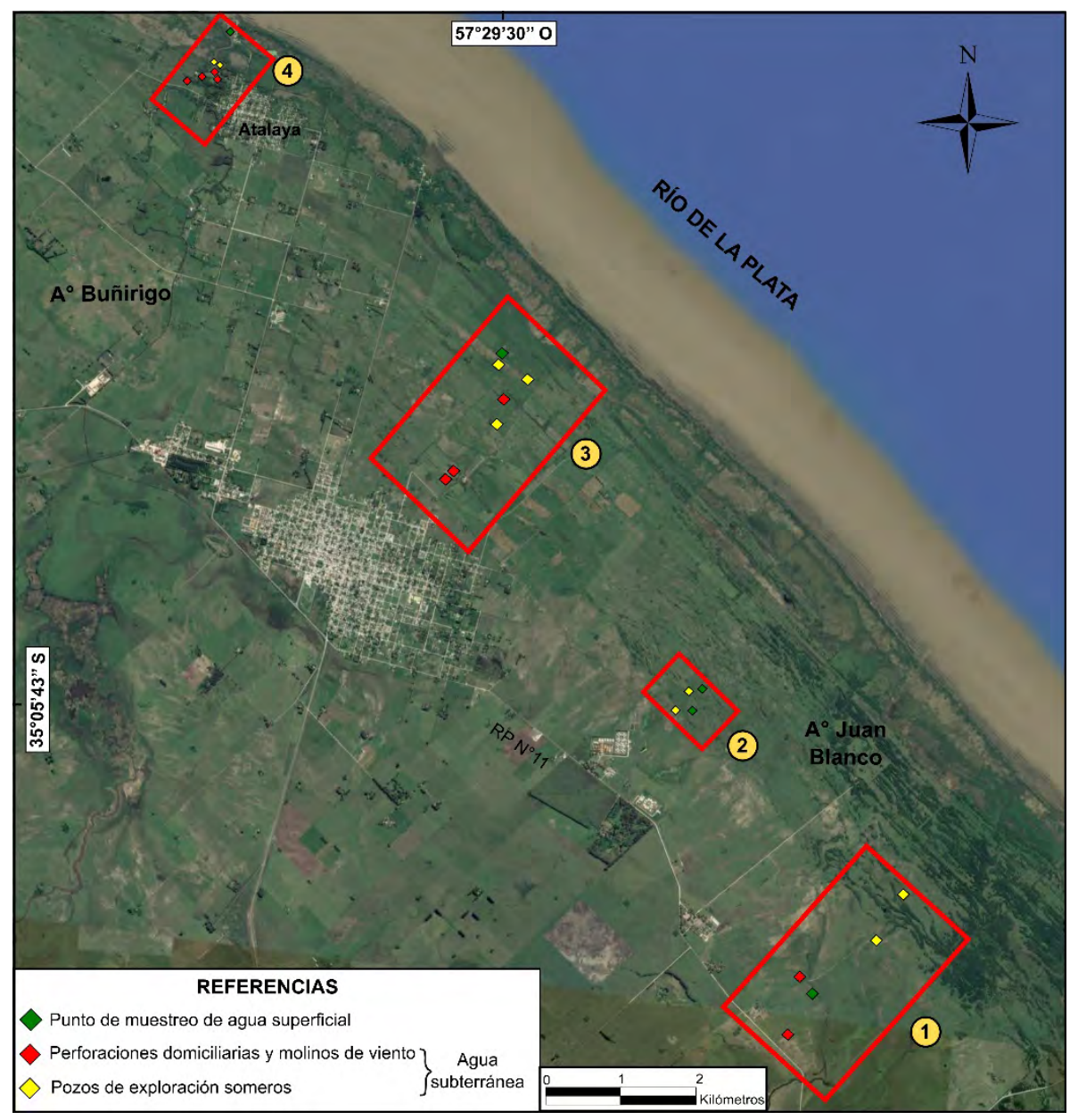

Figura 2.5. Ubicación de las transectas para los relevamientos geohidrológicos de la planice costera. (1) Establecimiento Juan Blanco, (2) Unidad Penitenciaria $\mathrm{N}^{\circ} 28$ del partido de Magdalena (3) Estancia Villa Villabona (4) Reserva Natural y Cultural El Saladero.

En la red de monitoreo de agua superficial y subterránea de cada transecta, la medición de los niveles freáticos se ejecutó con una sonda manual sonora de 10 metros de largo y los parámetros de conductividad eléctrica y temperatura del agua se midieron con un equipo portátil marca Thermo Scientific Orion 3 Star (Fig. 2.3a). Las mediciones se realizaron en los meses de abril y octubre de 2014 para poder establecer comparaciones en la medición de las distintas variables mencionadas.

En el sector correspondiente a la transecta 4, Reserva Natural y Cultural El Saladero, se instalaron sensores de registro continuo de nivel, temperatura y conductividad eléctrica del agua de tipo Levelogger y Barologger marca Solinst. Estos sensores se instalaron por un periodo de 3 meses y fueron relevados cada mes para corroborar su correcto funcionamiento.

En todos los puntos de la red de monitoreo se tomaron, en el mes de abril de 2014, muestras de agua subterránea y superficial para el análisis en laboratorio de iones mayoritarios, nitrato y bromuro. Sólo en algunos sitios se muestreó para la determinación de isótopos de ${ }^{18} \mathrm{O}$ y ${ }^{2} \mathrm{H}$ y microorganismos (bacterias 
coliformes totales y fecales y pseudomonas aeruginosa). Las muestras de agua subterránea somera se obtuvieron con un muestreador de tipo bailer (Fig. 2.3b). Previo a la toma de la muestra, los freatímetros fueron purgados extrayéndose un volumen cercano entre tres y diez veces el volumen contenido en la cañería del pozo para obtener una muestra representativa del acuífero. Las muestras de agua superficial se tomaron directamente del cauce con la botella de muestreo. El agua de todas las muestras fue recogida en botellas de plástico rotuladas de 1 litro. La recolección y preservación de las muestras de agua fue realizada según los protocolos establecidos por la American Public Health Association (1998).

En el laboratorio las muestras tomadas durante los trabajos de campo fueron analizadas para la determinación de pH, STD, iones mayoritarios (calcio, magnesio, sodio, potasio, bicarbonato, carbonato, sulfato y cloruro), nitrato y bromuro, isótopos de ${ }^{18} \mathrm{O}$ y ${ }^{2} \mathrm{H}$ y microorganismos. Las determinaciones químicas y microbiológicas fueron realizadas por el Grupo de Estudios del Medio Ambiente (G.E.M.A SRL) de la ciudad de La Plata. Las técnicas analíticas, el código de cada método y el límite de detección para la determinación de los parámetros físico-químicos y químicos se presentan en la tabla 2.1. El análisis de los isótopos de ${ }^{18} \mathrm{O}$ y ${ }^{2} \mathrm{H}$ se efectuó en el Instituto de Geocronología y Geología Isotópica (INGEIS) de la ciudad de Buenos Aires. Las relaciones isotópicas del hidrógeno $\left({ }^{2} \mathrm{H} /{ }^{1} \mathrm{H}\right)$ y oxígeno $\left({ }^{18} \mathrm{O} /{ }^{16} \mathrm{O}\right)$ se midieron siguiendo la técnica de Coleman et al. (1982) y Panarello y Parica (1984) para ${ }^{2} \mathrm{H} \mathrm{y}{ }^{18} \mathrm{O}$, respectivamente. Las mediciones fueron realizadas por espectroscopia laser en el equipo Los Gatos Research (Lis et al., 2008). Los resultados obtenidos se expresan como $\delta(\%)$ definido como:

$$
\delta=1000 \cdot \frac{R s-R p}{R p} \%
$$

En la ecuación (1), $\delta$ es la desviación isotópica en \%; $R$ s la relación isotópica $\left({ }^{2} \mathrm{H} /{ }^{1} \mathrm{H},{ }^{18} \mathrm{O} /{ }^{16} \mathrm{O}\right)$ de la muestra y $R p$ la relación isotópica $\left({ }^{2} \mathrm{H} /{ }^{1} \mathrm{H},{ }^{18} \mathrm{O} /{ }^{16} \mathrm{O}\right)$ de la referencia internacional. El patrón utilizado es Vienna Standard Mean Ocean Water (V-SMOW) (Gonfiantini, 1978). Las incertidumbres analíticas son de $\pm 0,2$ para $\delta^{18} \mathrm{O}$ y $\pm 0,1$ para $\delta^{2} \mathrm{H}$.

\subsection{TAREAS DE GABINETE POSTERIORES A LOS TRABAJOS DE CAMPO}

\subsubsection{Procesamiento de los datos geohidrológicos para las cuencas de los arroyos Buñirigo y Juan} Blanco

El análisis de las precipitaciones para las cuencas de los arroyos Buñirigo y Juan Blanco se estableció para un periodo de 12 años comprendido entre enero de 2003 y diciembre de 2015. Los datos fueron aportados por la Sociedad Rural de la ciudad de Magdalena ubicada sobre la Ruta Provincial $N^{\circ} 11$ en la entrada a la localidad, en la que se registra manualmente con un pluviómetro la precipitación diaria. Con los 
datos de precipitaciones diarias se calcularon las precipitaciones anuales y las medias mensuales para el período indicado.

El balance de agua en el suelo se estableció para el periodo 2003 - 2015 según la metodología de Thornthwaite y Mather (1957). Los registros de precipitación utilizados corresponden a los promedios mensuales de dicha serie de años mientras que los valores de evapotranspiración potencial (ETP) se obtuvieron a través de la fórmula empírica de Thornthwaite (1948). Para el cálculo de la reserva de agua útil máxima del suelo se tuvieron en cuenta las características de los suelos del área y se estableció para la misma un valor medio de $70 \mathrm{~mm}$. Mediante el balance modular se estimaron la evapotranspiración real (ETR) y los excesos y déficits hídricos para caracterizar el régimen hidrológico del área de estudio.

En base a los relevamientos de campo e imágenes satelitales se describieron las características geomorfológicas y geológicas, así como también los rasgos hidrológicos del paisaje. Para estudiar el flujo subterráneo en el acuífero freático se confeccionó un mapa isofreático. Para esto, se calculó la cota del nivel freático en metros sobre el nivel del mar ( $\mathrm{m} \mathrm{s.} \mathrm{n.} \mathrm{m.),} \mathrm{en} \mathrm{base} \mathrm{a} \mathrm{la} \mathrm{profundidad} \mathrm{del} \mathrm{nivel} \mathrm{medido} \mathrm{en} \mathrm{campo} \mathrm{y}$ la cota del terreno de cada punto de medición. La cota topográfica fue obtenida mediante la utilización de un modelo digital del terreno de alta resolución Tandem- $X$ adquirido por medio de un convenio con el Centro Aeroespacial Alemán. Dicho modelo fue corregido mediante la acotación de los puntos utilizando un GPS diferencial (Trimble ${ }^{\circledR} \mathrm{R} 2$ ). El mapa isofreático generado fue comparado con un mapa previamente realizado para el noreste de la provincia de Buenos Aires en donde se incluye al área de estudio de la tesis (Sala, 1972).

Los datos hidroquímicos obtenidos fueron representados mediante diagramas de Stiff (1951). Los mismos fueron posteriormente volcados en el Sistema de Información Geográfica libre QGIS para analizar la relación entre la composición química del agua y las características geológico - geomorfológicas del terreno.

\subsubsection{Procesamiento de los datos geohidrológicos para las transectas en el área de planicie costera}

Con los datos de profundidad del nivel freático y los valores de cotas del terreno se calculó la cota del nivel freático de cada punto de monitoreo y se efectuaron perfiles hidrogeológicos a fin de indicar, dentro de cada transecta, el flujo de agua subterránea y su relación con el agua superficial. Al igual que en el caso anterior (Apartado 2.3.1), la cota del terreno (para realizar los perfiles topográficos y calcular la cota del nivel freático) se determinó mediante la utilización de un modelo digital del terreno de alta resolución Tandem-X y la acotación de puntos se realizó utilizando un GPS diferencial (Trimble ${ }^{\circledR}$ R2). En estos perfiles también se volcó la información procedente de la geomorfología y geología de superficie relevada en campo y de las descripciones litológicas de las perforaciones someras realizadas para cada transecta.

Para determinar la relación entre los niveles de agua subterránea en los subambientes de planicie con cordones de conchilla y marisma se analizaron los datos de nivel, temperatura y conductividad eléctrica 
del agua procedentes de los sensores automáticos de registro continuo con una frecuencia horaria. En una primera instancia se corrigieron los valores del sensor Levelogger con los registros del Barologger. Posteriormente, los registros continuos se compararon con datos de precipitación diaria (aportados por la Sociedad Rural de Magdalena) y con los datos horarios de altura del Río de la Plata procedente del mareógrafo instalado en la localidad de Atalaya y brindados por el Servicio de Hidrografía Naval.

La clasificación de las muestras de agua en función del contenido de iones mayoritarios se realizó mediante diagramas de Stiff (1951). Las facies hidroquímicas obtenidas se volcaron en el Sistema de Información Geográfica con el fin de observar la variación química del agua en los distintos ambientes geomorfológicos que atraviesan las transectas. Asimismo, para el análisis e interpretación de los datos químicos se graficaron las relaciones iónicas e isotópicas y se determinaron los índices de saturación respecto de algunas fases minerales. La determinación de las especies solubles e índices de saturación se efectuó a partir del software PHREEQC (Parkhurst y Appelo, 1999) mediante el programa Diagrammes (Simler, 2009).

Para estudiar los procesos de evaporación como condicionantes de la química del agua se efectuaron modelos analíticos. En los modelos, se consideró que la evaporación aumenta la concentración de especies disueltas en el agua. La concentración de soluto puede expresarse como una función de la fracción de agua evaporada, por lo tanto, la concentración enriquecida C' puede estimarse de la siguiente manera:

$$
C^{\prime}=\frac{C_{0}}{(1-x)}
$$

En la ecuación (2), Co representa la concentración inicial y $x$ es la fracción de agua evaporada (por ejemplo, $x=V / V_{0}, 0<x<1$, donde $V$ es el volumen actual y $V_{0}$ el volumen inicial).

Para el cálculo del enriquecimiento isotópico producto de la evaporación se utilizaron las ecuaciones definidas por Gonfiantini (1986) y Craig y Gordon (1965) considerándose como concentración inicial al contenido isotópico de la lluvia local (Dapeña y Panarello, 2004) y una humedad relativa de 0,85 acorde a los datos climáticos del área.

Asimismo, en cada transecta se analizó el contenido de nitrato en agua conjuntamente con los datos bacteriológicos. Los resultados se interpretaron en función de la información relevada en el campo con el fin de identificar las posibles fuentes de aporte y de ingreso al agua subterránea de estos contaminantes.

\subsubsection{Formulación de modelos conceptuales}

Se generaron modelos conceptuales del funcionamiento geohidrológico de la planicie costera a partir de la integración de las observaciones de campo y los datos relevados. Dichos modelos incluyen las particularidades hidrodinámicas e hidrogeoquímicas de cada ambiente geohidrológico y considera tanto a 
las zonas naturales como aquellas modificadas por la acción antrópica. Los modelos se confeccionaron a través de diagramas tridimensionales en los sectores más representativos de la planicie costera. 


\section{Capítulo 3. GEOLOGÍA, GEOMORFOLOGÍA E HIDROGEOLOGÍA DEL NORESTE DE LA PROVINCIA DE BUENOS AIRES}

En el presente capítulo se expone una base general del conocimiento geológico y geomorfológicoedáfico del noreste de la provincia de Buenos Aires, región donde se ubica el área de estudio. Esto adicionado a un análisis de las precipitaciones y las unidades hidrogeológicas del área permite comprender el contexto geohidrológico regional donde se enmarca el área de estudio.

\subsection{GEOLOGÍA REGIONAL}

El área de estudio se enmarca en el extremo norte de la Cuenca del Salado, la cual forma parte de la Llanura Chaco Pampeana (Russo et al., 1979; Ramos, 1999). La cuenca está conformada por secuencias sedimentarias de edad Jurásico Tardío a Holoceno. Las secuencias sedimentarias más antiguas, de edad Jurásico Tardío - Plioceno, se encuentran en subsuelo y están representadas por una alternancia de depósitos continentales y marinos. Las secuencias más jóvenes, de edad Pleistoceno - Holoceno, se encuentran en superficie y corresponden a depósitos fluviales, eólicos y marinos.

\subsubsection{Geología de subsuelo}

La Cuenca del Salado exhibe una geometría elongada en la dirección NO - SE. El extremo noroeste se ubica en el centro norte de la provincia de Buenos Aires, mientras que el extremo sudeste intercepta en forma transversal el margen continental atlántico. Los límites noreste y sudeste corresponden a los altos de Martín García y Tandil, respectivamente (Fig. 3.1). Esta cuenca es interpretada como una cuenca de rift con fallas normales subparalelas entre sí escalonadas hacia el centro y un basamento que desciende hasta una profundidad aproximada de 6 kilómetros (Yrigoyen, 1975).

El origen de la cuenca se vincula con un punto triple asociado a la apertura de Océano Atlántico Sur, durante el Jurásico Tardío y Cretácico Temprano (Introcaso y Ramos, 1984). La evolución téctonosedimentaria de la Cuenca del Salado se caracteriza por cuatro estadíos o fases distintivas: prerift, rift, sag y margen pasivo (Yrigoyen, 1999; Tavella, 2005). 


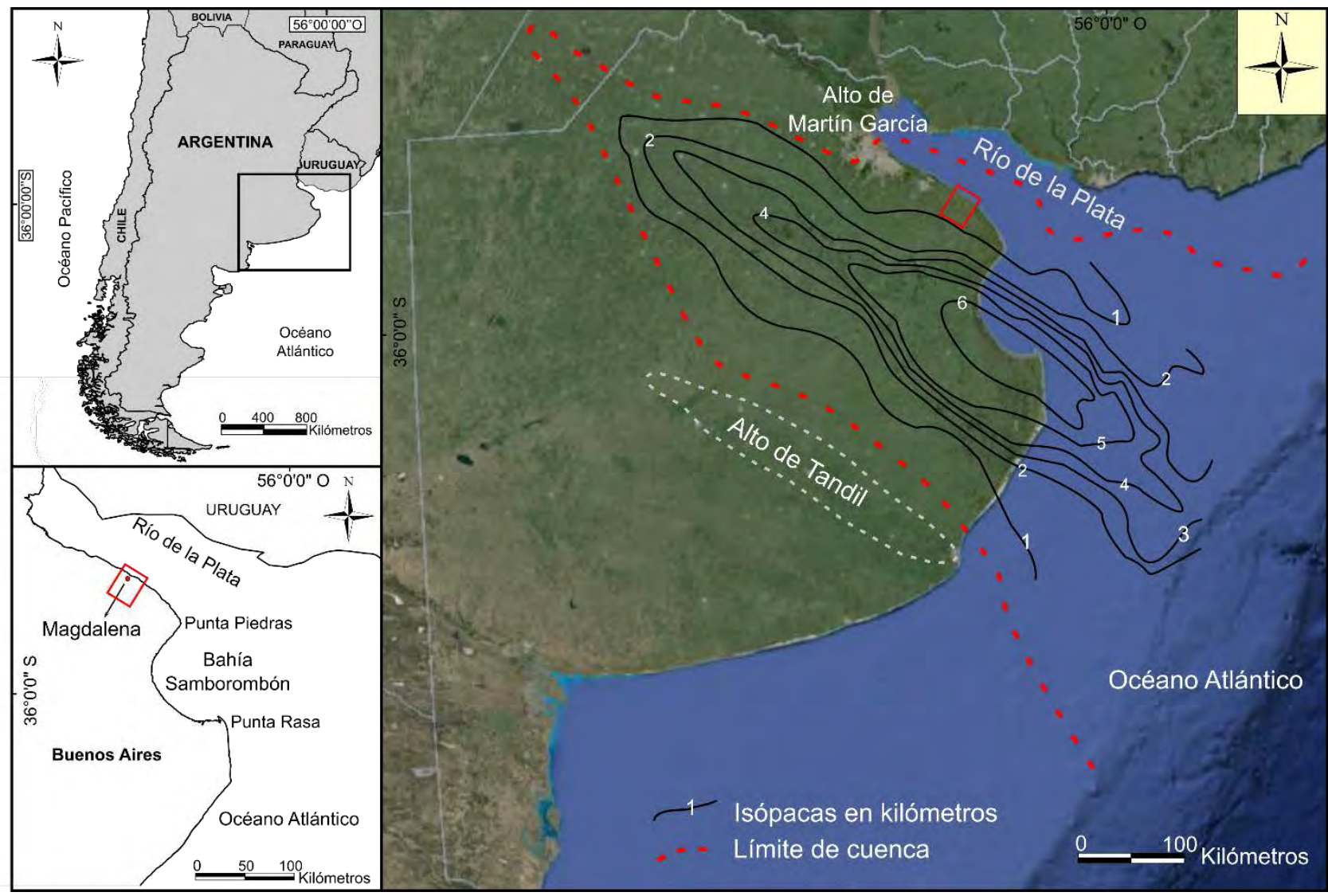

Figura 3.1. Situación regional de la Cuenca del Salado. Se muestran las isópacas y el límite de la cuenca, así como los altos estructurales con rocas de basamento paleoproterozoico (altos de Martín García y Tandil). El recuadro rojo corresponde al área de estudio.

El sustrato de prerift corresponde a las rocas de basamento cristalino sobre las cuales se depositó la secuencia sedimentaria del Jurásico Tardío - Holoceno. El basamento está conformado por rocas metamórficas e ígneas de edad Paleoproterozoica. Estas rocas cristalinas forman parte del denominado cratón del Río de la Plata que abarca la isla Martín García (Complejo Martín Gracía, Dalla Salda, 1981) y la región de Tandilia (Complejo Buenos Aires, Marchese y Di Paola, 1975) en la Argentina; y el oeste de la República Oriental del Uruguay.

El estadío de rift está asociado a deformación extensional que afectó al basamento cristalino. Este proceso produjo fallas con rumbo NO - SE en el basamento, que generaron el espacio de acomodación donde se depositó el primer relleno de la Cuenca del Salado (sinrift), durante el Jurásico Tardío - Cretácico Temprano. Este relleno se apoya en no conformidad sobre el basamento y se inicia con rocas efusivas y volcaniclásticas del Grupo Serra Geral (edad Jurásico Tardío - Cretácico Temprano). A esta unidad le siguen depósitos continentales constituidos por conglomerados, areniscas y fangolitas pardo rojizas (red beds) de la Formación Río Salado (edad Cretácico Temprano), también como parte del relleno de sinrift.

Durante la fase de sag se produce el momento de mayor estabilidad tectónica en la cuenca, donde la subsidencia es térmica. Esta fase está representada por las formaciones General Belgrano y Las Chilcas 
(Fig. 3.2). La Formación General Belgrano (edad Aptiano - Albiano hasta Cenomaniano) está constituida por facies proximales (red beds) de carácter continental, con areniscas rojas arcósicas de grano fino, intercaladas con limolitas de tonalidades rojizas. En su sección superior aparecen facies distales, con sedimentos marinos someros correspondientes a un ambiente proto-oceánico (Tavella, 2005). La Formación Las Chilcas representa la primer ingresión marina franca sobre toda la superficie de la cuenca. Los depósitos son de edad Maastrichtiano - Daniano y están formados por limolitas grises verdosas y arcilitas varicolores con areniscas, yeso y anhidrita subordinada (Yrigoyen, 1999).

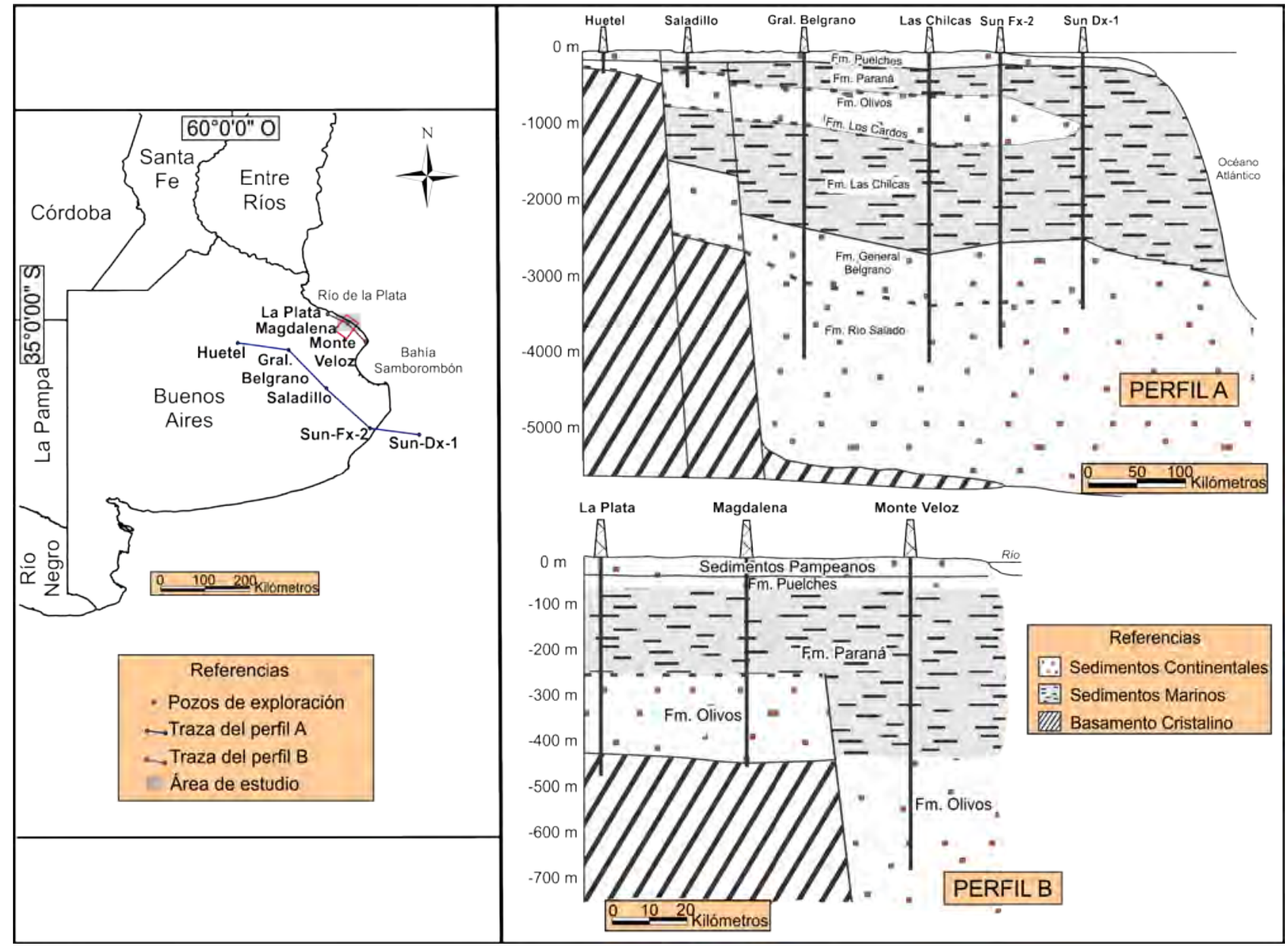

Figura 3.2. Secciones estrátigráficas longitudinales de la Cuenca del Salado (modificado de Yrigoyen, 1975). El recuadro rojo en la provincia de Buenos Aires corresponde al área de estudio.

Durante el estadío de margen pasivo se depositaron secuencias sedimentarias tanto continentales como marinas, de disposición transgresiva-regresiva que abarcan del Eoceno al Holoceno y se describen a continuación.

Sobre las unidades marinas de la Formación Las Chilcas continúan depósitos continentales transicionales y luego capas rojas regresivas de las formaciones Los Cardos y Olivos, respectivamente (Fig. 3.2). La Formación Los Cardos, está constituida por areniscas cuarzosas rosadas y blanquecinas de grano 
grueso, de ambiente continental fluvial. La Formación Olivos o "El Rojo" (Groeber, 1945) de edad OligocenoMioceno temprano, está formada principalmente por areniscas gruesas de colores castaño rojizo, que pasan a arcilitas pardo rojizas en la parte superior. Los depósitos son de origen eólico, lagunar y fluvial, y presentan frecuentes intercalaciones de yeso y anhidrita. Éstos, se apoyan directamente sobre el basamento cristalino en el margen NE de la Cuenca del Salado (Fig. 3.2). Sin embargo, hacia el eje de la cuenca, la Formación Olivos se apoya en unidades del Paleógeno, Cretácico y probablemente Paleozoico (Bracaccini, 1972).

En el Mioceno tardío se produce otra importante transgresión marina (Yrigoyen, 1999) representada por la Formación Paraná o "El Verde" (Fig. 3.2). La litología de la misma está conformada, principalmente, por arcilitas de coloración gris verdoso con abundante contenido fosilífero y, en menor medida, por areniscas finas a muy gruesas (Yrigoyen, 1975).

Durante el Plioceno tardío prosigue la sedimentación de arenas cuarzosas, claras y pardas amarillentas de la Formación Puelches (Santa Cruz, 1972). Se disponen en discordancia erosiva sobre las arcilitas de la Formación Paraná (Fig. 3.2).

\subsubsection{Geología de superficie}

La geología de superficie está representada por sedimentitas de origen continental, representadas por las formaciones Pampeano, La Postrera y Luján y sedimentos marino litorales constituidos por las formaciones Puente de Pascua y Canal de Las Escobas. El rango de edades para estas formaciones abarca desde el Pleistoceno al Holoceno.

La Formación Pampeano (González Bonorino, 1965) o Sedimentos Pampeanos (Fidalgo et al., 1975) son predominantemente limos más o menos arcillosos y/o arenosos, arenas limosas de grano muy fino y arcillas limosas de edad Pleistoceno, con una amplia distribución en la provincia de Buenos Aires. El color es generalmente castaño con distintas tonalidades que van del amarillento al rojizo oscuro. Casi toda la formación presenta cementación con carbonato de calcio (tosca) en forma de nódulos, concreciones irregulares (muñecos) o mantos horizontales. Presenta ausencia de estratificación y genéricamente se la conoce como loess o Loess Pampeano. Los Sedimentos Pampeanos sobreyacen a la Arenas Puelches mediante un estrato arcilloso de coloración grisácea.

La Formación La Postrera (Fidalgo et al., 1973a, 1973b) está constituida por limos arcillo arenosos de color amarillento y arenas limosas de color gris claro, de origen eólico. Esta formación, de amplia distribución en la provincia de Buenos Aires, se expone en divisorias de aguas y en paredes de valles (Fidalgo et al., 1973b; Fucks y Deschamps, 2008). La edad corresponde al Pleistoceno tardío - Holoceno. 
La Formación Luján (Fidalgo et al., 1973a, 1973b;) está compuesta por sedimentos de origen fluvial, asociados genéticamente a los valles de los cursos de agua más importantes de la región pampeana (Salado, Luján, Matanza, etc.). Los sedimentos están representados por una secuencia con arena limo arcillosa hasta limo arcillo arenoso de coloración verde a verde amarillento con base, a veces, de arenas finas color castaño rojizo; se apoyan en forma discordante sobre los Sedimentos Pampeanos. Fidalgo et al. (1973a) distinguen dentro de la Formación Luján, en sentido litoestratigráfico, al Miembro Guerrero (inferior) y al Miembro Río Salado (superior), en el ámbito de la Bahía Samborombón y relacionados principalmente al curso del río Salado.

Respecto a las unidades marinas litorales holocenas, denominadas también como sedimentos pospampeanos (formaciones Pascua y Canal de Las Escobas), a continuación se describen las mismas en base al esquema estratigráfico de Fidalgo et al. (1973b), modificado por Fucks et al. (2010). El perfil geológico (A B; Fig. 3.3) y los aspectos sedimentológicos de dichas unidades corresponden a los afloramientos descriptos en la Bahía Samborombón. Las unidades representadas en dicho perfil también son equivalentes en el área de estudio (Fig. 3.3).

La Formación Pascua (Fidalgo et al., 1973b) o Formación Puente de Pascua (Fucks et al., 2010) está constituida por sedimentos arenosos, con una alta concentración de valvas de moluscos. En el sector superior se encuentra fuertemente cementada con carbonato de calcio, constituyendo una coquina. Posee una distribución discontinua a lo largo del litoral bonaerense, aflorando en las proximidades de la Bahía Samborombón (Fucks et al., 2010) y en los partidos de Magdalena y La Plata (Imbellone et al., 2012). Los sedimentos están vinculados a la transgresión marina denominada Belgranense por Ameghino (1889) del Pleistoceno tardío y se intercalan en la parte superior de la Formación Pampeano acuñándose desde la costa hacia el continente.

La Formación Las Escobas (Fidalgo et al., 1973b) o Formación Canal de las Escobas (Fucks et al., 2010) agrupa los depósitos generados por el último ciclo transgresivo-regresivo, denominados Platense y Querandinense por Frenguelli (1957). Esta formación consta de cuatro miembros que se describen a continuación, de más antiguo a más joven, según Fucks et al. (2010).

El Miembro Destacamento Río Salado está constituido por sedimentos arcillosos a arcillo arenosos, de color negro a negro grisáceo. Esta unidad se apoya en discordancia sobre las formaciones Pampeano y Puente de Pascua (Fig. 3.3). El ambiente sedimentario en el cual se depositó es intermareal de llanura costera, de baja energía, con subambientes restringidos de lagunas costeras, barras y también estuáricos.

El Miembro Canal 18 presenta sedimentos fundamentalmente friables de textura areno limosa con intercalaciones arcillosas y con colores castaño amarillentos a castaño verdosos. Se ubica en discordancia 
sobre el Miembro Destacamento Río Salado y lateralmente hacia el oeste del Miembro Cerro de La Gloria (Fig. 3.3). La depositación de los sedimentos se vincula a un ambiente sedimentario de llanura de mareas en ambientes abiertos, la que se vio restringida al formarse la barrera con los cordones de tormentas.

El Miembro Cerro de La Gloria representa cordones litorales, con espesores de hasta 5 metros, compuestos casi exclusivamente por concentraciones esqueletales de moluscos y rodados subordinados y arenas. Constituyen geoformas positivas del terreno que se disponen en estratos de varios centímetros de espesor y longitudes variables y se apoya en discordancia sobre el Miembro Destacamento Río Salado (Fig. 3.3). Presenta una amplia distribución en el litoral bonaerense desde la localidad de Los Talas (Partido de La Plata) hasta las cercanías de Mar Chiquita (Arturi y Goya, 2004). La morfología cordoniforme y las estructuras sedimentarias permitirían asociarlo a un ambiente de playa de alta energía.

El Miembro Canal 15 está compuesto por sedimentos arcillosos de colores grises, verdes y castaño grisáceos, con gran cantidad de materia orgánica parcialmente descompuesta y óxidos de hierro. Se ubica en los sectores más litorales al este del Miembro Cerro de La Gloria y se deposita sobre el Miembro Destacamento Río Salado (Fig. 3.3). El ambiente sedimentario corresponde a llanuras de mareas que han gradado a marismas, en una costa en retroceso.

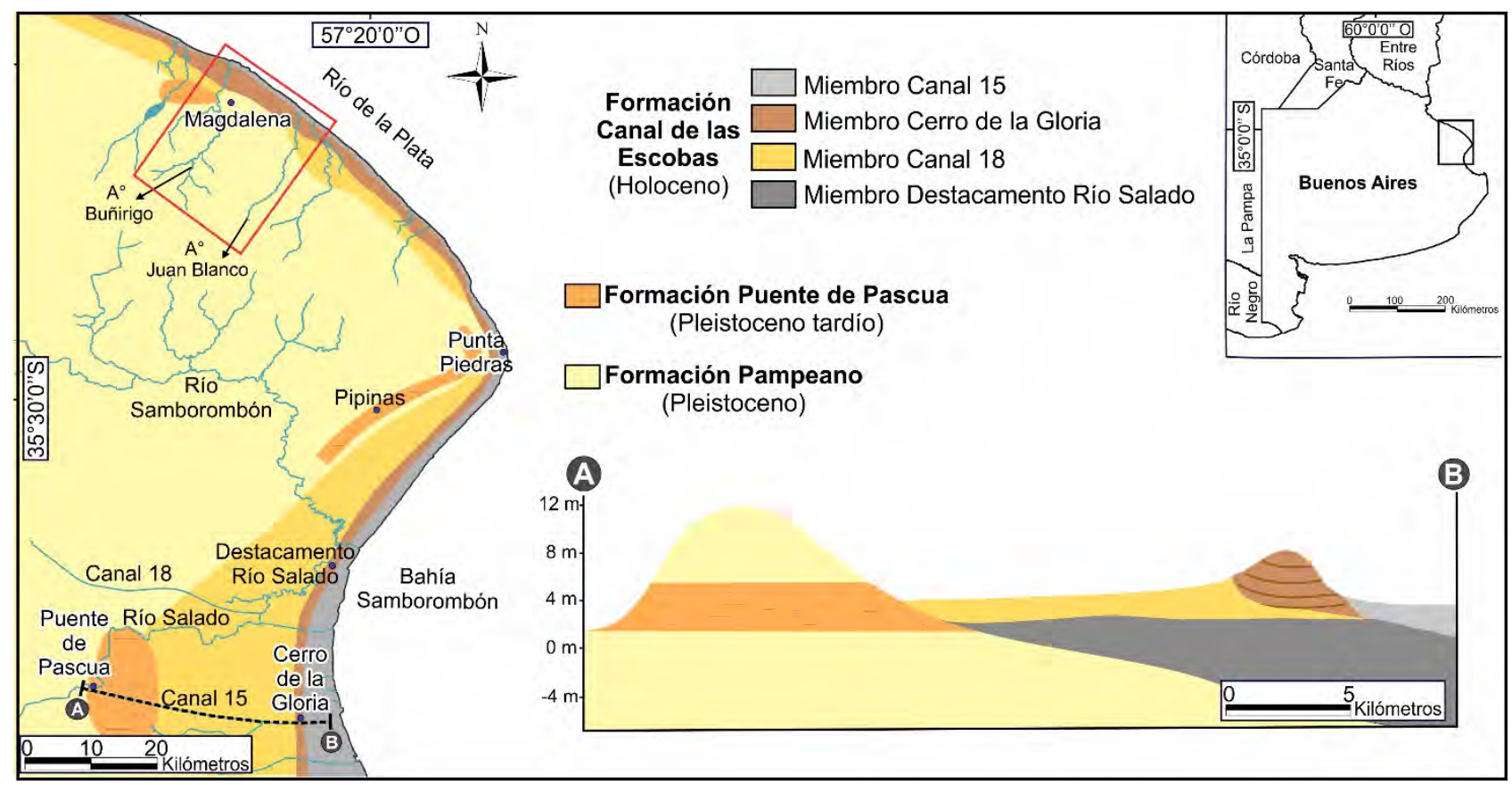

Figura 3.3. Mapa y perfil geológico de los depósitos marinos litorales del sector continental de la Bahía Samborombón y el noreste de la provincia de Buenos Aires (modificado de Fucks et al., 2010). El perfil sigue la traza del Canal 15. El recuadro rojo corresponde al área de estudio. 


\subsection{RASGOS GEOMORFOLÓGICOS Y EDÁFICOS}

Regionalmente, el área de estudio se encuadra en la subregión denominada Pampa Ondulada, la cual ocupa el noreste de la provincia de Buenos Aires y el sureste de la provincia de Santa Fe y de Córdoba (Fig. 3.4). La Pampa Ondulada constituye una franja extendida en dirección NO - SE limitada al norte por el Río Carcarañá (provincia de Santa Fe), al noreste con el Río Paraná y el Río de la Plata y al sur con el Río Samborombón. Esta subregión se caracteriza por la presencia de un relieve suavemente ondulado con una pendiente regional, en general, menor al $2 \%$. El modelado de dicho paisaje con sucesión de áreas de interfluvios y valles, en general planos, es consecuencia del desarrollo de una red de drenaje bien definida conformada por arroyos, cañadas y ríos orientados en dirección SO - NE.

En este contexto regional, los rasgos geomorfológicos se asocian a dos grandes unidades geomorfológicas. Por un lado, la llanura loessica (Carol, 2015; Carol et al., 2017), también denominada Terraza alta (Frenguelli, 1950), Zona interior (Fidalgo y Martínez, 1983) o Llanura alta (Cavallotto, 1995). Por otro lado, la planicie costera (Fidalgo y Martínez, 1983), también denominada Terraza baja (Frenguelli, 1950) o llanura costera (Cavallotto, 1995).

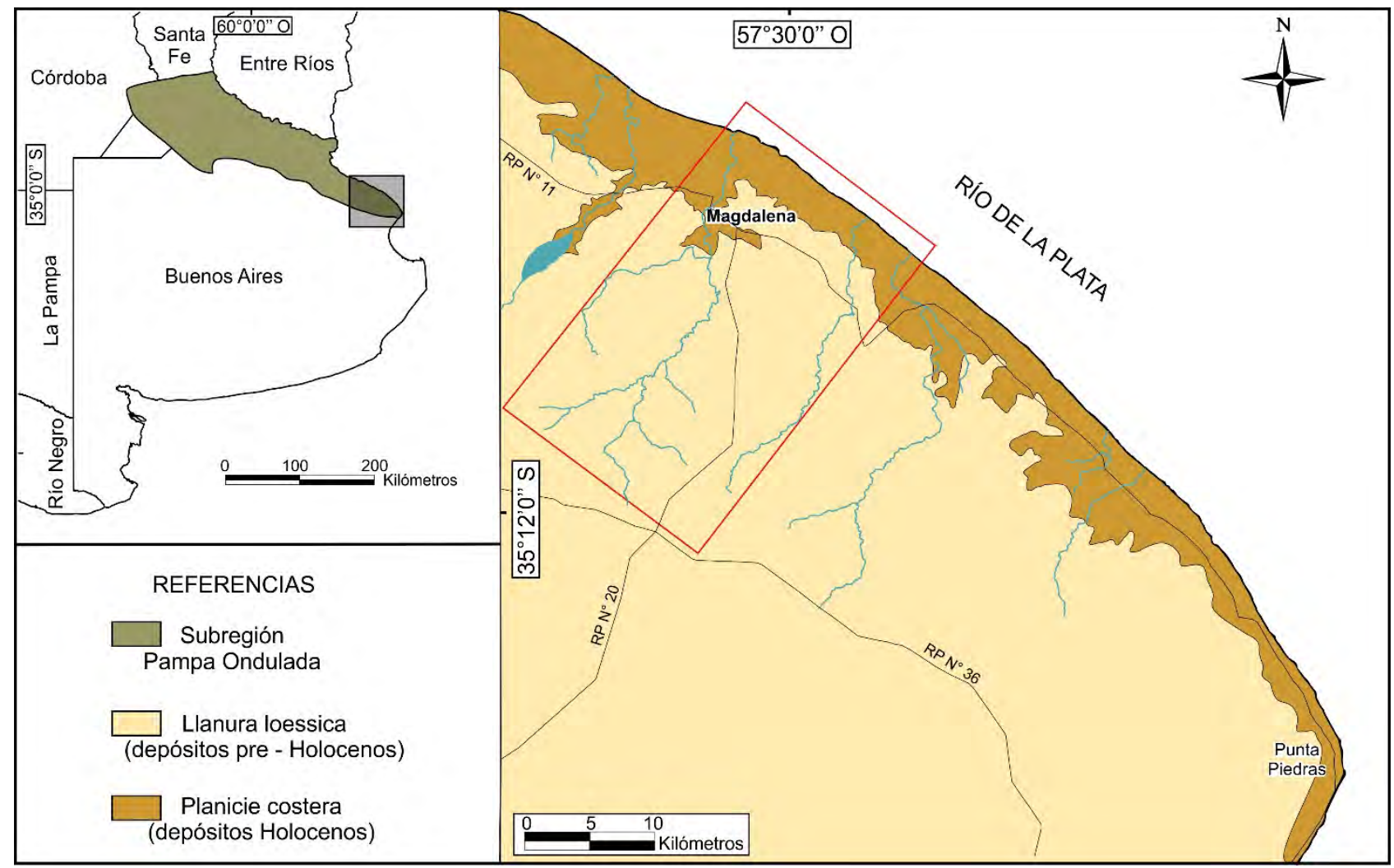

Figura 3.4. Subregión Pampa Ondulada. En este contexto regional, se indican en el mapa las unidades geomorfológicas principales para el sector noreste de la provincia de Buenos Aires. El recuadro rojo corresponde al área de estudio. 


\subsubsection{Llanura loessica}

La llanura loessica, localizada en los sectores más continentales de la provincia de Buenos Aires (Fig. 3.4), presenta un relieve suavemente ondulado con alturas entre los 5 y los 30 m s. n. m. (Fidalgo y Martínez, 1983). Este relieve se encuentra surcado por numerosas líneas de drenaje bien definidas, que originan cuencas de drenaje de variada dimensión. Los depósitos asociados a esta unidad geomorfológica son de edad Pleistocena y corresponden a los sedimentos loessicos de la Formación Pampeano (González Bonorino, 1965). El límite con la llanura costera se manifiesta mediante un escalón o cambio de pendiente irregular caracterizado por la presencia de entrantes y salientes que indica el límite más interno de erosión relacionado con la última transgresión marina (Cavallotto, 2002; Martínez et al., 2006).

En esta unidad geomorfológica, se desarrollaron distintos suelos vinculados a la evolución geomorfológica del paisaje. En base al mapa de suelos de la provincia de Buenos Aires (Salazar Lea Plaza y Moscatelli, 1989) y al trabajo de Hurtado et al. (2005), se establecieron los principales dominios edáficos y subgrupos, respectivamente, para la llanura loessica. Así, en las zonas de interfluvios se reconocen suelos profundos, bien drenados y con horizontes diferenciados del tipo Argiudol típico (dominio edáfico 8; Fig. 3.5) y, en menor medida, Argiudol vértico (dominio edáfico 7; Fig. 3.5). Los suelos de esta zona presentan una gran potencialidad y aptitud agrícola. Por otro lado, en los valles planos se registran suelos profundos, con horizontes de buen desarrollo y algo imperfectamente drenados del tipo Argialbol típico (dominio edáfico 10; Fig. 3.5). Estos suelos presentan un engrosamiento de su horizonte superficial por el lavado de partículas (horizonte E diagnóstico) y rasgos hidromórficos. En los valles pueden producirse también fenómenos de anegabilidad y sodicidad con desarrollo de suelos del tipo Natracuol típico, Natracualf típico y Natralbol típico (dominio edáfico 9; Fig. 3.5). Desde el punto de vista de la capacidad de uso estos suelos son mayormente empleados para la actividad ganadera.

\subsubsection{Planicie costera}

La planicie costera del Río de la Plata se encuentra ubicada en el noreste y este de la provincia de Buenos Aires, entre la Ciudad de Buenos Aires y Punta Rasa. En la zona de estudio, esta unidad geomorfológica abarca una franja irregular, con un ancho máximo de 9 kilómetros, de extensión paralela a la línea de costa entre las cotas de 0 y $5 \mathrm{~m} \mathrm{s.} \mathrm{n.} \mathrm{m.} \mathrm{(Fig.} \mathrm{3.4).} \mathrm{Presenta} \mathrm{un} \mathrm{relieve} \mathrm{muy} \mathrm{plano} \mathrm{con} \mathrm{pendientes}$ topográficas inferiores al 0,10\%. Debido a la baja pendiente y a las características litológicas, la red de drenaje de esta unidad está escasamente desarrollada, con pocos cursos principales y tributarios de carácter transitorio. Los cauces de los cursos de agua de la llanura loessica, al atravesar esta unidad pierden definición, por ende, la mayoría de ellos deben ser canalizados para facilitar su drenaje hacia el Río de la Plata. Los sedimentos que la constituyen son de origen marino y estúarico - fluvial generados por las variaciones 
relativas del nivel del mar a partir del último máximo glacial del Holoceno (Violante y Parker, 2000; Cavallotto, 2002).

En este ambiente litoral se desarrollan varios órdenes de suelos vinculados a la heterogeneidad de geoformas presentes. En líneas generales, y utilizando como base el mapa de suelos de la provincia de Buenos Aires (Salazar Lea Plaza y Moscatelli, 1989), los dominios edáficos correspondientes a esta unidad geomorfológica son el 9 y el 25. En el dominio edáfico 9 (Fig. 3.5) los suelos son de tipo Natracualf típico desarrollados en áreas bajas con deficiencia de drenaje donde pueden producirse fenómenos de anegabilidad evidenciados por la presencia de rasgos hidromórficos. Los horizontes superficiales, además, presentan altos contenidos de sodio intercambiable y sales solubles. Por sus características, estos suelos tienen muy baja capacidad de uso tanto agrícola como ganadero. Por otro lado, los principales suelos del dominio edáfico 25 (Fig. 3.5) son del tipo Pelludert típico; son suelos arcillosos de coloraciones oscuras con contenidos variables de materia orgánica en el perfil. Presentan marcados rasgos hidromórficos (moteados de hierro, concreciones de hierro - manganeso) debido a que se desarrollan en condiciones de anegamiento frecuente o con niveles freáticos muy cercanos a la superficie.

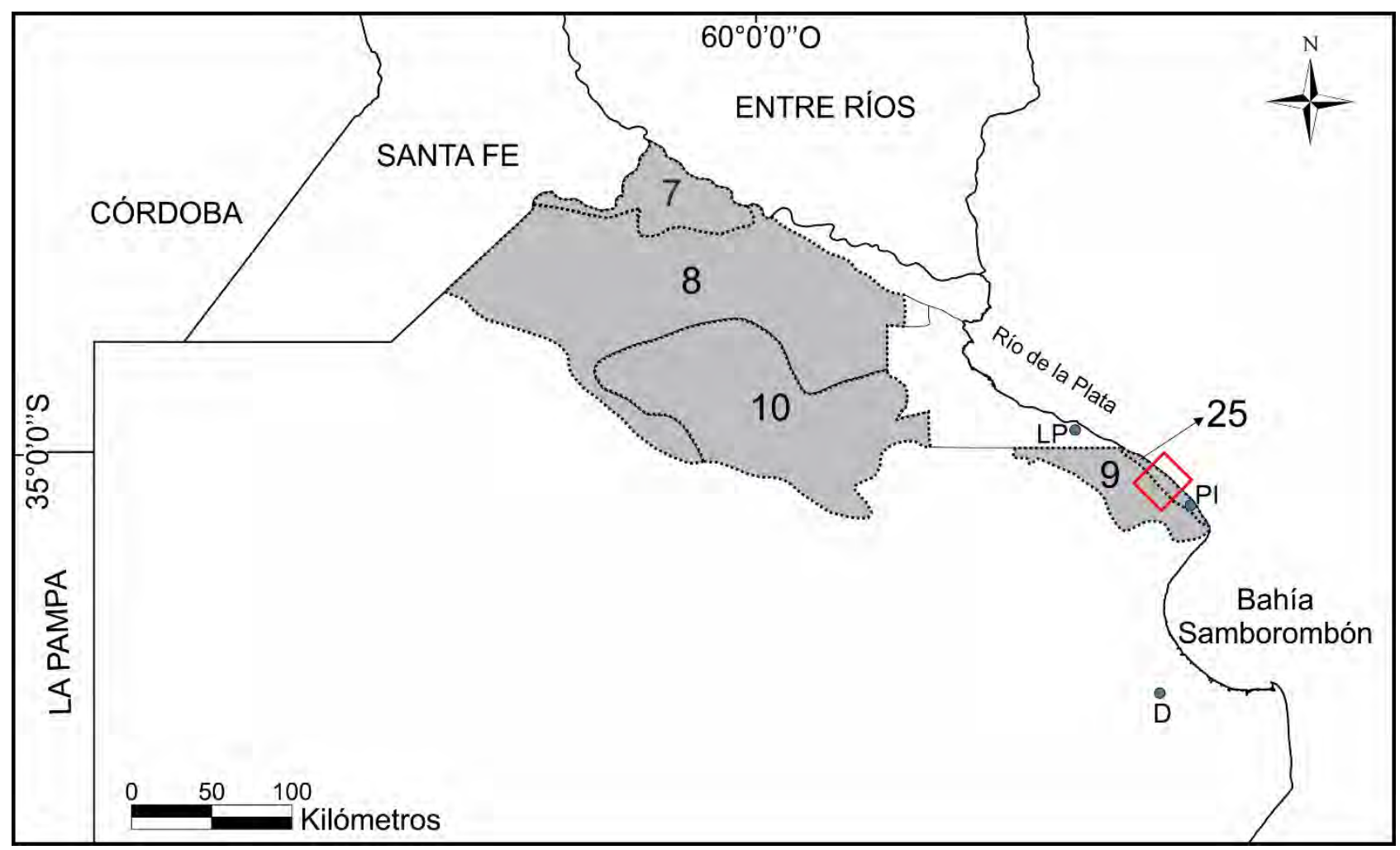

Figura 3.5. Mapa de dominios edáficos para las unidades geomorfológicas del noreste de la provincia de Buenos Aires (modificado de Salazar Lea Plaza y Moscatelli, 1989). Los números indican los dominios edáficos. Los suelos principales en cada dominio son: (7) Argiudol vértico; (8) Argiudol típico; (9) Natracualf típico; (10) Argialbol típico; (25) Pelludert típico. En esta figura, además, se indican las estaciones meteorológicas utilizadas en el análisis regional de las precipitaciones: (LP) La Plata; (PI) Punta Indio; (D) Dolores. EI recuadro rojo corresponde al área de estudio. 


\subsection{ANÁLISIS DE LAS PRECIPITACIONES}

Las condiciones climáticas regionales se interpretaron en base a los datos históricos registrados para un período de 84 años (1925 - 2009) en tres estaciones meteorológicas ubicadas al noroeste (La Plata), sureste (Punta Indio) y al sur (Dolores) de la zona de estudio (Fig. 3.5).

El análisis de las precipitaciones anuales indica que la región es climáticamente homogénea por no presentar notorias variaciones espaciales en las precipitaciones (Fig. 3.6). Los registros de lluvias anuales para las estaciones meteorológicas de La Plata, Punta Indio y Dolores coinciden en cuanto a su evolución y muestran una tendencia similar, lo que implica características análogas en las precipitaciones de toda la región, aunque con intensidades variadas para algunos años (p. ej. 1959, 1963, 1993).

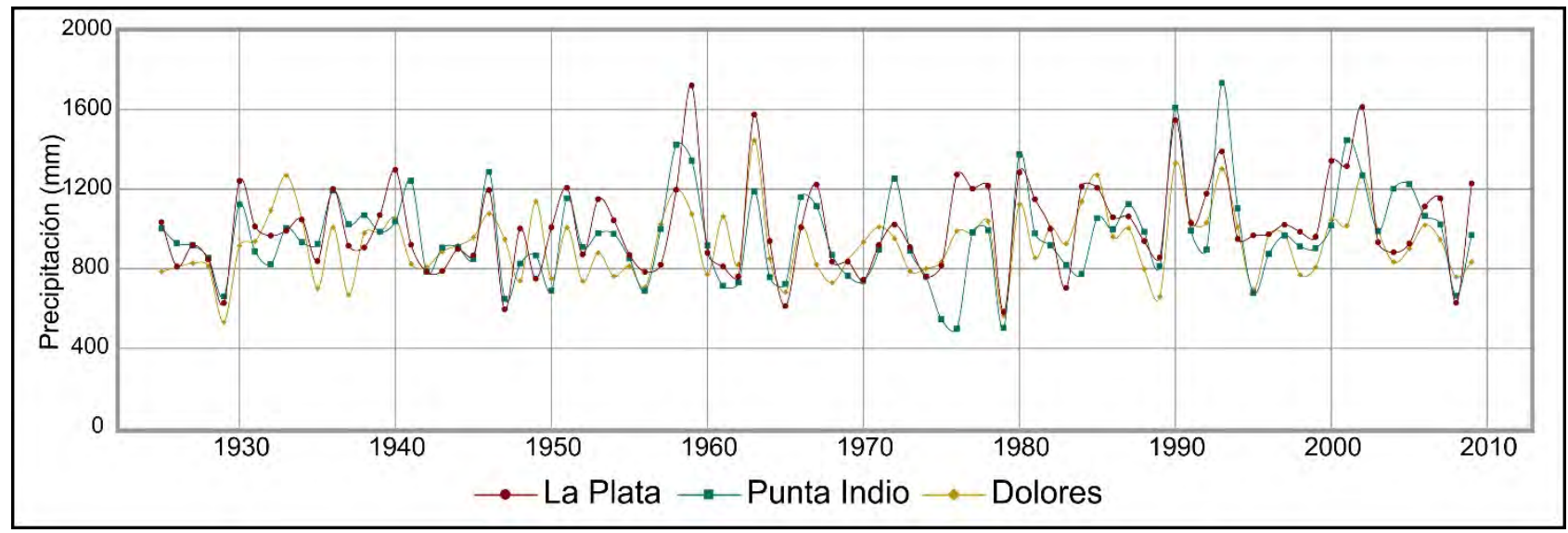

Figura 3.6. Serie histórica de precipitaciones anuales para el período 1925 - 2009 en las estaciones meteorológicas de La Plata, Punta Indio y Dolores.

En la estación meteorológica La Plata la precipitación media anual para el período estudiado es de 1007 mm; en el año 1959 se registró el valor máximo de lluvias con 1721 mm y en 1979 el mínimo con 582 $\mathrm{mm}$. En el caso de la estación meteorológica de Punta Indio la precipitación media anual es de $965 \mathrm{~mm}$ con un valor máximo de 1734 mm identificado en el año 1993 y un valor mínimo de 497 mm en el año 1976. En la estación meteorológica de Dolores, la precipitación media anual es de $928 \mathrm{~mm}$ y el año más lluvioso fue 1963 con $1446 \mathrm{~mm}$ y el menos lluvioso, 1929 con $531 \mathrm{~mm}$.

La figura 3.7 muestra los valores de precipitación media mensual para las estaciones meteorológicas estudiadas. Los registros de lluvias son homogéneos y presentan una distribución similar a lo largo del año lo que indica también condiciones climáticas homogéneas en toda la región. Los valores medios mensuales máximos se registran para las tres estaciones en el mes de marzo con 114, $81 \mathrm{~mm}$ para La Plata, 102,70 mm para Punta Indio y $95,90 \mathrm{~mm}$ para Dolores. Por otro lado, el mes menos lluvioso es junio y presenta promedios 
mensuales de $61,32 \mathrm{~mm}, 63,70 \mathrm{~mm}$ y $61,20 \mathrm{~mm}$ para las estaciones de La Plata, Punta Indio y Dolores, respectivamente.

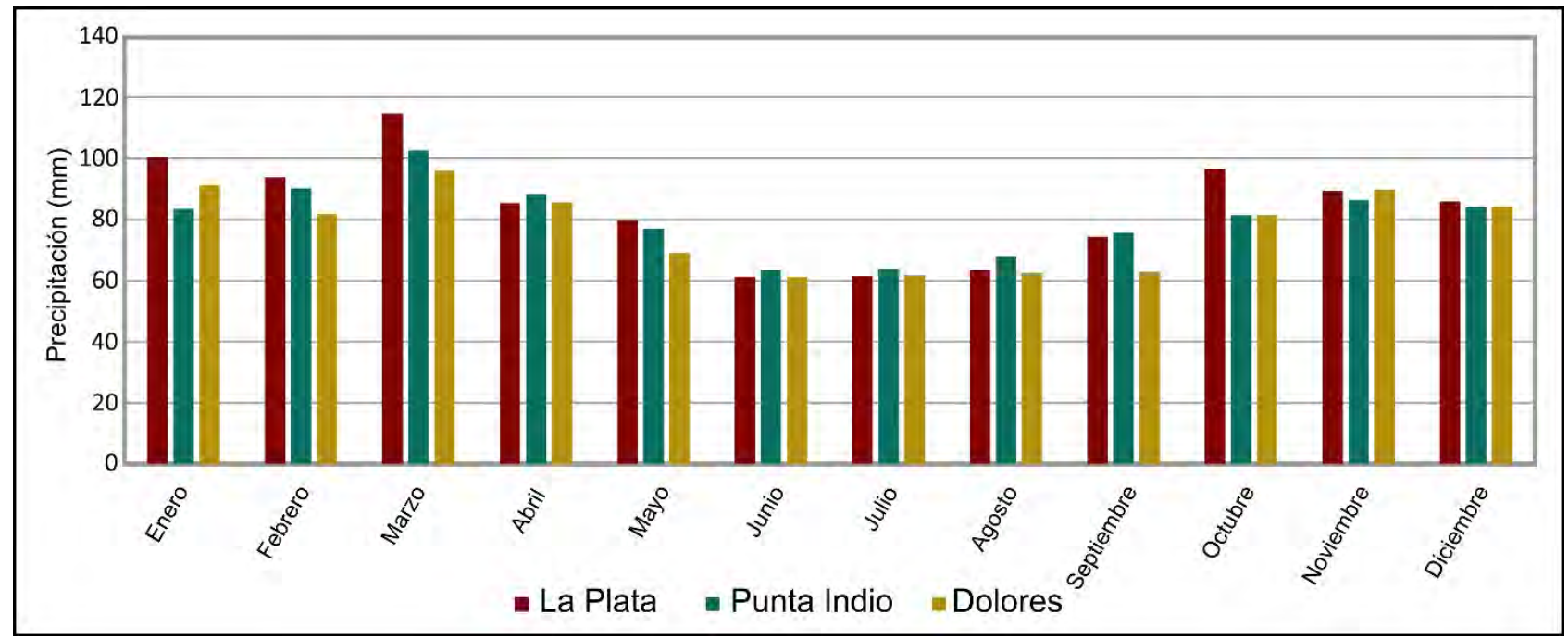

Figura 3.7. Precipitaciones medias mensuales para el período 1925-2009 en las estaciones meteorológicas de La Plata, Punta Indio y Dolores.

Adicionalmente, se obtuvieron las frecuencias relativas porcentuales para las lluvias registradas en el período 1925 - 2009, para caracterizar el régimen pluvial. Para esto, se utilizaron los valores mensuales de lluvia de cada uno de los años estudiados (un total de 1020 datos por estación). Los datos se agruparon en 21 clases con intervalos de $10 \mathrm{~mm}$ de amplitud y con un rango desde $0 \mathrm{~mm}$ hasta más de $200 \mathrm{~mm}$ (Fig. 3.8). En líneas generales, el histograma de frecuencias relativas porcentuales indica la pertenencia al mismo régimen pluvial y homogeneidad en las condiciones climáticas regionales. Para las tres estaciones estudiadas, las clases con una mayor probabilidad de ocurrencia son [20-30), [30-40), [40-50), [50-60) y [60-70). Por el contrario, las clases [150-160), [160-170), [170-180) y [180-190) presentan la menor probabilidad de ocurrencia con porcentajes menores al $2 \%$.

La figura 3.9 muestra las diferencias estacionales considerando los valores medios para la serie temporal 1925 - 2009 en las tres estaciones meteorológicas. El verano es la estación más lluviosa para La Plata y Dolores mientras que para Punta Indio lo es el otoño. A pesar de estas diferencias, los valores absolutos para el verano, otoño y primavera son muy similares en las tres estaciones. El invierno es la estación menos lluviosa para los tres casos analizados.

Sobre la base de los registros climáticos correspondiente al periodo 2000-2009 para las estaciones de La Plata, Punta Indio y Dolores se elaboraron balances hídricos seriados (Pascale y Damario, 1977) para caracterizar el sistema hidrológico de cada sitio. 


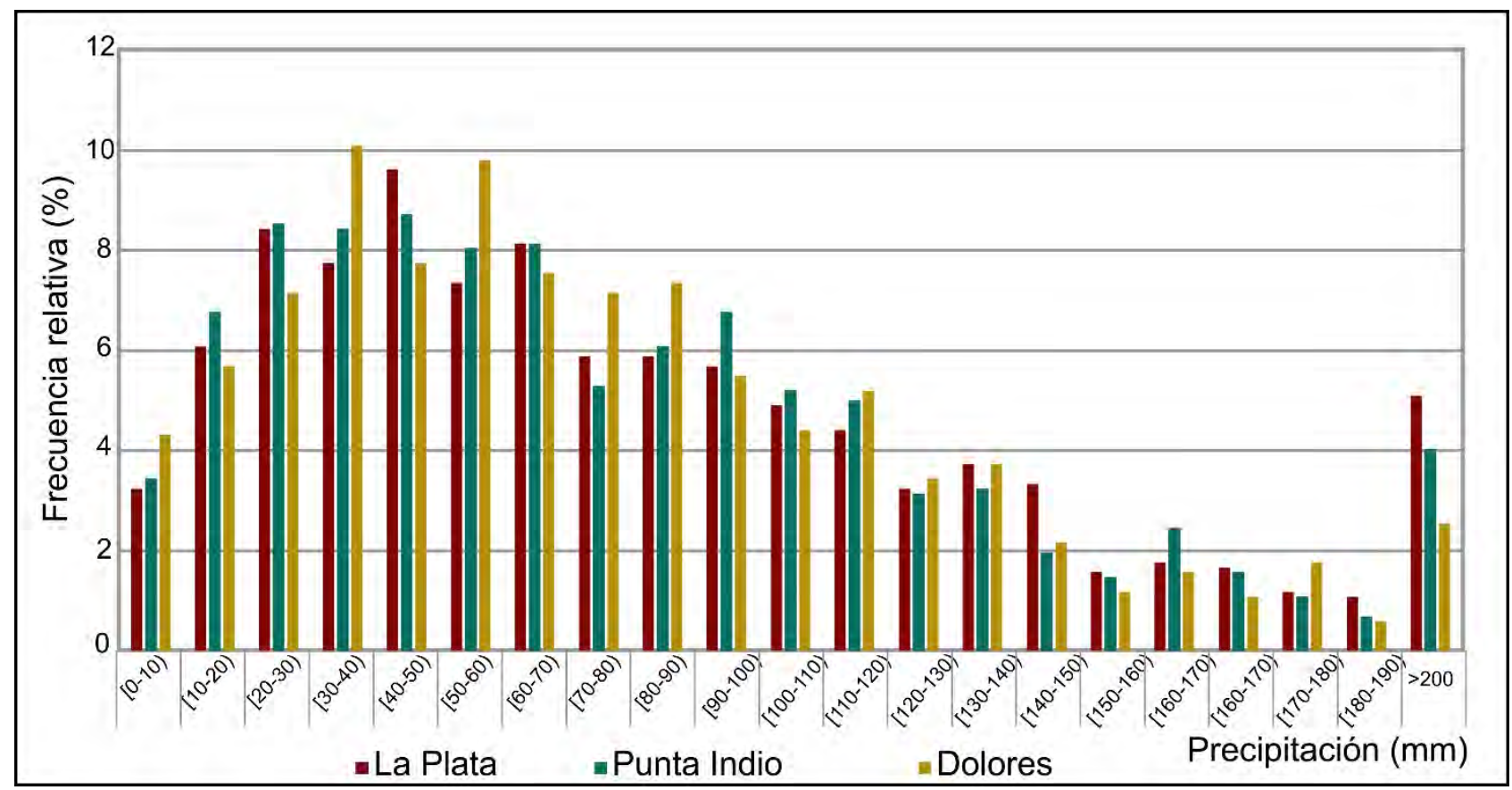

Figura 3.8. Frecuencias relativas porcentuales para las lluvias mensuales del período 1925 - 2009 en las estaciones meteorológicas de La Plata, Punta Indio y Dolores.

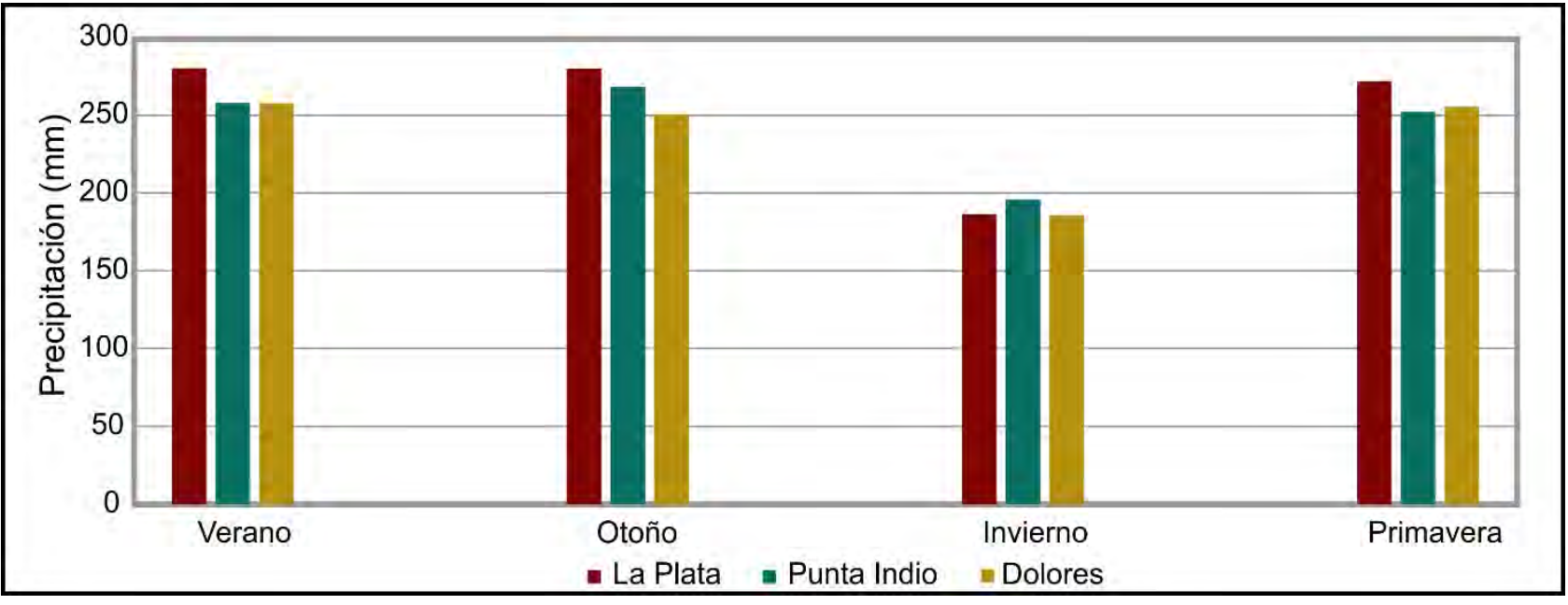

Figura 3.9. Diferencias estacionales para la serie temporal 1925 - 2009 en las estaciones meteorológicas de La Plata, Punta Indio y Dolores.

La evapotranspiración potencial (ETP) se obtuvo a través del método de FAO Penman-Monteith (Allen et al., 1994, 2006), y la reserva de agua útil máxima del suelo, también denominada capacidad de campo, se estableció teniendo en cuenta la textura del suelo presente en cada localidad.

Para la estación de La Plata los valores anuales, promedio, máximo y mínimo de precipitación, ETP, evapotranspiración real (ETR), excesos y déficits de agua en el suelo se muestran en la Tabla 3.1. A partir del balance hídrico seriado para esta estación (Fig. 3.10) se pudo determinar que, para la mayoría de los años analizados, entre los meses de marzo a septiembre la precipitación supera a la evapotranspiración, por lo tanto, la lluvia que no evapotranspira forma parte de la reserva de agua en el suelo o, si la reserva está 
completa, se producen excesos de agua. El déficit, a excepción de los años 2001 y 2002, se registra en el mes de enero. Además de este mes, el déficit se identifica en los meses de febrero y diciembre (para cuatro años del registro), noviembre (para tres años del registro), marzo (solo dos años del registro) y junio (solo un año del registro). Exclusivamente, en el año 2002 no se registra déficit para ningún mes. El uso de la reserva de agua en el suelo se produce, principalmente, en los meses de abril, septiembre, octubre, noviembre y diciembre.

Tabla 3.1. Parámetros característicos del balance hídrico seriado a nivel de suelo para la estación meteorológica de La Plata. P (precipitaciones), ETP (evapotranspiración potencial), ETR (evapotranspiración real).

\begin{tabular}{|c|c|c|c|c|c|}
\hline Año & $\mathbf{P}(\mathbf{m m})$ & ETP $(\mathbf{m m})$ & ETR $(\mathbf{m m})$ & $\begin{array}{c}\text { Exceso de } \\
\text { agua }(\mathbf{m m})\end{array}$ & $\begin{array}{c}\text { Déficit de } \\
\text { agua }(\mathbf{m m})\end{array}$ \\
\hline 2000 & 1342,10 & 908,00 & 804,20 & 537,90 & 103,80 \\
\hline 2001 & 1339,70 & 848,20 & 848,20 & 491,50 & 0,00 \\
\hline 2002 & 1644,70 & 866,20 & 866,20 & 778,50 & 0,00 \\
\hline 2003 & 933,00 & 895,00 & 841,80 & 91,20 & 53,20 \\
\hline 2004 & 881,70 & 901,00 & 710,40 & 171,30 & 190,60 \\
\hline 2005 & 927,00 & 926,00 & 787,00 & 140,00 & 139,00 \\
\hline 2006 & 1160,10 & 923,00 & 857,60 & 302,50 & 65,40 \\
\hline 2007 & 1153,20 & 909,00 & 719,50 & 433,70 & 189,50 \\
\hline 2008 & 627,90 & 931,00 & 622,60 & 5,30 & 308,40 \\
\hline 2009 & 1096,20 & 904,00 & 873,40 & 222,80 & 30,60 \\
\hline
\end{tabular}

\begin{tabular}{|c|c|c|c|c|c|}
\hline Promedio & 1110,56 & 901,14 & 793,09 & 317,47 & 108,05 \\
\hline Máximo & 1644,70 & 931,00 & 873,40 & 778,50 & 308,40 \\
\hline Mínimo & 627,90 & 848,20 & 622,60 & 5,30 & 0,00 \\
\hline
\end{tabular}

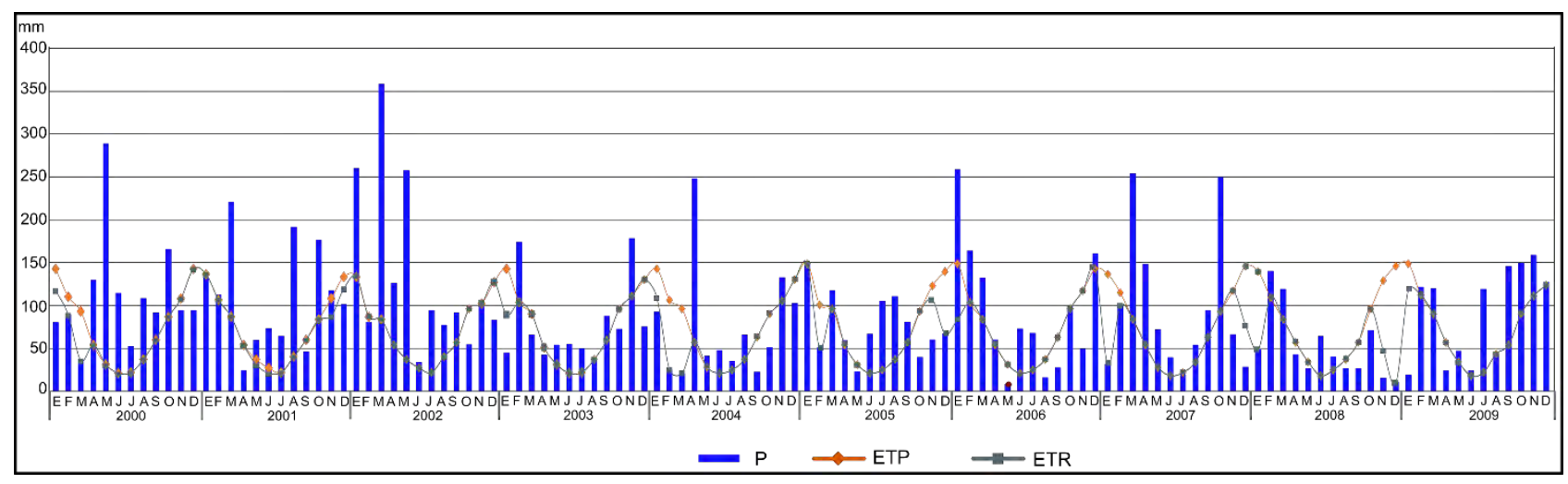

Figura 3.10. Valores mensuales de precipitación (P), evapotranspiración potencial (ETP) y real (ETR) para el período 2000-2009 en la estación meteorológica La Plata.

Para la estación Punta Indio los valores anuales, promedio, máximo y mínimo de precipitación, ETP, evapotranspiración real (ETR), excesos y déficits de agua en el suelo se muestran en la Tabla 3.2. El balance hídrico seriado para esta estación (Fig. 3.11) permite establecer que entre los meses de abril a octubre se 
producen excesos de agua en el suelo. Por su parte, en el mes de diciembre todos los años del registro (a excepción de 2001 y 2006) presentan déficit de agua en el suelo. Además, el déficit se registra en los meses de enero, marzo y noviembre. En los meses de noviembre y diciembre, principalmente, se registra el uso de la reserva de agua en el suelo.

Tabla 3.2. Parámetros característicos del balance hídrico seriado a nivel de suelo para la estación meteorológica de Punta Indio. P (precipitaciones), ETP (evapotranspiración potencial), ETR (evapotranspiración real).

\begin{tabular}{|r|c|c|c|c|c|}
\hline \multicolumn{1}{|c|}{ Año } & $P(\mathbf{m m})$ & ETP $(\mathbf{m m})$ & ETR $(\mathbf{m m})$ & $\begin{array}{c}\text { Exceso de } \\
\text { agua }(\mathbf{m m})\end{array}$ & $\begin{array}{c}\text { Déficit de } \\
\text { agua }(\mathbf{m m})\end{array}$ \\
\hline 2000 & 916,80 & 935,00 & 602,00 & 314,80 & 333,00 \\
\hline 2001 & 1444,30 & 935,00 & 935,00 & 511,30 & 0,00 \\
\hline 2002 & 1269,90 & 922,00 & 783,50 & 486,40 & 138,50 \\
\hline 2003 & 989,00 & 953,00 & 898,50 & 90,50 & 54,50 \\
\hline 2004 & 1201,60 & 950,80 & 950,80 & 250,80 & 0,00 \\
\hline 2005 & 1223,90 & 975,00 & 822,00 & 401,90 & 153,00 \\
\hline 2006 & 1064,70 & 950,00 & 906,10 & 158,60 & 43,90 \\
\hline 2007 & 1032,00 & 927,00 & 810,00 & 222,00 & 117,00 \\
\hline 2008 & 644,40 & 968,00 & 590,60 & 73,80 & 377,40 \\
\hline 2009 & 969,10 & 952,00 & 774,30 & 194,80 & 177,70 \\
\hline
\end{tabular}

\begin{tabular}{|c|c|c|c|c|c|}
\hline Promedio & 1075,57 & 946,78 & 807,28 & 270,49 & 139,50 \\
\hline Máximo & 1444,30 & 975,00 & 950,80 & 511,30 & 377,40 \\
\hline Mínimo & 644,40 & 922,00 & 590,60 & 73,80 & 0,00 \\
\hline
\end{tabular}

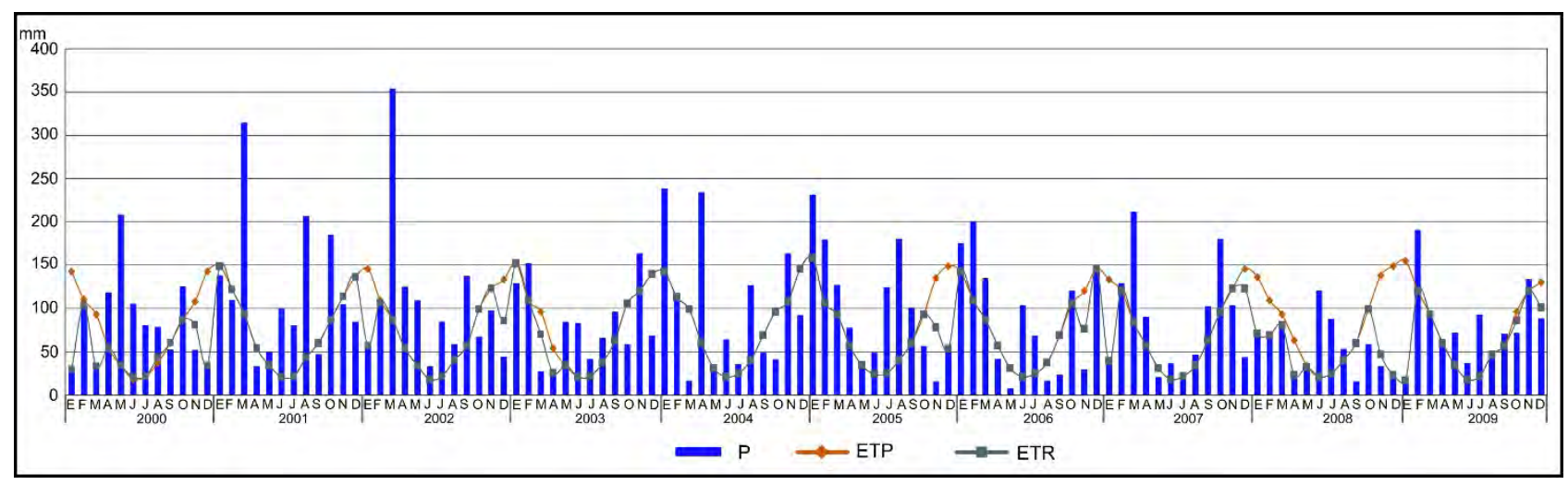

Figura 3.11. Valores promedios mensuales de precipitación (P), evapotranspiración potencial (ETP) y real (ETR) para el período 2000 2009 de la estación meteorológica Punta Indio.

Para la estación Dolores los valores anuales, promedio, máximo y mínimo de precipitación, ETP, evapotranspiración real (ETR), excesos y déficits de agua en el suelo se muestran en la Tabla 3.3. A partir del balance hídrico seriado (Fig. 3.12) se registra que, para la mayoría de los años del periodo estudiado, entre los meses de marzo a noviembre se producen excesos de agua. El déficit de agua se registra para todos los años (a excepción del año 2004) en el mes de diciembre. Además, el déficit se registra en los meses de 
septiembre, octubre y noviembre. En los meses de octubre y diciembre es donde, principalmente, se establece el uso de la reserva de agua en el suelo.

Tabla 3.3. Parámetros característicos del balance hídrico seriado a nivel de suelo para la estación meteorológica de Dolores. P (precipitaciones), ETP (evapotranspiración potencial), ETR (evapotranspiración real).

\begin{tabular}{|c|c|c|c|c|c|}
\hline Añ̄o & $P(\mathrm{~mm})$ & ETP $(\mathrm{mm})$ & ETR $(\mathrm{mm})$ & $\begin{array}{c}\text { Exceso de } \\
\text { agua }(\mathrm{mm})\end{array}$ & $\begin{array}{c}\text { Déficit de } \\
\text { agua }(\mathrm{mm})\end{array}$ \\
\hline 2000 & 1044,90 & 805,10 & 805,10 & 239,80 & 0,00 \\
\hline 2001 & 1015,90 & 805,00 & 724,60 & 291,30 & 80,40 \\
\hline 2002 & 1275,10 & 831,00 & 807,70 & 467,40 & 23,30 \\
\hline 2003 & 994,30 & 805,80 & 805,80 & 188,50 & 0,00 \\
\hline 2004 & 832,90 & 829,00 & 769,20 & 63,70 & 59,80 \\
\hline 2005 & 900,70 & 807,00 & 796,30 & 104,40 & 10,70 \\
\hline 2006 & 1019,80 & 821,00 & 817,40 & 202,40 & 3,60 \\
\hline 2007 & 944,20 & 832,00 & 820,50 & 123,70 & 11,50 \\
\hline 2008 & 758,80 & 865,00 & 711,30 & 47,50 & 153,70 \\
\hline 2009 & 832,90 & 838,00 & 713,10 & 119,80 & 124,90 \\
\hline
\end{tabular}

\begin{tabular}{|c|c|c|c|c|c|}
\hline Promedio & 961,95 & 823,89 & 777,10 & 184,85 & 46,79 \\
\hline Máximo & 1275,10 & 865,00 & 820,50 & 467,40 & 153,70 \\
\hline Mínimo & 758,80 & 805,00 & 711,30 & 47,50 & 0,00 \\
\hline
\end{tabular}

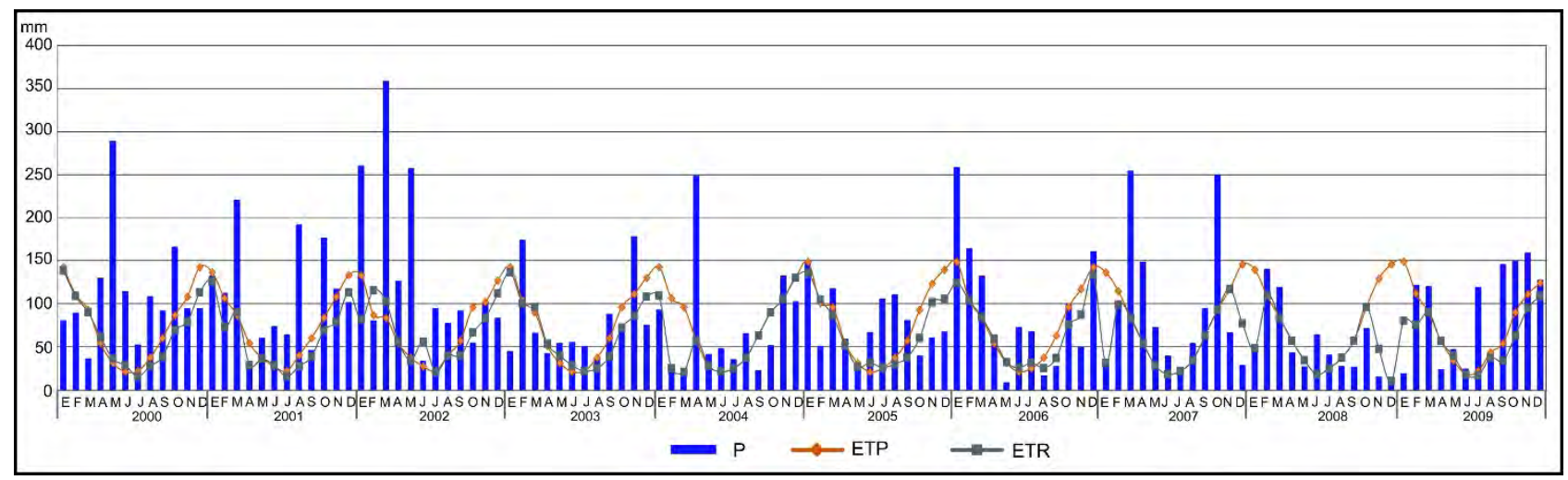

Figura 3.12. Valores promedios mensuales de precipitación (P), evapotranspiración potencial (ETP) y real (ETR) para el período 2000 2009 de la estación meteorológica Dolores.

\subsection{UNIDADES HIDROGEOLÓGICAS}

La zona de estudio se enmarca en la Región Hidrogeológica Noreste (González, 2005; Fig. 3.13). Esta unidad abarca una superficie de $31.900 \mathrm{~km}^{2}$ y se encuentra limitada al noroeste por el Arroyo del Medio (límite interprovincial entre las provincias de Santa Fe y Buenos Aires), al noreste por los ríos Paraná y de la Plata y al sur por la divisoria con la cuenca de los ríos Samborombón y Salado. 


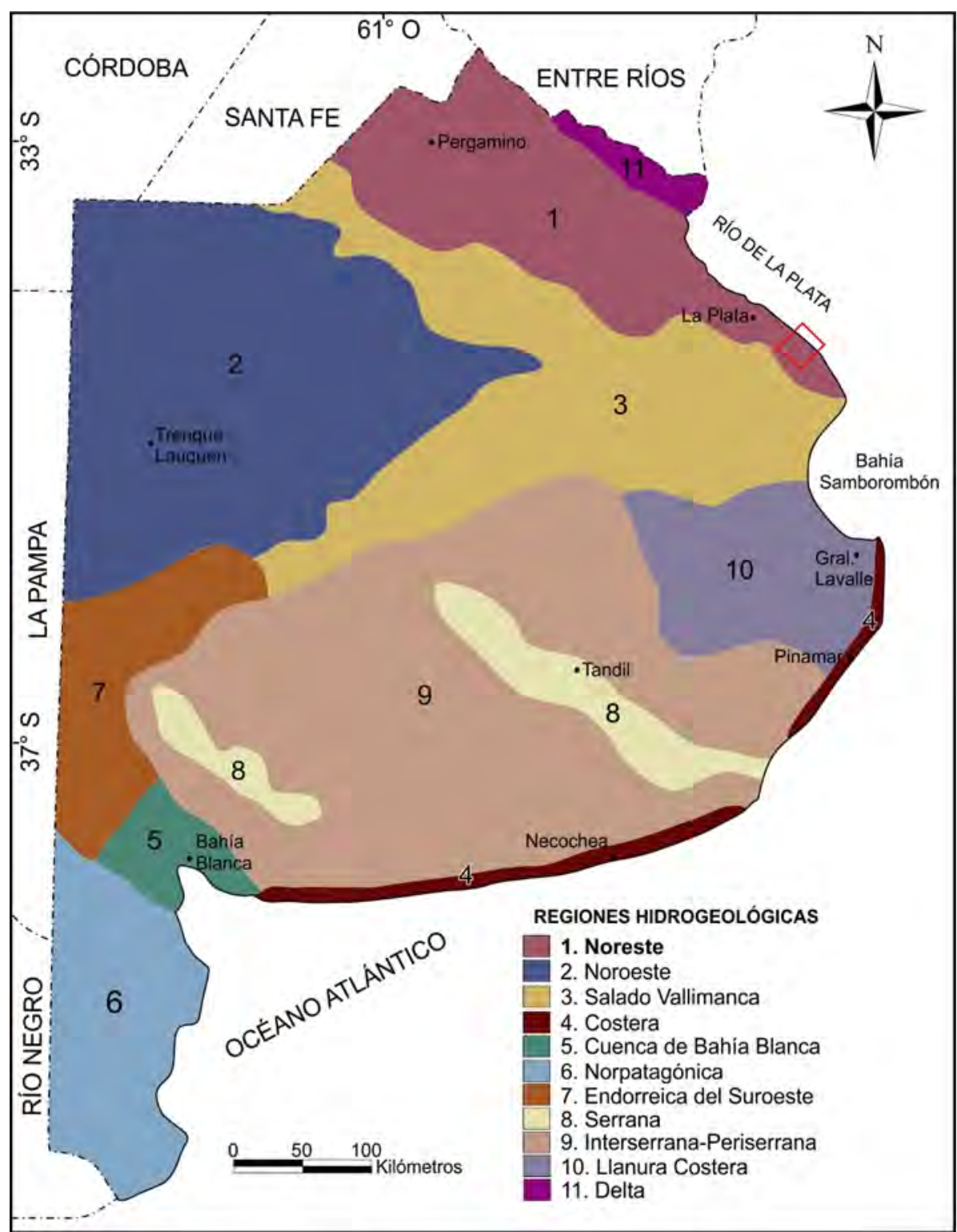

Figura 3.13. Regiones hidrogeológicas de la provincia de Buenos Aires (modificado de González, 2005). El recuadro rojo corresponde al área de estudio.

Las unidades geológicas descriptas previamente (Sección 3.1) muestran distintos comportamientos hidrolitológicos que definen la configuración física del sistema geohidrológico de la Región Hidrogeológica Noreste (González, 2005). Estas unidades y su comportamiento hidrolitológico se pueden describir a partir de la información antecedente de subsuelo proveniente de perforaciones de esta región. La perforación hecha por la Dirección Provincial de Hidráulica en la Plaza de Armas, ciudad de La Plata, fue realizada hasta una profundidad de $-476 \mathrm{~m}$ s. n. m. alcanzando el basamento cristalino (Fig. 3.14). Por otro lado, la perforación ejecutada por E.A.S.N.E. (Sala, 1972) en la localidad de Monte Veloz, partido de Punta Indio, alcanzó una profundidad de $-692,50$ m s. n. m. sin llegar al basamento (Fig. 3.14). Las dos perforaciones se ubican hacia el borde noreste de la Cuenca del Salado en el ámbito de la llanura loessica y representan las 
secuencias sedimentarias de edad Oligoceno - Pleistoceno. A continuación, se describen las unidades hidrogeológicas en orden temporal de la más antigua a la más joven (Fig. 3.14).

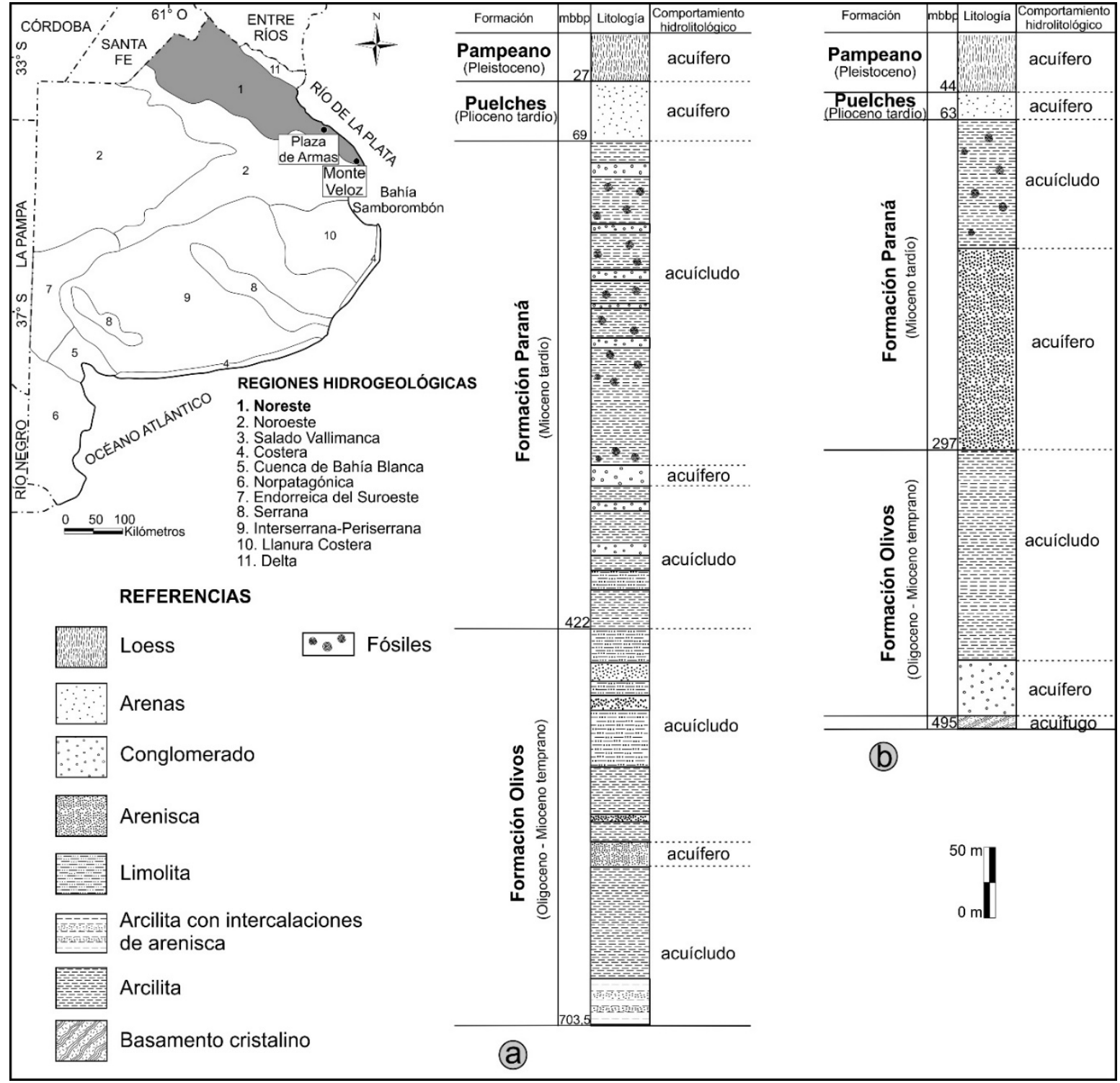

Figura 3.14. Columnas estratigráficas realizadas a partir de datos de las perforaciones existentes. (a) Monte Veloz, Partido de Punta Indio, ejecutada por el EASNE. (b) Plaza de Armas, La Plata, ejecutada por la Dirección Provincial de Hidráulica. Las columnas incluyen el comportamiento hidrolitológico de las unidades geológicas. La ubicación geográfica de las columnas se encuentra en el mapa de regiones hidrogeológicas de la provincia de Buenos Aires.

El basamento cristalino, que fue alcanzado a $-467 \mathrm{~m} \mathrm{~s}$. n. m. en la perforación Plaza de Armas, constituye el sustrato hidrogeológico de todas las unidades y presenta características acuífugas (Auge et al., 2002; González, 2005).

La Formación Olivos en el pozo Plaza de Armas se ubica entre los -467 y -316 m s. n. m. mientras que en Monte Veloz comienza a los -411 m s. n. m. hasta el final de la perforación. Esta formación constituye una unidad hidrogeológica de comportamiento acuífero confinado en su base y acuícludo en el techo (González, 2005). El agua de los sectores acuíferos es de tipo clorurada con una salinidad de $24 \mathrm{~g} / \mathrm{L}$ (Cellone et al., 2014b). 
La Formación Paraná se ubica entre los -411 y -58 m s. n. m. en el pozo Monte Veloz y entre los -316 y -44 m s. n. m. en Plaza de Armas. La sección basal de esta unidad geológica presenta un comportamiento de tipo acuífero; en el pozo de Plaza de Armas este nivel se encuentra ubicado entre los -278 y -135 m s. $\mathrm{n}$. m., mientras que en Monte Veloz se localiza entre los $-308,50$ y -239,70 m s. n. m. Por otro lado, la sección superior se comporta como acuícluda y se encuentra en Plaza de Armas entre los -138 y $-44 \mathrm{~m} \mathrm{~s}$. n. m. y en Monte Veloz entre los -218,80 y -58 m s. n. m. El nivel acuífero de la sección basal de la Formación Paraná presenta aguas de tipo clorurada - sulfatada con salinidades de 1,97 g/L (Cellone et al., 2014b).

Por encima de las arcilitas de la Formación Paraná se encuentran las arenas de la Formación Puelches. En las perforaciones estudiadas el techo de esta unidad se ubica a -16 m s. n. m. en Plaza de Armas y a -33 m s. n. m. en Monte Veloz. Las arenas de la Formación Puelches alojan a un acuífero homónimo que es semiconfinado por las arcillas que conforman el techo de dicha formación. Este nivel acuífero presenta aguas de tipo bicarbonatada sódica con salinidades inferiores a $2 \mathrm{~g} / \mathrm{L}$ y debido a la buena calidad del agua y productividad constituye la principal fuente de abastecimiento de agua de la región (Auge et al., 2002; González, 2005).

La última unidad geológica identificada en las perforaciones estudiadas corresponde a la Formación Pampeano. Los limos que componen a esta formación alojan al acuífero Pampeano o freático. En algunos sectores existe un nivel de tosca dentro de los Sedimentos Pampeanos que hace que algunos autores dividan a este último acuífero en acuífero Pampeano (en la parte inferior) y freático (González, 2005). El acuífero Pampeano presenta un espesor de 16 metros en la perforación Monte Veloz y de 25 metros en Plaza de Armas (Fig. 3.14) y contiene agua bicarbonatada (con variedades sódica, cálcica y magnésica) con salinidades inferiores a 0,50 g/L (Cellone et al., 2014b). La recarga del acuífero Pampeano es autóctona y directa (a través de los excedentes hídricos) y constituye además la vía para la recarga del acuífero Puelche (indirecta por filtración vertical a través del acuitardo). Este flujo vertical descendente desde el acuífero Pampeano hacia el Puelche ocurre, principalmente, en las áreas de divisorias de cuenca ubicadas al oeste. Hacia la planicie costera del Río de la Plata, estudios efectuados en zonas adyacentes al área de estudio muestran que, si bien el nivel freático es levemente superior al nivel del acuífero semiconfinado, esta relación tendería a invertirse en la zona de plataforma del Río de la Plata donde ocurriría la descarga del acuífero Puelche (Kruse et al., 2013; Santucci et al., 2017a).

Las formaciones Puelches y Pampeano conforman un acuífero multicapa que representa la unidad hidrogeológica más superficial en la zona de llanura loessica. En la planicie costera distintas unidades hidrogeológicas se reconocen en los sedimentos más superficiales y serán descriptas en detalle en el Capítulo 4. 


\section{Capítulo 4. LAS CUENCAS DE LOS ARROYOS BUÑIRIGO Y JUAN BLANCO}

Los arroyos Buñirigo y Juan Blanco son los cursos de agua principales del área de estudio. El sector de planicie costera estudiado forma parte de la cuenca baja de ambos arroyos. En este capítulo se caracterizan distintos aspectos de las cuencas de los arroyos como son la geomorfología, la hidrodinámica e hidroquímica de las aguas superficiales, así como el comportamiento hidrolitológico de las unidades geológicas de subsuelo y la hidrodinámica e hidroquímica de las aguas subterráneas. Además, se analizan las precipitaciones lo cual, junto a otros parámetros climáticos, permite realizar el balance hídrico de las cuencas. La caracterización de todos estos aspectos para las cuencas de los arroyos Buñirigo y Juan Blanco permitirá describir y analizar en más detalle la hidrodinámica e hidroquímica de la planicie costera en los Capítulos 5 y 6 , respectivamente.

\subsection{GEOMORFOLOGÍA}

Los arroyos Buñirigo y Juan Blanco conforman cuencas hidrográficas de configuración aproximadamente rectangular y orientación suroeste - noreste y drenaje de tipo dendrítico (Fig. 4.1). La cuenca del arroyo Buñirigo presenta una superficie de $223 \mathrm{~km}^{2}$ y abarca un área dedicada principalmente a la actividad agrícola y ganadera, existiendo, además, en el tramo medio a bajo de la cuenca tres industrias (dos alimenticias y una curtiembre). Por su parte, el arroyo Juan Blanco presenta una superficie de $126 \mathrm{~km}^{2}$ y, principalmente, en su cuenca alta y media se desarrollan actividades agropecuarias. Las divisorias en nacientes de ambas cuencas tienen cotas cercanas a los $20 \mathrm{~m} \mathrm{~s}$. n. m., las cuales disminuyen a valores próximos a 0 m s. n. m. en su desembocadura, en el Río de la Plata. A continuación, se describen las unidades geomorfológicas, así como los suelos y vegetación asociada para ambas cuencas. Para esto se diferenció un sector de cuenca alta y media desarrollado en la llanura loessica y otro sector de cuenca baja correspondiente a la planicie costera.

\subsubsection{Cuenca alta y media de los arroyos Buñirigo y Juan Blanco}

\subsubsection{Llanura loessica}

La cuenca alta y media de los arroyos Buñirigo y Juan Blanco se desarrolla en la llanura loessica entre las cotas de 5 y 20 m s. n. m. (Fig. 4.1). 


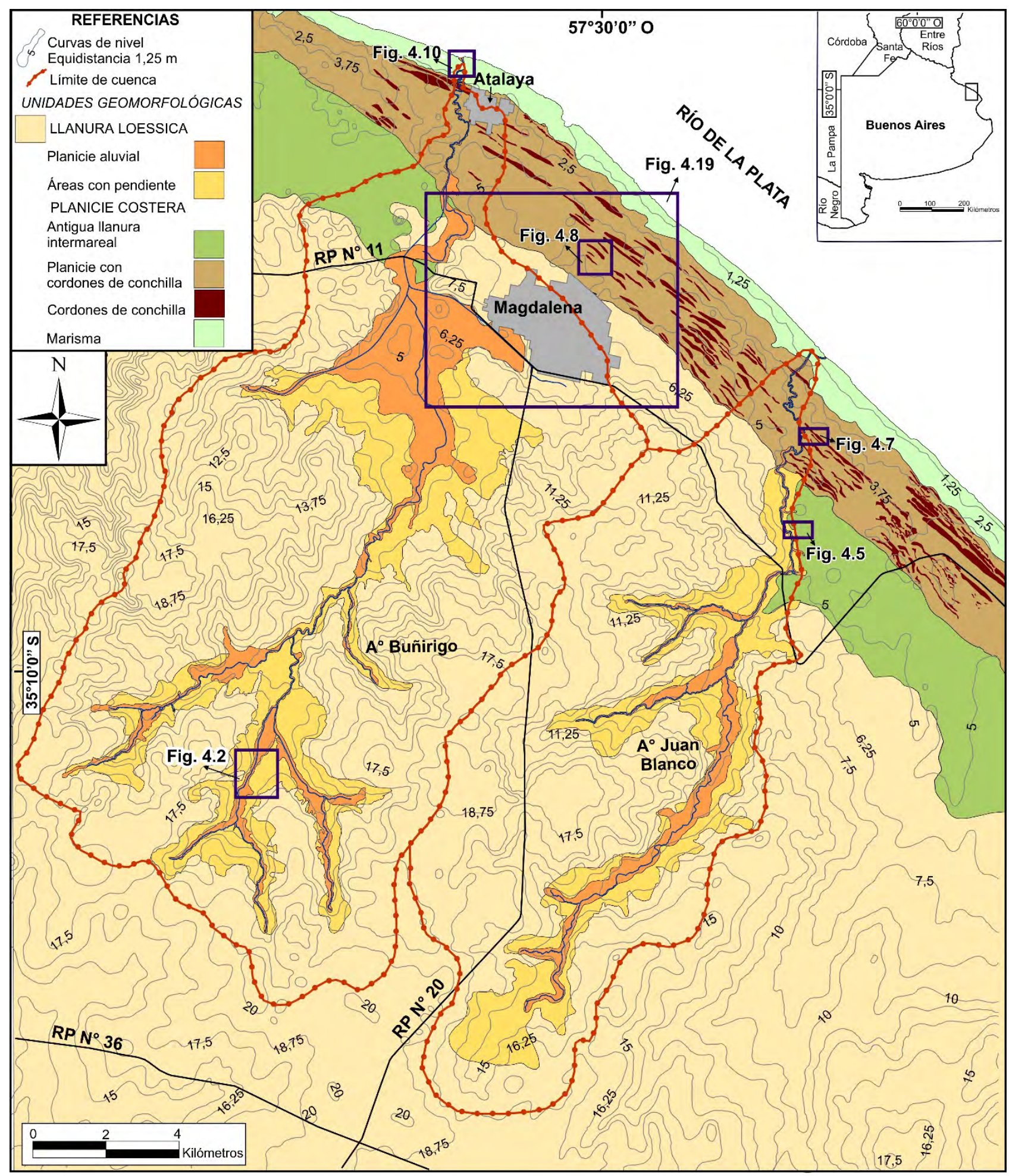

Figura 4.1. Mapa topográfico y geomorfológico del área de las cuencas de los arroyos Buñirigo y Juan Blanco, en el ámbito de la Ilanura loessica y la planicie costera. La figura, además, muestra la ubicación de las figuras 4.2, 4.5, 4.7, 4.8, 4.10 y 4.19.

En esta unidad geomorfológica, las zonas de divisorias de cuenca se caracterizan por presentar escasa pendiente (inferior a $1.10^{-3}$ ). Las planicies aluviales de ambos arroyos, formadas por depósitos de origen fluvial, comprenden las áreas adyacentes a los cauces (Fig. 4.1). Entre la llanura loessica y las planicies 
aluviales se reconocen sectores con pendientes del orden de $1.10^{-2}$ y con rasgos marcados de erosión hídrica (áreas con pendiente, Hurtado et al. 2006; Fig. 4.2).

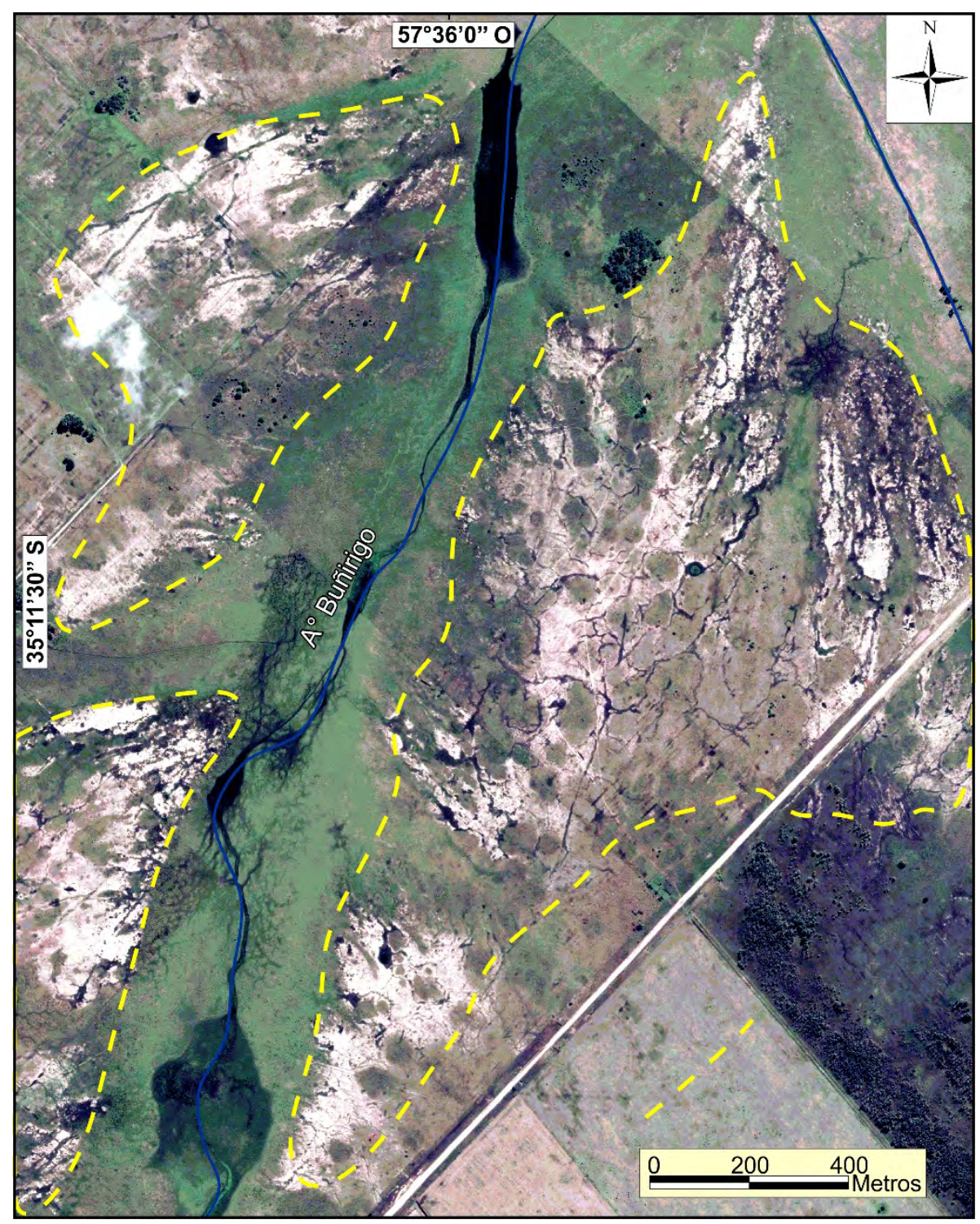

Figura 4.2. Imagen satelital de un sector de la cuenca superior del arroyo Buñirigo. Las líneas punteadas corresponden a las áreas con pendiente que presentan rasgos de erosión hídrica. Ubicación regional en la figura 4.1.

En las zonas próximas a las divisorias de ambos arroyos se desarrollan suelos de tipo Paleudol vértico (margen izquierda del arroyo Buñirigo, Fig. 4.3) y Hapludert típico (margen derecha del arroyo Buñirigo y ambas márgenes del arroyo Juan Blanco, Fig. 4.3). Los suelos presentan perfiles arcillo - limosos hasta los dos metros de profundidad, y son pobremente drenados con escurrimiento y permeabilidad lenta (INTA, 2011). Debido a estas características, se producen anegamientos en periodos lluviosos por recarga rechazada (Fig. 4.4). 


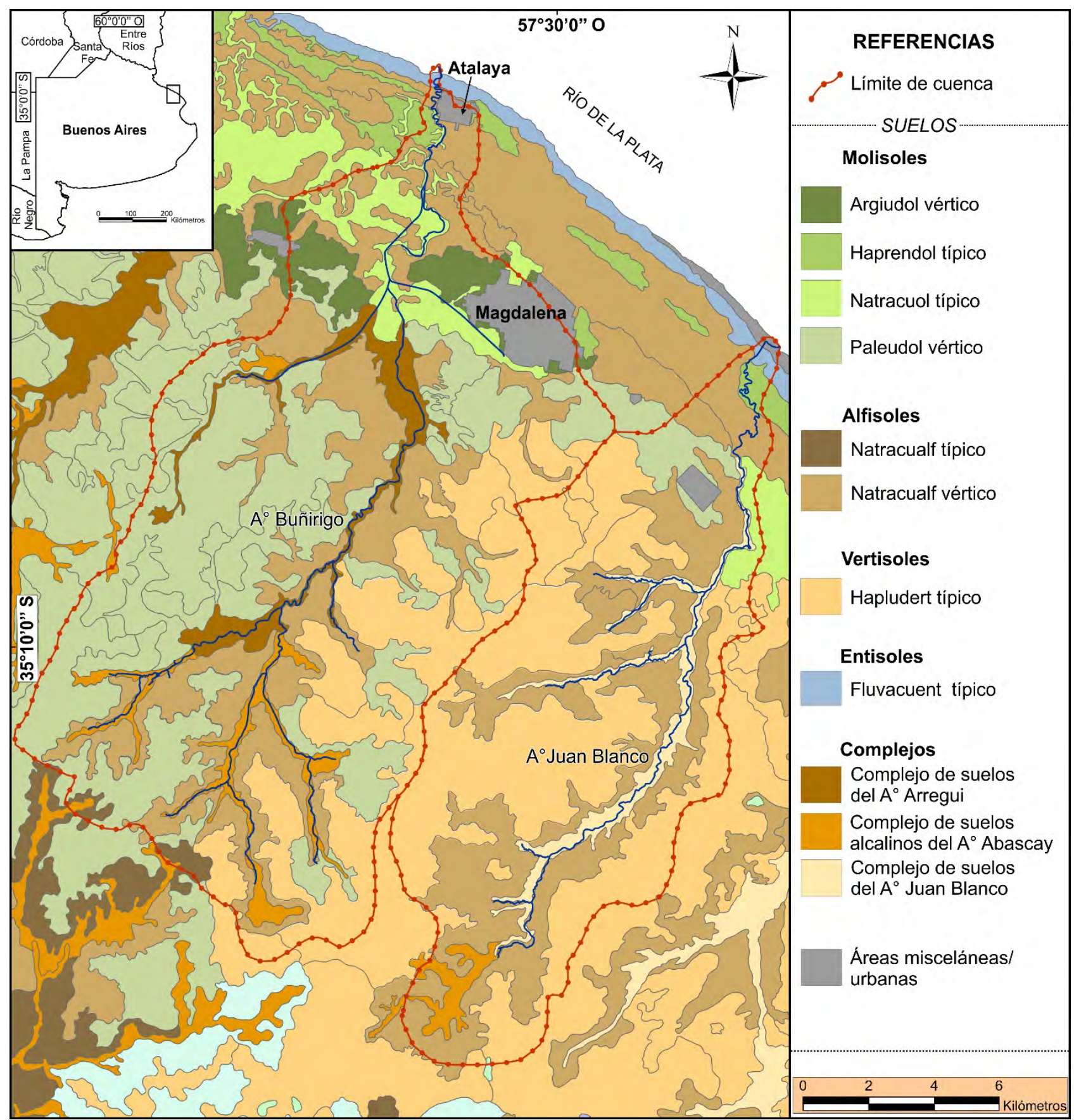

Figura 4.3. Mapa de suelos para las cuencas de los arroyos Buñirigo y Juan Blanco (mapa basado en las cartas de suelos del INTA, 2011).

La vegetación de las zonas próximas a las divisorias de los arroyos Buñirigo y Juan Blanco está constituida por pasto miel (Paspalum dilatatum), cebadilla (Bromus unioloides), cardo de castilla (Cynara cardunculus), abrojo (Xanthium spinosum) y gramilla (Cynodon dactylon) (INTA, 2011).

Las áreas con pendiente presentan suelos de tipo Natracualf vértico (Fig. 4.3), con un perfil arcillo limoso. Son suelos pobremente drenados, característica que junto con la mayor pendiente favorece el escurrimiento superficial. Presentan alcalinidad sódica (presencia de sodio intercambiable) que afecta la 
estructura del suelo ocasionando que el material superficial se desagregue y sea más fácilmente erosionable (INTA, 2011). En este tipo de suelos la vegetación característica es el pelo de chancho (Distichlis scoparia). Por su capacidad de uso estos suelos se utilizan principalmente en la actividad ganadera.

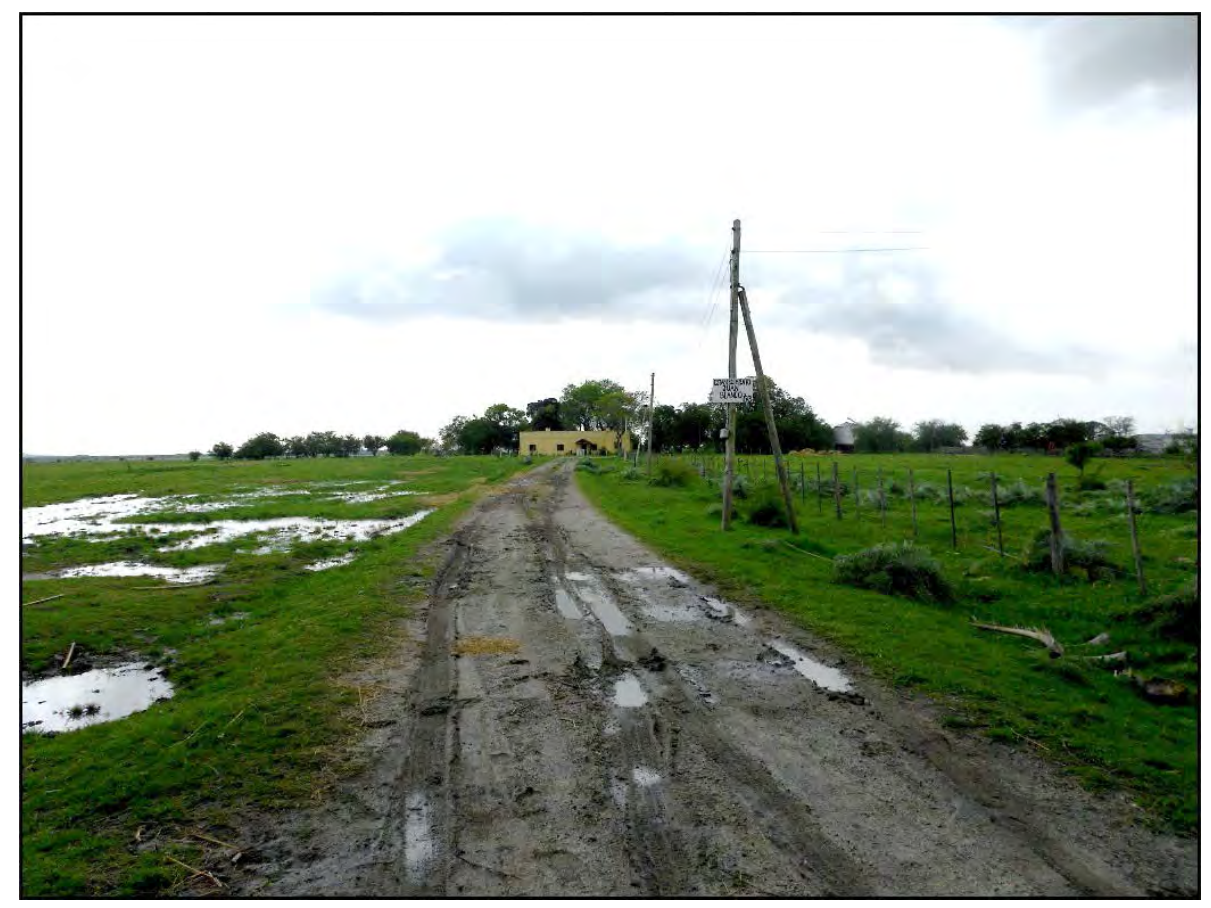

Figura 4.4. Anegamiento por recarga rechazada en la margen izquierda del arroyo Juan Blanco.

\subsubsection{Cuenca baja de los arroyos Buñirigo y Juan Blanco}

La cuenca baja de los arroyos Buñirigo y Juan Blanco se desarrolla en la planicie costera entre las cotas de 5,00 y $0 \mathrm{~m} \mathrm{s.} \mathrm{n.} \mathrm{m.} \mathrm{En} \mathrm{este} \mathrm{ámbito} \mathrm{se} \mathrm{reconocen} \mathrm{distintas} \mathrm{geoformas:} \mathrm{antigua} \mathrm{llanura} \mathrm{intermareal,}$ planicie con cordones de conchilla y marisma (Cellone et al. 2014a; Fig. 4.1).

\subsubsection{Antigua llanura intermareal}

Constituye la unidad más interna de la planicie costera. Presenta una superficie llana desarrollada entre las cotas de 5,00 y 3,75 m s. n. m. con un ancho máximo aproximado de 5 kilómetros. Representa la zona intermareal vinculada a una profusa red de drenaje con un sistema de antiguos canales de marea (Fig. 4.5). En este subambiente, pueden distinguirse dos tipos de suelos, uno asociado a los antiguos canales de marea y el otro vinculado a las zonas más elevadas comprendidas entre dichos canales (INTA, 2011).

Los suelos asociados a los antiguos canales de marea son de moderado desarrollo, pobremente drenados y de permeabilidad lenta. Presentan texturas franco limosas a franco arcillosas en los horizontes superficiales a arcillo limosas en profundidad. Son débilmente salinos y presentan una fuerte alcalinidad, con valores elevados de sodio intercambiable. Por sus características los suelos se clasifican como Natracuol 
típico (Fig. 4.3). La vegetación encontrada en los antiguos canales de marea está constituida por pajonales de carda con Eryngium eburneum como especie dominante y duraznillares (Solanum glaucophyllum) (Fig. 4.6).

Los suelos que se desarrollan entre los antiguos canales de marea se clasifican como Natracualf vértico (Fig. 4.3). Son suelos muy pobremente drenados y de lenta permeabilidad, debido a que presentan un perfil con textura arcillosa que pasa a franco arenosa al metro de profundidad. Son fuertemente alcalinos en casi todo el perfil a causa de los muy altos valores de sodio intercambiable. Algunos horizontes presentan también altos contenidos de sales solubles. La cobertura vegetal en este tipo de suelos es muy baja ya que son pocas las comunidades de plantas que pueden adaptarse a estas condiciones. Las especies dominantes pertenecen a comunidades de pradera halófila y son principalmente Distichlis spicata y Distichlis scoparia.

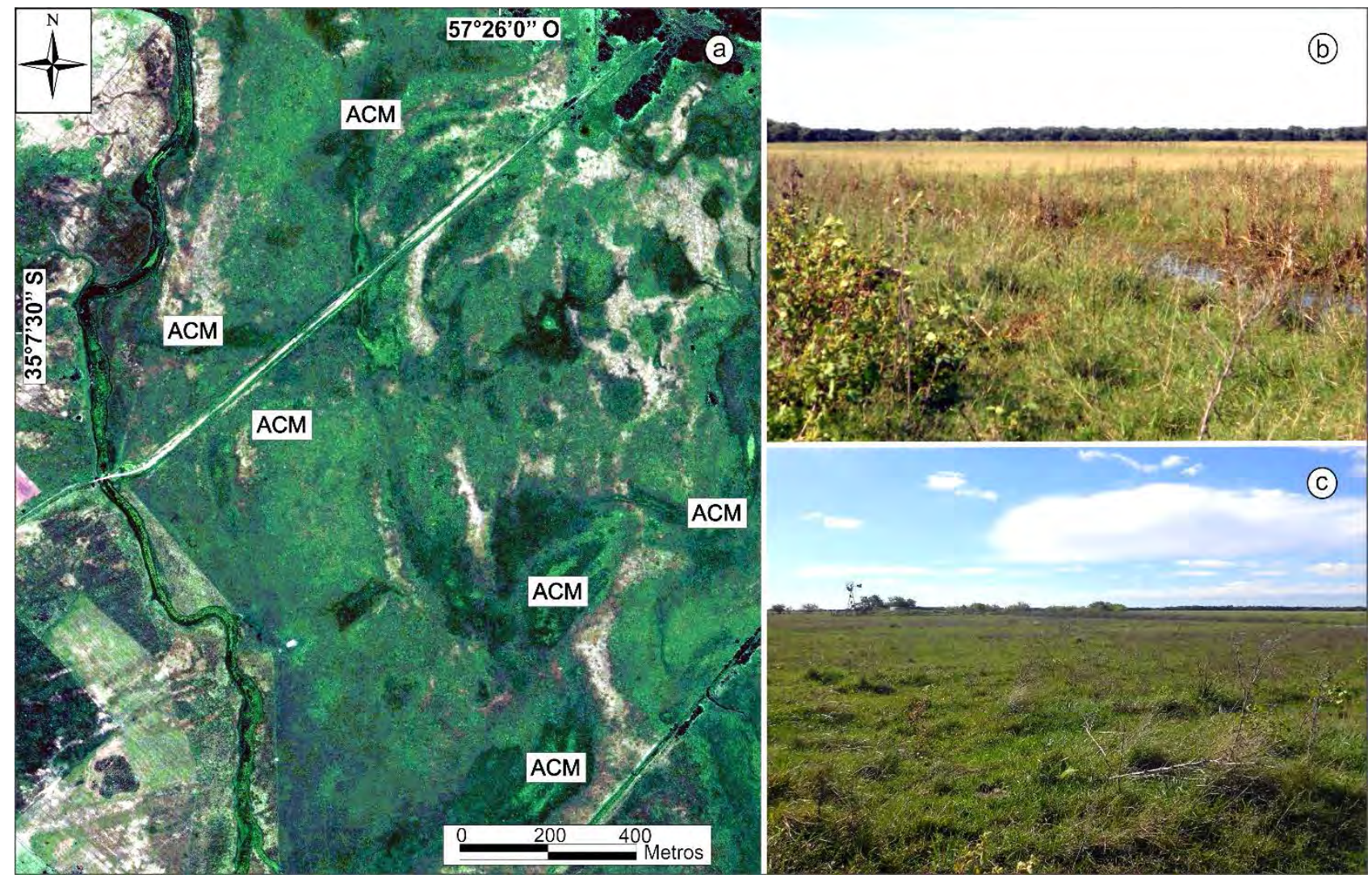

Figura 4.5. Antigua llanura intermareal. (a) Imagen satelital mostrando los antiguos canales de marea (ACM). (b) y (c) Fotografías que ilustran este subambiente de la planicie costera. La ubicación regional de la imagen satelital se muestra en la figura 4.1. 


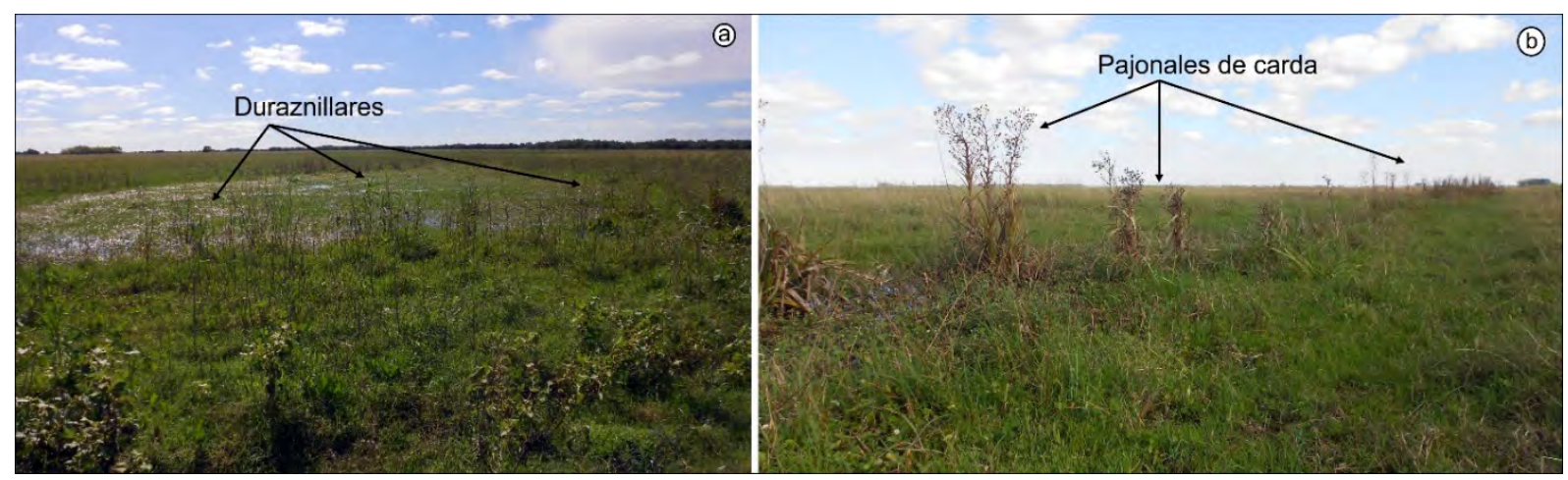

Figura 4.6. Vegetación característica del subambiente de antigua llanura intermareal. (a) Duraznillares. (b) Pajonales de carda.

\subsubsection{Planicie con cordones de conchilla}

Representa el rasgo topográfico más notable de la planicie costera (Fig. 4.1). Los cordones de conchilla constituyen geoformas longitudinales de relieve positivo con cotas que se encuentran aproximadamente entre los 5,00 y $2,50 \mathrm{~m} \mathrm{~s}$. n. m. Se disponen en forma subparalela entre sí y a la costa actual, y están separados por zonas denominadas intercordones. En su estado natural, en imágenes satelitales, los cordones se distinguen fácilmente por su abundante cobertura vegetal y, en el campo, estos constituyen suaves ondulaciones del terreno (Fig. 4.7).

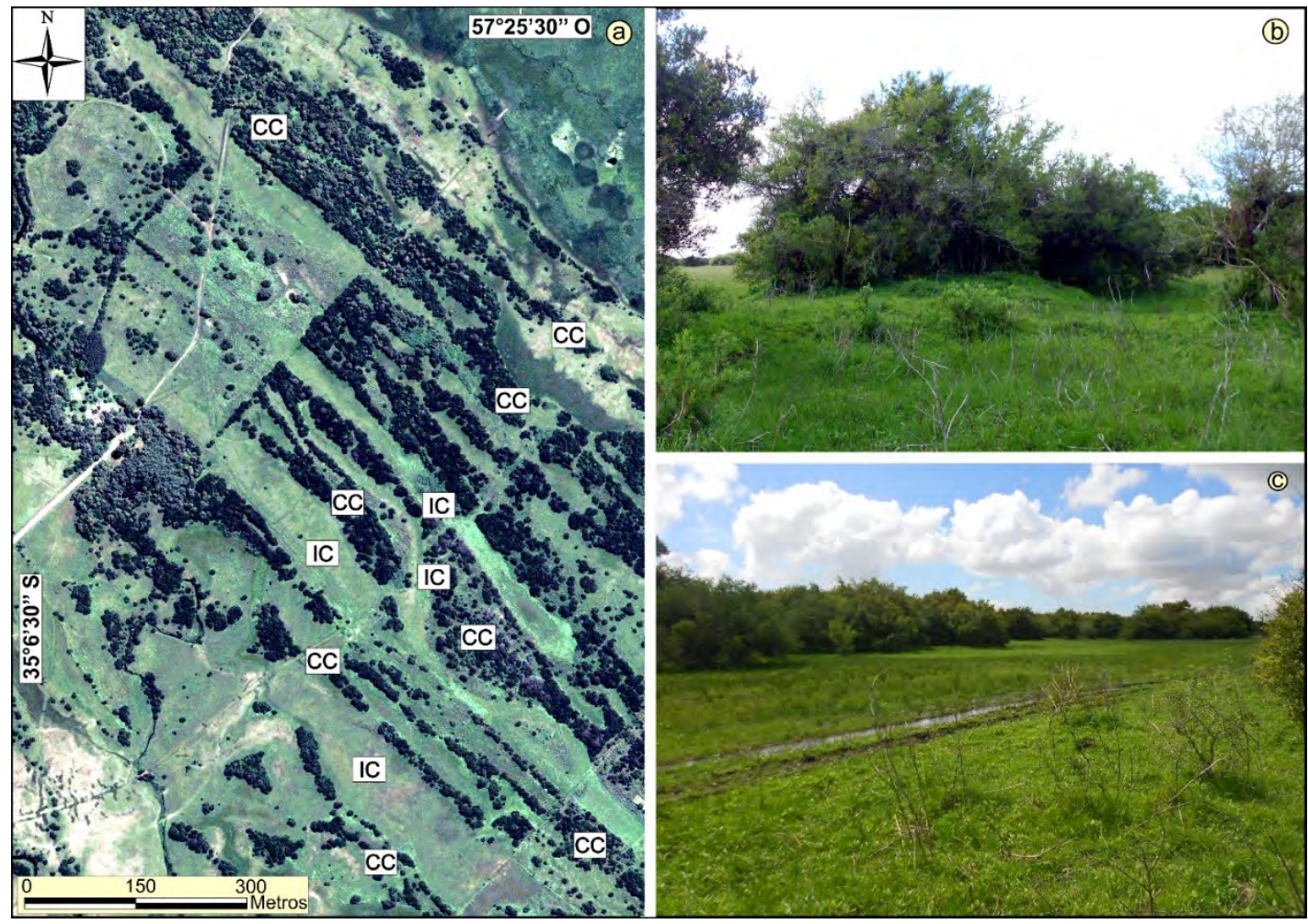

Figura 4.7. Planicie con cordones de conchilla. (a) Imagen satelital. Las geoformas longitudinales con abundante vegetación corresponden a los cordones de conchilla (CC). Las áreas sin vegetación ubicadas entre los cordones de conchilla corresponden a los intercordones (IC). (b) y (c) Fotografías de los cordones de conchilla con su vegetación característica (bosques de tala). La ubicación regional de la imagen satelital se muestra en la figura 4.1. 
Los cordones están constituidos por restos de valvas de moluscos en grados diversos de conservación que alternan con niveles de arenas y arcillas. En las zonas de intercordón los sedimentos más superficiales tienden a ser arcillosos pasando luego a capas de arenas y conchilla similares a las reconocidas en el cordón. Desde el siglo XX, los cordones son explotados como material carbonático y áridos. Esta actividad minera, entre principios y mediados del siglo XX, no contaba con ninguna regulación minero - ambiental, por lo tanto, hoy en día no existe un registro concreto de las superficies y volúmenes explotados. En la actualidad, gran parte de los cordones de conchilla perdieron su morfología original debido a que, por ejemplo, fue removida su vegetación autóctona para la siembra de pasturas (Fig. 4.8).

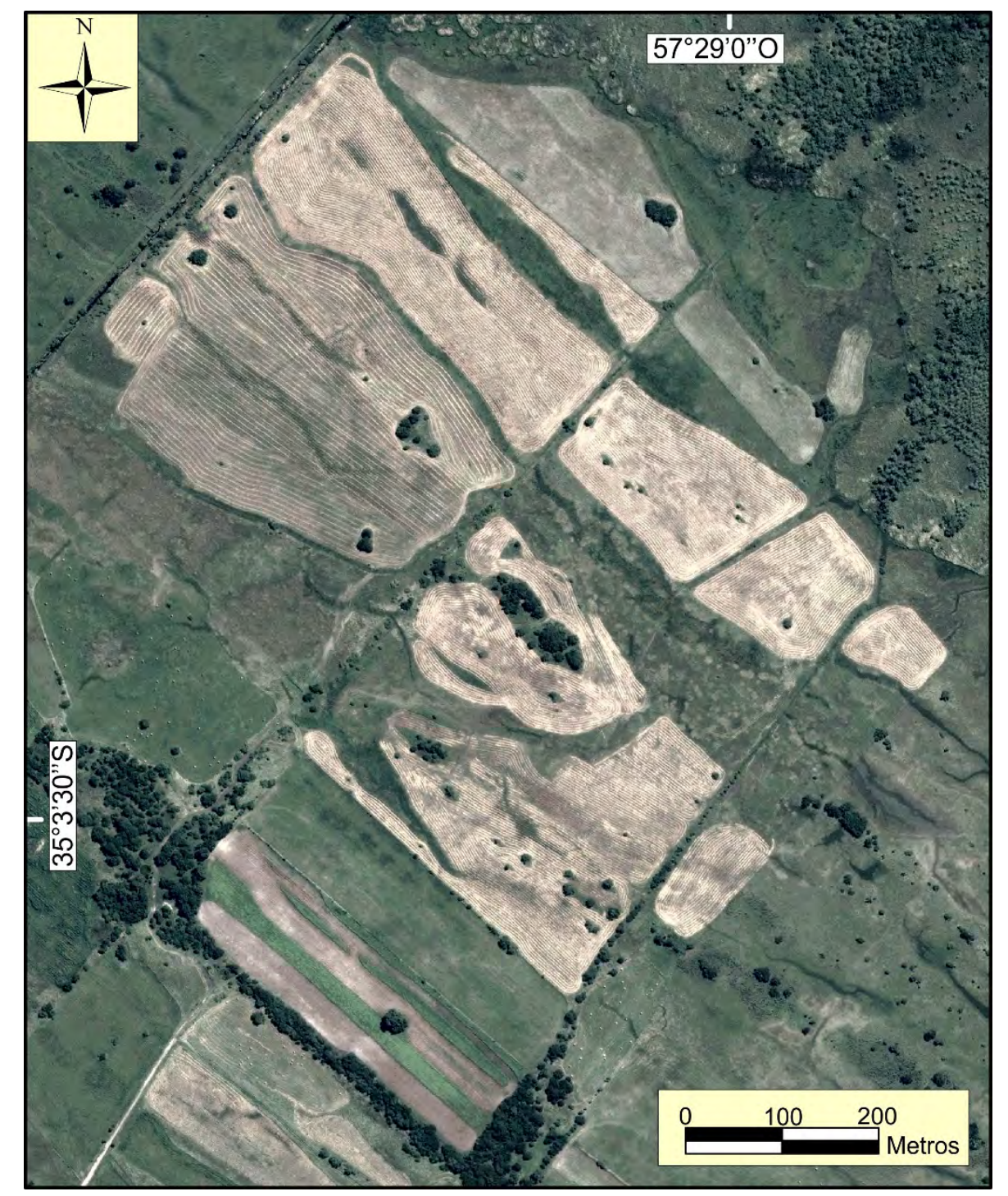

Figura 4.8. Imagen satelital de cordones de conchilla sembrados con pasturas para el desarrollo de la actividad ganadera. La ubicación regional de la imagen satelital se indica en la figura 4.1. 
Los suelos desarrollados en los cordones de conchilla se clasifican taxonómicamente como Haprendol típico (Fig. 4.3). Presentan un drenaje excesivo, una permeabilidad modera y tienen perfiles con un incipiente desarrollo de horizontes debido al efecto de floculación del calcio. La textura va de franco arenosa a areno franca en profundidad. Son suelos sin alcalinidad sódica ni salinidad (INTA, 2011). La vegetación asociada a estos suelos está representada por los bosques de talas (Figs. 4.7 b y c). Éstos pueden estar dominados por el tala (Celtis tala), por el coronillo (Scutia buxifolia) o presentar ambas especies (Arturi y Goya, 2004; Fig. 4.9). Además de las especies dominantes pueden hallarse Jodina rhombifolia, Schinus longifolius, Sambucus australis y Phytolacca dioica como especies acompañantes.

El intercordón presenta suelos de tipo Natracualf vértico; el primer metro de estos suelos posee textura arcillosa que luego pasa de forma abrupta a franco - arenosa (INTA, 2011). La vegetación presente en los intercordones corresponde a pastizales hagrófilos con comunidades como Eryngium cabrerae y Stipa charruana y Eryngium cabrerae (Cagnoni et al., 1996).

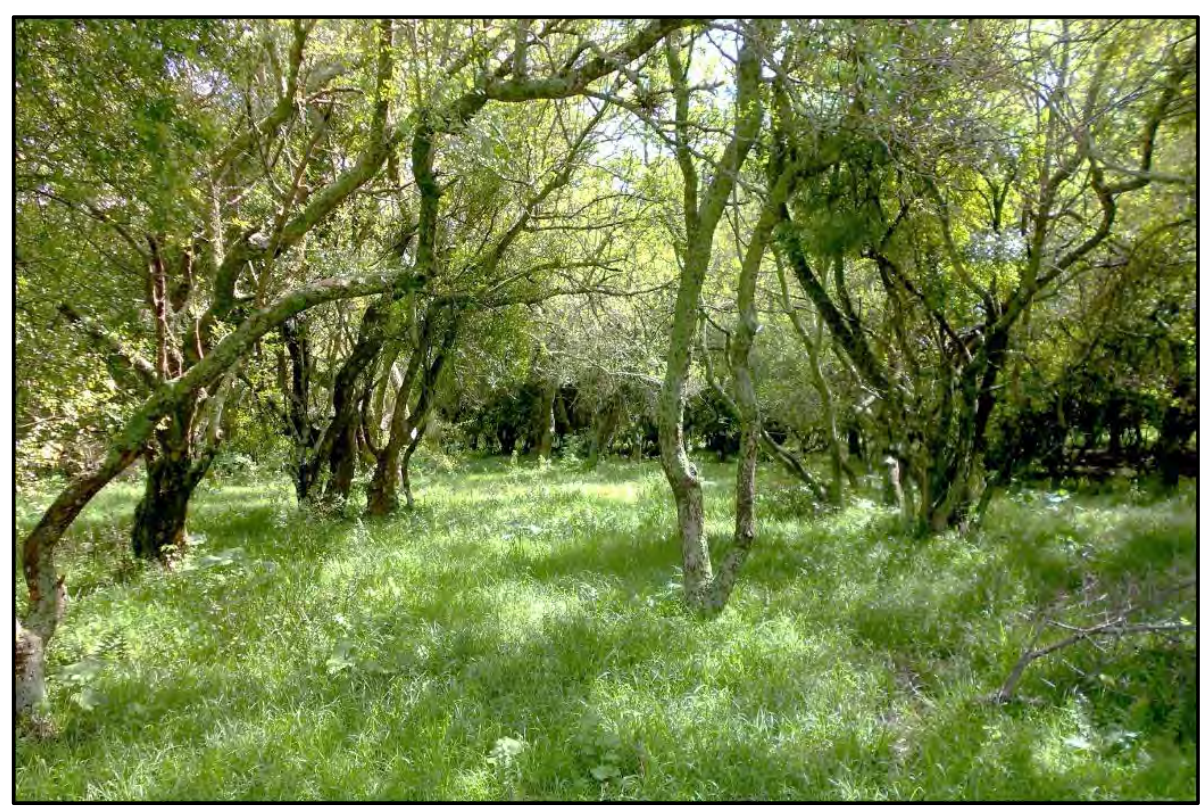

Figura 4.9. Bosque de tala (Celtis tala), Vegetación típica del subambiente de planicie con cordones de conchilla.

\subsubsection{Marisma}

La marisma constituye una franja paralela al Río de la Plata de aproximadamente 700 metros de ancho, emplazada por debajo de la cota de 2,50 m s. n. m. (Fig. 4.1). Es un área inundable, con agua en superficie durante gran parte del año, que recibe el flujo mareal desde el estuario (Fig. 4.10). Los suelos de este ambiente son Natracualf típico, Epiacuert típico y Fluvacuent típico (INTA, 2011; Fig. 4.3). Los Natracualf típico presentan altos contenidos de sodio intercambiable y sales solubles en los horizontes superficiales, además de rasgos hidromórficos, debido a que se desarrollan en áreas bajas con deficiencia de drenaje. Los 
Epiacuert típico presentan un drenaje pobre por anegamiento frecuente, rasgos hidromórficos (moteados de hierro, concreciones de hierro y manganeso) y vérticos muy bien expresados y permeabilidad muy lenta. Por su parte, los Fluvacuent típico son suelos con poco grado de edafización, muy pobremente drenados, bajo contenido de materia orgánica y de escurrimiento muy lento a nulo, lo que ocasiona que se encuentren húmedos gran parte del año y saturados en profundidad. La vegetación asociada a este ambiente está adaptada para vivir por largos períodos de tiempo en suelos con saturación de agua, y está representada por comunidades herbáceas ribereñas (Cagnoni et al., 1996; Fig. 4.11).

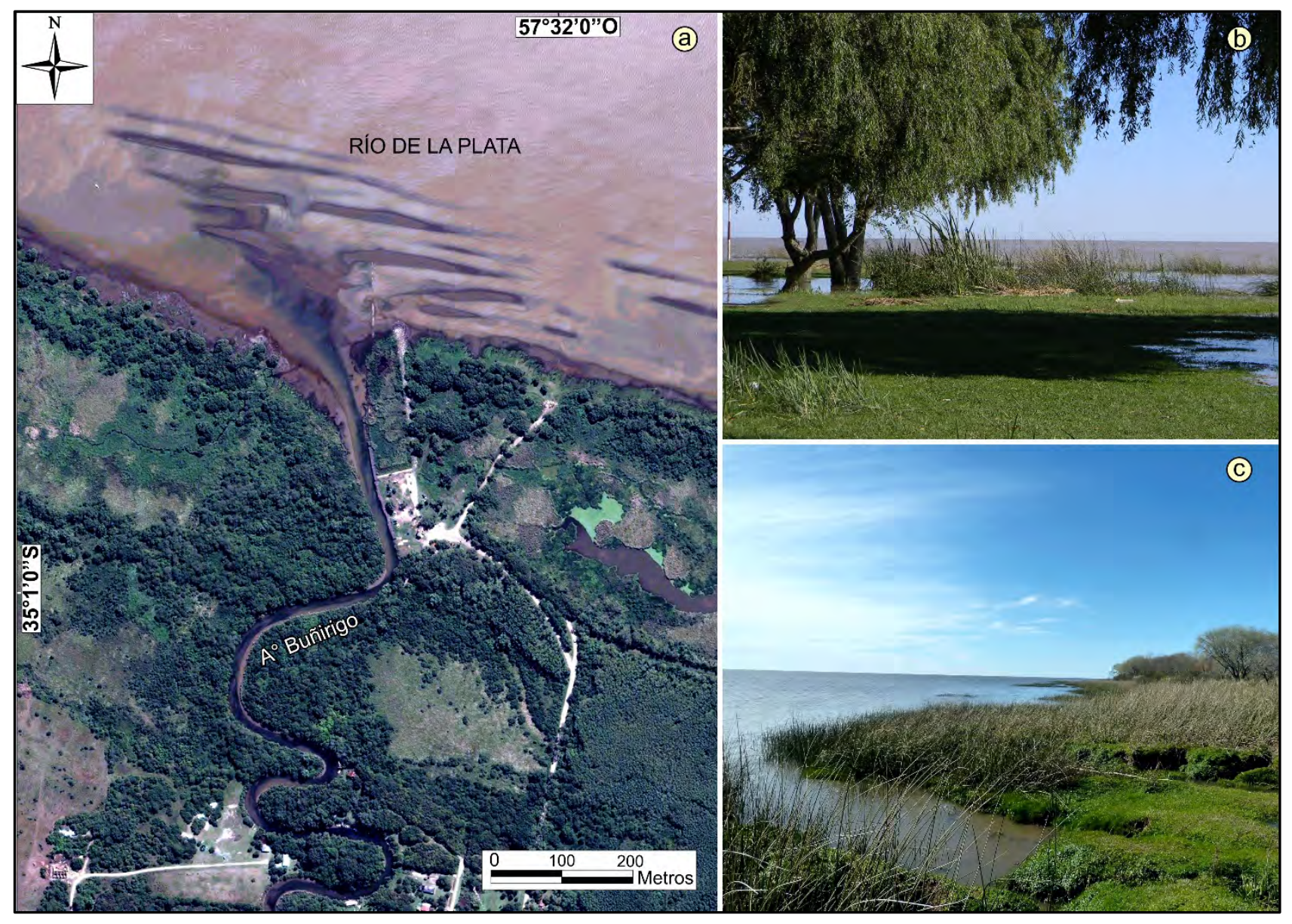

Figura 4.10. Marisma. (a) Imagen satelital de la marisma en la zona de desembocadura del arroyo Buñirigo, en la costa del Río de la Plata. (b) y (c) Marisma en la zona costera del Río de la Plata (Balneario Municipal de Atalaya). La ubicación regional de la imagen satelital se indica en la figura 4.1 . 


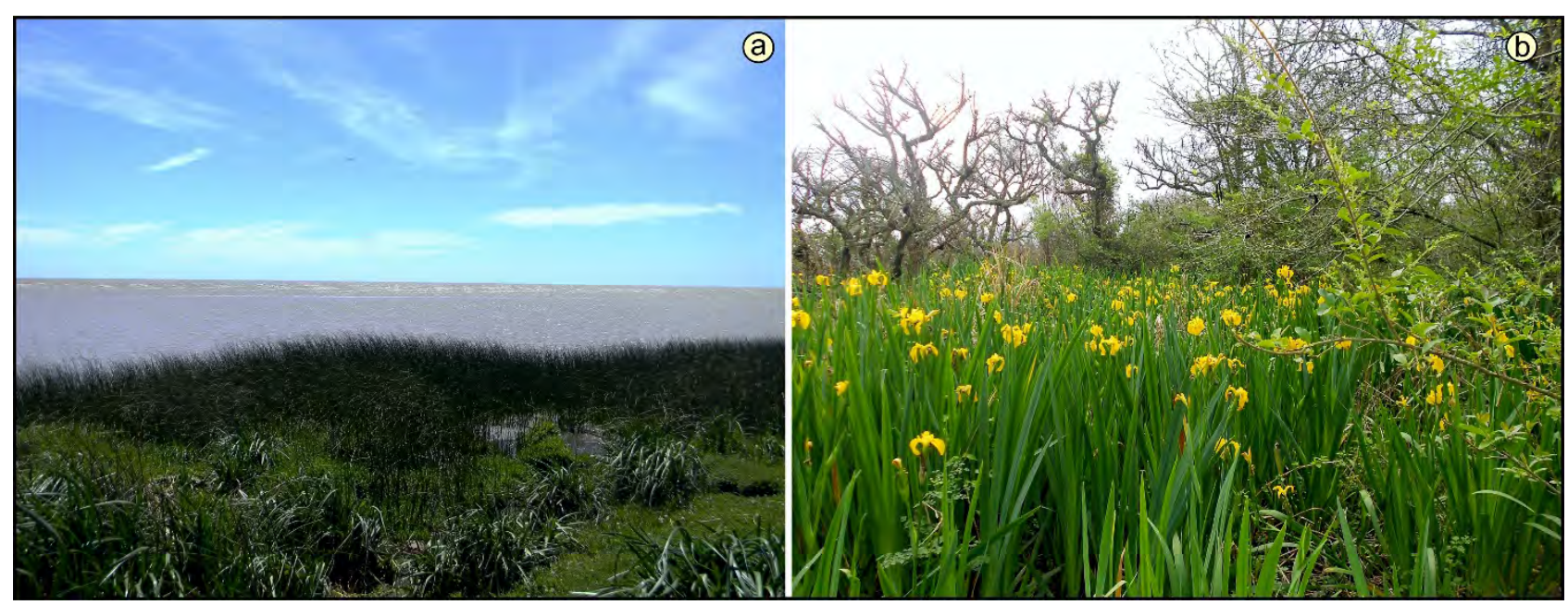

Figura 4.11. Vegetación en el subambiente de la marisma. (a) Juncales (Schoenoplectus californicus) en la costa del Río de la Plata. (b) Lirios amarillos (Iris pseudacorus) en la margen del arroyo Buñirigo.

\subsection{PRECIPITACIONES Y BALANCE HÍDRICO}

El análisis de las precipitaciones para las cuencas de los arroyos Buñirigo y Juan Blanco se realizó en base a un registro de 12 años que abarca desde enero de 2003 hasta diciembre de 2015. Los registros corresponden a la cuenca baja del arroyo Buñirigo $\left(35^{\circ} 4^{\prime} 24^{\prime \prime} \mathrm{S}-57^{\circ} 32^{\prime} 3^{\prime \prime}\right.$ ) ) y fueron aportados por la Sociedad Rural de Magdalena. Los datos de precipitación conciernen a mediciones diarias registradas en un pluviómetro instalado en el predio de dicha institución. Con los datos se calcularon las precipitaciones anuales y las medias mensuales para el período indicado.

La precipitación media anual para la zona de estudio es de $1035 \mathrm{~mm}$. Teniendo en cuenta este valor promedio se registraron los años más y menos lluviosos (Fig. 412). De esta manera, el 2003 (1148 mm), 2006 (1212 mm), 2007 (1148 mm), 2010 (1119 mm) y $2012(1075 \mathrm{~mm})$ son años muy lluviosos con valores de precipitaciones anuales por encima de la media. Por otro lado, los años menos lluviosos, con registros anuales por debajo del promedio, son el 2004 (1007,5 mm), 2005 (958 mm), $2013(979 \mathrm{~mm})$ y $2015(984 \mathrm{~mm})$. Se identificaron también los años extremos teniendo en cuenta el valor de la media más o menos un desvío estándar ( $\pm 242 \mathrm{~mm}$ ). De esta manera además de la tendencia central de los datos del registro se tiene en cuenta la dispersión de los datos respecto de este valor. Así, el año 2014 con un registro de 1546 mm es el año más lluvioso y los años 2008 y 2011 con 553 y 673 mm respectivamente, son los años con menores precipitaciones. 


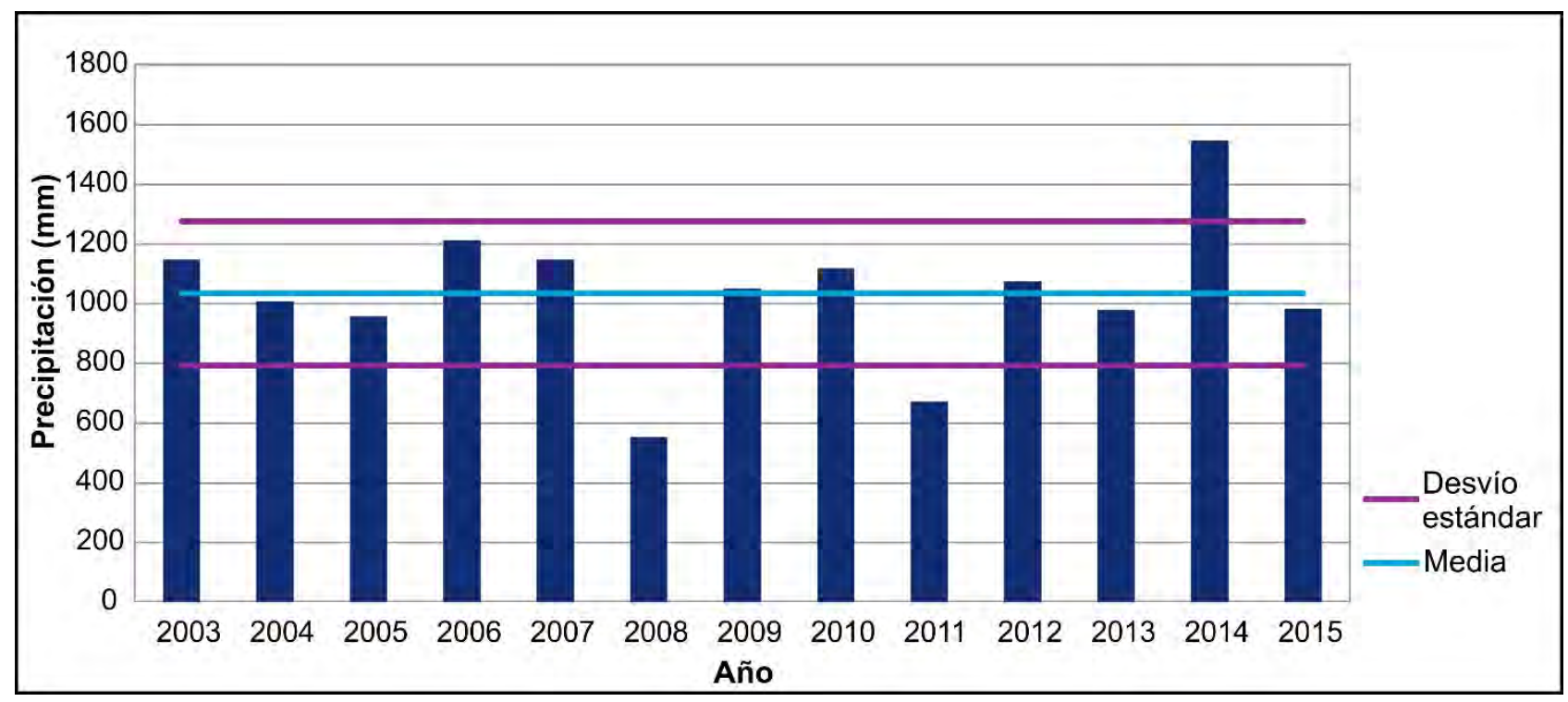

Figura 4.12. Precipitaciones anuales para el período 2003-2015. Datos aportados por la Sociedad Rural de Magdalena.

Respecto a las precipitaciones medias mensuales, febrero con $131,50 \mathrm{~mm}$ y mayo con $59,92 \mathrm{~mm}$ son los meses con mayores y menores precipitaciones, respectivamente, de todo el registro (Fig. 4.13). El valor máximo de precipitación mensual se presenta en el mes de enero de 2006 con 314 mm y el menor valor en el mes de agosto de 2013 con $6 \mathrm{~mm}$.

En líneas generales, durante los meses de verano se presenta el mayor porcentaje $(30,90 \%)$ del total de las precipitaciones (Fig. 4.14). Si bien el resto de las estaciones (primavera, invierno y otoño) representan porcentajes similares del total de la precipitación, el mayor porcentaje consignado en la época estival, puede ser explicado por las lluvias extremas registradas en el mes de enero de 2006 (314 mm) y 2014 (257 mm) y en el mes de febrero de 2010 ( $276 \mathrm{~mm}$ ) y 2014 (223 mm).

El balance de agua a nivel del suelo realizado según Thornthwaite y Mather (1957) para el área de estudio indica una evapotranspiración real media anual de $800 \mathrm{~mm}$ con excesos del orden de $235 \mathrm{~mm}$ que se producen desde el mes de mayo y hasta noviembre, y no registra déficit para ningún mes (Fig. 4.13). 


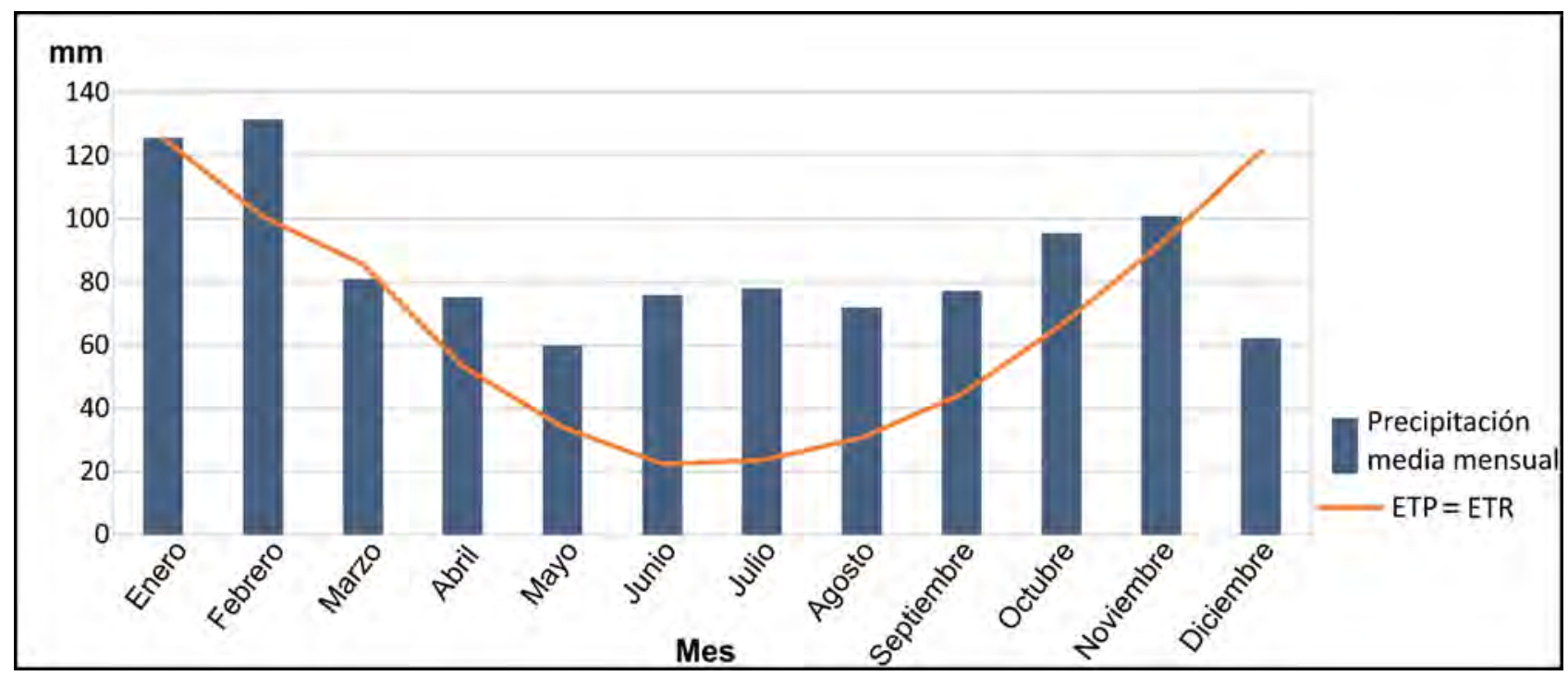

Figura 4.13. Valores mensuales de precipitación, evapotranspiración potencial (ETP) y real (ETR) correspondiente al período 20032015 en Magdalena. Datos aportados por la Sociedad Rural de Magdalena.

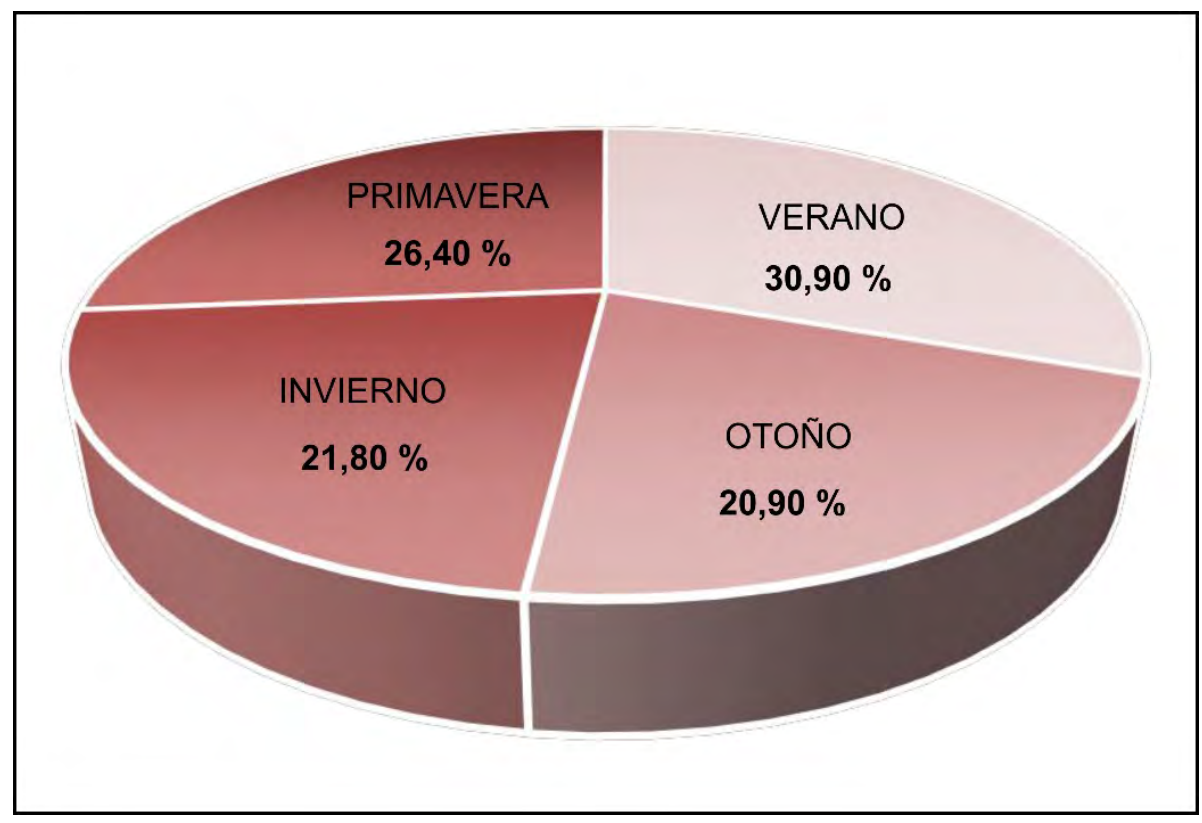

Figura 4.14. Distribución porcentual de las precipitaciones según las estaciones del año para el período 2003 - 2015. Datos aportados por la Sociedad Rural de Magdalena.

\subsection{AGUAS SUPERFICIALES}

\subsubsection{Hidrodinámica}

Las aguas de los arroyos Buñirigo y Juan Blanco escurren en dirección SO - NE. Por su carácter efluente respecto a las aguas subterráneas, los arroyos son permanentes siendo la descarga del escurrimiento subterráneo local la que posibilita el mantenimiento del caudal. Ambos arroyos desembocan en el Río de la 
Plata el cual presenta un régimen de tipo micromareal semidiurno ( $D^{\prime}$ Onofrio et al., 1999). Durante la pleamar, y principalmente en las pleamares de sicigia, la marea se propaga hacia el continente por los cauces de los arroyos, generando una inversión del flujo de agua en el sector de cuenca baja.

Con respecto al caudal del arroyo Buñirigo, en la zona de cabeceras (cuenca alta; Fig. 4.15a) no se pudo establecer debido a que su valor se encuentra por debajo del límite de detección del instrumental utilizado para la medición. En la cuenca baja, el caudal se determinó para los meses de febrero y marzo de 2013 en dos puntos de muestreo (Fig. 4.15b). El punto I se sitúa aguas arriba de las industrias localizadas en la cuenca baja del arroyo Buñirigo mientras que el punto II se ubica aguas abajo de las mismas y de canales tributarios. Para el mes de febrero el valor de caudal fue de $0,02 \mathrm{~m}^{3} / \mathrm{seg}$ en el punto I y de $0,20 \mathrm{~m}^{3} / \mathrm{seg}$ en el punto II. En marzo, el caudal registró valores de $0,05 \mathrm{~m}^{3} / \mathrm{seg}$ en el punto I y 0,11 $\mathrm{m}^{3} / \mathrm{seg}$ en el punto II. La profundidad del curso durante los muestreos osciló entre 0,30 y 1 metro. En base a los datos presentados, puede interpretarse que el caudal del arroyo Buñirigo aumenta desde la cuenca alta a la cuenca baja. El aumento en el valor de caudal de un punto a otro en ambos meses puede estar relacionado al aporte de los tributarios, así como al vertido de efluentes industriales y, en menor medida, a la descarga subterránea. En eventos de precipitaciones intensas, aumentan los niveles de agua y el caudal del arroyo produciendo el desborde de su cauce (Fig. 4.16).

El caudal del arroyo Juan Blanco no pudo determinarse debido a que la velocidad del agua en los periodos muestreados fue inferior a $0,15 \mathrm{~m} / \mathrm{s}$ (valor correspondiente al límite de detección del instrumental utilizado para la medición). El registro de estos bajos caudales en gran parte del año favorece el crecimiento de abundante vegetación acuática que cubre parcialmente el cauce del arroyo (Figs. 4.15c y d). La profundidad del cauce en la cuenca baja oscila entre 0,30 y 0,80 metros; esta característica sumada al escaso caudal permite considerar que el arroyo tenga un comportamiento hidrológico similar a un cuerpo lagunar. A pesar de esto, observaciones realizadas durante los periodos lluviosos evidenciaron que el arroyo drena los excesos hídricos. No obstante, no fue posible el acceso al mismo para realizar las mediciones de caudal. 


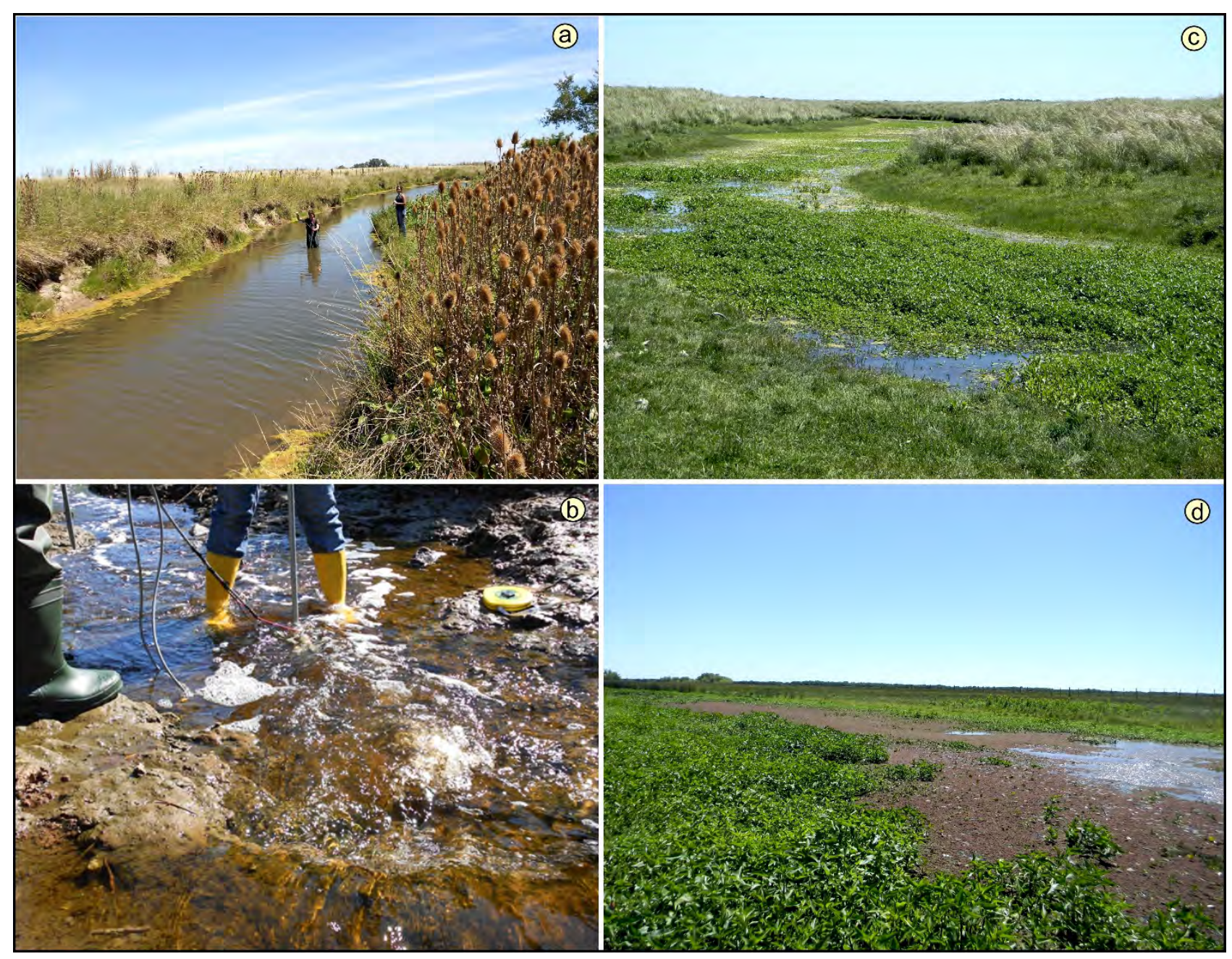

Figura 4.15. Aguas superficiales. Medición de caudal en el arroyo Buñirigo: (a) cuenca alta y (b) cuenca baja. Desarrollo de vegetación acuática en el arroyo Juan Blanco: (c) cuenca alta y (d) cuenca baja.

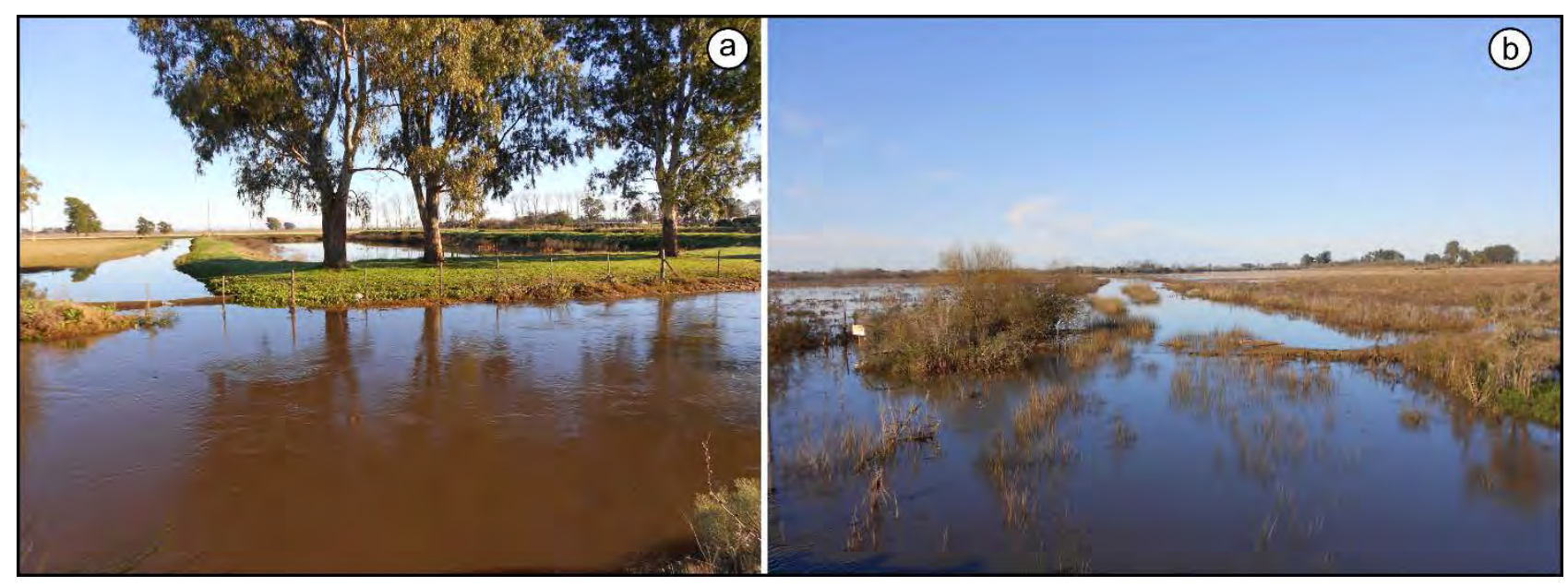

Figura 4.16. Evento de precipitación intensa registrado en la cuenca baja del arroyo Buñirigo. Aumento del nivel de agua del arroyo (aguas abajo de la Ruta Provincial $N^{\circ} 11$ ): (a) sector canalizado y (b) curso natural. 


\subsubsection{Hidroquímica}

Las características hidroquímicas del agua superficial para las cuencas de los arroyos Buñirigo y Juan Blanco se determinaron a partir del contenido en iones mayoritarios $\left(\mathrm{Cl}^{-}, \mathrm{HCO}_{3}^{-}\right.$y $\left.\mathrm{SO}_{4}{ }^{2-} ; \mathrm{Na}^{+}, \mathrm{K}^{+}, \mathrm{Ca}^{2+} \mathrm{y} \mathrm{Mg}^{2+}\right)$ definiendo facies de aguas a partir de diagramas de Stiff (1951) (Fig. 4.17). Asimismo, se analizó la conductividad eléctrica y $\mathrm{pH}$ del agua a partir de determinaciones efectuadas durante el muestreo. Las muestras para análisis químico y las determinaciones de conductividad eléctrica y $\mathrm{pH}$ se obtuvieron en base a una red de monitoreo de agua superficial distribuida a lo largo de la cuenca alta, media y baja del arroyo Buñirigo y en la cuenca baja del arroyo Juan Blanco.

El arroyo Buñirigo, en la cuenca alta y media, presenta aguas de tipo bicarbonatada cálcica con una conductividad eléctrica de $614 \mu \mathrm{s} / \mathrm{cm}$ y pH de 7,80, a bicarbonatada sódica con valores de conductividad eléctrica de $964 \mu \mathrm{s} / \mathrm{cm}$ y pH de 8,70. En su cuenca baja, el arroyo exhibe aguas de tipo clorurada sódica con un valor de conductividad eléctrica media de $3796 \mu \mathrm{s} / \mathrm{cm}$ y pH de 7,31. Los valores de cloruro varían entre 142,10 y $3820 \mathrm{mg} / \mathrm{L}$ y los de sodio entre 75,50 y 1990,50 mg/L. La facies de agua clorurada sódica corresponde a puntos de muestreo tomados próximo al vertido de efluentes de una industria como así también aguas abajo de ésta y otras industrias ubicadas en la cuenca baja del arroyo.

En el arroyo Juan Blanco el agua es de tipo bicarbonatada cálcica a bicarbonatada sódica con valores medios de conductividad eléctrica y pH de $195 \mu \mathrm{s} / \mathrm{cm}$ y 7,10, respectivamente. 


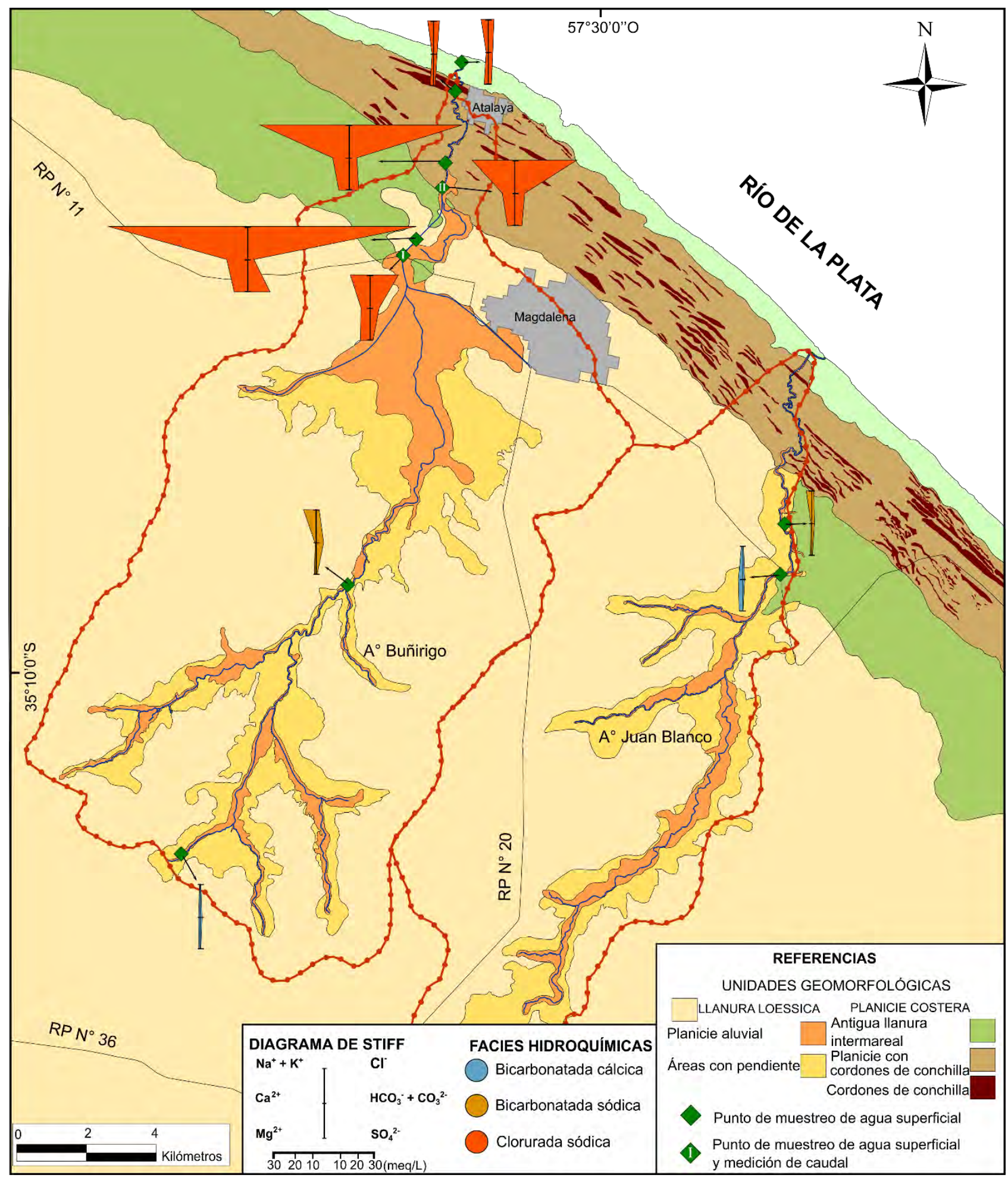

Figura 4.17. Mapa geomorfológico donde se ilustran las características hidroquímicas del agua superficial para los arroyos Buñirigo y Juan Blanco. Los diagramas de Stiff están coloreados en base a las facies hidroquímicas que representan. 


\subsection{AGUAS SUBTERRÁNEAS}

\subsubsection{Unidades hidrogeológicas}

El esquema hidrogeológico local resulta del análisis e interpretación de perforaciones disponibles en el área de estudio, y es comparable con la parte superior del esquema hidrogeológico regional descripto en el Capítulo 3. Las perforaciones se denominan Fábrica Nestlé, Plaza Garibaldi y Usina Eléctrica. Las primeras dos perforaciones se localizan en el ámbito de la llanura loessica y corresponden a la cuenca alta del arroyo Buñirigo, mientras que la perforación Usina Eléctrica se localiza en la planicie costera en el sector de divisorias de ambas cuencas. A continuación, se describen, por un lado, las perforaciones Fábrica Nestlé y Plaza Garibaldi y por otro, la perforación Usina Eléctrica para caracterizar hidrogeológicamente la llanura loessica y la planicie costera, respectivamente.

Las perforaciones Fábrica Nestlé y Plaza Garibaldi alcanzaron una profundidad total de $-57,50 \mathrm{~m}$ s. n. m. y $-62,65$ m s. n. m., respectivamente (Fig. 4.18a). En la base de ambas perforaciones se encuentra una arcilla de coloración verdosa de comportamiento hidrolitológico tipo acuícludo, y que puede atribuirse a la Formación Paraná. Por encima de esta unidad geológica comienzan arenas finas a gruesas de coloración amarilla clara y comportamiento acuífero, interpretadas como Formación Puelches. Para la zona de estudio, el espesor de estas arenas tiene en promedio 23,70 metros. Continúan en las columnas estratigráficas de ambas perforaciones sedimentos arcillosos de coloración gris plomizo con un espesor promedio de 14,40 metros y de comportamiento acuitardo, a los que le siguen sedimentos limosos de coloración parda rojiza a amarillenta con abundante material calcáreo (tosca) de comportamiento acuífero. Estos sedimentos arcillosos y limosos se interpretan como pertenecientes a la Formación Puelches (Tófalo et al., 2005). El techo de esta unidad se encuentra a los -26,50 m s. n. m. para la perforación Fábrica Nestlé y a los $-26,30 \mathrm{~m} \mathrm{s.} \mathrm{n.} \mathrm{m.}$ para el pozo Plaza Garibaldi. En síntesis, en el ámbito de la llanura loessica se reconocen dos acuíferos: uno alojado en la parte superior de la Formación Pampeano de carácter freático o libre, y el otro en la Formación Puelches de carácter semiconfinado (Fig. 4.18a). 


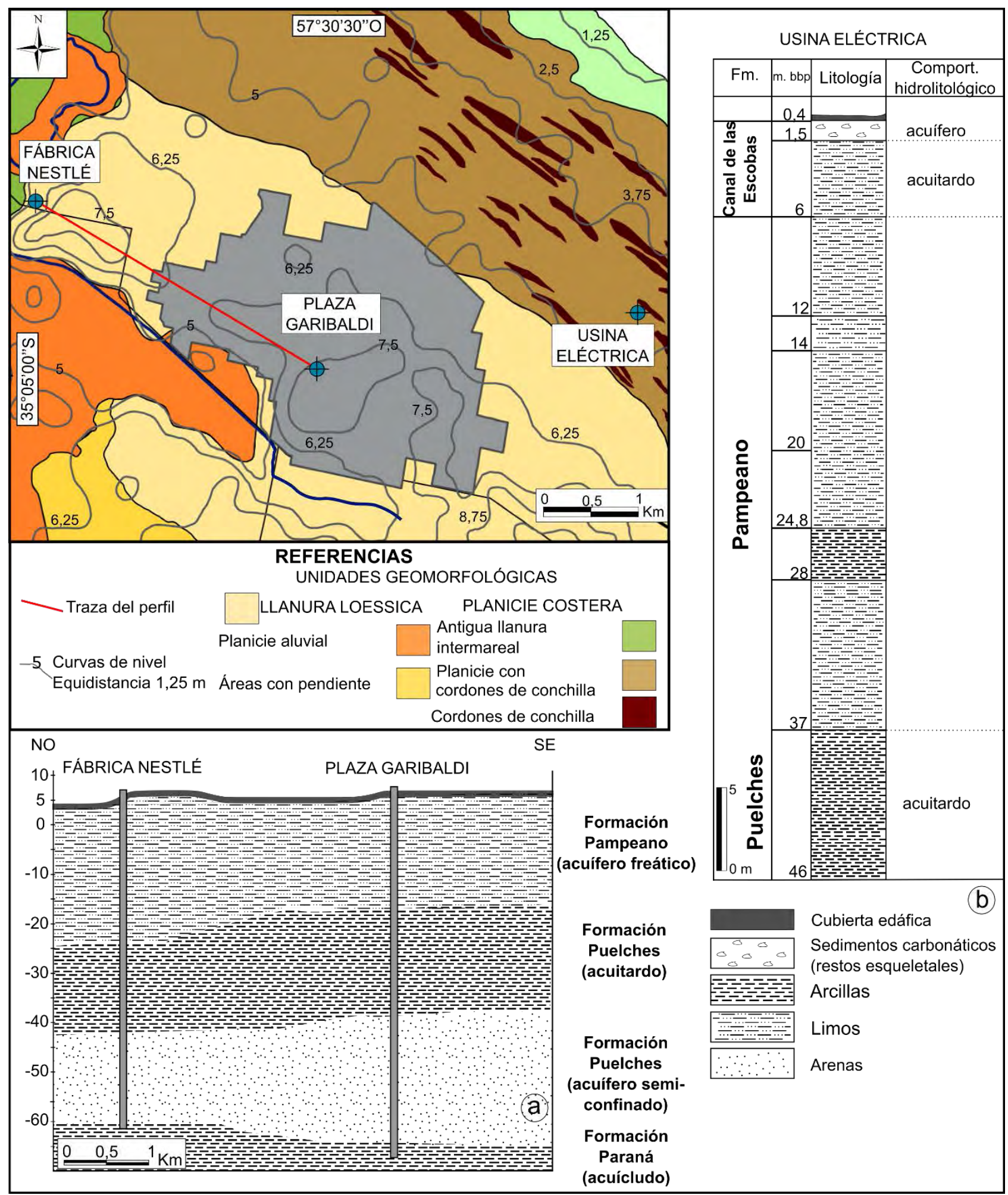

Figura 4.18. Esquema hidrogeológico del área de estudio. (a) Perfil geológico entre la Fábrica Nestlé y Plaza Garibaldi que caracteriza las unidades hidrogeológicas en la llanura loessica. (b) Columna estratigráfica Usina Eléctrica que define las unidades hidrogelógicas en la planicie costera. El mapa geomorfológico muestra la localización de las perforaciones analizadas. 
La perforación Usina Eléctrica (Fig. 4.18b) alcanzó una profundidad total de -39,75 m s. n. m. Desde la base hasta los $-30,75 \mathrm{~m} \mathrm{~s}$. n. m. hay arcillas de coloración gris plomizo que pueden asignarse al techo de la Formación Puelches (Tófalo et al., 2005). Continúan en la columna hasta los $0,25 \mathrm{~m} \mathrm{s.} \mathrm{n}$. $\mathrm{m}$ limos arcillosos y arenosos pardos rojizos a grisáceos que pueden atribuirse a la Formación Pampeano. Las litologías mencionadas pueden correlacionarse con los sedimentos de la misma unidad descriptos en los pozos de la Ilanura loessica. Las arcillas presentan un comportamiento de tipo acuitardo mientras que los sedimentos limosos tienen un comportamiento acuífero. Sobre estos sedimentos se apoyan limos gris verdosos (espesor de 4,50 metros) y conglomerados calcáreos (espesor de 1,10 metros) asignables a los miembros Canal 18 y Cerro de la Gloria de la Formación Canal de las Escobas (sedimentos pospampeanos), respectivamente. Los sedimentos del Miembro Canal 18, presentan un comportamiento de tipo acuitardo debido a la baja permeabilidad de sus sedimentos. Por el contrario, la elevada permeabilidad de los sedimentos del Miembro Cerro de la Gloria le confiere a esta unidad un carácter acuífero. En síntesis, en la planicie costera el agua subterránea somera se asocia al acuífero freático que se aloja en los sedimentos pampeanos y pospampeanos. En los Capítulos 5 y 6 se caracterizará y analizará con más detalle el acuífero freático para comprender su evolución en el ambiente de planicie costera.

\subsubsection{Características hidrodinámicas del acuífero freático}

El análisis del mapa isofreático confeccionado en base a los datos relevados en 2014 (Fig. 4.19), muestra que, en el sector de cabeceras de ambas cuencas, el nivel freático se ubica cercano a 12,50 m s. $\mathrm{n}$. m. mientras que en el sector próximo a la desembocadura está a 1,80 m s. n. m. Localmente, el agua freática descarga en los arroyos, proceso que se aprecia en las márgenes con barrancas, principalmente en la cuenca alta (Fig. 4.20). Además, esta característica se identifica en el mapa con líneas de flujo convergentes hacia el arroyo. El escurrimiento subterráneo regional es hacia el Río de la Plata (dirección SO-NE) con un gradiente hidráulico promedio de $3,90.10^{-4}$. 


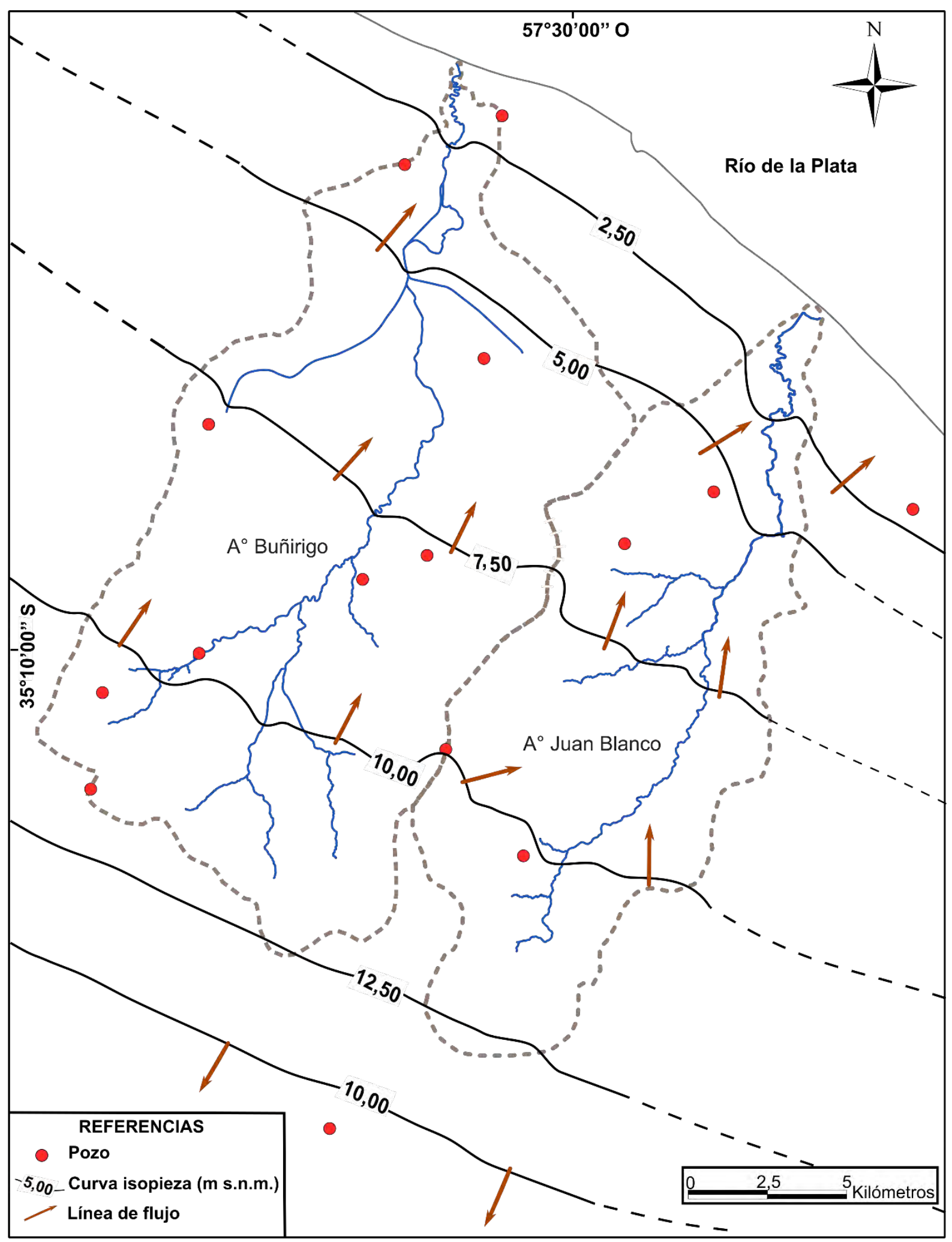

Figura 4.19. Mapa isofreático para el agua subterránea somera (acuífero freático) en las cuencas de los arroyos Buñirigo y Juan Blanco, basado en datos de campo. Las líneas de puntos corresponden a los límites de las cuencas. 


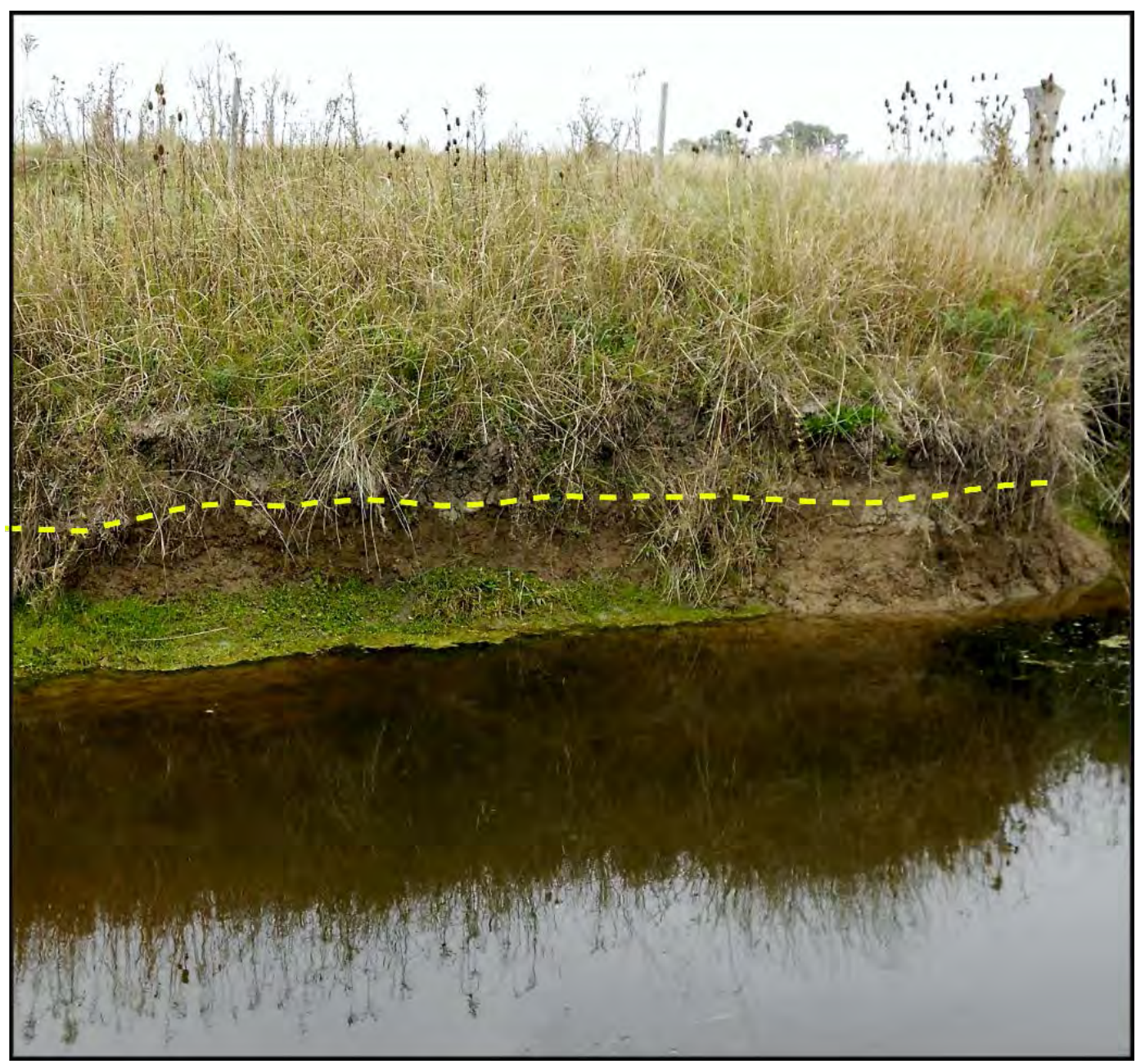

Figura 4.20. Descarga subterránea en la margen del arroyo Buñirigo. La línea punteada indica el nivel del acuífero freático.

Si se compara el mapa isofreático obtenido para los datos relevados en 2014 con el confeccionado por el E.A.S.N.E. (Sala, 1972) para el noreste de la provincia de Buenos Aires (Fig. 4.21) para principios de la década del 70, se observa que la posición de los niveles freáticos registra un leve descenso para el año 2014. No obstante, es importante remarcar que el detalle en el diseño de las curvas es distinto y esta comparación puede no ser del todo correcta. 


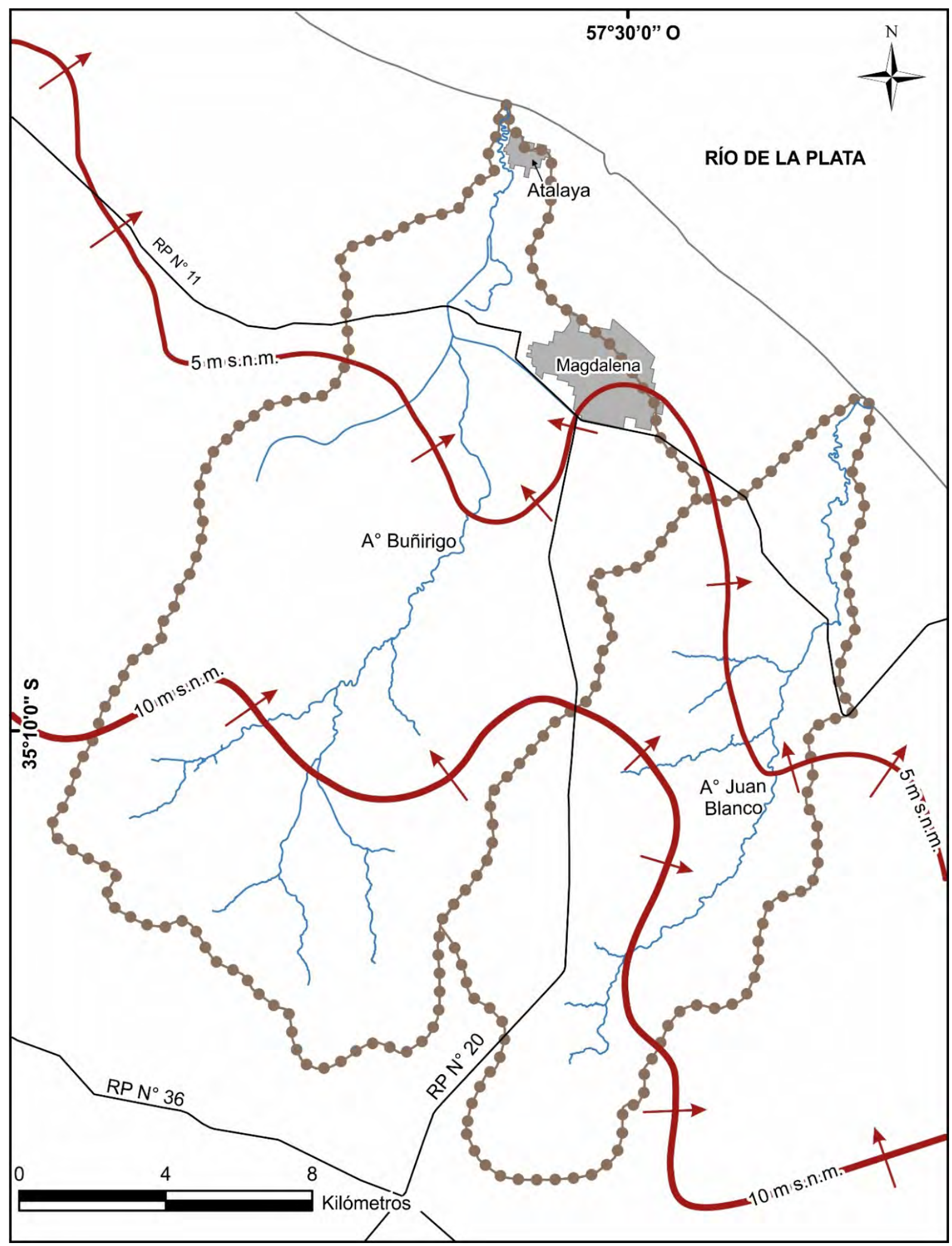

Figura 4.21. Mapa isofreático para el agua subterránea somera (acuífero freático) en las cuencas de los arroyos Buñirigo y Juan Blanco, basado en Sala, 1972. Las líneas de puntos corresponden a los límites de las cuencas. 


\subsubsection{Características hidroquímicas del acuífero freático}

La red de monitoreo de agua subterránea de las cuencas de los arroyos Buñirigo y Juan Blanco comprende tanto el área de planicie costera del Río de la Plata como la zona de llanura loessica, y está constituida por perforaciones domiciliarias y molinos de viento de las localidades de Magdalena y Atalaya y por los pozos de exploración someros construidos para este estudio. La caracterización hidroquímica de cada unidad hidrogeológica se efectuó a partir del contenido en iones mayoritarios $\left(\mathrm{Cl}^{-}, \mathrm{HCO}_{3}{ }^{-}\right.$y $\mathrm{SO}_{4}{ }^{2-} ; \mathrm{Na}^{+}, \mathrm{K}^{+}, \mathrm{Ca}^{2+}$ y $\mathrm{Mg}^{2+}$ ) definiendo facies hidroquímicas a partir de diagramas de Stiff (1951). Los valores de conductividad eléctrica del agua se determinaron durante el muestreo. Las facies hidroquímicas de cada subambiente se muestran en la figura 4.22 .

En la llanura loessica el agua subterránea tiene en promedio una conductividad eléctrica de 1165 $\mu \mathrm{S} / \mathrm{cm}$ (con un valor extremo de $2014 \mu \mathrm{S} / \mathrm{cm}$ ) y un pH de 7,81. El agua es de tipo bicarbonatada sódica con una concentración promedio de bicarbonato de $453,20 \mathrm{mg} / \mathrm{L}$ y sodio de 191,80 mg/L.

En la antigua llanura intermareal el agua presenta una conductividad eléctrica de $1681 \mu \mathrm{S} / \mathrm{cm}$ y un $\mathrm{pH}$ de 7,71. El agua es de tipo bicarbonatada sódica con un valor de bicarbonato de $940 \mathrm{mg} / \mathrm{L}$ y de sodio de $358,80 \mathrm{mg} / \mathrm{L}$.

En la planicie con cordones de conchilla (zonas de intercordón) el valor promedio de conductividad eléctrica es de $3214 \mu \mathrm{S} / \mathrm{cm}$ y el de $\mathrm{pH}$ de 7,40. En este subambiente domina el agua de tipo bicarbonatada sódica y clorurada sódica. El valor promedio de bicarbonato es de 705,83 mg/L, el de cloruro de 1673,80 mg/L y el sodio de $657,60 \mathrm{mg} / \mathrm{L}$. Además de las facies mencionadas, en la planicie con cordones de conchilla, se identificaron aguas de tipo bicarbonatada cálcica y clorurada magnésica.

Las muestras extraídas de pozos ubicados sobre los cordones de conchilla son predominantemente de tipo clorurada sódica con una concentración promedio de cloruro de $361,70 \mathrm{mg} / \mathrm{L}$ y de sodio de 370,90 mg/L. Además, en los cordones de conchilla, se determinó la facies bicarbonatada magnésica y sódica.

Por su parte, en el área de marisma el agua presenta un valor promedio de conductividad eléctrica de $1227 \mu \mathrm{S} / \mathrm{cm}$ y de $\mathrm{pH}$ de 6,02. El agua en este subambiente está representada por la facies hidroquímica clorurada sódica con un valor promedio de cloruro y sodio de 180,55 mg/L y $116 \mathrm{mg} / \mathrm{L}$, respectivamente. Además de esta facies también se identificaron aguas de tipo bicarbonatada sódica. 


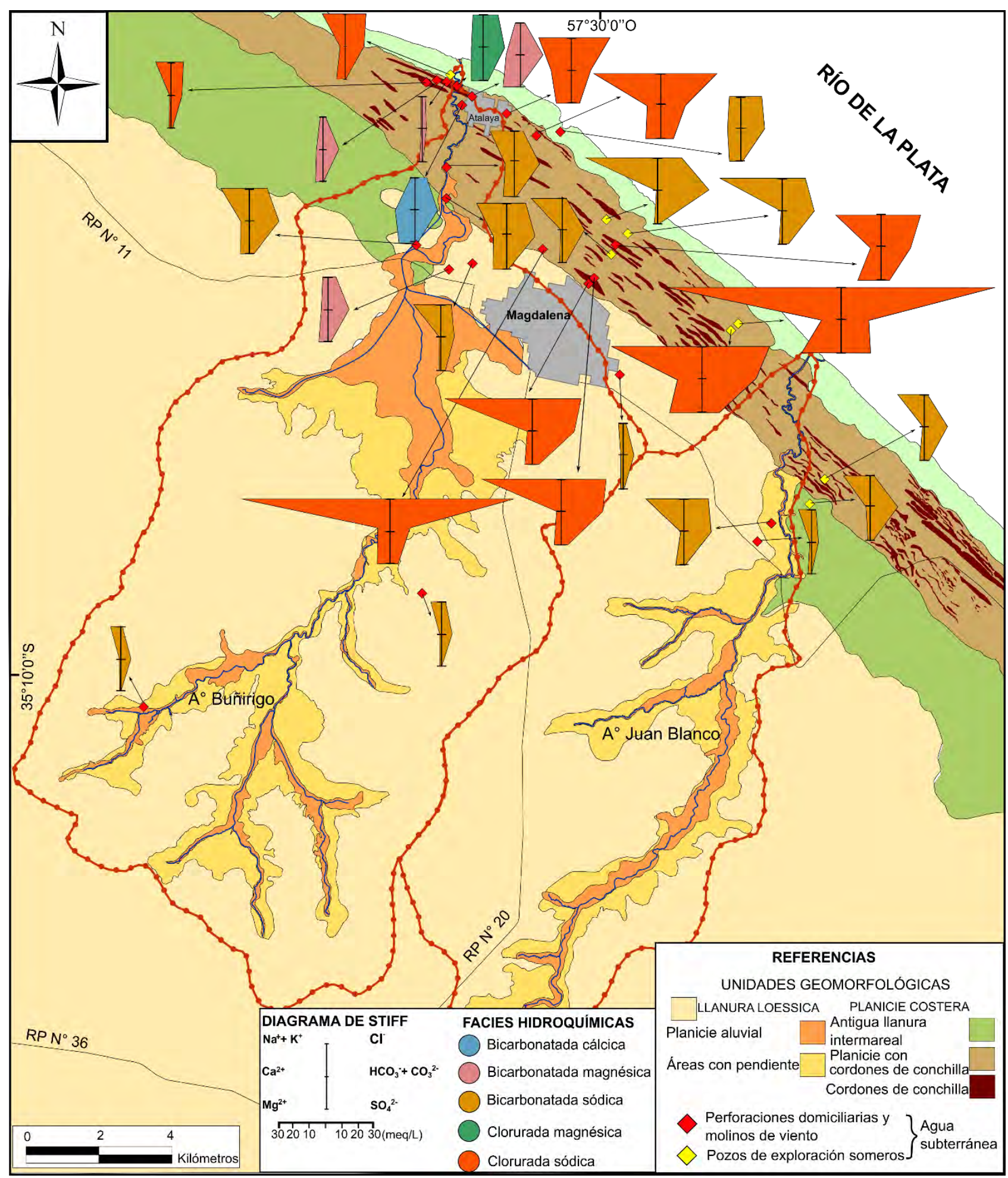

Figura 4.22. Mapa geomorfológico donde se ilustran las características hidroquímicas del agua subterránea para la llanura loessica y planicie costera en las cuencas de los arroyos Buñirigo y Juan Blanco. Los diagramas de Stiff, están coloreados en base a las facies hidroquímicas que representan. 


\section{Capítulo 5. HIDRODINÁMICA DE LA PLANICIE COSTERA DEL RÍO DE LA PLATA MEDIO EN EL LITORAL DEL PARTIDO DE MAGDALENA}

En este capítulo se describe y analiza en detalle hidrodinámica del agua superficial y subterránea somera para cada subambiente de la planicie costera, utilizando como base la caracterización determinada en el Capítulo 4. Para esto, se utilizan datos obtenidos de una red de monitoreo que comprende cuatro transectas, perpendiculares a la línea de costa, en los principales subambientes de la planicie costera. Estas transectas se distribuyen en toda el área de estudio abarcando ambientes naturales y modificados por la acción antrópica.

\subsection{RED DE MONITOREO (TRANSECTAS)}

\subsubsection{Transecta 1}

La transecta 1 corresponde al Establecimiento Juan Blanco ubicado en las proximidades del arroyo Juan Blanco. La transecta abarca, en el extremo sudoeste, el límite entre la llanura loessica y la antigua llanura intermareal (Figs. 5.1 y 5.2). Esta última unidad se desarrolla hasta la parte central de la transecta pasando hacia el noreste a la planicie con cordones de conchilla. En la llanura loessica se encuentra el casco de estancia y un pequeño feedlot, mientras que en la antigua llanura intermareal y planicie con cordones de conchilla se desarrolla la ganadería extensiva. Los puntos de medición y muestreo corresponden a pozos de exploración construidos para este estudio (EJB1 y EJB2), molinos de viento (MEJB1 y MEJB2) y una muestra del arroyo Juan Blanco (AJB).

\subsubsection{Transecta 2}

La transecta 2 se definió en las cercanías de la Unidad Penitenciaria № 28 del partido de Magdalena y se ubica completamente en el subambiente de planicie con cordones de conchilla (Figs. 5.1 y 5.3). Los campos en esta zona están destinados a la ganadería extensiva. Este sector es atravesado en dirección SO NE por un canal artificial de desagüe de efluentes cloacales pertenecientes a la Unidad Penitenciaria $\mathrm{N}^{\circ} 28$. Además, en el área se desarrollan, de forma paralela a la costa, cañadas donde el agua se acumula en superficie. Estas cañadas se forman en los sectores de intercordón. Los sitios de medición y muestreo 
corresponden a dos pozos de exploración (UP1 y UP2) y a dos muestras de agua superficial provenientes de un canal artificial (CUP1) y una pequeña cañada (CUP2).

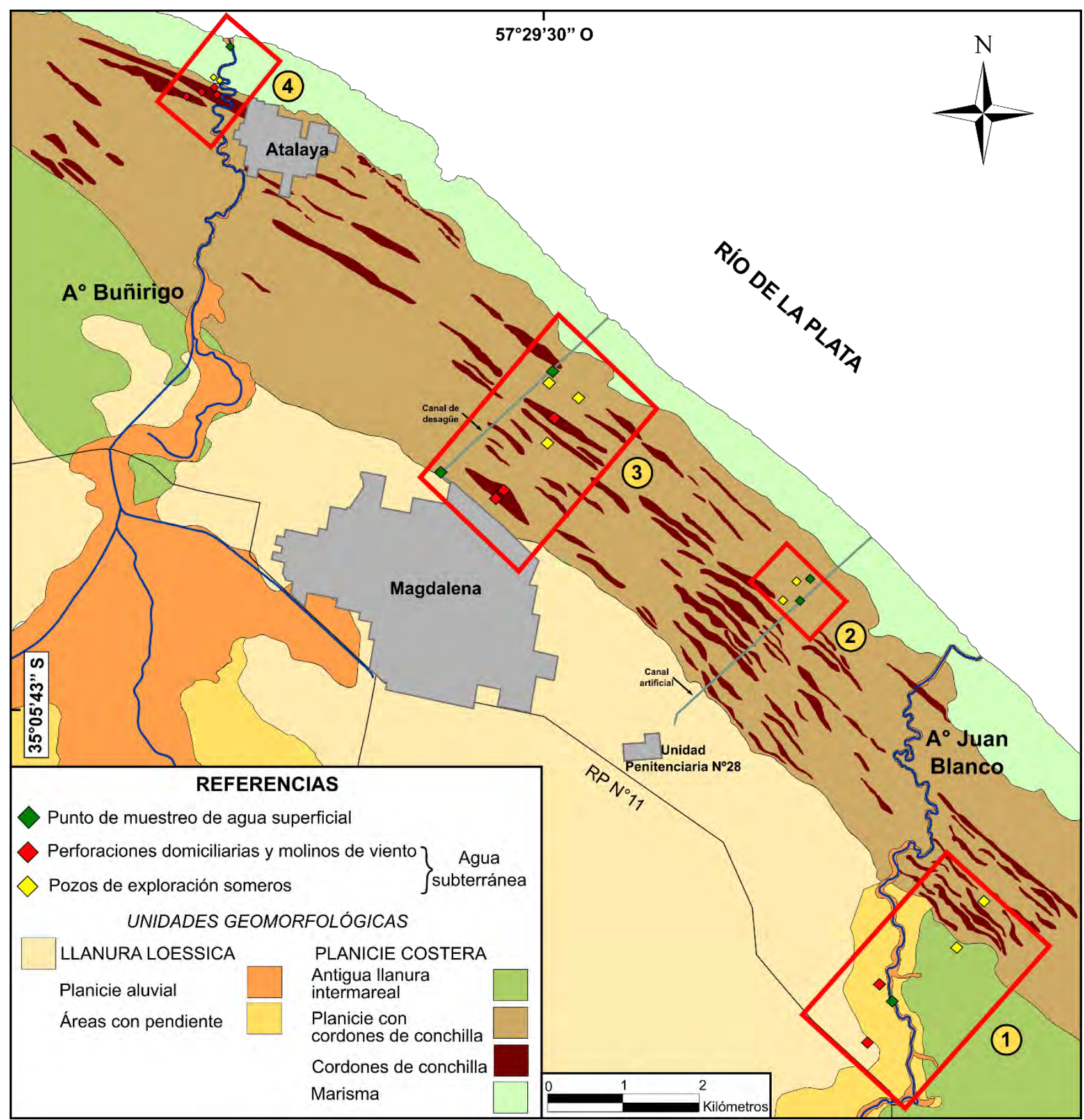

Figura 5.1. Mapa geomorfológico donde se orientan las cuatro transectas en los principales subambientes de la planicie costera. El recuadro rojo indica el área aproximada donde se ubica cada una y el número corresponde a cada transecta descripta. (1) Transecta en el Establecimiento Juan Blanco. (2) Transecta en la Unidad Penitenciaria $N^{\circ}$ 28. (3) Transecta en la Estancia Villa Villabona. (4) Transecta en la Reserva Natural y Cultural El Saladero. 


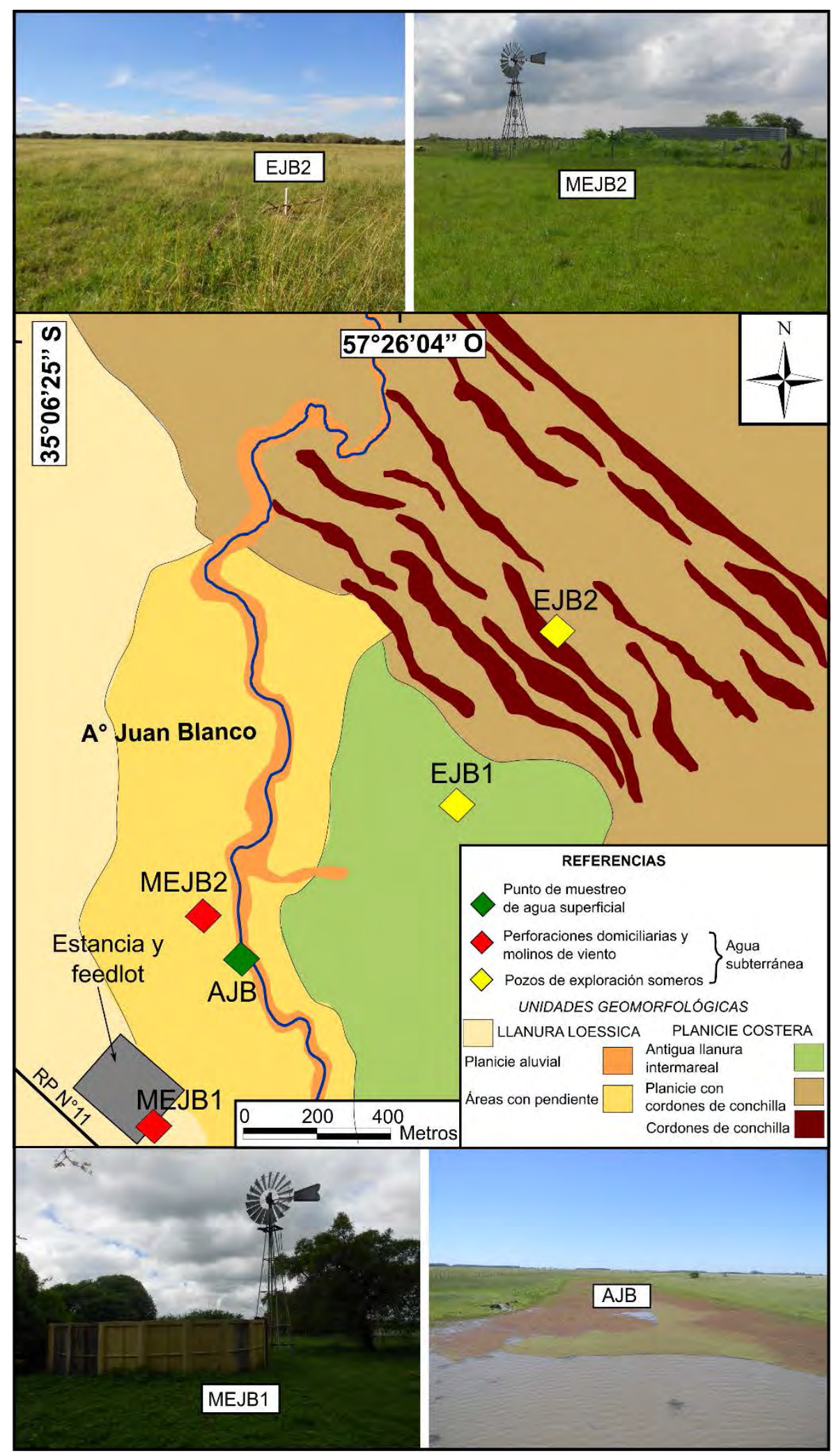

Figura 5.2. Mapa geomorfológico con la ubicación de detalle de la transecta 1 y los puntos de medición y muestreo de agua superficial y subterránea. Las fotografías ilustran algunos de estos puntos. La ubicación regional se presenta en la figura 5.1. 


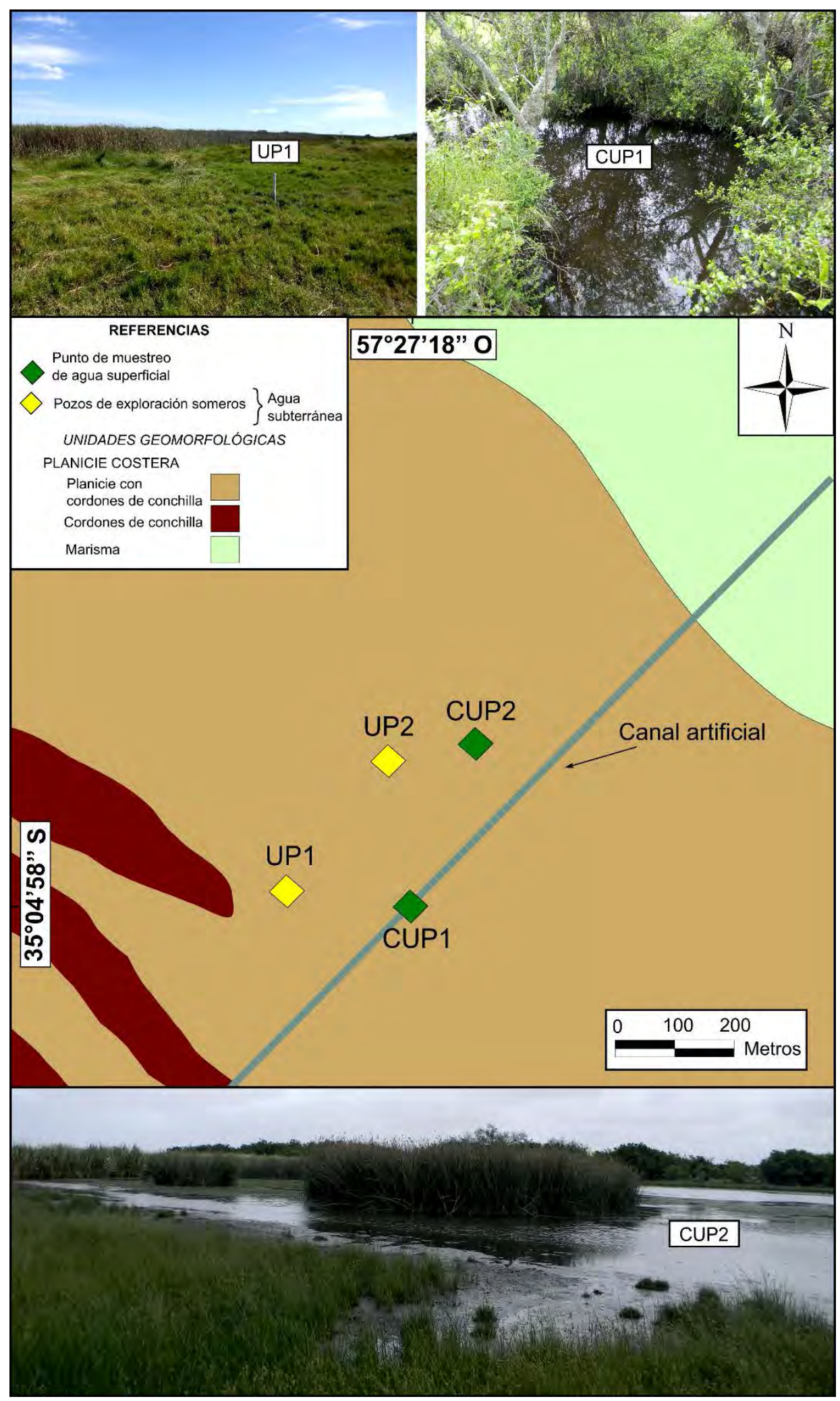

Figura 5.3. Mapa geomorfológico con la ubicación de detalle de la transecta 2 y los puntos de medición y muestreo de agua superficial y subterránea. Las fotografías ilustran algunos de estos puntos. La ubicación regional se presenta en la figura 5.1. 


\subsubsection{Transecta 3}

La transecta 3 corresponde a la Estancia Villa Villabona, dedicada a la actividad ganadera vinculada a la producción de leche, y abarca en su totalidad al subambiente de planicie con cordones de conchilla (Figs. 5.1 y 5.4$)$.

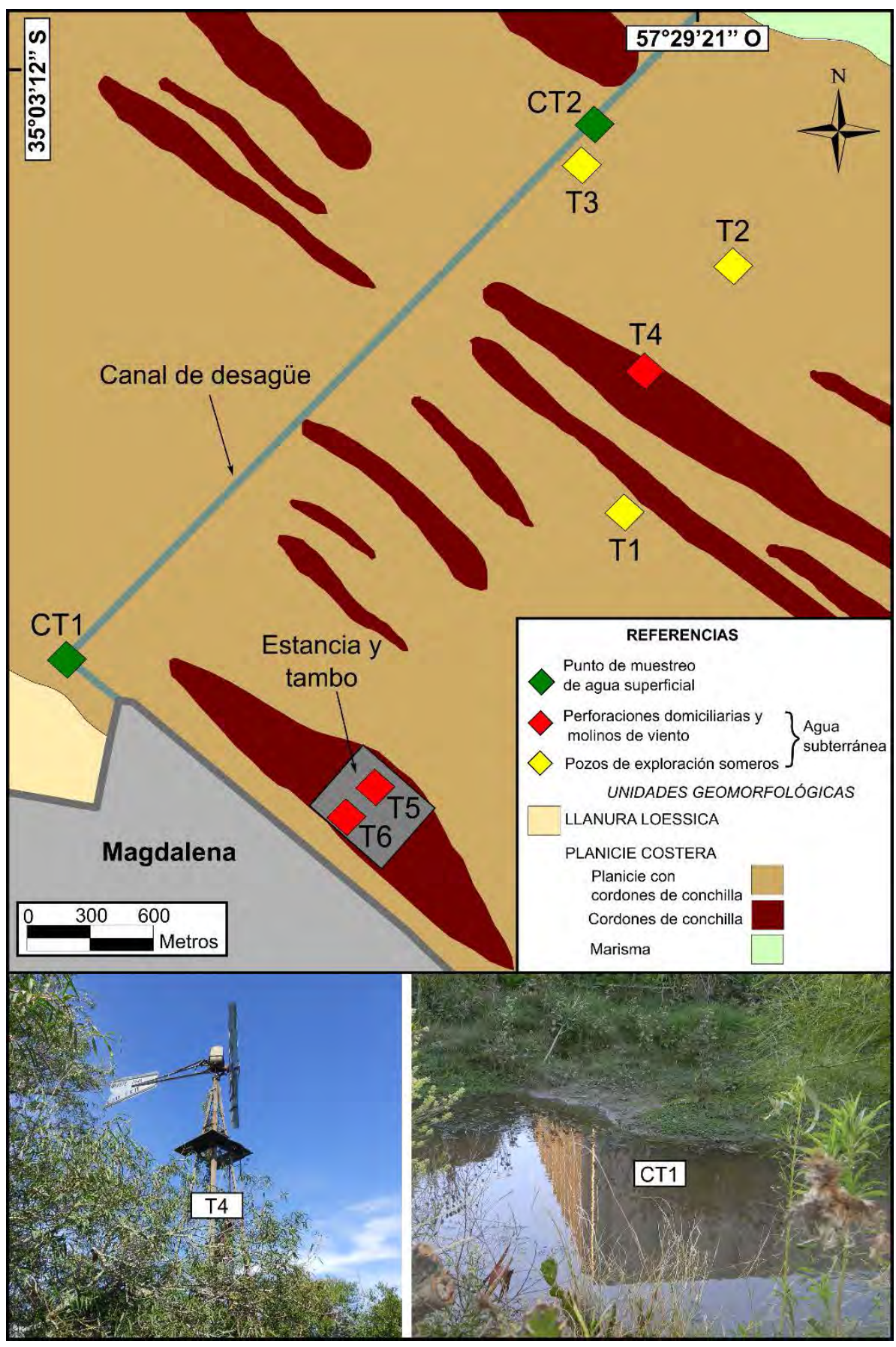

Figura 5.4. Mapa geomorfológico con la ubicación de detalle de la transecta 3 y los puntos de medición y muestreo de agua superficial y subterránea. Las fotografías ilustran algunos de estos puntos. La ubicación regional se presenta en la figura 5.1. 
El casco de estancia y el tambo (lugar de ordeñe y producción de la leche) se encuentran en el extremo sudoeste de la transecta sobre un cordón de conchilla. El campo es atravesado (en dirección sudoeste-noreste) por un canal de desagüe de la planta depuradora de efluentes cloacales de la localidad de Magdalena. Los puntos de medición y muestreo de agua subterránea pertenecen a tres pozos de exploración construidos para este estudio ( $T 1, T 2$ y $T 3$ ), una muestra de un molino de viento (T4), un pozo de abastecimiento exclusivo para el tambo (T5) y un pozo domiciliario (T6); para el agua superficial las muestras provienen del canal de desagüe (CT1 y CT2).

\subsubsection{Transecta 4}

La transecta 4 se ubica en la Reserva Natural y Cultural El Saladero, próxima a la localidad de Atalaya, e intercepta el subambiente de planicie con cordones de conchilla y la marisma (Figs. 5.1 y 5.5). En dicha reserva las principales actividades son el turismo y la producción ovina extensiva. Se utilizaron como puntos de medición y muestreo tres perforaciones existentes y de uso domiciliario (RES1, RES3 y RES4), una perforación existente destinada a un bebedero de ganado (RES2), dos pozos construidos (RES5 y RES6) y una muestra del arroyo Buñirigo (AB).

\subsection{HIDRODINÁMICA DE LAS UNIDADES GEOMORFOLÓGICAS DE LA PLANICIE COSTERA}

La interpretación de los datos obtenidos en el conjunto de transectas muestra que cada subambiente geomorfológico presenta un comportamiento hidrodinámico distintivo. A continuación, se interpreta la dinámica de la relación entre el agua superficial y subterránea, y se analiza la variación espacial que puede existir en dicho comportamiento hidrodinámico en cada subambiente de la planicie costera.

\subsubsection{Antigua llanura intermareal}

Las características hidrolitológicas e hidrodinámicas de la planicie intermareal se estudiaron en la transecta 1 (Fig. 5.2). Los sondeos someros (aproximadamente a 2 metros de profundidad) efectuados en este subambiente muestran una dominancia de sedimentos arcillo limosos que pasan en profundidad a limos arcillosos y limos. La topografía del área es baja con alturas que varían entre 5,00 y 3,75 m s. n. m., disminuyendo en los sectores de canales de marea hasta 50 centímetros respecto del nivel de la llanura adyacente. Durante los eventos de lluvia, el agua de las precipitaciones infiltra y recarga localmente al agua subterránea. Esta infiltración es lenta debido a la baja permeabilidad de los sedimentos limo arcillosos que afloran en este subambiente lo que produce que el agua de lluvia, en los sectores con escasa pendiente, permanezca un tiempo en superficie antes de infiltrar. En periodos muy lluviosos, esta escasa infiltración y el lento escurrimiento del agua, sumado a la profundidad muy somera del nivel freático, provocan el ascenso 
de la franja capilar o la aparición de zonas saturadas temporalmente originando en el perfil de suelo recarga rechazada.

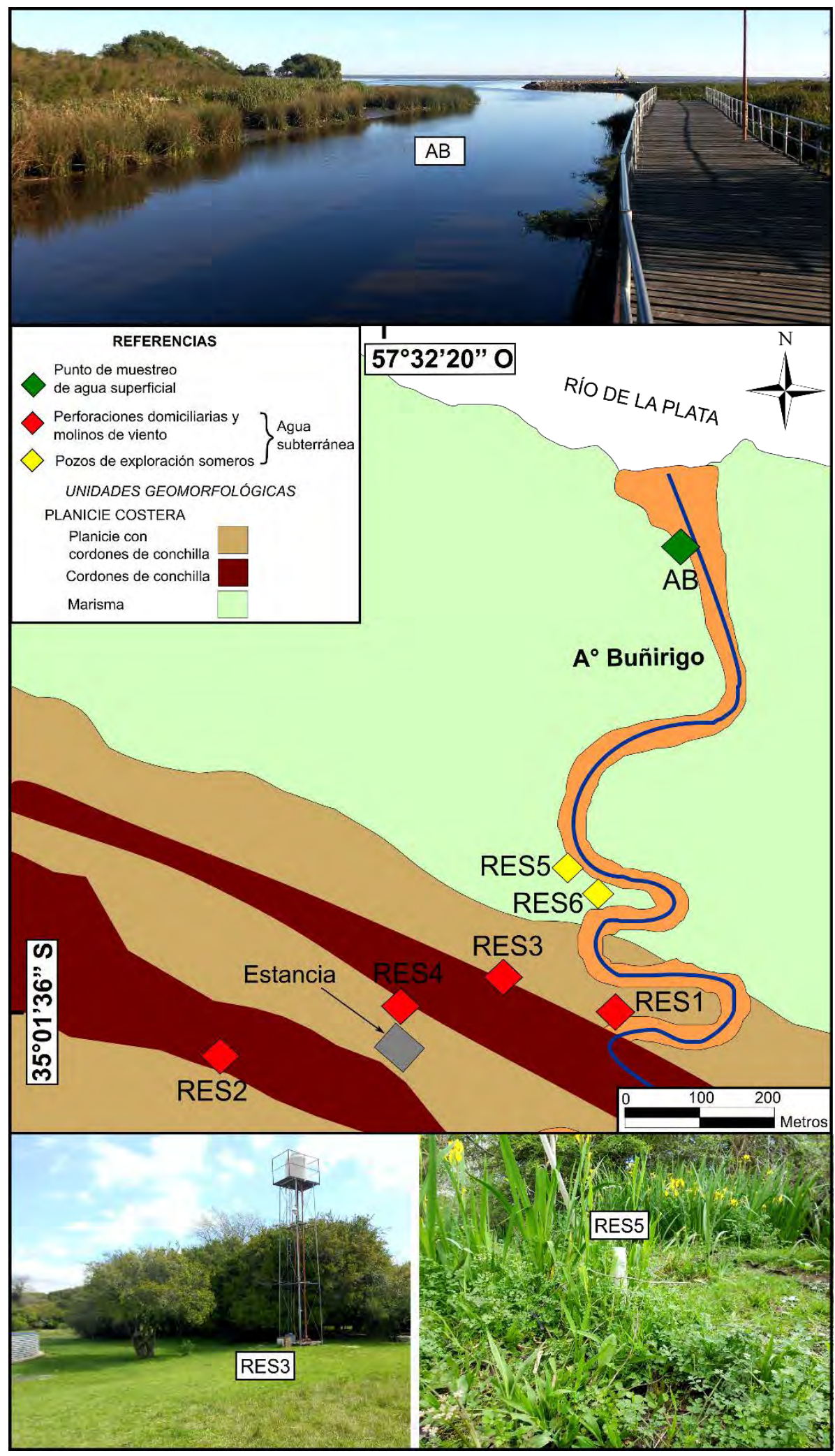

Figura 5.5. Mapa geomorfológico con la ubicación de detalle de la transecta 4 y los puntos de medición y muestreo de agua superficial y subterránea. Las fotografías ilustran algunos de estos puntos. La ubicación regional se presenta en la figura 5.1. 
Los antiguos canales de marea, que constituyen geoformas deprimidas del terreno, se presentan frecuentemente anegados. La relación entre el agua superficial acumulada y la subterránea somera en las adyacencias de los antiguos canales (traza del perfil figura 5.6a) fue estudiada a partir de los datos de niveles registrados en dos periodos hidrológicamente distintos.

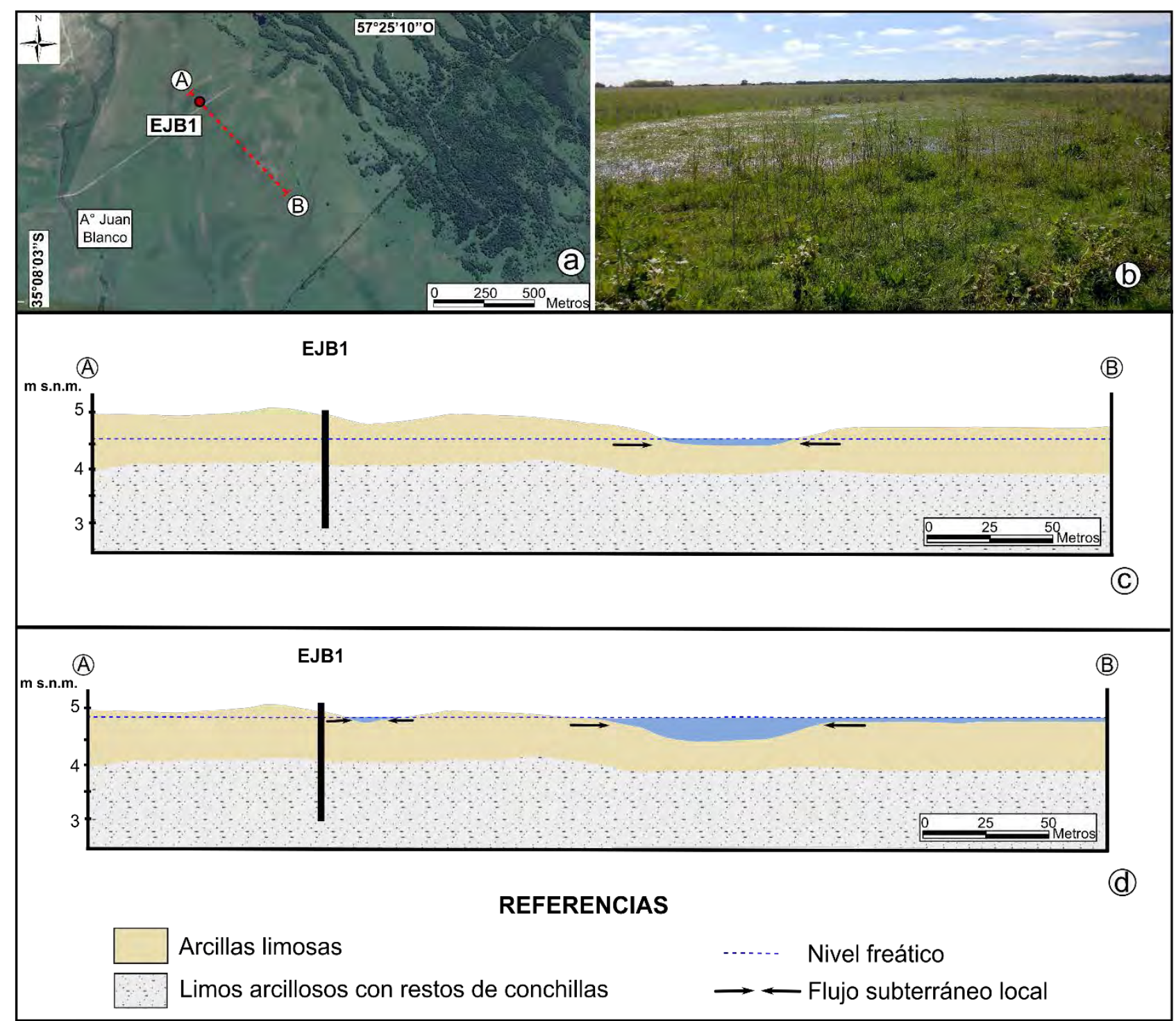

Figura 5.6. Antigua llanura intermareal. (a) Imagen satelital mostrando los antiguos canales de marea (ACM) y la ubicación de la traza del perfil A-B. (b) Fotografía que ilustra un antiguo canal de marea en donde el nivel freático aflora y constituye una pequeña cañada donde el agua se acumula superficialmente. (c) Perfil del flujo subterráneo y su relación con los ACM correspondiente al muestreo del día 14 de abril de 2014. (d) Perfil del flujo subterráneo y su relación con los ACM correspondiente al muestreo del día 6 de octubre de 2014.

Las mediciones de niveles efectuadas en un periodo de escaso déficit hídrico muestran que los antiguos canales de marea topográficamente más elevados no presentan acumulación de agua en superficie (Fig. 5.6c). Por su parte, en aquellos más profundos se acumula una lámina de agua de menos de 30 
centímetros. El nivel freático se encuentra a 4,58 m s. n. m. (0,42 metros de profundidad) y muestra, en relación al nivel de agua superficial, un flujo de descarga local hacia los antiguos canales de marea (Fig. 5.6c). En los canales de marea topográficamente más elevados el nivel freático se localiza, aproximadamente, a 0,25 metros de profundidad. Las mediciones realizadas en un periodo de excesos hídricos evidencia que el área de llanura intermareal se encuentra anegada en porcentajes muy altos cuando la densidad de canales de marea es elevada. En estos casos, la acumulación de agua superficial en los canales de marea más profundos alcanza un valor cercano a 0,50 metros (Fig. 5.6d). El nivel frético en las adyacencias se encuentra aflorando o a menos de 0,20 metros; los niveles de agua medidos en los sectores en donde no aflora evidencian una descarga del agua subterránea hacia los canales de marea.

El gradiente hídrico muy bajo del flujo subterráneo regional (valor de 9,1.10-4; descarga regional hacia el Río de la Plata; ver Capítulo 4), sumado a la baja permeabilidad de los sedimentos de la antigua llanura intermareal, hace que la velocidad del flujo subterráneo sea lenta en esta unidad geomorfológica.

A lo largo de la transecta 1 también se identificó la descarga subterránea local en el arroyo Juan Blanco. Fuera del área de dicha transecta la descarga subterránea, además, se registró en el arroyo Buñirigo y en los canales artificiales que atraviesan este subambiente. Particularmente, el curso del arroyo Buñirigo, en el subambiente de la antigua llanura intermareal, fue rectificado (Fig. 5.1). El antiguo curso del arroyo, que presenta un diseño meandroso, conforma una geoforma deprimida donde se acumula agua en superficie producto de la descarga subterránea y de los excedentes hídricos al igual que fue descripto para los antiguos canales de marea.

\subsubsection{Planicie con cordones de conchilla}

La planicie con cordones de conchilla se representa en su estado natural en las transectas 1 y 4 donde se registran numerosos cordones de conchilla que alternan con las zonas deprimidas de intercordón (Figs. 5.2, 5.5, 5.7a y c). El ancho de este subambiente, en ambas transectas, es de aproximadamente 2 kilómetros. En estos sectores, los cordones llegan a tener hasta 3 kilómetros de longitud y, generalmente, el ancho no supera los 200 metros. En base a los sondeos realizados, la litología para este subambiente se conforma, para el caso de los cordones de conchilla, por restos de valvas de moluscos que alternan con niveles de arenas y arcillas (Fig. 5.7b) mientras que para la zona de intercordón los sedimentos más superficiales tienden a ser arcillosos pasando luego a limos arenosos y limos arcillosos con restos de valvas.

La elevada permeabilidad de los sedimentos que forman los cordones de conchilla permite la rápida infiltración del agua de lluvia y su almacenamiento, motivo por el cual representan zonas de recarga directa preferencial en el ámbito de la planicie costera. A partir de los sondeos realizados en la zona de intercordón se registró que, luego de traspasar la capa arcillosa más superficial y perforar en las arenas, el nivel freático 
ascendía ubicándose muy próximo a la superficie del suelo. Esto indica que, muy localmente, en estas zonas los sedimentos arcillosos confinan al acuífero alojado en las arenas y conchillas subyacentes. En periodos muy lluviosos la baja permeabilidad de los sedimentos más superficiales del intercordón permite que el agua de lluvia se acumule superficialmente.

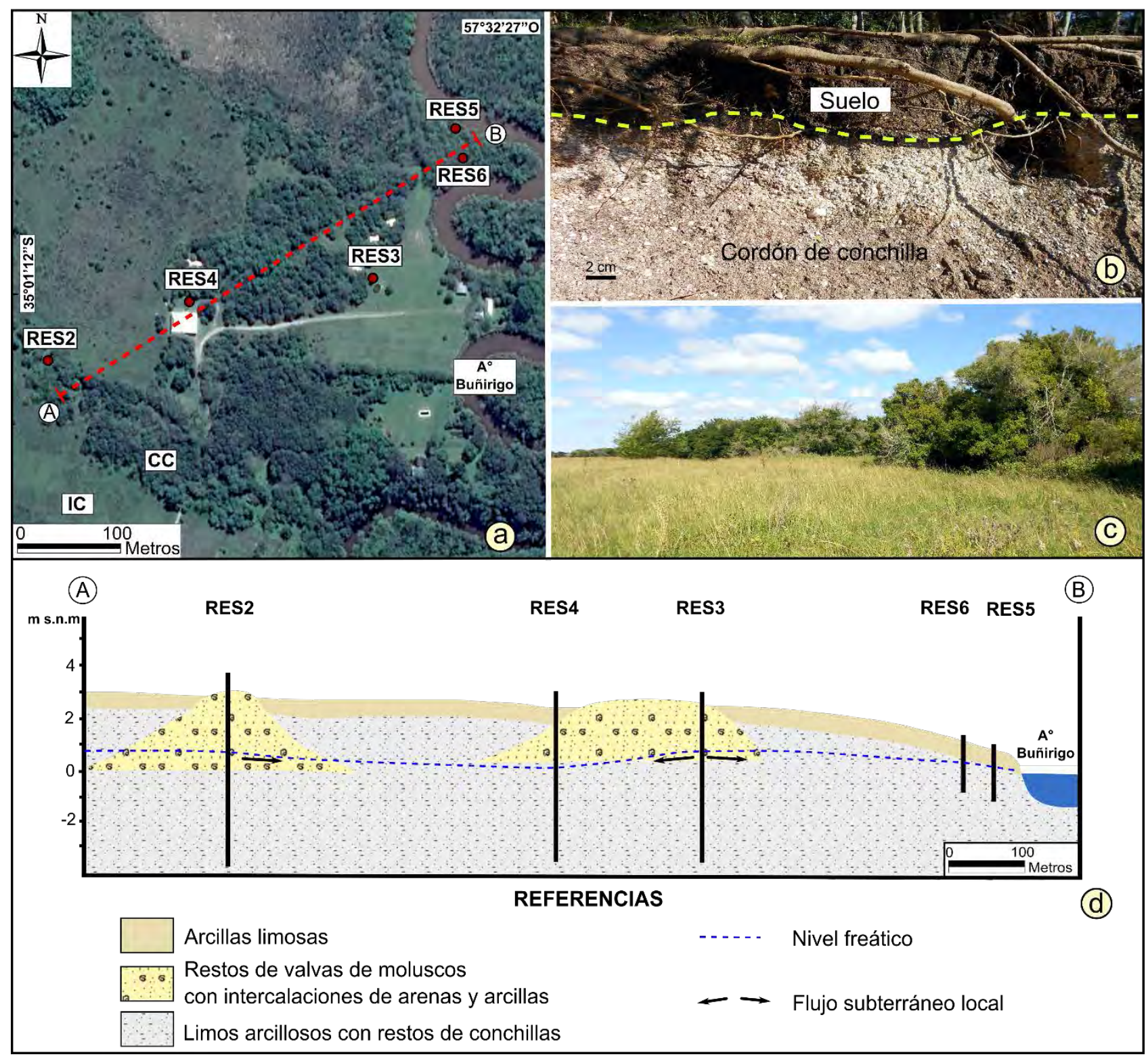

Figura 5.7. Planicie con cordones de conchilla en condiciones naturales. (a) Imagen satelital mostrando el cordón de conchilla (CC), el intercordón (IC) y la ubicación de la traza del perfil A-B. (b) Fotografía del perfil de suelo (Haprendol típico) de un cordón de conchilla. (c) Fotografía del subambiente de planicie con cordones de conchilla. La zona arbolada se desarrolla sobre los cordones de conchilla. (d) Perfil de la dinámica del flujo subterráneo correspondiente al muestreo del día 16 de abril de 2013.

El comportamiento del flujo subterráneo somero, para los cordones de conchilla en condiciones naturales, se estudió en detalle a partir de la información relevada en campo en la transecta 4 (Reserva Natural y Cultural El Saladero). En este sector, las mediciones topográficas muestran que las cotas de los 
cordones de conchilla alcanzan los 2,55 m s. n. m., mientras que en el intercordón y marisma adyacente las cotas son inferiores con valores de 2,40 y $0,90 \mathrm{~m} \mathrm{s.} \mathrm{n.} \mathrm{m.,} \mathrm{respectivamente.} \mathrm{Con} \mathrm{los} \mathrm{registros} \mathrm{de} \mathrm{la} \mathrm{profundidad}$ del nivel del agua y en base a las cotas topográficas se confeccionó un mapa de isopiezas y un perfil de flujo (traza del perfil Fig. 5.7a). En los sectores de cordones, el nivel freático se encuentra entre 2,30 y 1,75 metros de profundidad (con cotas del nivel entre 0,75 y 0,40 m s. n. m.) mientras que en el intercordón y marisma oscila entre 2,25 y 0,70 metros (con cotas del nivel entre 0,15 y $0,26 \mathrm{~m} \mathrm{s.} \mathrm{n.} \mathrm{m.),} \mathrm{respectivamente.} \mathrm{El} \mathrm{nivel}$ freático acompaña a la topografía con un flujo local desde la cresta del cordón hacia los bordes, descargando en las zonas de intercordón y en la planicie costera adyacente (Fig. 5.7d). Este flujo subterráneo local se produce con un gradiente hídrico de 4,9.10-3 (Fig. 5.8).

Un análisis más detallado de la hidrodinámica de este ambiente en relación a la marisma adyacente y a los flujos mareales y precipitaciones se realiza en el Apartado 5.2.3.

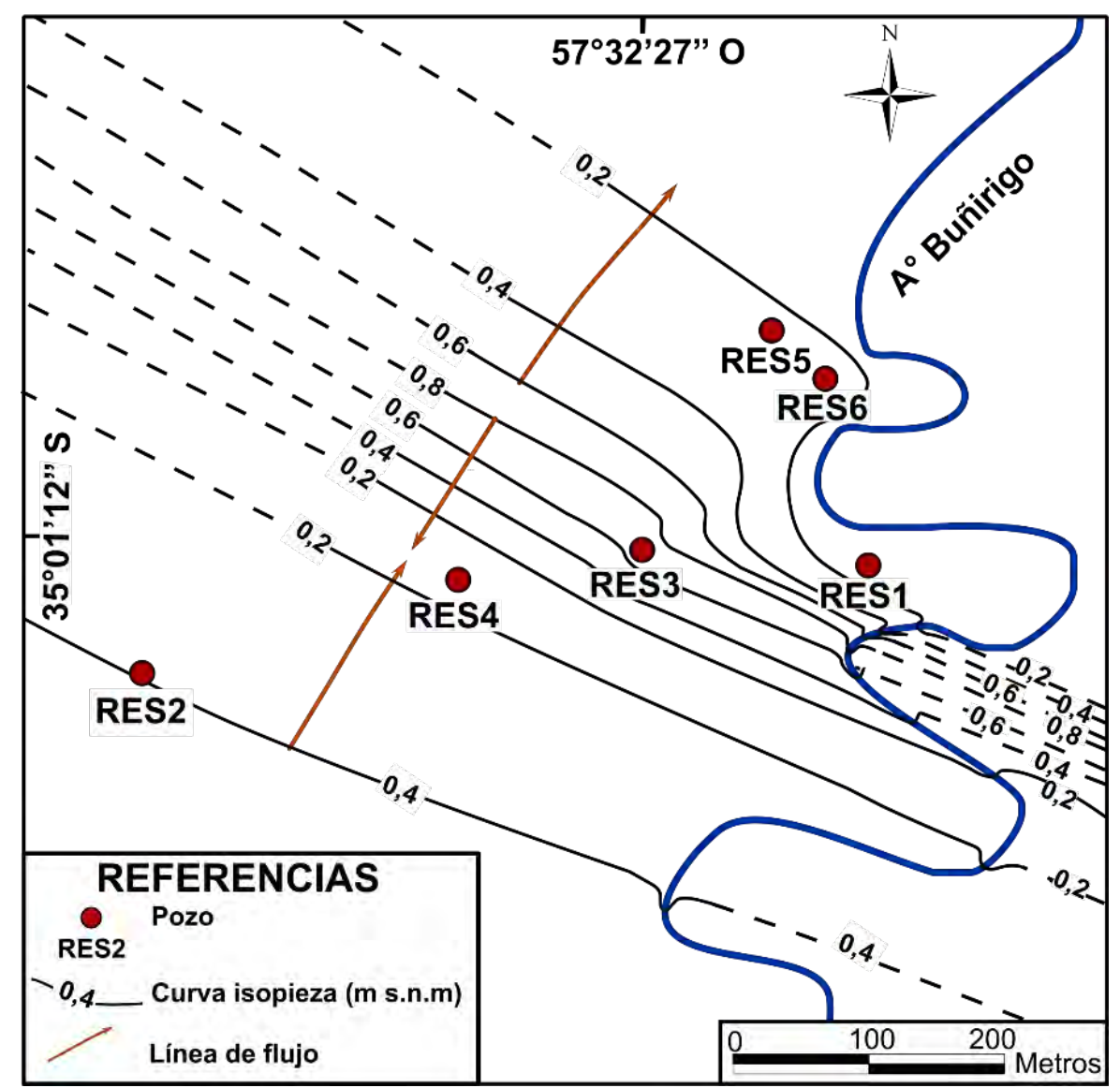

Figura 5.8. Mapa de flujo subterráneo para el sector correspondiente a la transecta 4 (Reserva Natural y Cultural El Saladero). Los valores de cota del nivel de agua corresponden al muestreo realizado el 16 de abril de 2013.

En varios sectores de la planicie costera los cordones de conchilla perdieron su morfología original por la acción antrópica vinculada, principalmente, a la minería, actividades agropecuarias o urbanización. 
Debido a la explotación minera, muchas áreas de cordones se encuentran actualmente como excavaciones irregulares donde, en ocasiones, el agua subterránea somera aflora (Figs. 5.9b y c).

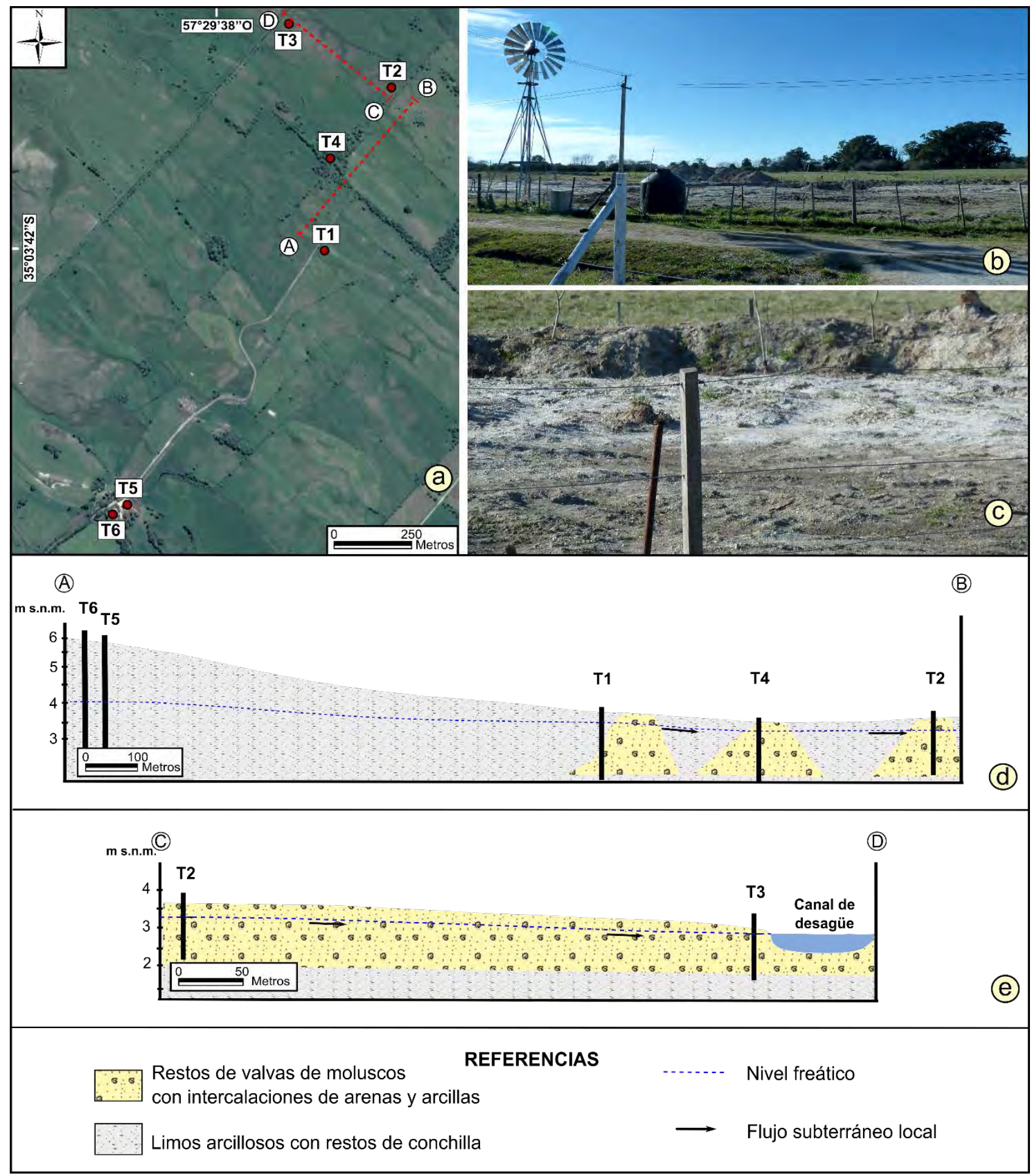

Figura 5.9. Planicie con cordones de conchilla modificada por las actividades antrópicas. (a) Imagen satelital mostrando cordones de conchilla modificados para el desarrollo de la actividad ganadera y la ubicación de las trazas de los perfiles A-B y C-D. (b) y (c) Fotografías que ilustran la explotación de los cordones de conchilla. (d) y (e) Perfiles de la dinámica del flujo subterráneo somero. 
Otros cordones, luego de la explotación minera, fueron nivelados y se presentan como suaves ondulaciones dominadas por pastizales o cultivos donde la cota topográfica rara vez supera los 2,50 m s. $\mathrm{n}$. m. Este tipo de morfología se identifica en la transecta 3 (Fig. 5.4) en la cual, actualmente, el área de cordones litorales es una zona llana destinada al cultivo con forraje para el ganado (Fig. 5.9a).

Para comprender el comportamiento del flujo subterráneo en este sector de la planicie costera se utilizaron los datos topográficos y de niveles relevados en campo para confeccionar un mapa isofreático y dos perfiles de flujo (traza de los perfiles Fig. 5.9a). A diferencia del perfil anterior, que ilustraba los cordones conchiles en condiciones naturales (Fig. 5.7), en esta situación no se aprecia que los cordones sean zonas de recarga preferencial donde el nivel freático se posiciona más elevado. En estos casos, la pérdida de la morfología positiva, conlleva a que éstas áreas se comporten como zonas de tránsito del flujo subterráneo (Fig. 5.9d). A pesar de esto, siguen siendo sectores de mayor permeabilidad respecto de la antigua llanura y marisma adyacente. En consecuencia, en periodos lluviosos el agua de lluvia infiltra preferencialmente en estas zonas y se acumula subterráneamente, siendo explotada para abastecimiento mediante molinos por el propietario del campo. El flujo subterráneo descarga en el Río de la Plata con un gradiente hídrico del orden de $1,96.10^{-4}$ (Fig. 5.10). Además de este flujo regional, se identificó la descarga subterránea hacia el canal de desagüe (Fig. 5.9e) localizado al noroeste del establecimiento.

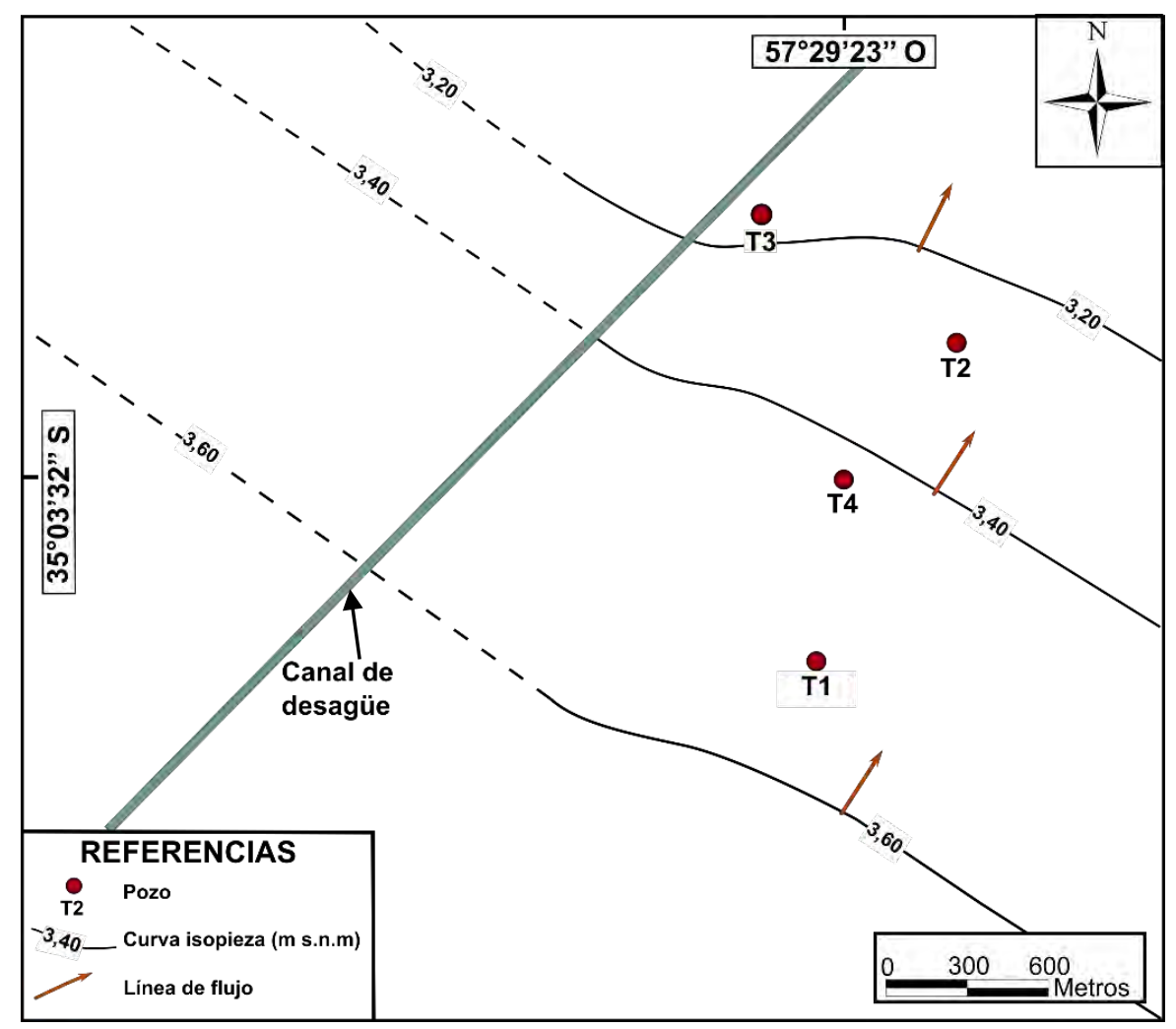

Figura 5.10. Mapa de flujo subterráneo para el sector correspondiente a la transecta 3 (Estancia Villa Villabona). Los valores de cota del nivel de agua corresponden al muestreo realizado el 14 de abril de 2014. 


\subsubsection{Marisma}

La interacción entre los flujos mareales y el agua subterránea somera para el subambiente de marisma fue estudiada en detalle en la transecta 4 (Fig. 5.5). Los sedimentos más superficiales se componen de arenas finas transportadas por el río en los eventos de pleamar o mareas extraordinarias que inundan a la marisma. Por debajo de éstos, los sedimentos se hacen más arcillosos hasta 1,10 metros de profundidad pasando luego a sedimentos limosos hasta los 3,50 metros de profundidad en que fueron efectuados los sondeos manuales. Dado que la marea inunda periódicamente a la marisma, es un ambiente donde frecuentemente presenta agua en superficie gran parte del año (Fig. 5.11).

El sector de la transecta 4 seleccionado para el estudio hidrodinámico se localiza en la cuenca baja del arroyo Buñirigo el cual recibe la influencia mareal desde el Río de la Plata. El régimen micromareal hace que los períodos de sicigia y cuadratura sean poco distinguibles, oscilando la marea entre 1,17 y -0,65 m s. $\mathrm{n}$. m. (Figs. 5.12 y 5.13). Para estudiar la relación entre el agua subterránea y los flujos mareales se utilizaron dos pozos de exploración de agua subterránea, uno ubicado en la marisma (RES5) y otro situado en la planicie con cordones de conchilla adyacente (RES3) (Fig. 5.5). En los pozos de exploración se realizaron mediciones horarias de niveles, temperatura y conductividad eléctrica del agua con sensores de registro continuo por un período de tres meses (entre el 16 de abril hasta el 15 de julio de 2013). Estos parámetros fueron comparados con datos de precipitación diaria y altura horaria de la marea en el Río de la Plata. Los datos de la altura de la marea corresponden al mareógrafo de Prefectura Naval Argentina localizado en la costa de Atalaya.

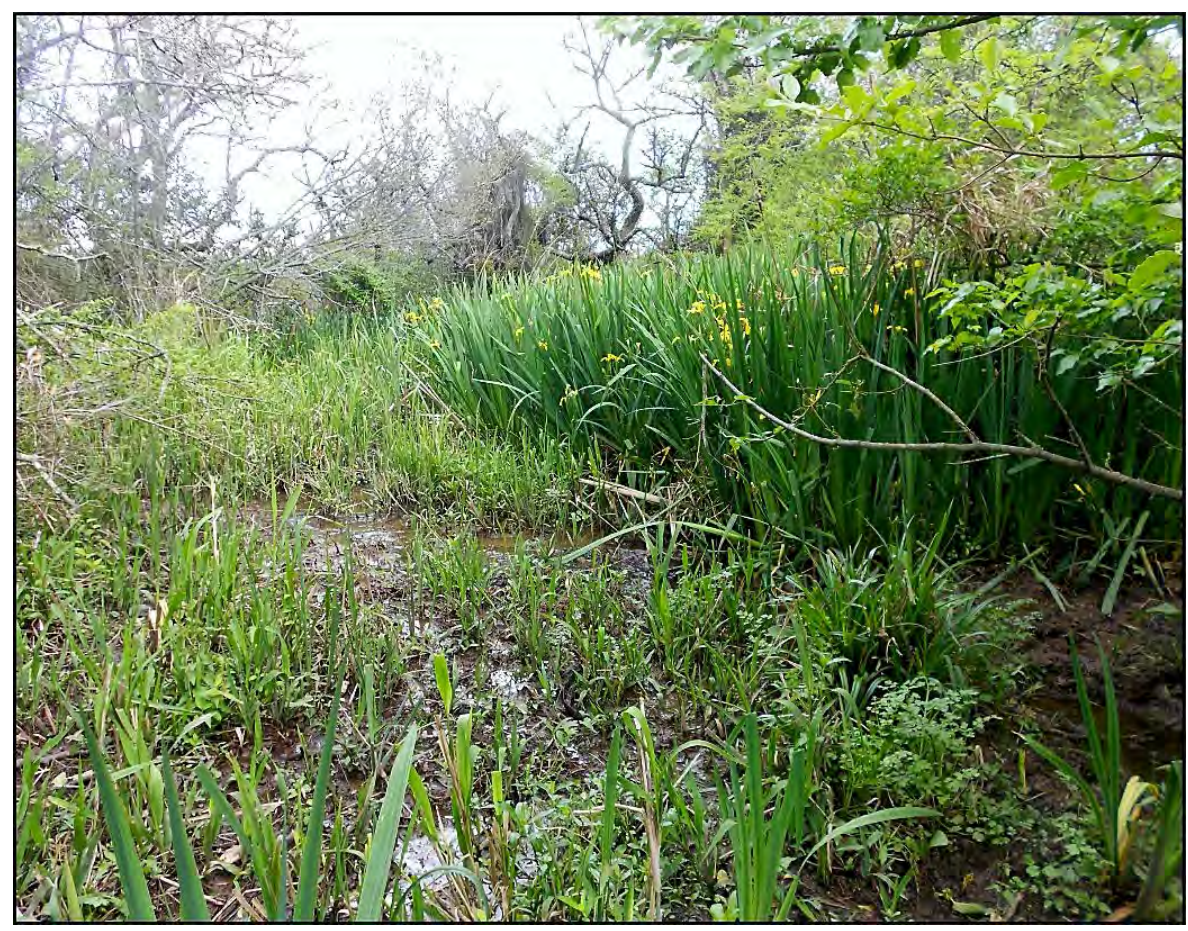

Figura 5.11. Fotografía de un sector de marisma, próximo a la desembocadura del arroyo Buñirigo, donde puede observarse la acumulación del agua en superficie. 


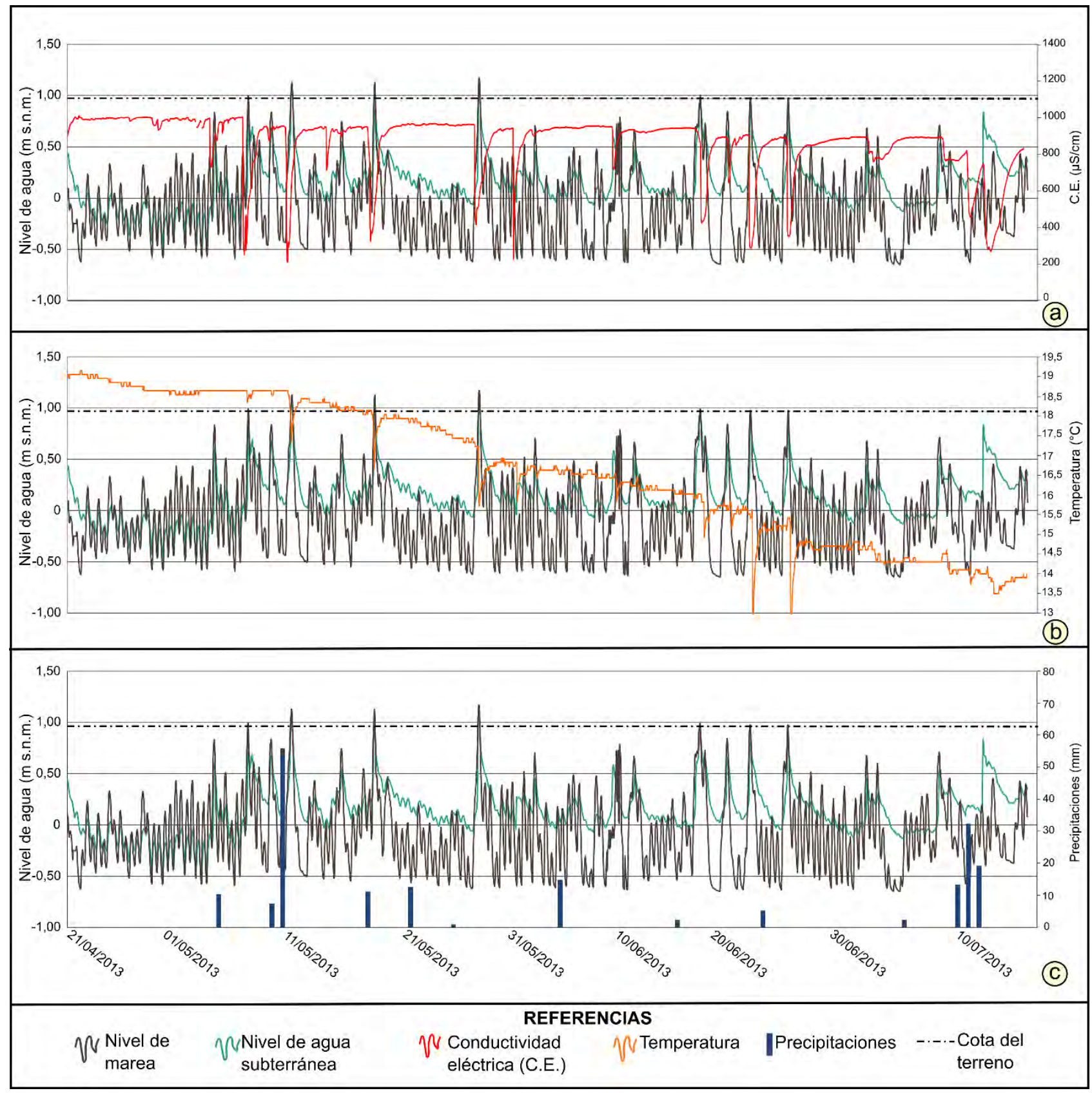

Figura 5.12. Registro del sensor en el subambiente de marisma. (a) Valores de niveles y conductividad eléctrica del agua subterránea comparados con los niveles de marea en el río. (b) Valores de niveles y temperatura del agua subterránea comparados con los niveles de marea en el río. (c) Valores de niveles del agua subterránea comparados con las precipitaciones diarias y con los niveles de marea en el río.

El análisis de los registros de marea manifiesta que la pleamar inunda periódicamente los sectores más bajos de la marisma, mientras que los más elevados sólo se inundan durante las pleamares extraordinarias. Además, la marea se propaga hacia el continente por el curso del arroyo Buñirigo, observándose en relevamientos de campo, que dentro del arroyo la marea puede propagarse hasta más de un kilómetro desde la línea de costa. En el pozo ubicado en la marisma, próximo a la margen del arroyo (RES5; Fig. 5.5), se registra que los niveles freáticos responden a las oscilaciones de las mareas, dado que los picos 
de ascenso del nivel coinciden con las pleamares. Por ejemplo, para la máxima amplitud de marea registrada de 1,80 metros, en el pozo de la marisma se observan ascensos del nivel del agua de hasta 1,20 metros (para el día 25 de mayo de 2013). Dado que este pozo se encuentra muy próximo a la margen del arroyo por donde se propaga la marea (distancia de 2 metros), es que la influencia mareal puede registrarse rápidamente. Asimismo, cabe aclarar que, si bien el pozo se construyó en la zona de marisma, alrededor del caño existe una elevación del terreno que, sumada a la cementación del pozo, impide que el agua mareal ingrese por el espacio anular. Por tal motivo, el ascenso de niveles registrado en este pozo se debe a la propagación lateral de la marea desde la margen del arroyo hacia el acuífero cuando la pleamar no inunda a la marisma adyacente, a lo que se le suma el ingreso del flujo mareal desde superficie cuando la pleamar supera la cota de la marisma.

Debido a que el agua del Río de la Plata en este sector del estuario presenta una salinidad media de $0,45 \mathrm{~g} / \mathrm{L}$ (valor estimado a partir de la conductividad eléctrica) y el agua subterránea de la marisma tiene en promedio una salinidad de $0,60 \mathrm{~g} / \mathrm{L}$, el ingreso del flujo mareal al acuífero produce, durante la pleamar, una disminución periódica en la conductividad eléctrica del agua subterránea. Esto se observa en el registro de los sensores donde, junto con el ascenso del nivel que ocurre durante la pleamar, el agua subterránea de la marisma presenta una disminución en la conductividad eléctrica (Fig. 5.12a). Con respecto a la temperatura, se registra un descenso de $18,70^{\circ} \mathrm{C}$ a $14,10^{\circ} \mathrm{C}$ desde abril a julio, relacionado a la variación estacional de la temperatura atmosférica que ocurre de otoño a invierno (Fig. 5.12b). No obstante, en el pozo de la marisma se registran pequeños picos de descenso de temperatura asociados a las pleamares lo cual evidencia el ingreso del agua del Río de la Plata de menor temperatura respecto a la de la marisma en la capa freática. En relación a las precipitaciones sólo se observa una respuesta del nivel de agua subterránea en los eventos de lluvia que superan los $40 \mathrm{~mm}$ diarios (Fig. 5.12c). La infiltración del agua de lluvia produce un leve ascenso en los niveles medios del agua subterránea, el cual se observa en los días posteriores a las lluvias del 2 de mayo (76 $\mathrm{mm}$ ) y 9 de julio (44 $\mathrm{mm})$.

En el pozo ubicado en la zona de planicie con cordones de conchilla, adyacente a la marisma (RES3; Fig. 5.5), las oscilaciones de los niveles de agua subterránea en relación a la marea son menores que en la marisma (Figs. 5.12 y 5.13). Para el máximo registro de amplitud de marea en el río de 1,80 metros, el nivel freático registra un ascenso máximo de 0,35 metros (para el día 25 de mayo de 2013). Los registros continuos de conductividad eléctrica del agua subterránea en este pozo son de un periodo más breve, comprendido entre el 16 de abril al 03 de mayo de 2013; no obstante, puede observarse que los valores son poco variables (Fig. 5.13a). 


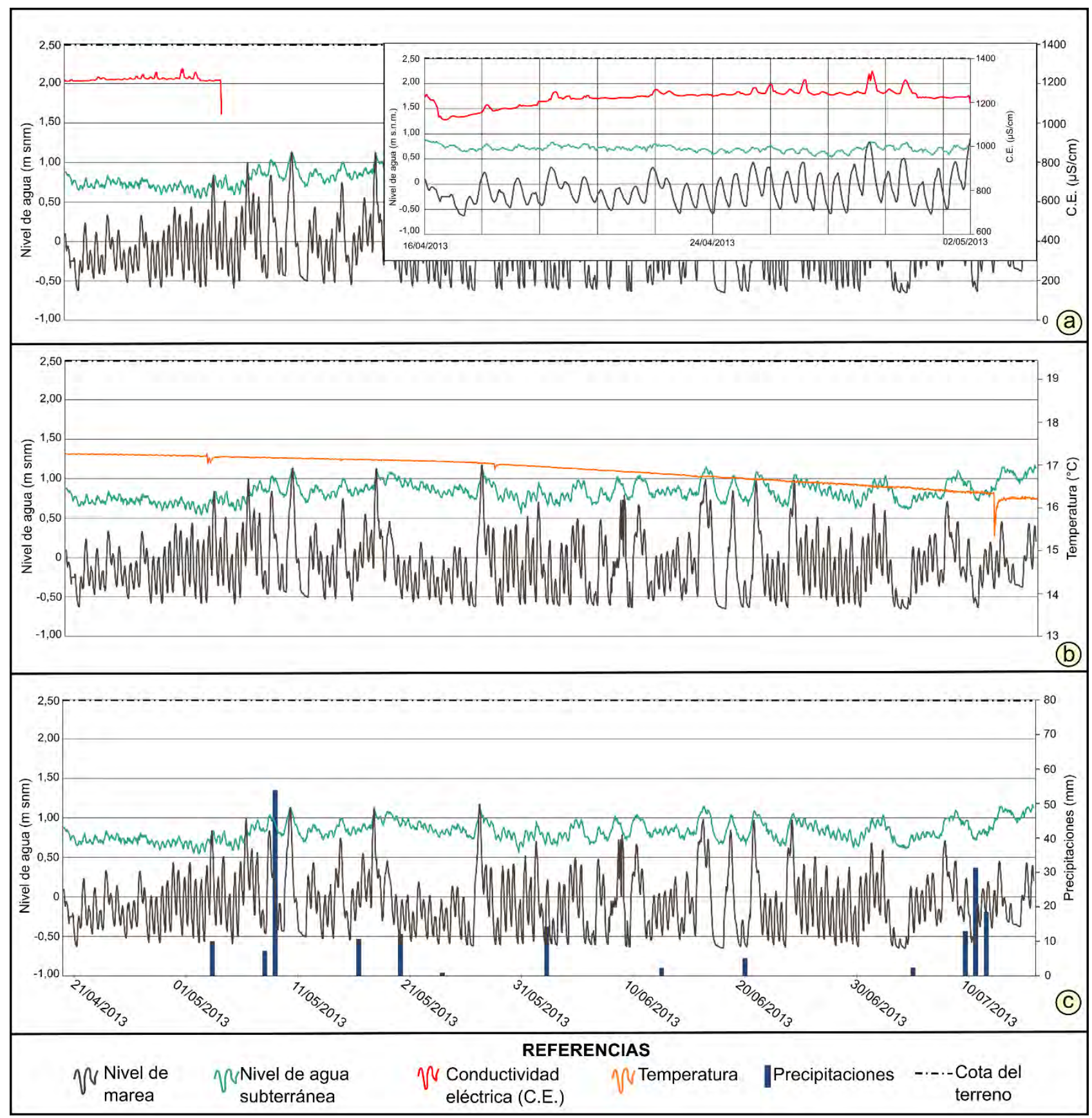

Figura 5.13. Registro del sensor en el subambiente de planicie con cordones de conchilla. (a) Valores de niveles y conductividad eléctrica del agua subterránea comparados con los niveles de marea en el río. Se presenta un gráfico en detalle entre los días 24 de abril y 02 de mayo que corresponde al período registrado por el sensor. (b) Valores de niveles y temperatura del agua subterránea comparados con los niveles de marea en el río. (c) Valores de niveles del agua subterránea comparados con las precipitaciones diarias y con los niveles de marea en el río.

La temperatura del agua subterránea sólo registra variaciones estacionales mostrando un descenso de $17,60{ }^{\circ} \mathrm{C}$ en abril a $16,40^{\circ} \mathrm{C}$ en julio (Fig. 5.13b). Esta variación en el nivel freático, que acompaña a la marea pero que ocurre sin cambios en la temperatura y conductividad eléctrica del agua, se debe a un efecto hidráulico y mecánico inducido por la marea producto de la fuerza que ejerce la columna de agua mareal 
durante la pleamar en los sedimentos que contienen al acuífero y que se extienden hacia el sector de plataforma del estuario (Guarracino et al., 2012). Por su parte, en relación a las precipitaciones se observa, al igual que en la marisma, que las lluvias diarias superiores a $40 \mathrm{~mm}$ producen un ascenso en la posición media del nivel freático (Fig. 5.13c).

Si se analizan en conjunto los valores registrados por los sensores en los dos pozos de exploración y los datos de la altura de la marea para condiciones extremas (máximos y mínimos) puede apreciarse que existen distintas situaciones para cada pozo (Fig. 5.14). En bajamar, el flujo subterráneo es desde la zona de planicie con cordones de conchilla hacia la marisma y en este subambiente la descarga subterránea es hacia el arroyo Buñirigo y el Río de la Plata. La figura 5.14a representa la situación en donde se reconoce que, durante una bajamar, los valores de la cota del nivel del agua, tanto en el pozo RES5 como en el RES3, son los más bajos del registro.

En la pleamar se eleva el nivel de agua en el arroyo producto de la propagación de la onda de marea desde el estuario. Cuando el nivel de agua en el arroyo sobrepasa al nivel freático en la marisma se produce el ingreso del agua mareal hacia el acuífero ocurriendo una inversión local en el sentido del escurrimiento subterráneo. Debido a que el pozo de exploración de la marisma se encuentra muy próximo al arroyo (2 metros de distancia) y a la presencia de sedimentos limosos en el acuífero, la propagación de la marea hacia el acuífero se registra rápidamente en el sensor del pozo. En consecuencia, ascienden los niveles freáticos y como el agua mareal es menos salina y de menor temperatura, disminuye la salinidad y temperatura del agua subterránea en la marisma (Fig. 5.14b). En el pozo de la planicie con cordones conchiles, si bien también ocurre un ascenso del nivel durante la pleamar, éste se produce por la combinación de un efecto hidráulico y mecánico (Guarracino et al., 2012) tal como fue descripto anteriormente. Por consiguiente, dado que no existe un ingreso de agua mareal en este sector del acuífero no se registran cambios ni en la temperatura ni en la conductividad eléctrica del agua.

El máximo valor de ascenso de nivel freático en el pozo de exploración de la planicie con cordones conchiles se registra con cuatro días de posterioridad a las precipitaciones (Fig. 514c). Esto evidencia, como se mencionó en el Apartado 5.2.2, que la litología de los cordones permite que el agua de lluvia infiltre preferencialmente y que estas geoformas constituyan zonas de recarga directa en la planicie costera. 


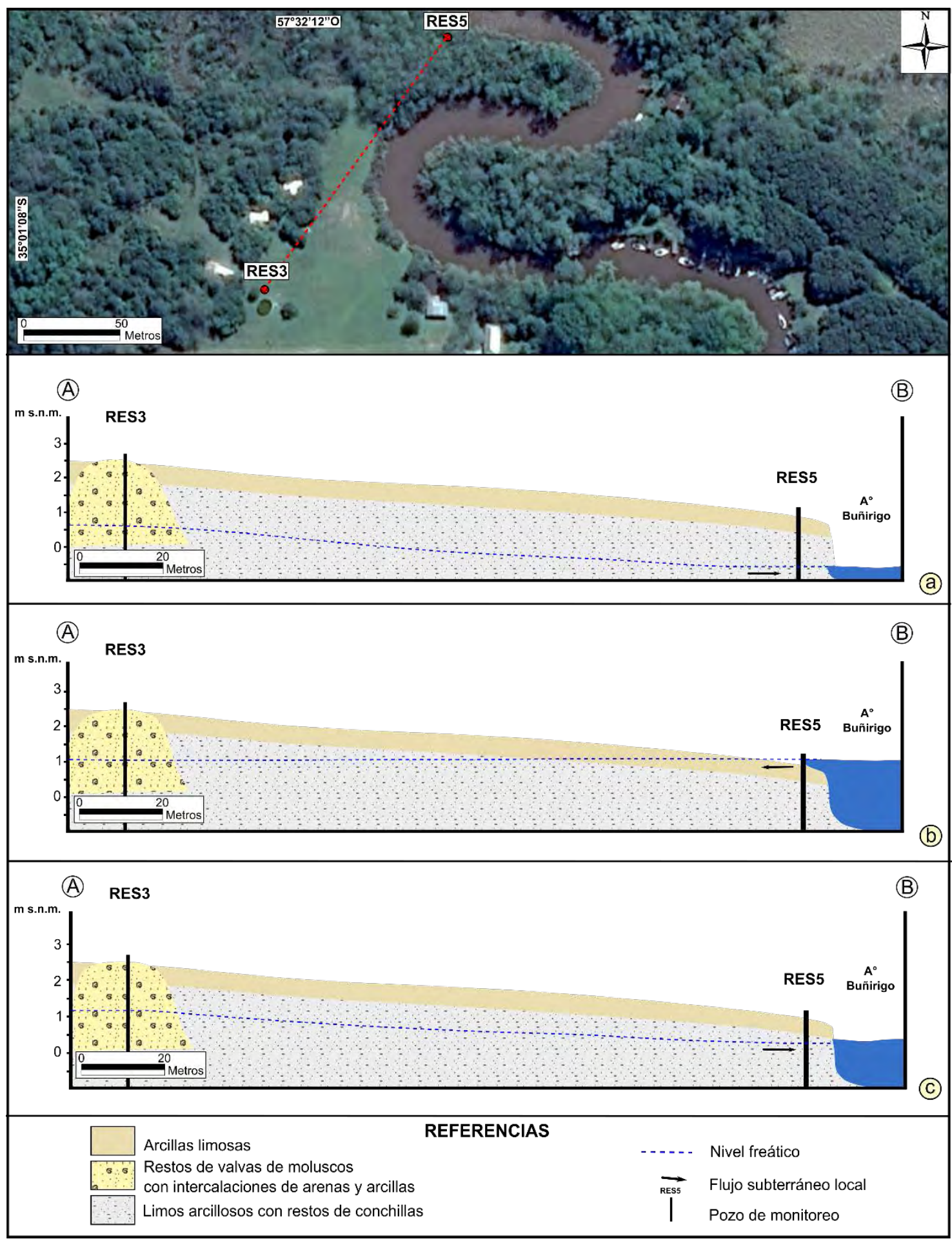

Figura 5.14. Perfil del funcionamiento dinámico del agua subterránea en relación a los flujos mareales. (a) Valor más bajo para la cota del nivel del agua en ambos pozos estudiados correspondiente al registro del día 29 de abril de 2013 (2:00 hs). Estos valores coinciden con una bajamar (uno de los valores más bajos del registro) del río. (b) Valor más alto para la cota del nivel del agua registrado en el pozo RES5 correspondiente al día 25 de mayo de 2013 (2:00 hs). Este valor se relaciona con la máxima altura registrada para la marea en el río (pleamar extraordinaria). (c) Valor más alto para la cota del nivel del agua identificado en el pozo RES3 ocurrido el día 15 de julio de 2013 (8:00 hs). Este valor se registra luego de las precipitaciones que acontecieron los días 09, 10 y 11 de julio de 2013 $(18,44$ y $26 \mathrm{~mm}$, respectivamente. 


\section{Capítulo 6. HIDROGEOQUÍMICA DE LA PLANICIE COSTERA DEL RÍO DE LA PLATA MEDIO EN EL LITORAL DEL PARTIDO DE MAGDALENA}

En este capítulo se analizan los principales procesos geoquímicos que regulan la calidad del agua en cada subambiente de la planicie costera. Los datos utilizados provienen de la red de monitoreo descripta en el Capítulo 5 la cual comprende cuatro transectas, perpendiculares a la línea de costa, que abarcan los principales subambientes de la planicie costera. La evaluación de los procesos geoquímicos que ocurren por la interacción entre el agua superficial, el agua subterránea y el sedimento-suelo es esencial para determinar los factores que condicionan la calidad del agua en los distintos subambientes de la planicie costera.

\subsection{HIDROQUÍMICA DE LAS UNIDADES GEOMORFOLÓGICAS DE LA PLANICIE COSTERA}

El análisis en detalle de la química del agua para cada subambiente de la planicie costera se realizó en base a los muestreos de agua superficial y subterránea efectuados en la red de monitoreo (Fig. 5.1). En cada sitio estudiado se identificaron los tipos de aguas a través de diagramas de Stiff (1951), así como el contenido salino y de nitrato. Conjuntamente con el nitrato se analizó la presencia de bacterias coliformes totales y fecales con el fin de establecer las posibles fuentes de aporte (naturales o antrópicas) y de ingreso al agua subterránea de este contaminante. Posteriormente, se efectuó un análisis integral de todas las muestras a partir de diagramas de isótopos ambientales $\left({ }^{2} \mathrm{H} \mathrm{y}^{18} \mathrm{O}\right)$ y de relaciones iónicas para identificar los principales procesos geoquímicos que determinan la calidad del agua en la planicie costera.

\subsubsection{Tipos de agua}

Los resultados obtenidos en las cuatro transectas muestran que existen diferentes tipos de agua y que estas diferencias pueden estar asociadas a cambios de subambiente dentro de la planicie costera así como a variaciones espaciales dentro de un mismo subambiente.

En la transecta 1 se observa que tanto las muestras de agua subterránea como la de agua superficial son de tipo bicarbonatada sódica (Fig. 6.1) aunque presentan variaciones en el contenido salino. Las muestras de los molinos de viento ubicados en la llanura loessica (MEJB1 y MEJB2), que captan agua a una profundidad de entre 8 a 12 metros, presentan un menor contenido salino (promedio de salinidad de 0,67 g/L) que las muestras de agua subterránea de la planicie con cordones de conchilla (EJB2 con 1,07 g/L) y la antigua llanura 
intermareal (EJB1 con 0,98 g/L) tomadas de los pozos de exploración someros construidos a una profundidad de 2 metros. Por su parte, la muestra del arroyo Juan Blanco (AJB) presenta un valor de salinidad mucho menor respecto de las muestras de agua subterránea $(0,10 \mathrm{~g} / \mathrm{L})$.

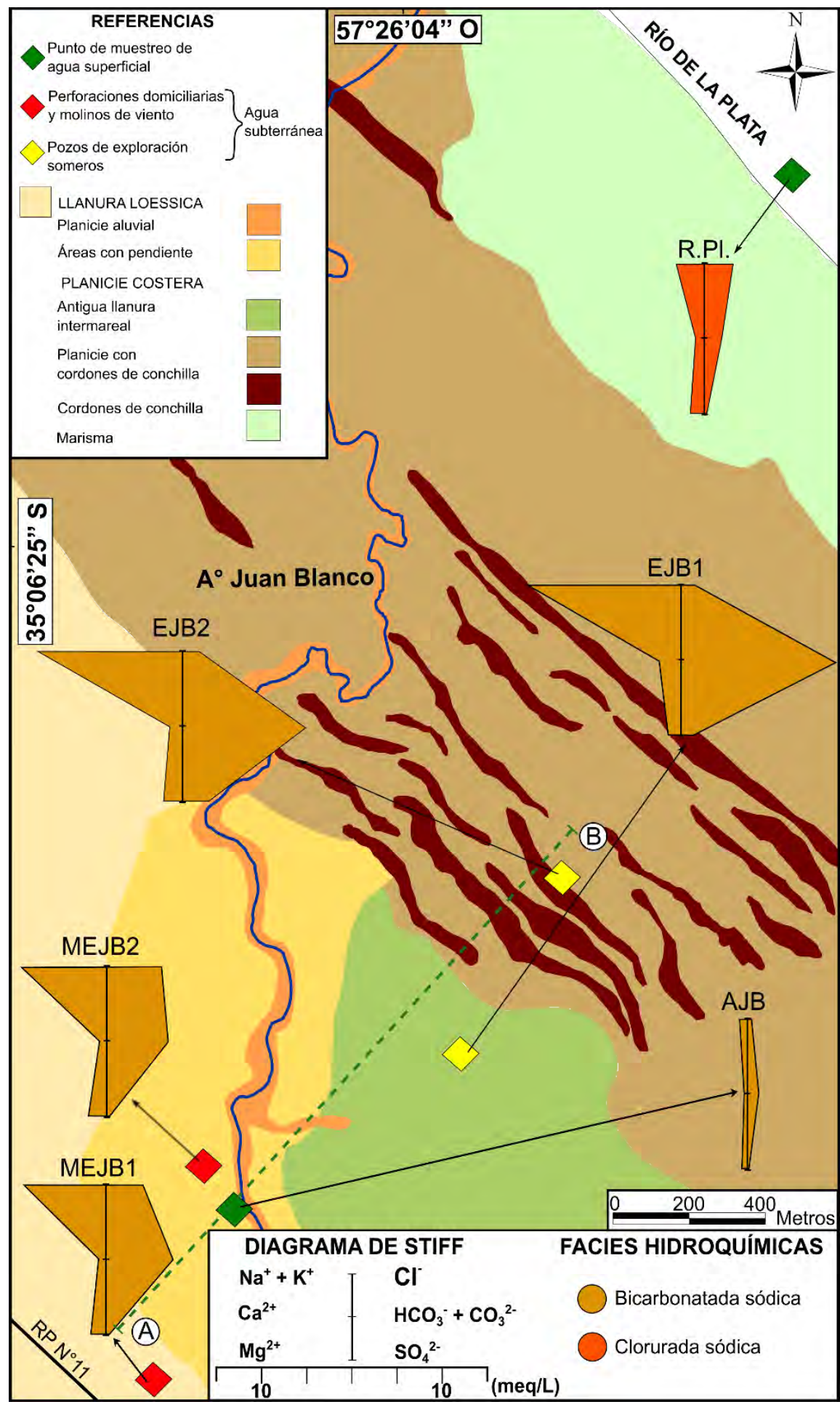

Figura 6.1. Mapa geomorfológico donde se indican las facies hidroquímicas para el agua subterránea y superficial en el Establecimiento Juan Blanco (transecta 1). Los diagramas de Stiff, están coloreados en base a las facies hidroquímicas que representan. La línea AB indica la traza del perfil esquemático representado en la figura 6.2. 
Además de las muestras analizadas para cada una de las transectas, se incluyó en el estudio de cada área una muestra correspondiente al Río de la Plata (R. PI., Figs. 6.1, 6.3, 6.5 y 6.7). La misma es de tipo clorurada sódica y presenta una salinidad de $0,43 \mathrm{~g} / \mathrm{L}$.

Las concentraciones de nitrato más elevadas $(30,00 \mathrm{mg} / \mathrm{L})$ se observan en el pozo próximo al pequeño feedlot y casco de la estancia (MEJB1), registrándose también en este pozo la presencia de bacterias coliformes totales y Escherichia coli. En la antigua Ilanura intermareal y planicie con cordones de conchilla las concentraciones de nitrato varían entre $18,20 \mathrm{mg} / \mathrm{L}$ y $2,40 \mathrm{mg} / \mathrm{L}$, respectivamente (Fig. 6.2).

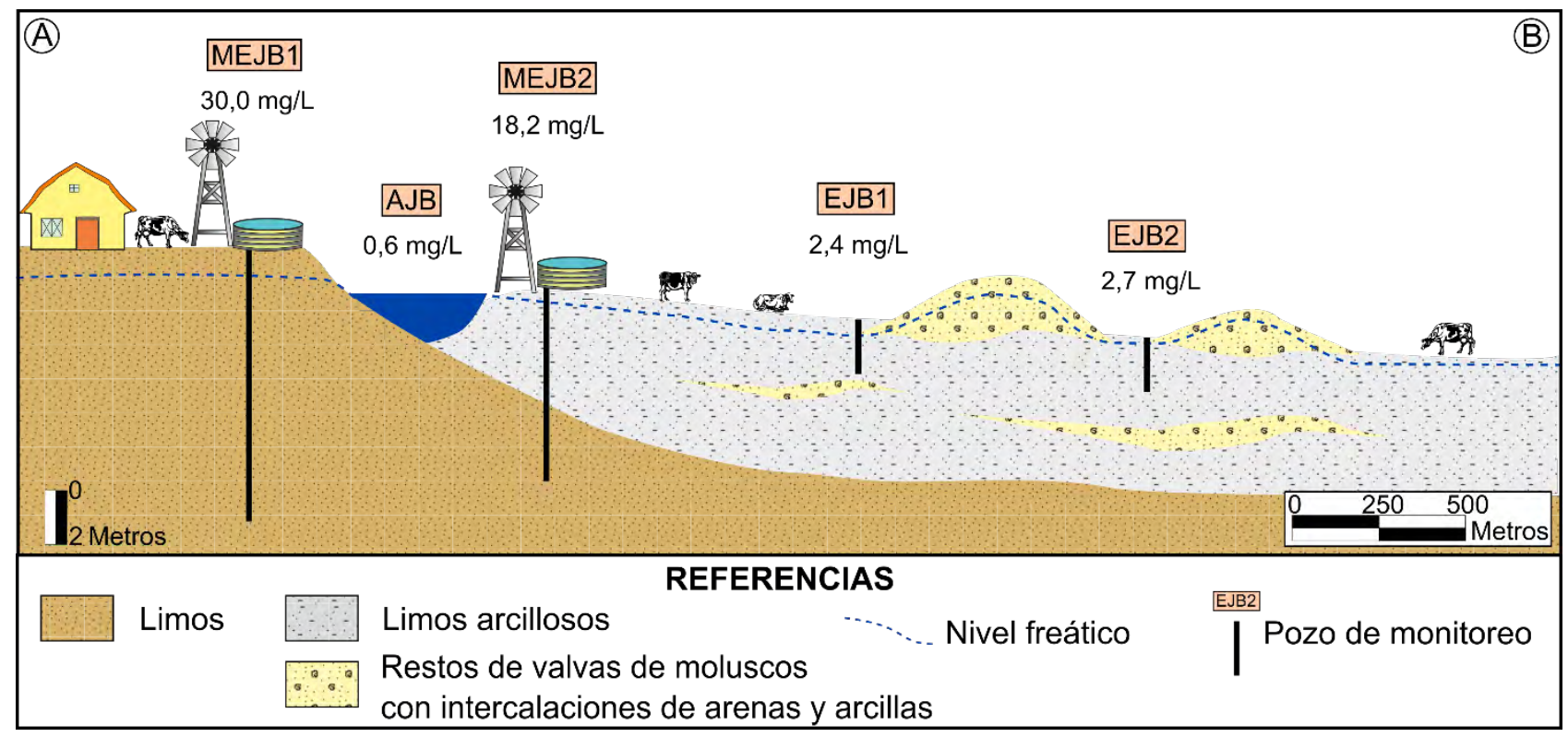

Figura 6.2. Transecta para el Establecimiento Juan Blanco. Se ilustran de manera esquemática las unidades geológicas y geomorfológicas para el área además de la relación entre el agua superficial y subterránea. El valor expresado en mg/L hace referencia al contenido de nitrato para cada pozo de monitoreo. La traza del perfil se indica en la figura 6.1.

En la transecta 2, si bien todos los puntos de muestreo se encuentran dentro del subambiente de planicie con cordones de conchilla, se observa que la composición del agua subterránea presenta un contenido de iones mayoritarios distintos a los del agua superficial. Las muestras correspondientes al agua subterránea (UP1 y UP2) extraídas de la zona de intercordón son de tipo clorurada sódica mientras que las muestras de agua superficial (CUP1 y CUP2) son bicarbonatada sódica (Fig. 6.3). La diferencia en salinidad es notable si se comparan las muestras de agua subterránea y superficial. Si bien las muestras de agua subterránea son de tipo clorurada sódica la muestra UP2, ubicada en una zona deprimida, presenta una fuerte dominancia de estos iones y elevadas concentraciones salinas $(4,28 \mathrm{~g} / \mathrm{L})$. Para el caso de la muestra UP1, ubicada próxima a un cordón de conchilla, el contenido de cloruro es levemente superior al de bicarbonato y la salinidad es de 3,62 g/L. Las muestras de agua superficial, tomadas del canal artificial (CUP1) y la cañada (CUP2), presentan contenidos iónicos similares y salinidades bajas con un valor de 0,56 g/L. 


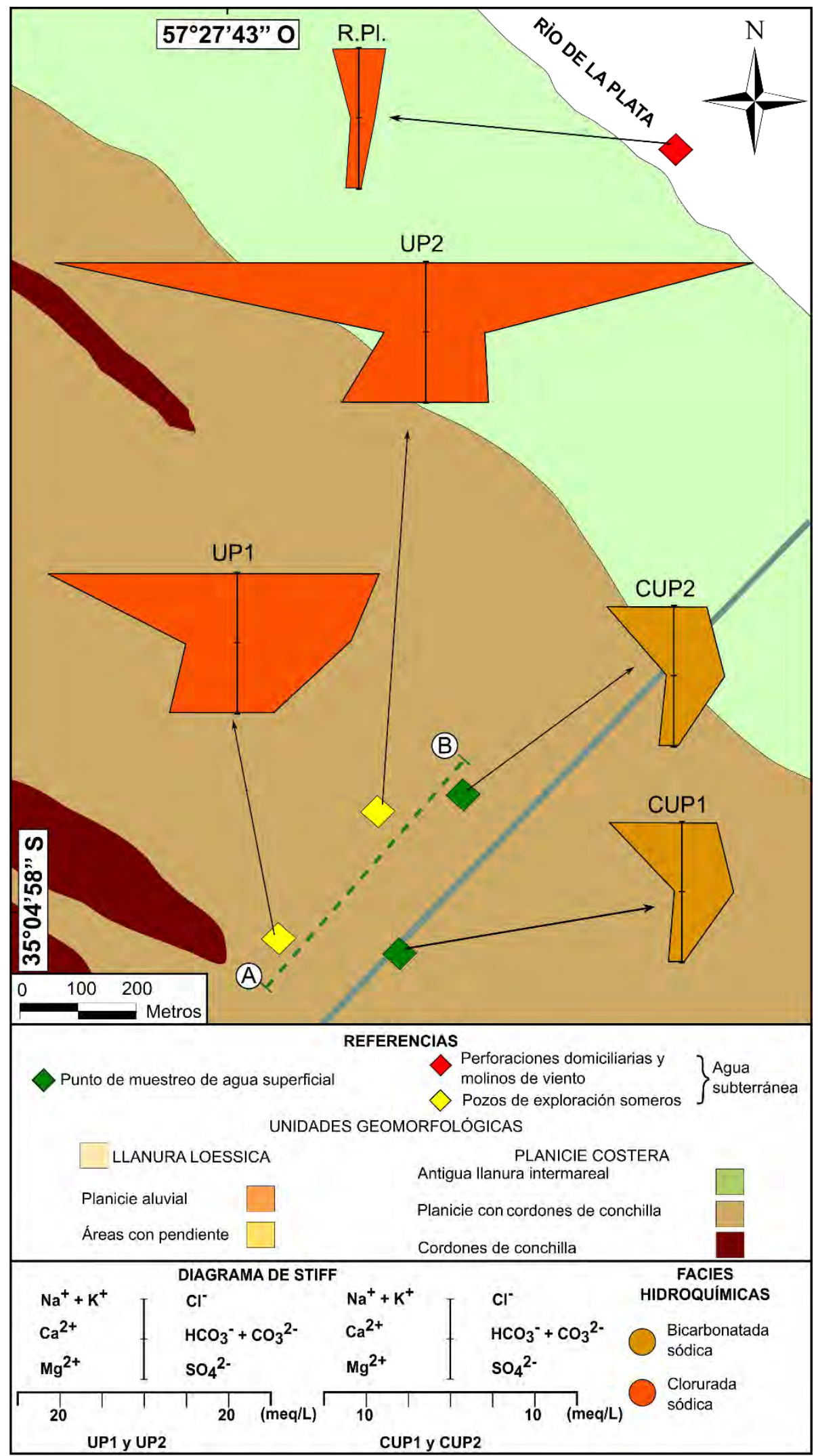

Figura 6.3. Mapa geomorfológico donde se ilustran las facies hidroquímicas para el agua subterránea y superficial en la Unidad Penitenciaria N²8 (transecta 2). Los diagramas de Stiff, están coloreados en base a las facies hidroquímicas que representan. La línea A-B indica la traza del perfil esquemático representado en la figura 6.4. 
Para el sector de la transecta 2 los valores de nitrato para los pozos de exploración UP1 y UP2 son de 23,20 y $29,50 \mathrm{mg} / \mathrm{L}$, respectivamente (Fig. 6.4). En ambas muestras, además, se registra la presencia de coliformes totales y fecales. Para el caso de las muestras de agua superficial, los valores de nitrato son bajos y registran valores de 3,30 mg/L (CUP1) y 3,10 mg/L (CUP2) (Fig. 6.4). En ambos sitios de muestreo hay una cantidad elevada de coliformes totales (más de 1100 NMP en $100 \mathrm{ml}$ de agua) y presencia de Escherichia coli sólo en la muestra CUP2.

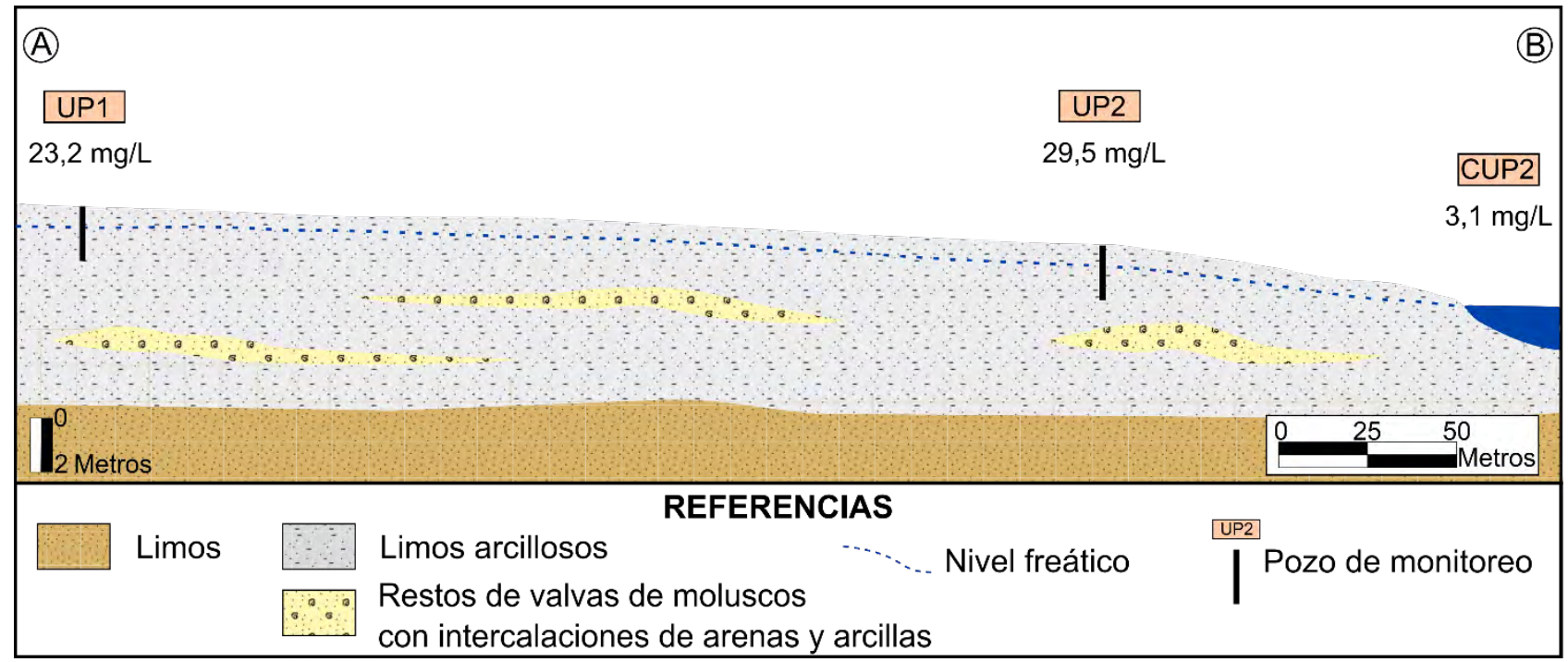

Figura 6.4. Transecta para la Unidad Penitenciaria $N^{\circ} 28$. Se ilustran de manera esquemática las unidades geológicas y geomorfológicas para el área además de la relación entre el agua superficial y subterránea. El valor expresado en $\mathrm{mg} / \mathrm{L}$ hace referencia al contenido de nitrato para cada pozo de monitoreo. La traza del perfil se indica en la figura 6.3.

En la transecta 3, si bien todos los puntos de monitoreo se ubican en el subambiente de planicie con cordones de conchilla, se reconocen variaciones en los tipos de agua y contenidos salinos (Fig. 6.5). Por un lado, agua de tipo bicarbonatada sódica (muestras T1, T2, T3, CT1 y CT2) y, por otro, agua de tipo clorurada sódica (muestras T4, T5 y T6). Las muestras de agua subterránea extraídas de los pozos de exploración someros (T1, T2 y T3) presentan una salinidad promedio de 0,92 g/L. Las muestras de agua subterránea procedentes de molinos de viento y pozos de abastecimiento de la estancia y tambo (T4, T5 y T6), que captan agua a una mayor profundidad (aproximadamente 10 metros), son levemente clorurada sódica y presentan valores de salinidad que varían entre 1,08 y 1,34 g/L. Las muestras de agua superficial, correspondientes al canal de desagüe (CT1 y CT2), son similares con respecto a los contenidos iónicos y presentan una salinidad promedio de $0,66 \mathrm{~g} / \mathrm{L}$.

Para la transecta 3 los valores más elevados de nitrato en el agua subterránea se observan en las muestras de los pozos correspondientes al casco de estancia $(43,80 \mathrm{mg} / \mathrm{L}, \mathrm{T} 6)$ y al tambo $(40,00 \mathrm{mg} / \mathrm{L}, \mathrm{T} 5)$ (Fig. 6.6). En el tambo las bacterias coliformes totales son menores a 3 NMP por cada $100 \mathrm{ml}$ de agua y no se registró la presencia de Escherichia coli. En las muestras de agua subterránea extraídas en las zonas de 
ganadería extensiva los valores de nitrato oscilan entre 5,00 y $10,10 \mathrm{mg} / \mathrm{L}$ (Fig. 6.6). Las muestras de agua superficial tomadas del canal de desagüe de la planta depuradora de efluentes cloacales, presentan valores bajos de nitrato $(2,20 \mathrm{mg} / \mathrm{L}$ y $2,60 \mathrm{mg} / \mathrm{L}$; Fig. 6.6) pero una cantidad elevada de coliformes totales (más de 1100 NMP en $100 \mathrm{ml}$ de agua) y presencia de Escherichia coli.

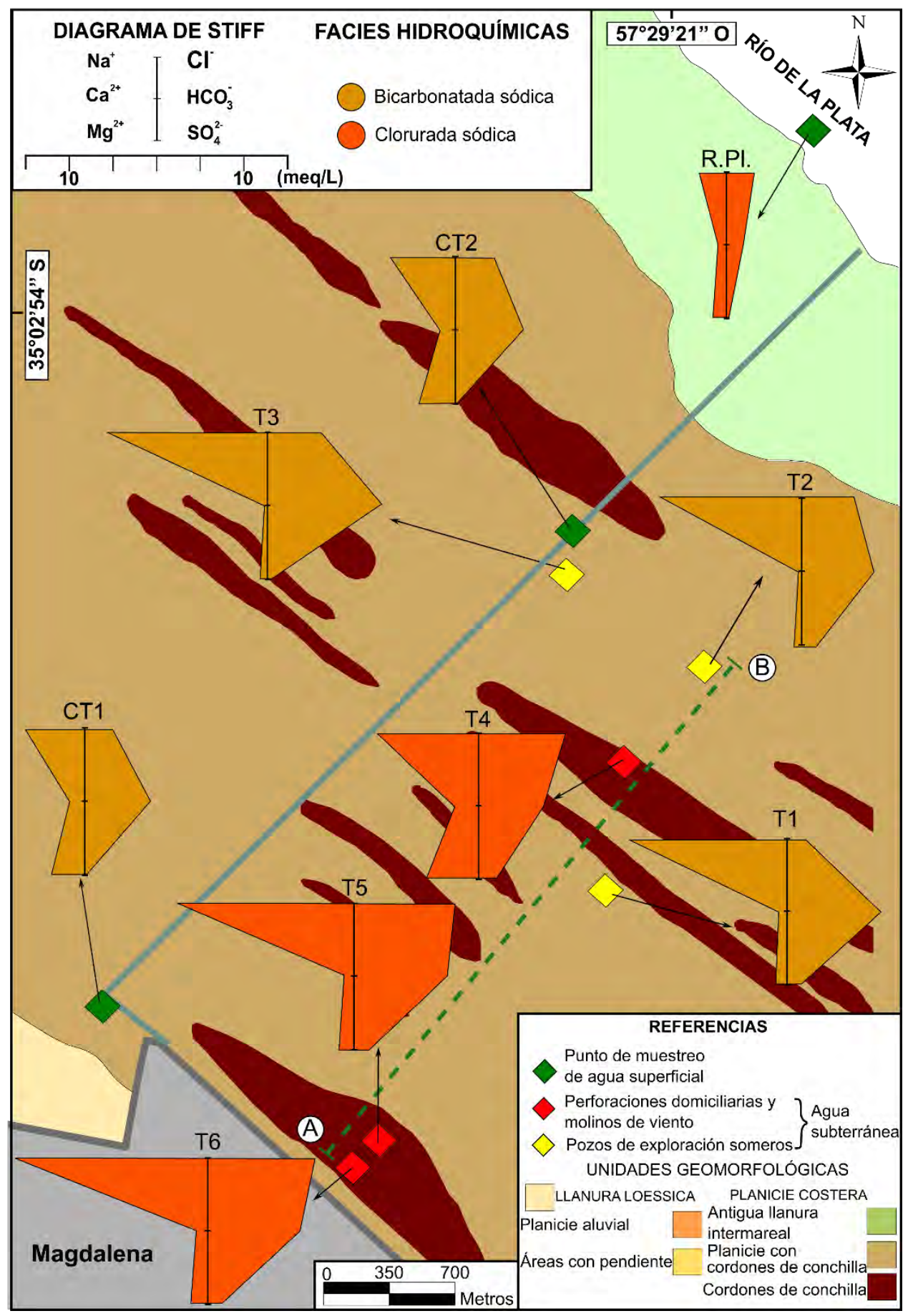

Figura 6.5. Mapa geomorfológico donde se ilustran las facies hidroquímicas para el agua subterránea y superficial en la Estancia Villa Villabona (transecta 3). Los diagramas de Stiff, están coloreados en base a las facies hidroquímicas que representan. La línea A-B indica la traza del perfil esquemático representado en la figura 6.6. 


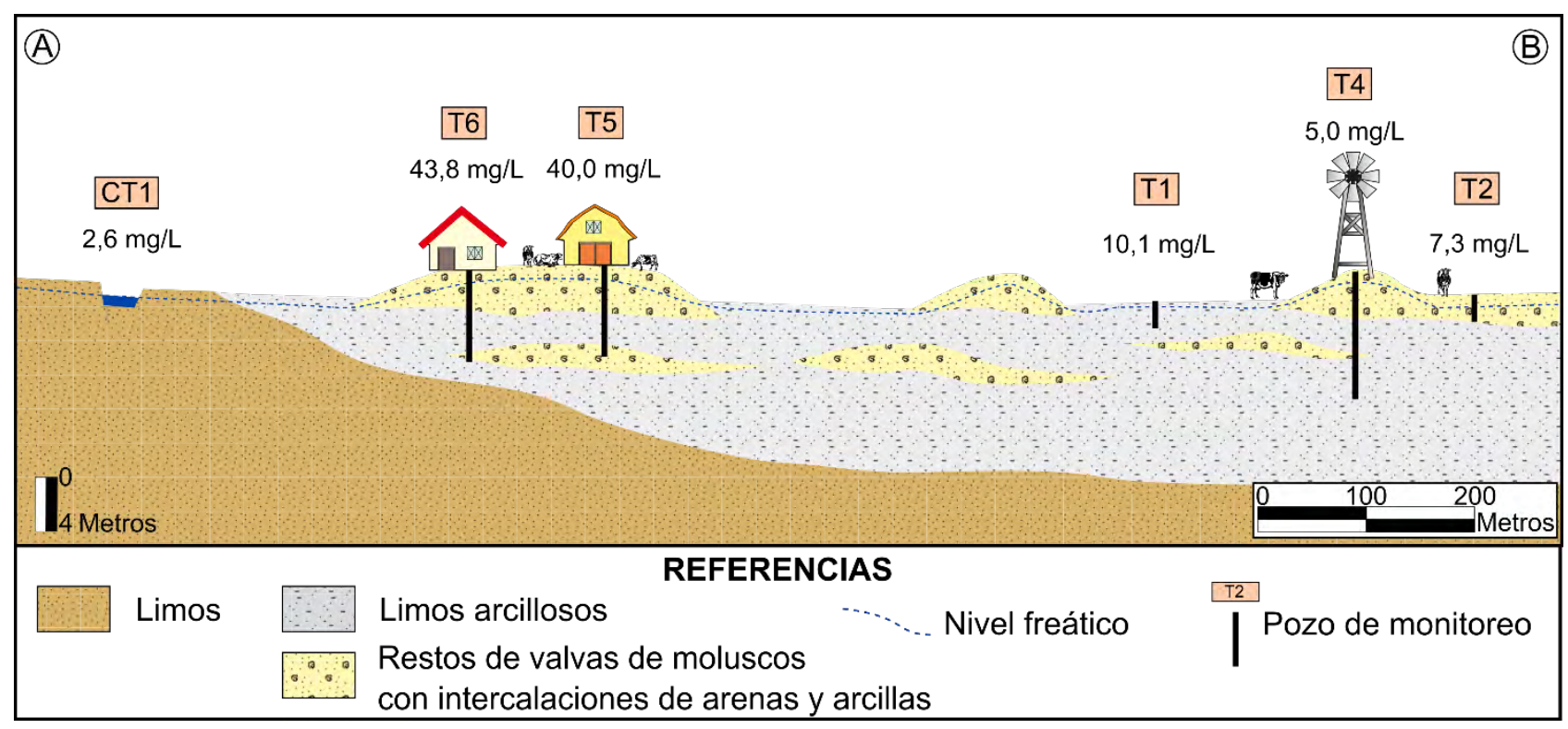

Figura 6.6. Transecta para la Estancia Villa Villabona. Se ilustran, de manera esquemática, las unidades geológicas y geomorfológicas para el área además de la relación entre el agua superficial y subterránea. El valor expresado en $\mathrm{mg} / \mathrm{L}$ hace referencia al contenido de nitrato para cada pozo de monitoreo. La traza del perfil se indica en la figura 6.5.

En la transecta 4, las muestras se distribuyen en el ambiente de planicie con cordones de conchilla y marisma y se identifican tres facies hidroquímicas: bicarbonatada magnésica (RES3 y RES4), clorurada sódica (RES2, RES5, RES6 y AB) y clorurada magnésica (RES1) (Fig. 6.7). Además de una diferencia en las facies hidroquímicas, las muestras ubicadas en el subambiente de planicie con cordones de conchilla presentan una salinidad variable. Las muestras de agua subterránea ubicadas en la zona de intercordón, tomadas de pozos existentes destinados a consumo domiciliario que captan agua a una profundidad aproximada de 12 metros, presentan valores de salinidad entre $0,53 \mathrm{~g} / \mathrm{L}$ (RES4) y 1,48 g/L (RES1). Por su parte, la muestra ubicada en un cordón de conchilla (RES2), extraída de una perforación realizada a aproximadamente 10 metros de profundidad, tiene un contenido salino de $0,78 \mathrm{~g} / \mathrm{L}$. Las muestras localizadas en el subambiente de marisma fueron tomadas de pozos de exploración someros construidos para este estudio. La muestra RES5 ubicada próxima a la margen del arroyo Buñirigo presenta una salinidad de 0,67 g/L mientras que la muestras RES6, más alejada del arroyo, tiene una salinidad $(0,37 \mathrm{~g} / \mathrm{L})$ y contenido iónico muy similar a la muestra correspondiente al Río de la Plata. La muestra de agua superficial, tomada del arroyo Buñirigo, posee un contenido salino de 0,52 g/L equivalente a la muestra RES5. Si bien las muestras RES5 y RES6 se encuentran próximas entre sí, la diferencia de salinidad entre éstas podría estar asociada a la influencia del arroyo Buñirigo en el contenido iónico del agua subterránea.

Para la transecta 4, las concentraciones de nitrato registradas en los dos subambientes son bajas y varían entre 0,2 y $1,8 \mathrm{mg} / \mathrm{L}$ en la planicie con cordones y entre 2,3 y $2,8 \mathrm{mg} / \mathrm{L}$ en la marisma (Fig. 6.8). Pese a 
esto, en el pozo de abastecimiento de estancia (RES4) se registra la presencia de bacterias coliformes totales (930 NMP en $100 \mathrm{ml}$ de agua) y fecales.

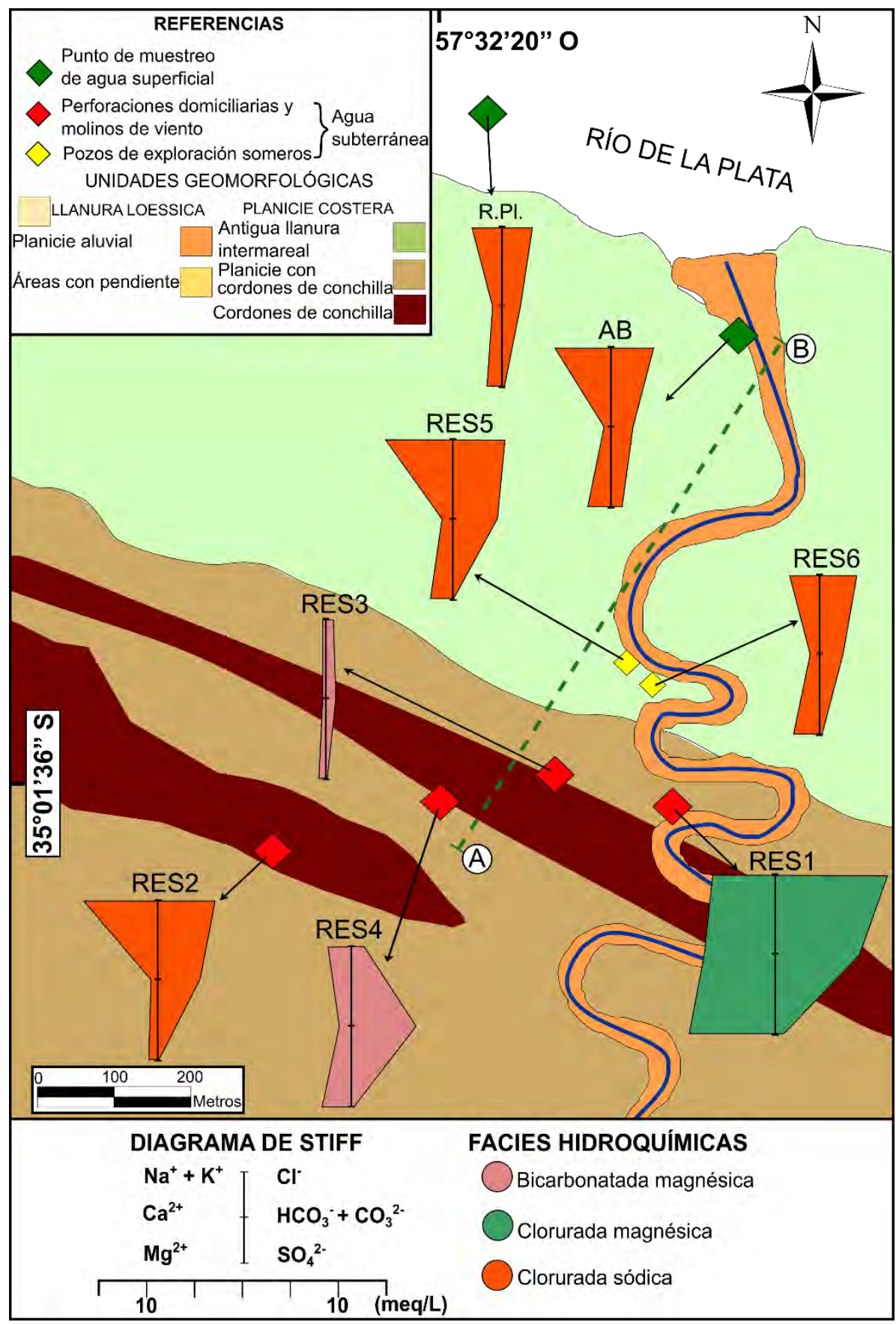

Figura 6.7. Mapa geomorfológico donde se ilustran las facies hidroquímicas para el agua subterránea y superficial en la Reserva Natural y Cultural El Saladero (transecta 4). Los diagramas de Stiff, están coloreados en base a las facies hidroquímicas que representan. La línea A-B indica la traza del perfil esquemático representado en la figura 6.8. 


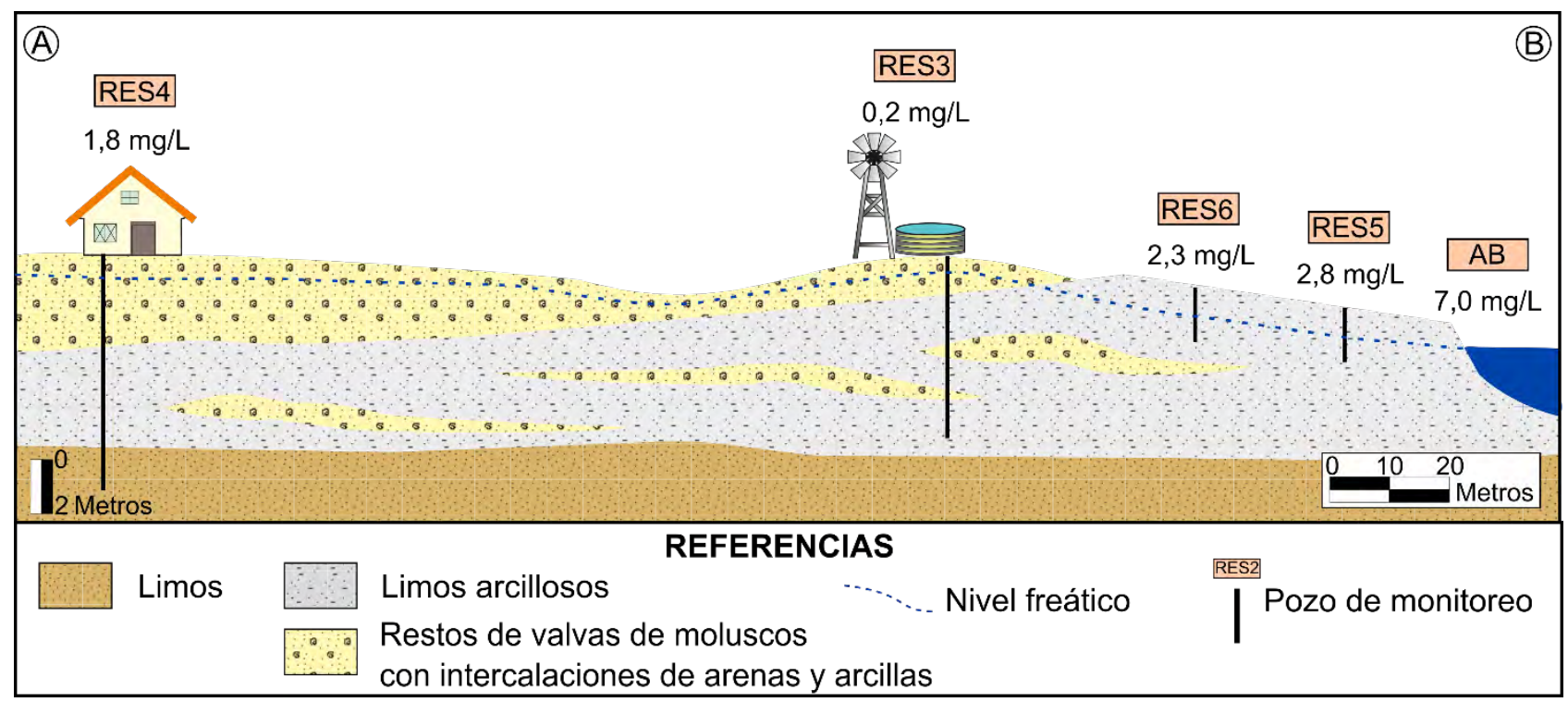

Figura 6.8. Transecta para la Reserva Natural y Cultural El Saladero. Se ilustran, de manera esquemática, las unidades geológicas y geomorfológicas para el área además de la relación entre el agua superficial y subterránea. El valor expresado en mg/L hace referencia al contenido de nitrato para cada pozo de monitoreo. La traza del perfil se indica en la figura 6.7.

\subsubsection{Identificación de procesos geoquímicos a partir de relaciones isotópicas e iónicas}

En relación al contenido en isótopos ambientales se observan diferencias entre las muestras de agua subterránea y superficial. El agua subterránea presenta valores de $\delta^{18} \mathrm{O}$ entre $-7,90$ y $-4,50 \%$ y de $\delta^{2} \mathrm{H}$ entre $-46,70$ y $-22,90 \%$ y la totalidad de las muestras se ubican en torno a la recta meteórica local $\left(\delta^{2} \mathrm{H}=8 \delta^{18} \mathrm{O}+\right.$ 14\%;; Fig. 6.9a) definida por Dapeña y Panarello (2004). Esto muestra que pese a las diferencias litológicas de las distintas unidades geomorfológicas el agua de lluvia infiltra sin previa evaporación recargando al agua subterránea somera. Este comportamiento también se aprecia en el gráfico de exceso de deuterio en función de $\delta^{18} \mathrm{O}$ (Fig. 6.9b) donde las muestras de agua subterránea de todos los ambientes presentan valores de exceso de deuterio entre 6,60 y 14,90\% similares a los de la lluvia local (Dapeña y Panarello, 2004). Por su parte, las muestras de agua superficial se ubican en torno a la recta de evaporación estimada según Gonfiantini (1986). Dentro de las muestras analizadas se observa que la del arroyo Juan Blanco (AJB) presenta un porcentaje de evaporación menor al 5\%, la del arroyo Buñirigo (AB) del 5\% y las muestras CUP1 y CUP2 (canal artificial y cañada, respectivamente) cercano al 8\% (Fig. 6.9a). Estos bajos porcentajes de evaporación también se reflejan en los valores de exceso de deuterio entre 5 y 10\% que presentan dichas muestras (Fig. $6.9 b)$.

En el gráfico de $\delta^{18} \mathrm{O}$ en función de la conductividad eléctrica del agua se aprecia que las muestras de agua superficial presentan un leve aumento en la salinidad producto, principalmente, de la evaporación (Fig. 6.10). Por su parte, el agua subterránea muestra una tendencia al aumento de salinidad sin enriquecimiento isotópico característica que indica la disolución de sales del sedimento (Clark, 2015). Dentro de la planicie 
costera, los iones mayoritarios registrados en el agua subterránea pueden derivar de la hidrólisis incongruente de silicatos o de la disolución de carbonatos, yeso o halita (Carol et al., 2009), estos tres últimos minerales como fuente principal de los aniones $\mathrm{HCO}_{3}{ }^{-}, \mathrm{SO}_{4}{ }^{2-} \mathrm{y} \mathrm{Cl}^{\text {, }}$, respectivamente. La relación existente entre uno de los isótopos estables, por ejemplo $\delta^{18} \mathrm{O}$, y estos aniones conjuntamente con el cálculo de los índices de saturación permite identificar qué procesos hidroquímicos ocurren en cada subambiente de la planicie costera.

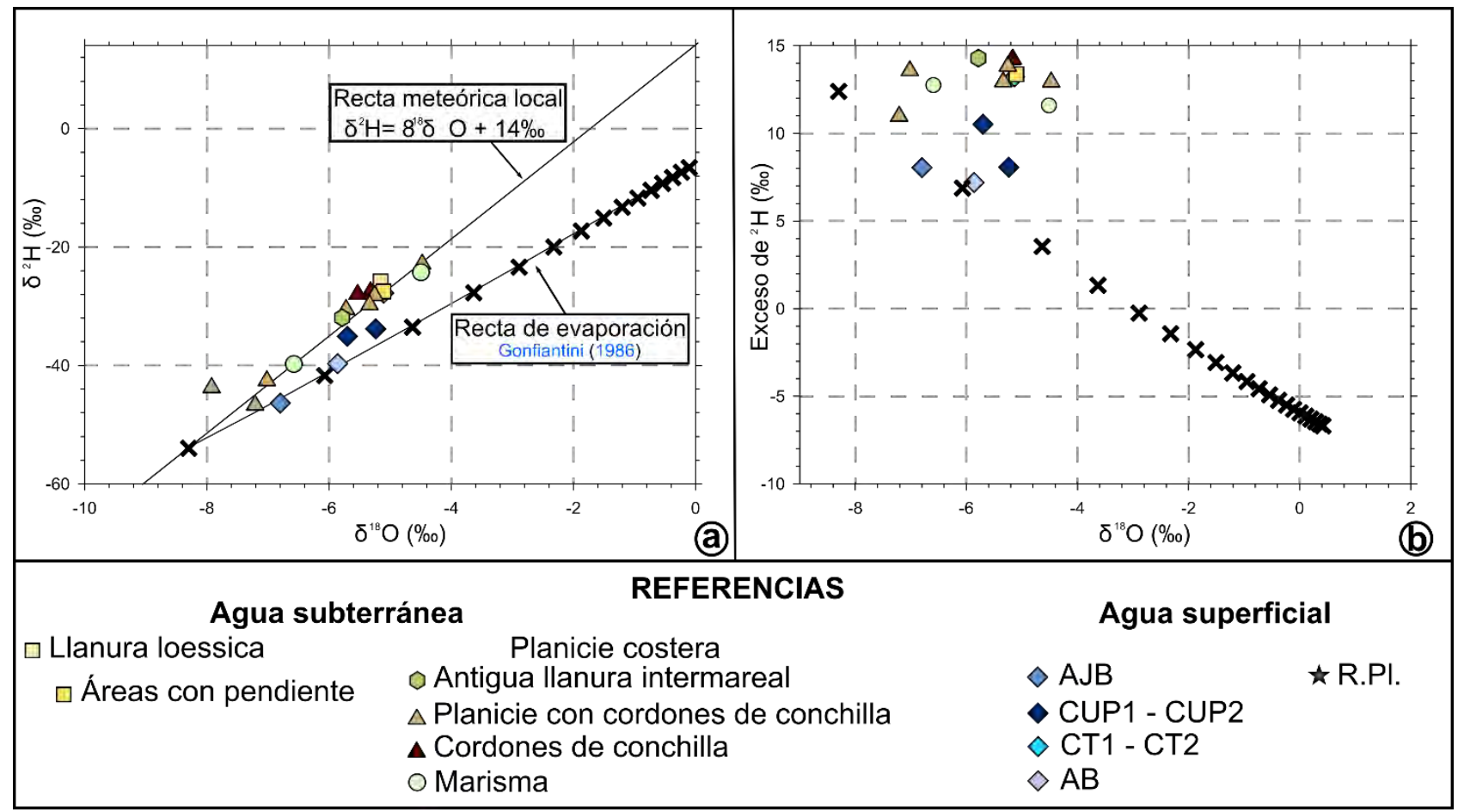

Figura 6.9. Relación de isótopos ambientales para las muestras de agua subterránea y superficial. (a) Relación de $\delta^{18} \mathrm{O}$ en función de $\delta^{2} \mathrm{H}$. (b) Relación entre $\delta^{18} \mathrm{O}$ en función del exceso de ${ }^{2} \mathrm{H}$.

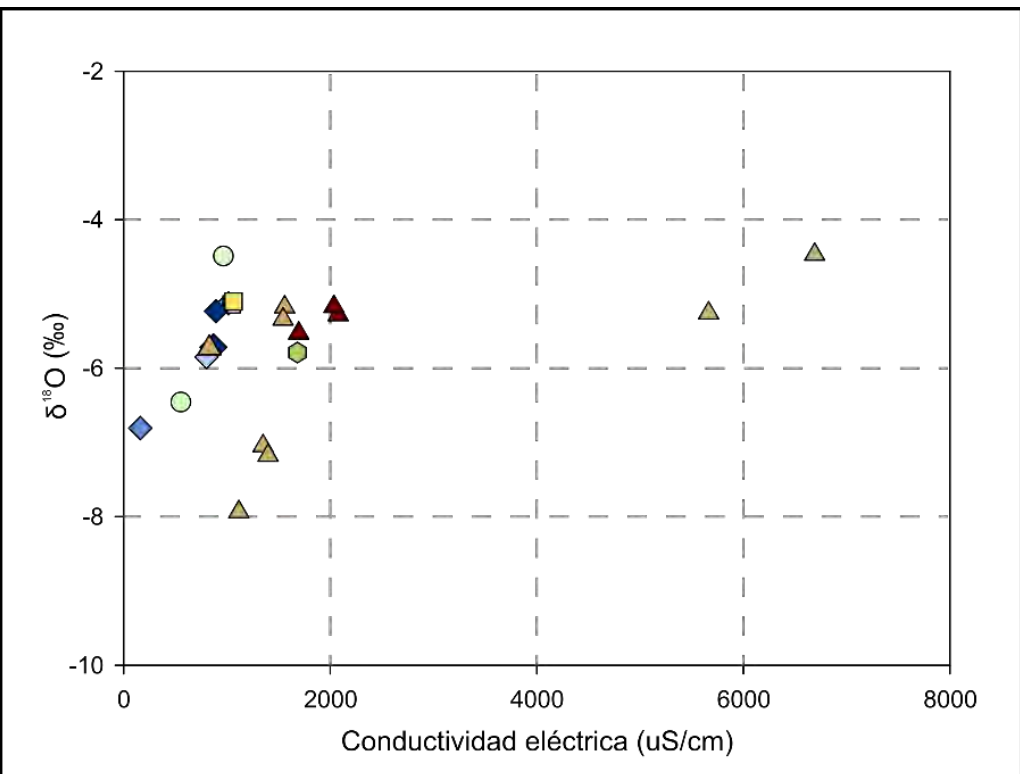

\section{REFERENCIAS}

Agua subterránea

$\square$ Llanura loessica $\square$ Áreas con pendiente

Planicie costera

- Antigua llanura intermareal $\triangle$ Planicie con cordones de conchilla $\Delta$ Cordones de conchilla o Marisma

\section{Agua superficial}

$$
\begin{aligned}
& \diamond \mathrm{AJB} \\
& \diamond \mathrm{CUP} 1-\mathrm{CUP} 2 \\
& \diamond \mathrm{CT} 1-\mathrm{CT} 2 \\
& \diamond \mathrm{AB}
\end{aligned}
$$

Figura 6.10. Relación de $\delta^{18} \mathrm{O}$ en función de la conductividad eléctrica para las muestras de agua subterránea y superficial. 
En la relación $\delta^{18} \mathrm{O}$ en función de la concentración de $\mathrm{HCO}_{3}{ }^{-}$se observa que las muestras de agua subterránea y, en menor medida, las de agua superficial muestran un aumento en la concentración de $\mathrm{HCO}_{3}{ }^{-}$ sin enriquecimiento isotópico (Fig. 6.11). Esto indica que el agua de lluvia al infiltrar disuelve el carbonato presente en el sedimento en los subambientes de planicie con cordones de conchilla y antigua llanura intermareal.

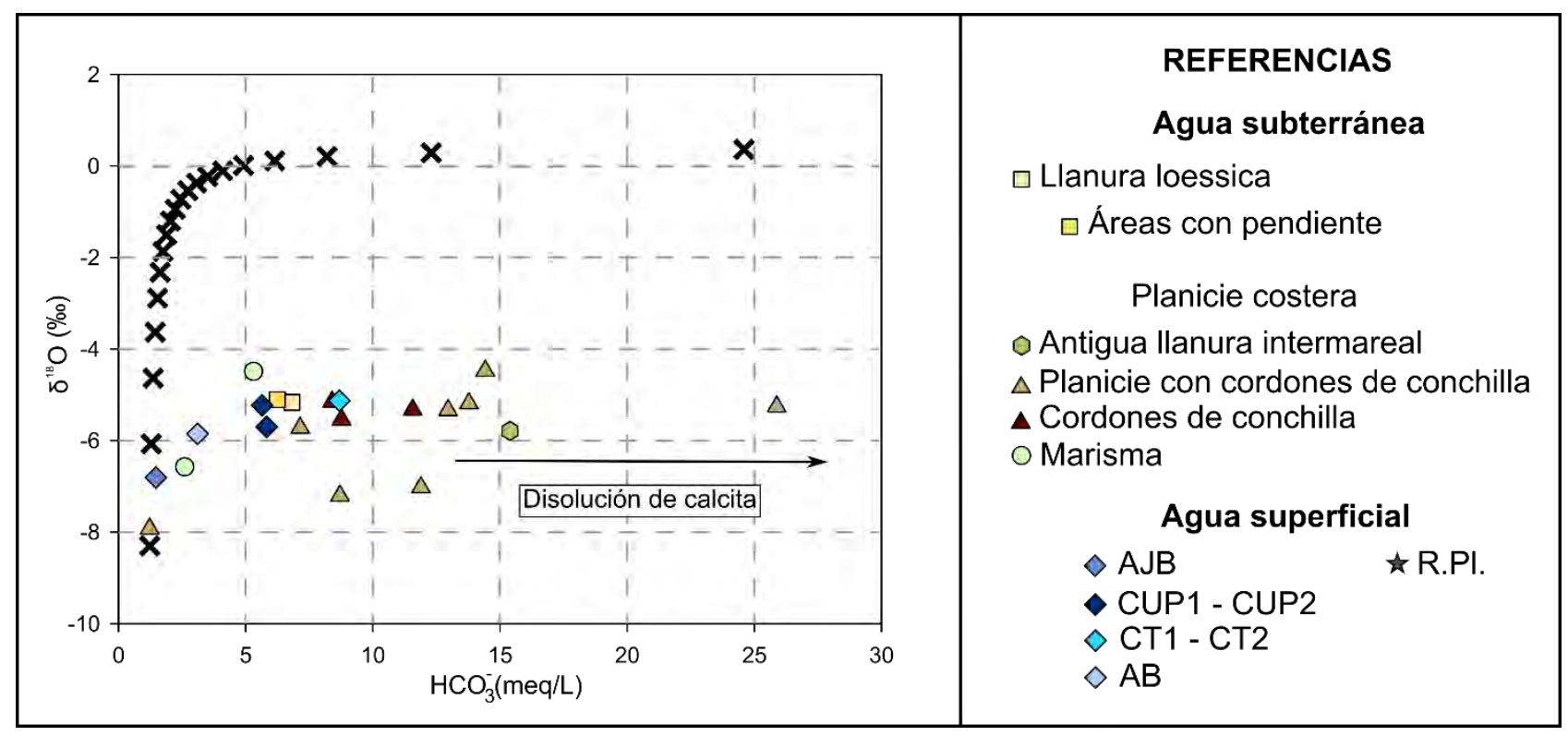

Figura 6.11. Relación de $\delta^{18} \mathrm{O}$ en función de la concentración de bicarbonato para las muestras de agua subterránea y superficial. Las cruces indican porcentajes de evaporación estimados cada $5 \%$.

El proceso de disolución de minerales carbonáticos ocurre principalmente en la zona no saturada o en los sectores más superficiales de la zona saturada. Dicho proceso está regulado por el $\mathrm{CO}_{2(\mathrm{~g})}$ y el pH del agua tal como lo demuestran las ecuaciones (1) y (2):

$$
\begin{aligned}
& \mathrm{CaCO}_{3}+\mathrm{H}_{2} \mathrm{O}+\mathrm{CO}_{2} \leftrightarrow \mathrm{Ca}^{2+}+2 \mathrm{HCO}_{3}^{-} \\
& \mathrm{CaCO}_{3}+\mathrm{H}^{+} \leftrightarrow \mathrm{Ca}^{2+}+\mathrm{HCO}_{3}^{-}
\end{aligned}
$$

Estas ecuaciones muestran que la disolución de $\mathrm{CaCO}_{3}$ aumenta cuando se incrementa la presión parcial de dióxido de carbono (ecuación 1) y disminuye el pH (ecuación 2). El agua de lluvia y superficial presentan concentraciones de $\mathrm{CO}_{2}$ en equilibrio con la atmósfera. El agua que infiltra incorpora el $\mathrm{CO}_{2}$ (g) producido en la zona no saturada, debido a la descomposición aeróbica de materia orgánica y la respiración

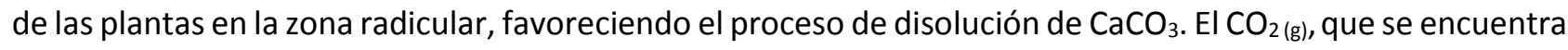
en elevadas concentraciones en los poros del suelo, constituye la principal fuente de acidez del agua. Esta acidez hace que el agua sea muy agresiva con los carbonatos y silicatos en la zona no saturada la cual constituye un sistema abierto con respecto al $\mathrm{CO}_{2(\mathrm{~g})}$. Cuando el agua de infiltración ingresa a la zona saturada, 
la cual es un sistema cerrado con respecto al $\mathrm{CO}_{2}(\mathrm{~g})$, no hay aportes de acidez, el pH tiende a aumentar y el agua pierde su capacidad de disolver carbonatos y alterar silicatos (Appelo y Postma, 2005).

Los índices de saturación (IS) con respecto a calcita evidencian que la mayor parte de las muestras de agua subterránea presentan valores sobresaturados (Fig. 6.12). Esto indica que el agua subterránea disolvió los carbonatos del sedimento hasta saturarse y en esas condiciones el carbonato de calcio ya no se disuelve y podría reprecipitarse (p. ej. si el pH es favorable). Esta reprecipitación del carbonato de calcio puede ocurrir especialmente en los periodos de déficit hídrico donde este mineral tiende a formar pequeñas concreciones carbonáticas (Imbellone y Giménez, 1997; Carol y Kruse, 2016). Sólo algunas muestras de agua subterránea del subambiente de planicie con cordones de conchilla y las de la marisma, y las muestras de agua superficial tienen valores de índice de saturación con respecto a calcita subsaturados (Fig. 6.12) lo que indica que las fases carbonatadas presentes en los sedimentos podrían disolverse y aportar iones $\mathrm{HCO}_{3}{ }^{-}$y $\mathrm{Ca}^{2+}$ en solución al agua subterránea y superficial.

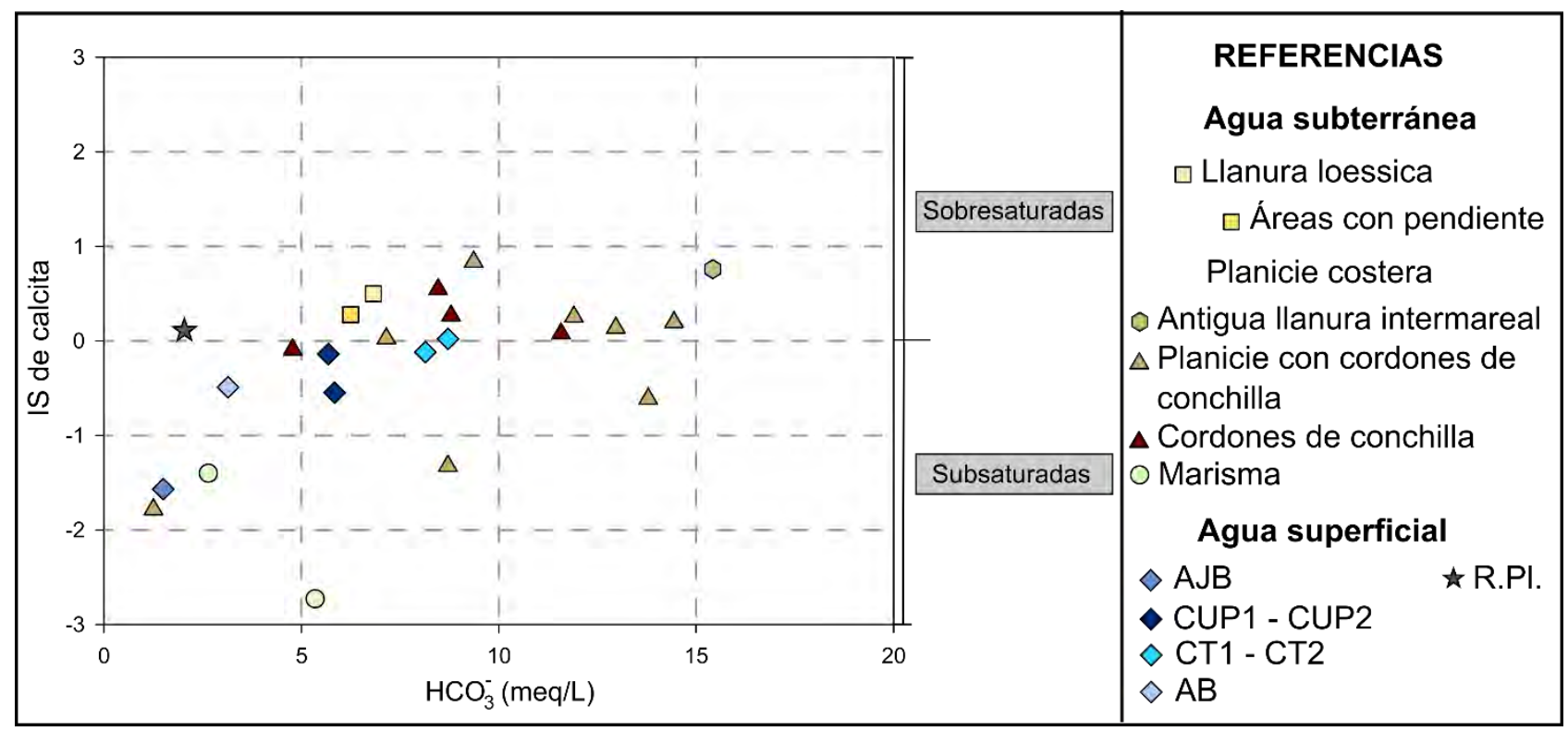

Figura 6.12. Índice de saturación (IS) de la calcita para las muestras de agua subterránea y superficial con respecto al aumento de la concentración del anión bicarbonato.

El proceso de disolución de carbonato de calcio, asociado a la disolución de $\mathrm{CO}_{2(\mathrm{~g})}$, genera el doble de iones $\mathrm{HCO}_{3}{ }^{-}$respecto a los de $\mathrm{Ca}^{2+}$ (ecuación 1 ) mientras que en la disolución de este mineral asociada a bajos pH la relación es 1:1 (ecuación 2). Esta tendencia sólo se observa en algunas muestras (Fig. 6.13) lo que evidencia que otro proceso podría estar controlando la concentración de iones $\mathrm{Ca}^{2+}$ y $\mathrm{HCO}_{3}{ }^{-}$en el agua subterránea. Este tema será tratado más adelante en este capítulo. 


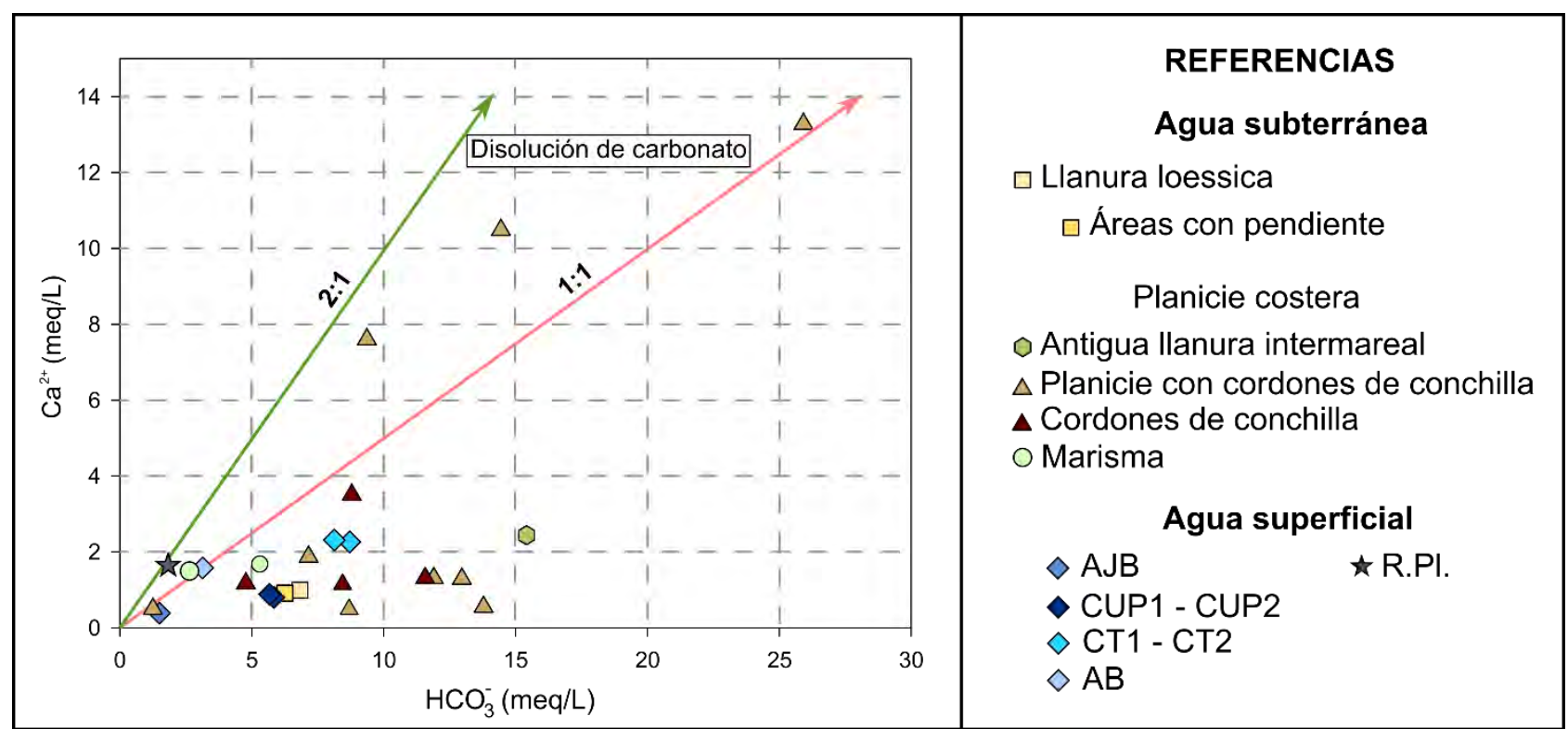

Figura 6.13. Relación entre la concentración de calcio en función de la concentración de bicarbonato para las muestras de agua subterránea y superficial.

En la relación $\delta^{18} \mathrm{O}$ en función de la concentración de $\mathrm{SO}_{4}{ }^{2-}$ se aprecia que algunas muestras de agua subterránea, procedentes del subambiente de planicie con cordones de conchilla, tienen una tendencia al aumento en la concentración de $\mathrm{SO}_{4}{ }_{4}^{2-}$ sin enriquecimiento isotópico lo cual evidencia procesos de disolución de yeso (Fig. 6.14). Estas muestras, además, registran un aumento en la concentración de $\mathrm{SO}_{4}{ }^{2-}$ asociado a una relación $\mathrm{Ca}^{2+} / \mathrm{SO}_{4}{ }^{2-}$ cercana a 1 (Figs. 6.15a y b). Es necesario destacar que todas las muestras presentan índices de saturación con respecto al yeso negativos, lo que indica que todas están subsaturadas; los valores más próximos a la saturación en yeso se registran en las muestras que evidencian procesos de disolución de este mineral (Figs. 6.14, 6.15 y 6.16).

En la relación $\delta^{18} \mathrm{O}$ en función de la concentración de $\mathrm{Cl}^{-}$se observa que algunas muestras de agua subterránea, ubicadas en el subambiente de planicie con cordones de conchilla, exhiben una tendencia al aumento en la concentración de dicho anión sin enriquecimiento isotópico lo cual manifiesta procesos de disolución de halita (Fig. 6.17). En las muestras destacadas, además, la relación $\mathrm{Na}^{+} / \mathrm{Cl}^{-}$es cercana a 1 (Figs. 6.18a y b). En relación a los índices de saturación con respecto a halita se observa que todas las muestras tienen valores subsaturados (Fig. 6.19). Las muestras que evidencian procesos de disolución de halita registran los valores del índice de saturación menos negativos. Además de lo que indican los índices de saturación la alta solubilidad de este mineral favorece su disolución. 


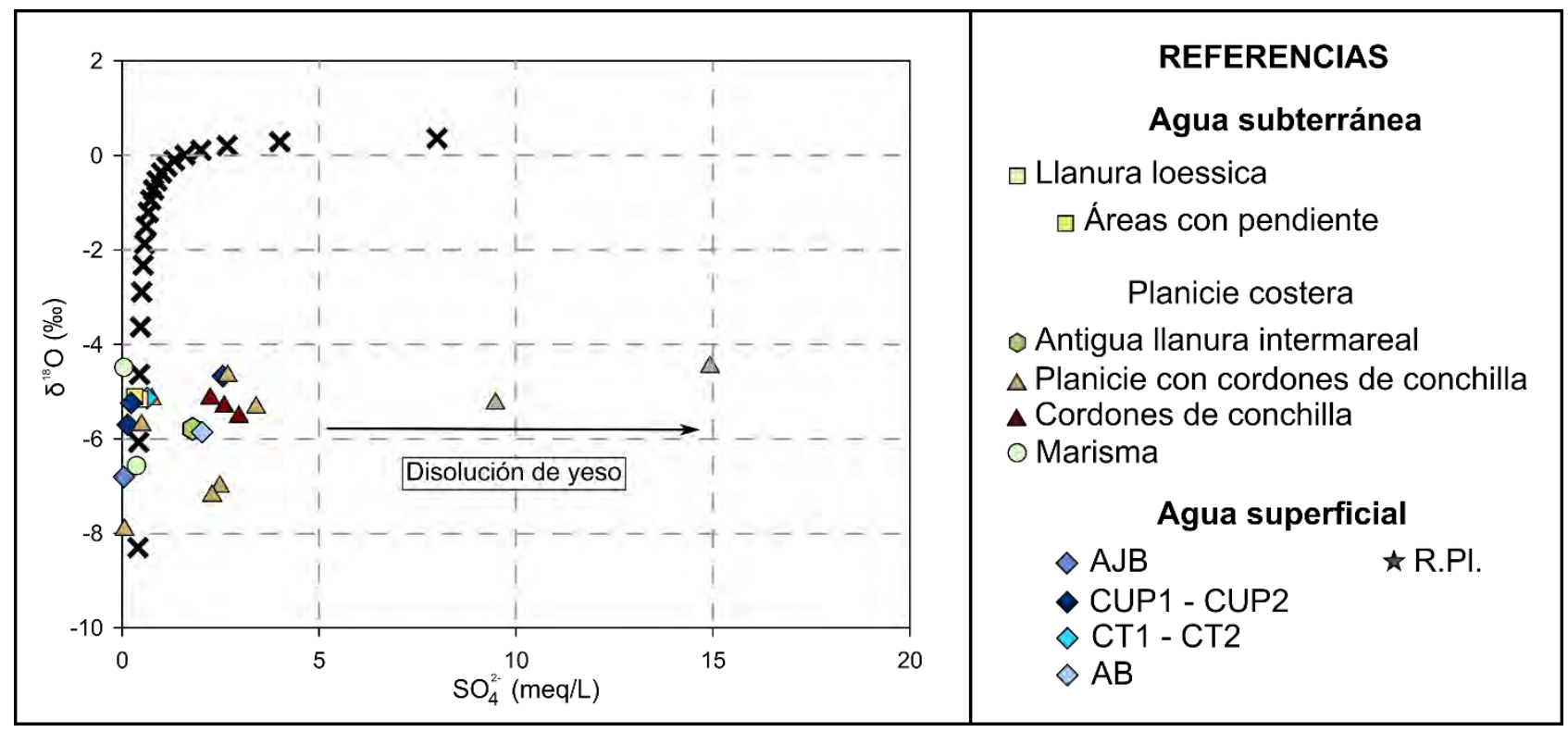

Figura 6.14. Relación entre el contenido de $\delta^{18} \mathrm{O}$ en función de la concentración de sulfato para las muestras de agua subterránea y superficial. Las cruces indican porcentajes de evaporación estimados cada 5\%.

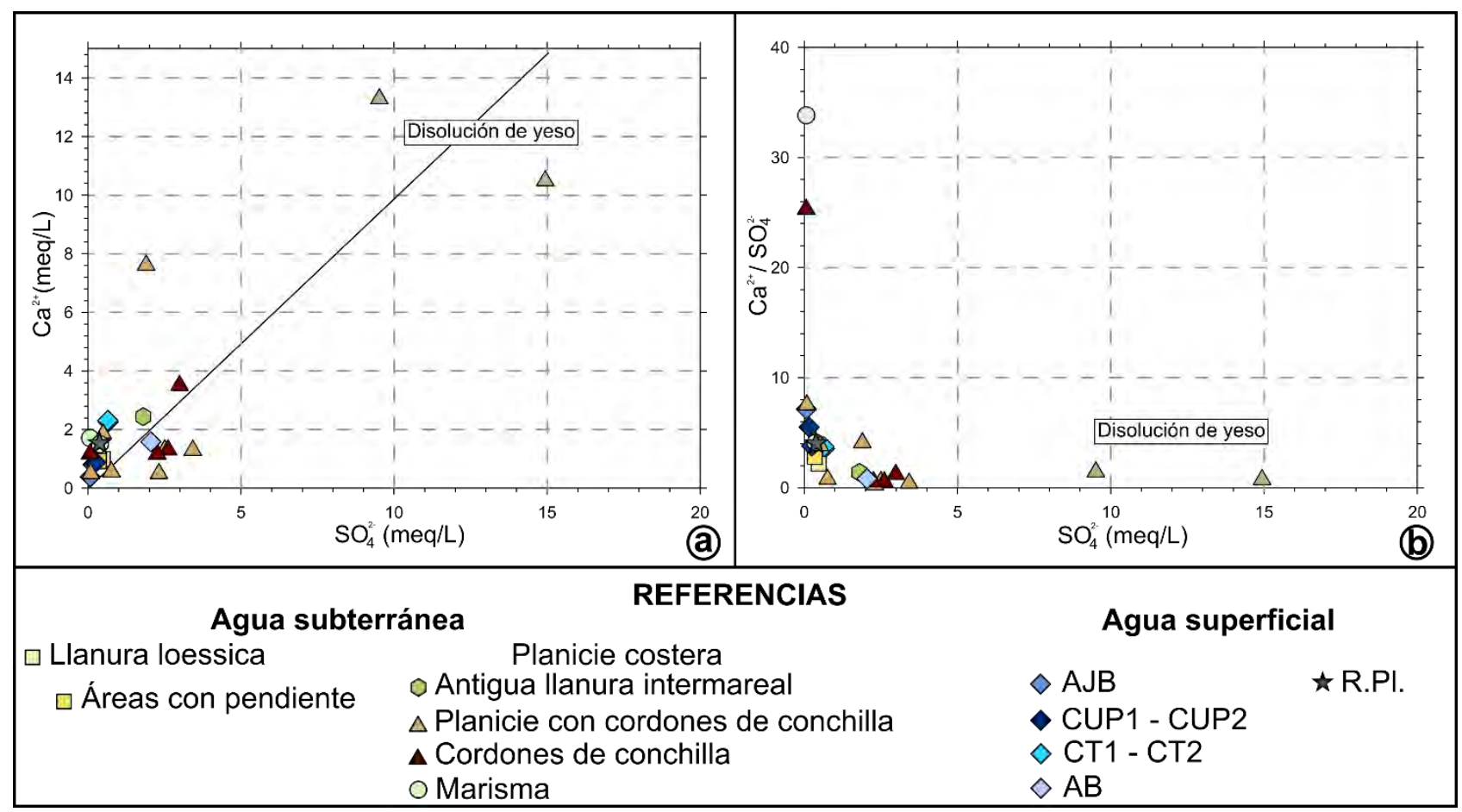

Figura 6.15. (a) Relación entre la concentración de calcio en función de la concentración de sulfato para las muestras de agua subterránea y superficial. (b) Relación entre la concentración calcio/sulfato respecto a la concentración de sulfato para las muestras de agua subterránea y superficial. 


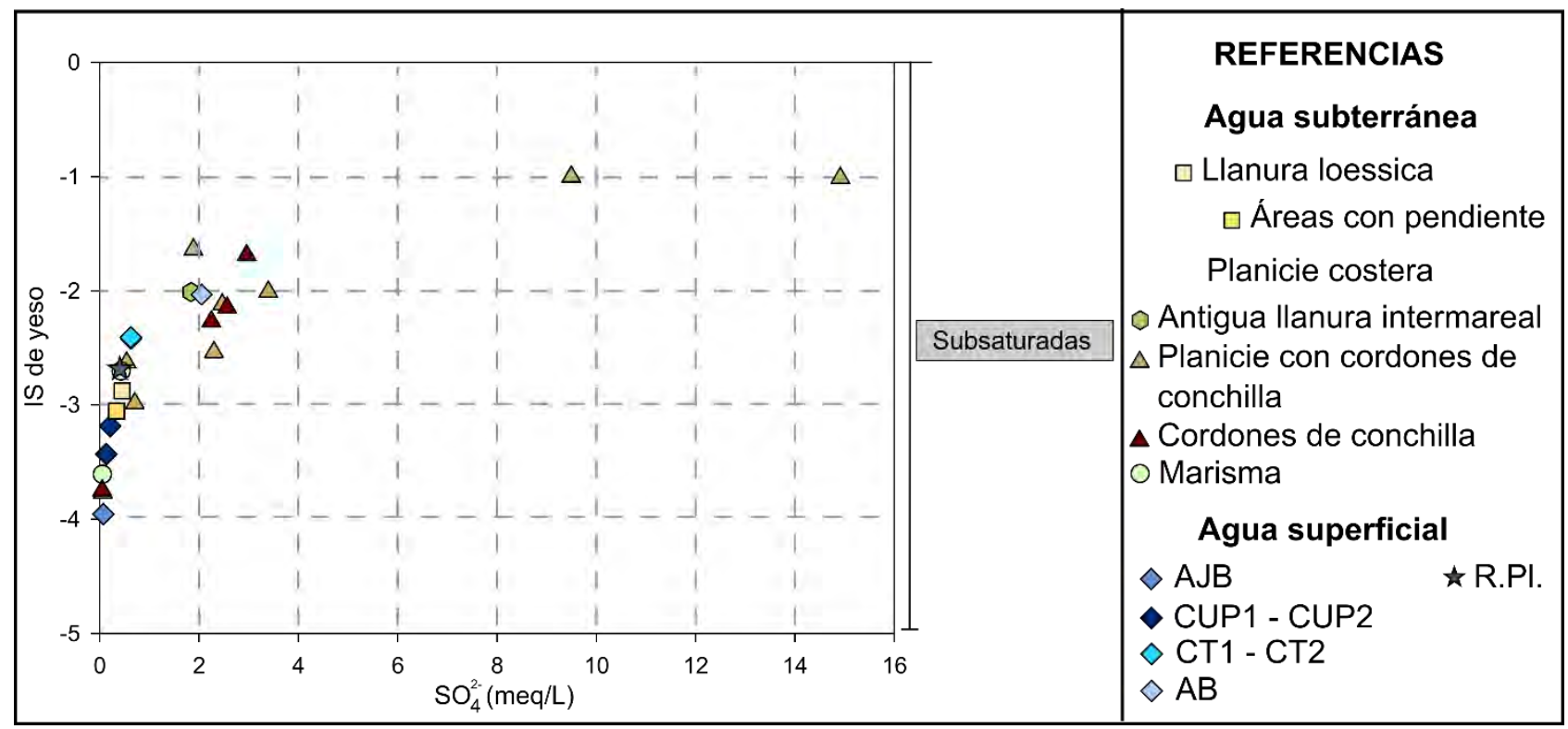

Figura 6.16. Índice de saturación (IS) del yeso para las muestras de agua subterránea y superficial con respecto al aumento de la concentración del anión sulfato.

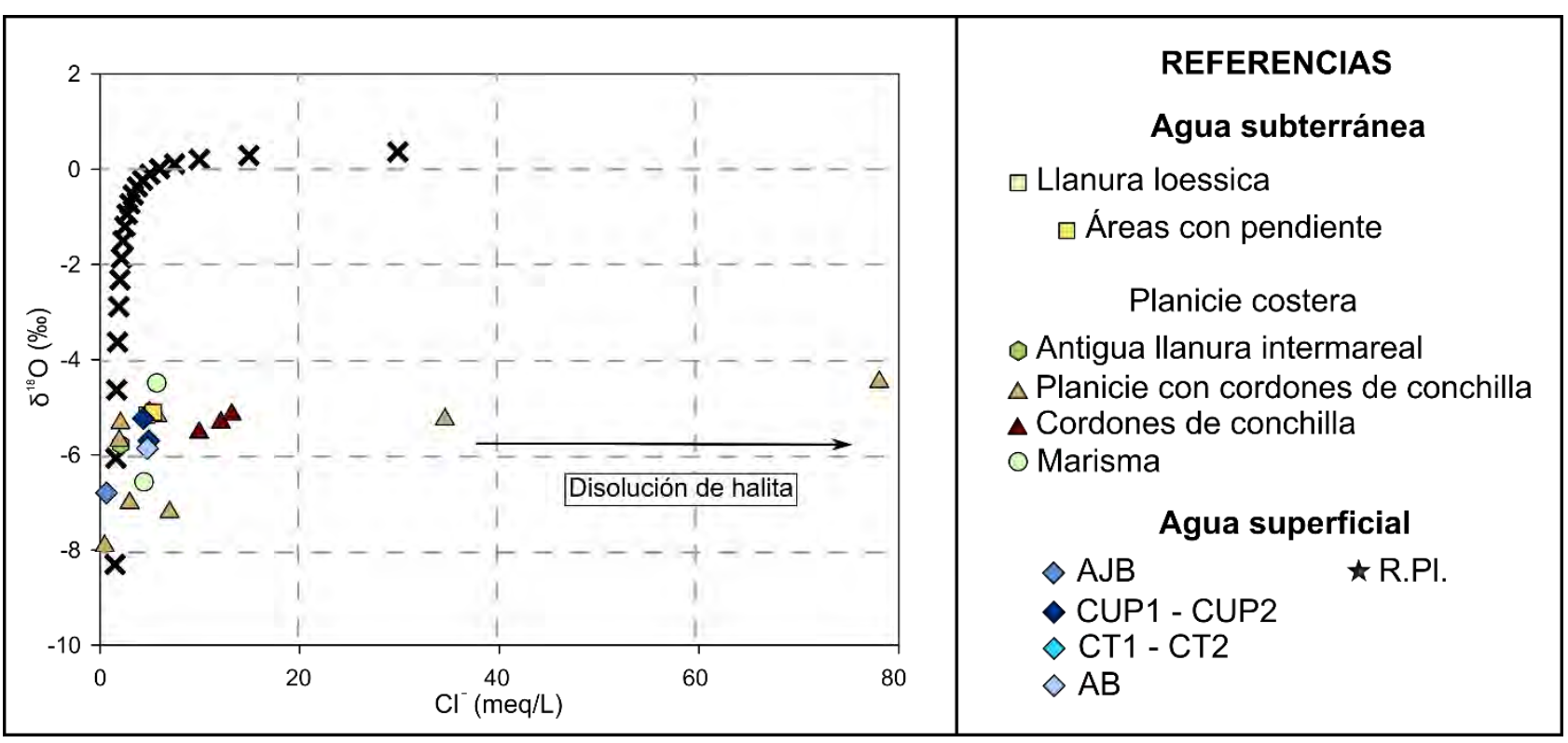

Figura 6.17. Relación entre el contenido de $\delta^{18} \mathrm{O}$ en función de la concentración de cloruro para las muestras de agua subterránea y superficial. Las cruces indican porcentajes de evaporación estimados cada 5\%. 


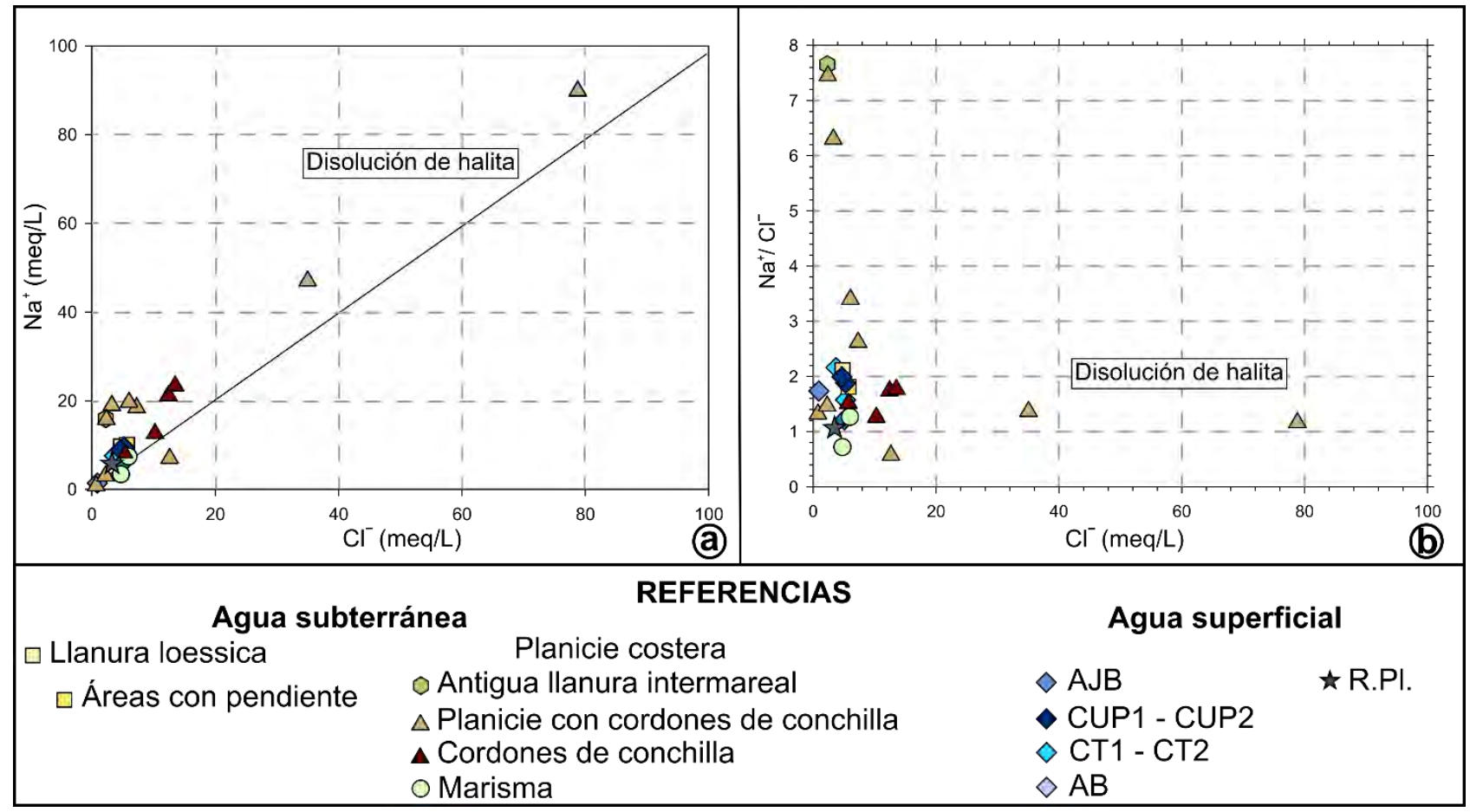

Figura 6.18. (a) Relación entre la concentración de sodio en función de la concentración de cloruro para las muestras de agua subterránea y superficial. (b) Relación entre la concentración sodio/cloruro respecto a la concentración de cloruro para las muestras de agua subterránea y superficial.

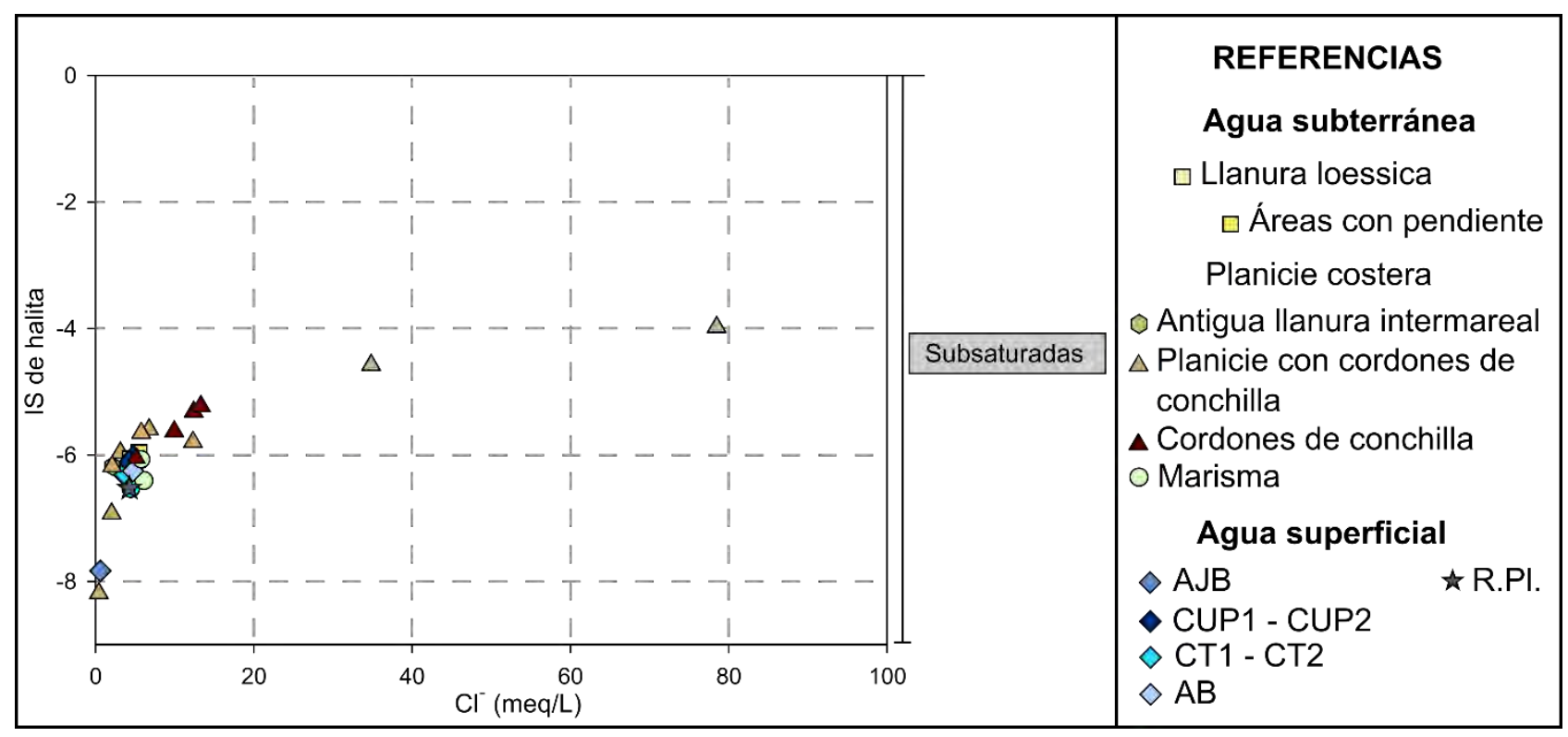

Figura 6.19. Índice de saturación (IS) de la halita para las muestras de agua subterránea y superficial con respecto al aumento de la concentración del anión cloruro.

La relación $\mathrm{Cl}^{-} / \mathrm{Br}^{-}$en función de $\mathrm{Cl}^{-}$(Alcalá y Custodio, 2008) evidencia, al igual que las relaciones isotópicas, que el agua subterránea somera recarga a partir de la infiltración de las precipitaciones y que en las muestras de la planicie con cordones de conchilla existen procesos de disolución de sales del sedimento del tipo halita (Fig. 6.20). 
La disolución de yeso y halita es un proceso que puede ocurrir, probablemente, durante la infiltración del agua de lluvia asociado a eventos de precipitaciones que se producen luego de periodos secos. Estos minerales se encuentran comúnmente en la superficie de los suelos salinos de la planicie costera formando costras (Carol et al., 2009). La lluvia disuelve las sales de yeso y halita rápidamente debido a su alta solubilidad incrementando la salinidad del agua con sus iones en solución.

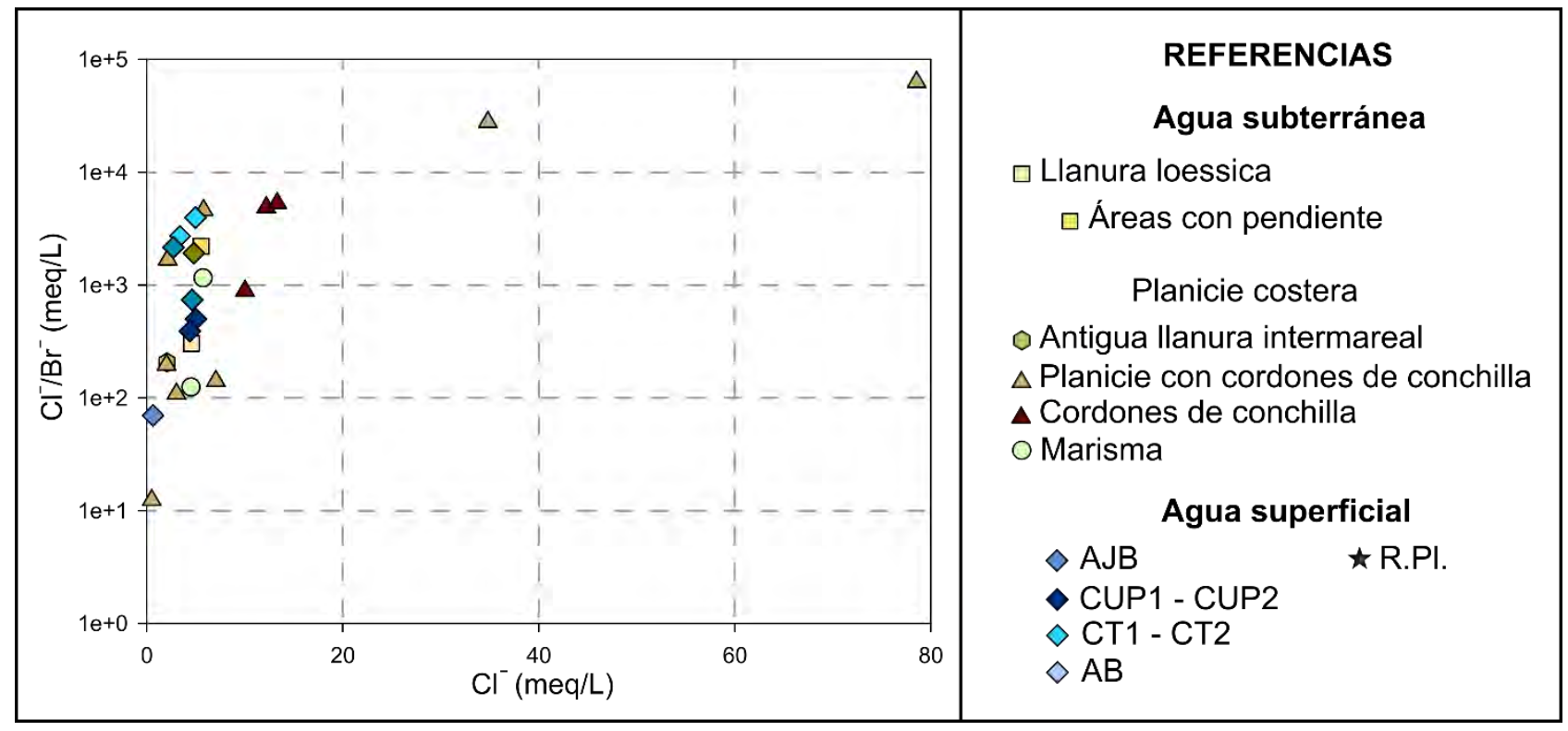

Figura 6.20. Relación entre la relación $\mathrm{Cl}^{-} / \mathrm{Br}^{-}$en función de la concentración de cloruro para las muestras de agua subterránea y superficial.

El proceso de disolución de carbonato, yeso y halita anteriormente explicado se observa claramente en los aniones disueltos en el agua pero no así en los cationes. Esto se debe, tal como se mencionó precedentemente, a que deben existir otros procesos que condicionan la concentración de los cationes en el agua subterránea.

Los valores de $\mathrm{Na}^{+}$- $\mathrm{Cl}^{-}$varían entre 0,14 y 15,75 meq/L (a excepción de valores negativos para dos muestras, una correspondiente al subambiente de planicie con cordones y otra a la marisma) indicando un exceso de $\mathrm{Na}^{+}$. Por otro lado, la diferencia entre $\left(\mathrm{Ca}^{2+}+\mathrm{Mg}^{2+}\right)-\left(\mathrm{HCO}_{3}{ }^{-}+\mathrm{SO}_{4}{ }^{2-}\right)$ varía con valores entre $-13,02$ y -0,37 meq/L (con excepción de valores positivos para tres muestras del subambiente de planicie con cordones de conchilla y una de la marisma) evidenciando una deficiencia en estos cationes. Los excesos de $\mathrm{Na}^{+}$y deficiencias de $\mathrm{Ca}^{2+}$ y $\mathrm{Mg}^{2+}$ presentan una relación lineal cercana a 1 (Fig. 6.21). Otra evidencia del exceso de $\mathrm{Na}^{+}$son los valores negativos, entre $-6,84$ y -0,17, en la relación $\mathrm{Cl}^{-}-\left(\mathrm{Na}^{+}+\mathrm{K}^{+}\right) / \mathrm{Cl}^{-}$(a excepción de una única muestra del subambiente de marisma que presenta un valor positivo) (Fig. 6.22).

Una posible explicación del exceso de $\mathrm{Na}^{+}$en las muestras de agua podría ser el intercambio iónico. Los minerales del grupo de las arcillas presentan adsorbidos en su superficie cationes que pueden ser 
intercambiados por otros presentes en la solución. Así, por ejemplo, el sodio adsorbido por la fracción arcillosa del sedimento puede ser intercambiado por el calcio presente en la solución según la ecuación (3) (Appelo y Postma, 2005):

$$
\mathrm{X}-\mathrm{Na}^{+}+\mathrm{Ca}^{2+} \leftrightarrow \mathrm{X}-\mathrm{Ca}^{2+}+2 \mathrm{Na}^{+}
$$

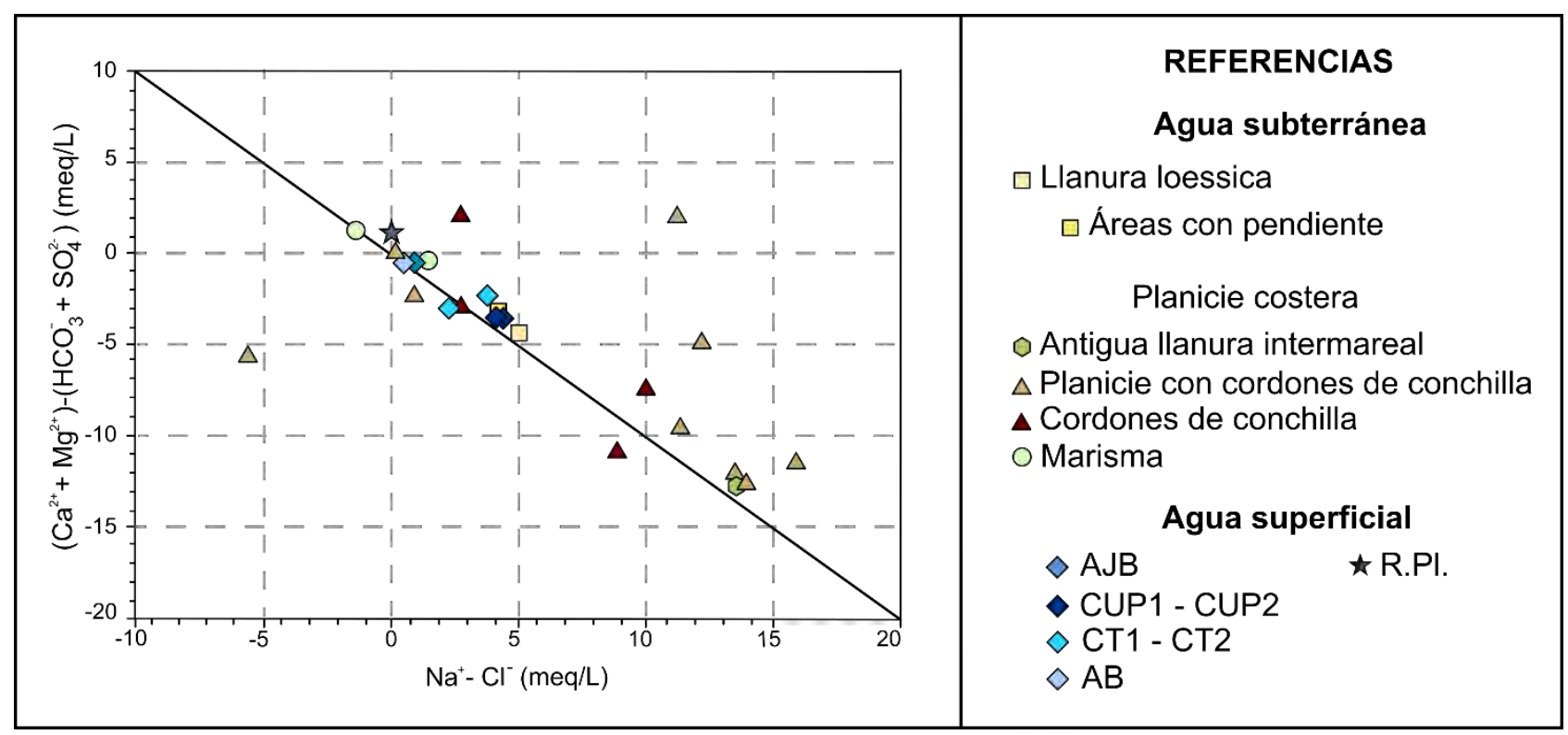

Figura 6.21. Relación entre la deficiencia de $\mathrm{Ca}^{2+}+\mathrm{Mg}^{2+}$ y exceso de $\mathrm{Na}^{+}$para las muestras de agua subterránea y superficial.

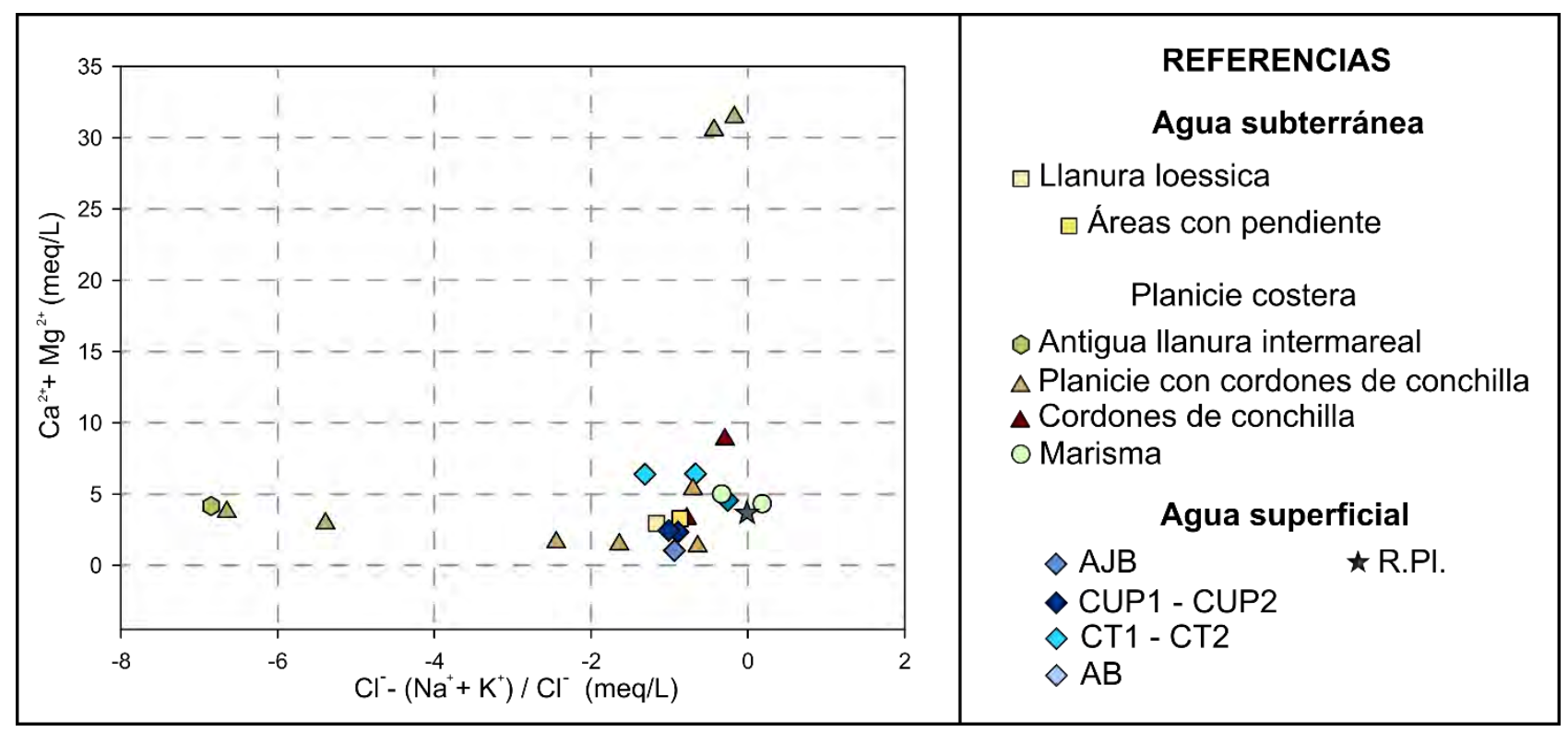

Figura 6.22. Relación entre la deficiencia de $\mathrm{Ca}^{2+}+\mathrm{Mg}^{2+}$ y exceso de $\mathrm{Na}^{+}$para las muestras de agua subterránea y superficial.

Otro proceso que puede contribuir con el exceso de $\mathrm{Na}^{+}$en el agua es la hidrólisis incongruente de silicatos. La mineralogía presente en los sedimentos (Carol et al., 2012b) indica que la ocurrencia de este 
proceso podría ser favorable. La hidrólisis incongruente de plagioclasas puede enunciarse a través de las siguientes ecuaciones (Kortatsi, 2006):

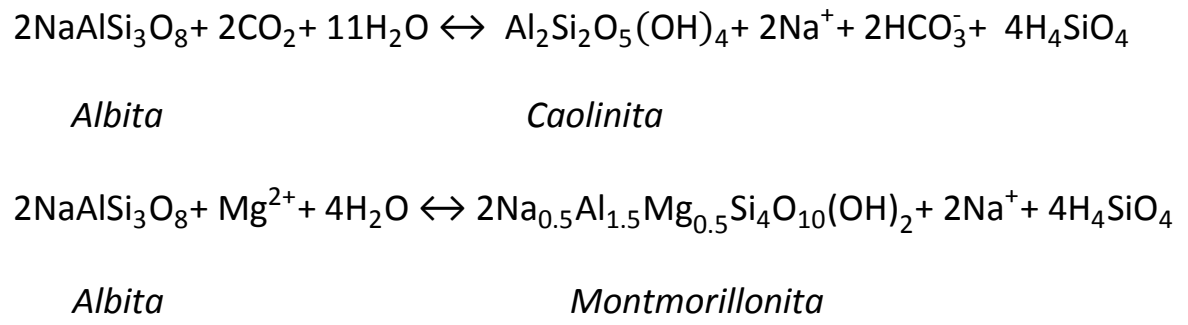

Albita

Caolinita

$2 \mathrm{NaAlSi}_{3} \mathrm{O}_{8}+\mathrm{Mg}^{2+}+4 \mathrm{H}_{2} \mathrm{O} \leftrightarrow 2 \mathrm{Na}_{0.5} \mathrm{Al}_{1.5} \mathrm{Mg}_{0.5} \mathrm{Si}_{4} \mathrm{O}_{10}(\mathrm{OH})_{2}+2 \mathrm{Na}^{+}+4 \mathrm{H}_{4} \mathrm{SiO}_{4}$

Albita

Montmorillonita 


\section{Capítulo 7. MODELOS GEOHIDROLÓGICOS CONCEPTUALES}

Los modelos hidrológicos constituyen en la actualidad una herramienta de suma utilidad para la gestión de los recursos hídricos y del medio ambiente (Devia et al., 2015). Sorooshian et al. (2008) proponen que un modelo conceptual hidrológico es una representación simplificada de los componentes físicos del medio y del conjunto de procesos modificadores que actúan en el sistema considerado.

En este capítulo se integran las características hidrodinámicas e hidrogeoquímicas de la planicie costera del Río de la Plata medio en el litoral del partido de Magdalena, estudiadas en los capítulos 4, 5 y 6 , con el fin de generar modelos conceptuales del funcionamiento geohidrológico de esta unidad. En los modelos conceptuales propuestos en este capítulo se describe el comportamiento de cada subambiente de la planicie costera en condiciones naturales y contemplando las modificaciones como consecuencia de la acción antrópica. La información antecedente obtenida se presenta de forma simplificada a través de esquemas tridimensionales donde se resumen los principales procesos que condicionan la dinámica y química del agua superficial y subterránea. Asimismo, se analizan las variaciones espaciales que existen en la planicie costera del Río de la Plata comparando los modelos conceptuales generados con los estudios efectuados en otros sectores de esta unidad geomorfológica.

\subsection{FUNCIONAMIENTO GEOHIDROLÓGICO REGIONAL DE LA PLANICIE COSTERA}

En un marco geohidrológico regional la planicie costera constituye un ámbito de circulación del agua subterránea que proviene de la llanura loessica (zona de recarga) y que descarga en el Río de la Plata, con un flujo subterráneo regional en sentido sudoeste a noreste (Figs. 4.20 y 7.1). En referencia a la composición hidroquímica del agua subterránea, en la llanura loessica el agua es de baja salinidad y de tipo bicarbonatada sódica, mientras que en la planicie costera la salinidad del agua subterránea tiende a aumentar y se reconocen distintas facies vinculadas a los subambientes reconocidos en esta unidad geomorfológica (Fig. 4.22). 


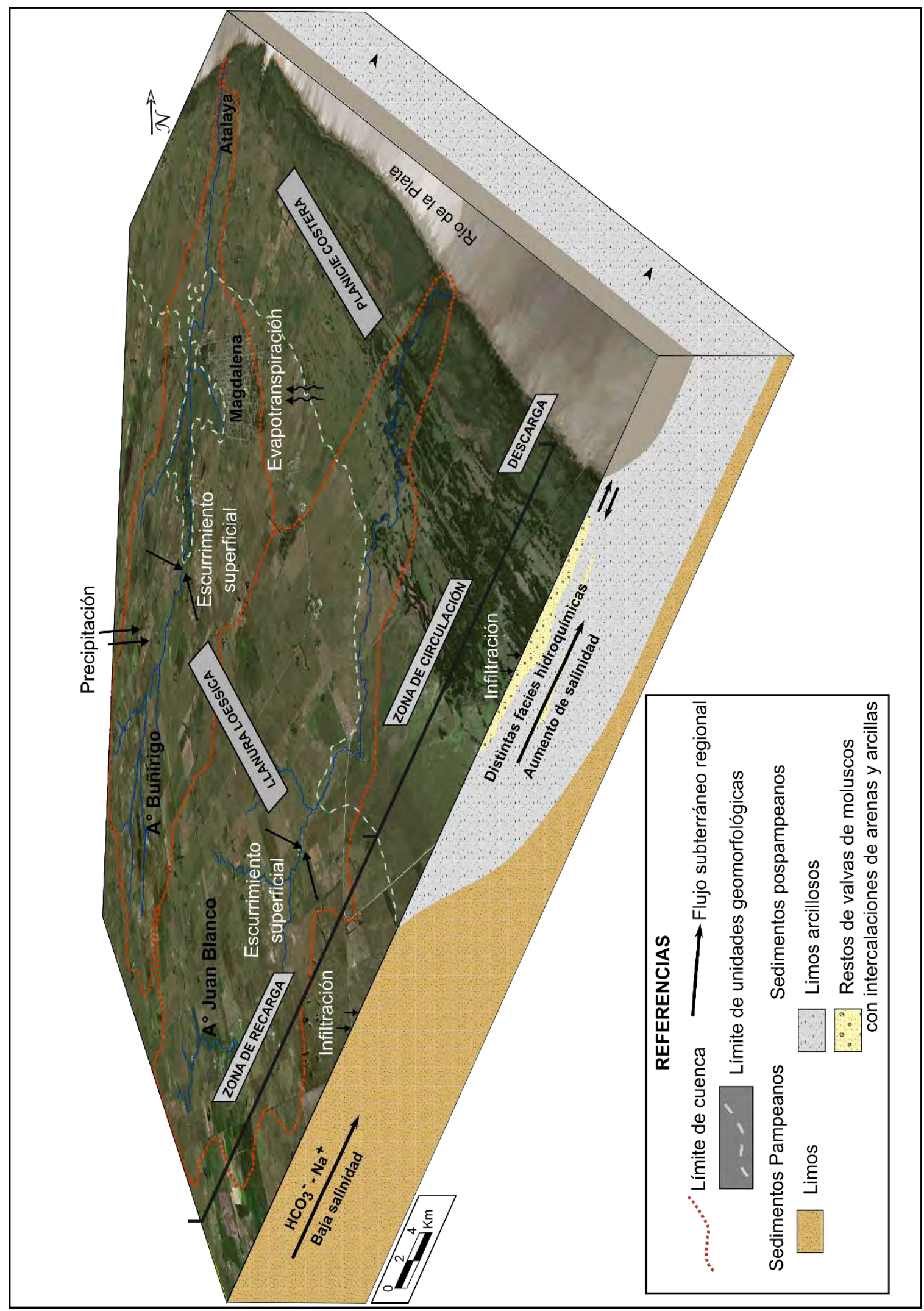

Figura 7.1. Funcionamiento geohidrológico regional de la planicie costera del Río de la Plata medio. La facies hidroquímica representativa de cada unidad geomorfológica se expresa a partir de la fórmula química de los iones dominantes (p. ej. $\mathrm{HCO}_{3}{ }^{-}-\mathrm{Na}^{+}$indica una facies bicarbonatada sódica). 
Los arroyos Buñirigo y Juan Blanco reciben la descarga del agua subterránea más somera y el aporte del escurrimiento superficial durante los eventos de lluvia. El agua del arroyo Juan Blanco, el cual presenta un comportamiento natural, tiene una baja salinidad a lo largo de todo su curso. Esto muestra que el aporte de la descarga subterránea al arroyo en el sector de planicie costera es escaso frente al que proviene del escurrimiento superficial y/o la descarga subterránea desde la llanura loessica. Probablemente este fenómeno esté controlado por la baja velocidad del flujo subterráneo en la planicie costera dada por la dominancia de sedimentos de baja permeabilidad en esta unidad. El comportamiento natural de este sistema fluvial no se evidencia en el tramo de planicie costera del arroyo Buñirigo dado que el vertido de efluentes industriales condiciona fuertemente la salinidad y el contenido iónico de sus aguas.

\subsection{FUNCIONAMIENTO GEOHIDROLÓGICO DE LOS SUBAMBIENTES QUE COMPONEN LA PLANICIE COSTERA}

Las características dinámicas y químicas tanto del agua superficial como del agua subterránea más somera de los distintos subambientes de la planicie costera permiten caracterizar el funcionamiento geohidrológico local de esta unidad geomorfológica. El agua subterránea somera en todos los subambientes recibe la recarga directa de las lluvias. Esto queda evidenciado en el contenido isotópico del agua subterránea, que en toda la planicie costera presenta valores similares a los de la recta meteórica local (Fig. 6.9). De esta manera, pese a las diferencias litológicas de los distintos subambientes, el agua de la precipitación infiltra con muy poca evaporación, y recarga localmente al agua subterránea somera. También parte del agua de la lluvia escurre superficialmente hacia las zonas deprimidas (p.ej. arroyos y canales de marea antiguos y activos) y se evapotranspira produciendo un leve enriquecimiento isotópico en el agua el cual es, según los datos relevados, menor al 10\% (Fig. 6.9). Si bien el proceso de recarga es similar para todos los subambientes, las características del flujo subterráneo, la relación con el agua superficial y los flujos mareales y los procesos geoquímicos que regulan la calidad del agua subterránea son distintos en cada subambiente. A continuación se describen estas singularidades.

\subsubsection{Antigua llanura intermareal}

En la antigua llanura intermareal (Fig. 7.2) la infiltración del agua de las precipitaciones se realiza de forma efectiva pese a la baja permeabilidad de los suelos y sedimentos, dado que la pendiente del terreno es extremadamente baja $\left(10^{-3}\right)$ favoreciendo la infiltración por sobre el escurrimiento superficial. Luego del proceso de infiltración, se produce la recarga local del agua subterránea somera cuyo nivel freático se localiza, por lo general, a menos de un metro de profundidad. Las depresiones sinuosas que forman los antiguos canales de marea interceptan al nivel freático constituyendo zonas de descarga subterránea local, 
en donde además se acumula el agua de las precipitaciones. De esta manera los antiguos canales de marea, que actualmente carecen de un drenaje integrado, forman cañadas dentro del subambiente de llanura intermareal (Fig. 5.6).

La composición del agua subterránea somera en relación al contenido de iones mayoritarios evidencia que los iones dominantes son el bicarbonato y el sodio (Fig. 6.1). Esta facies hidroquímica estaría controlada por la composición original del agua meteórica y los distintos procesos que ocurren durante la interacción entre el agua, el suelo y los sedimentos. En base a la litología presente en los sedimentos de este subambiente se puede determinar que los procesos geoquímicos que pueden aportar iones $\mathrm{HCO}_{3}{ }^{-}$y $\mathrm{Ca}^{2+}$ son la disolución de $\mathrm{CO}_{2(\mathrm{~g})}$ y de minerales carbonáticos mientas que el aporte de $\mathrm{Na}^{+}$puede estar regulado por el intercambio iónico y la disolución incongruente de plagioclasas (Figs. 6.11, 6.12, 6.21 y 6.22). Es importante resaltar que estos procesos se identificaron en el agua subterránea somera y, en profundidad, el agua tiende a aumentar la salinidad y pasar a facies clorurada sódica (Fig. 7.2). Esto se debe, posiblemente, a que en profundidad el flujo subterráneo responde a procesos regionales con alto tiempo de residencia producto de la baja permeabilidad de los sedimentos y escaso gradiente hídrico. Estos últimos factores determinan que el flujo subterráneo profundo sea muy lento y en consecuencia exista una fuerte interacción entre el agua subterránea y el sedimento lo que favorecería al aumento en la salinidad con tendencia a facies clorurada sódica (Tóth, 1999).

\subsubsection{Planicie con cordones de conchilla}

En la planicie con cordones de conchilla (Fig. 7.2) la infiltración del agua de lluvia ocurre de manera preferencial en la zona de cordones de conchilla debido a la alta permeabilidad que caracteriza a los suelos y sedimentos de este subambiente. Por su parte, la textura arcillosa más superficial de los suelos presentes en las zonas de intercordón hace que la infiltración del agua de lluvia sea lenta en estos lugares. Por tal motivo, en estos sectores la recarga es menor y en periodos muy lluviosos el agua de lluvia puede acumularse superficialmente.

La composición del agua subterránea en relación al contenido de iones mayoritarios permite realizar una diferenciación en cuatro facies hidroquímicas para el subambiente de planicie con cordones de conchilla, las facies bicarbonatada sódica, bicarbonatada cálcica, bicarbonatada magnésica y clorurada sódica. La facies bicarbonatada sódica se registra en los pozos de exploración someros realizados sobre este subambiente (Figs. 4.22, 6.1 y 6.5). Las facies bicarbonatada cálcica y magnésica se desarrollan exclusivamente en los cordones de conchilla, extendiéndose aproximadamente entre 10 y 12 metros de profundidad (Figs. 4.22 y 6.7). La facies clorurada sódica se reconoce a profundidades mayores y similares a las que llegan las facies bicarbonatada cálcica y magnésica, en todo el subambiente (Figs. 4.22, 6.5 y 6.7). Además, la facies clorurada sódica se identificó en los pozos someros realizados en los intercordones de la transecta 2 (Fig. 6.3). 


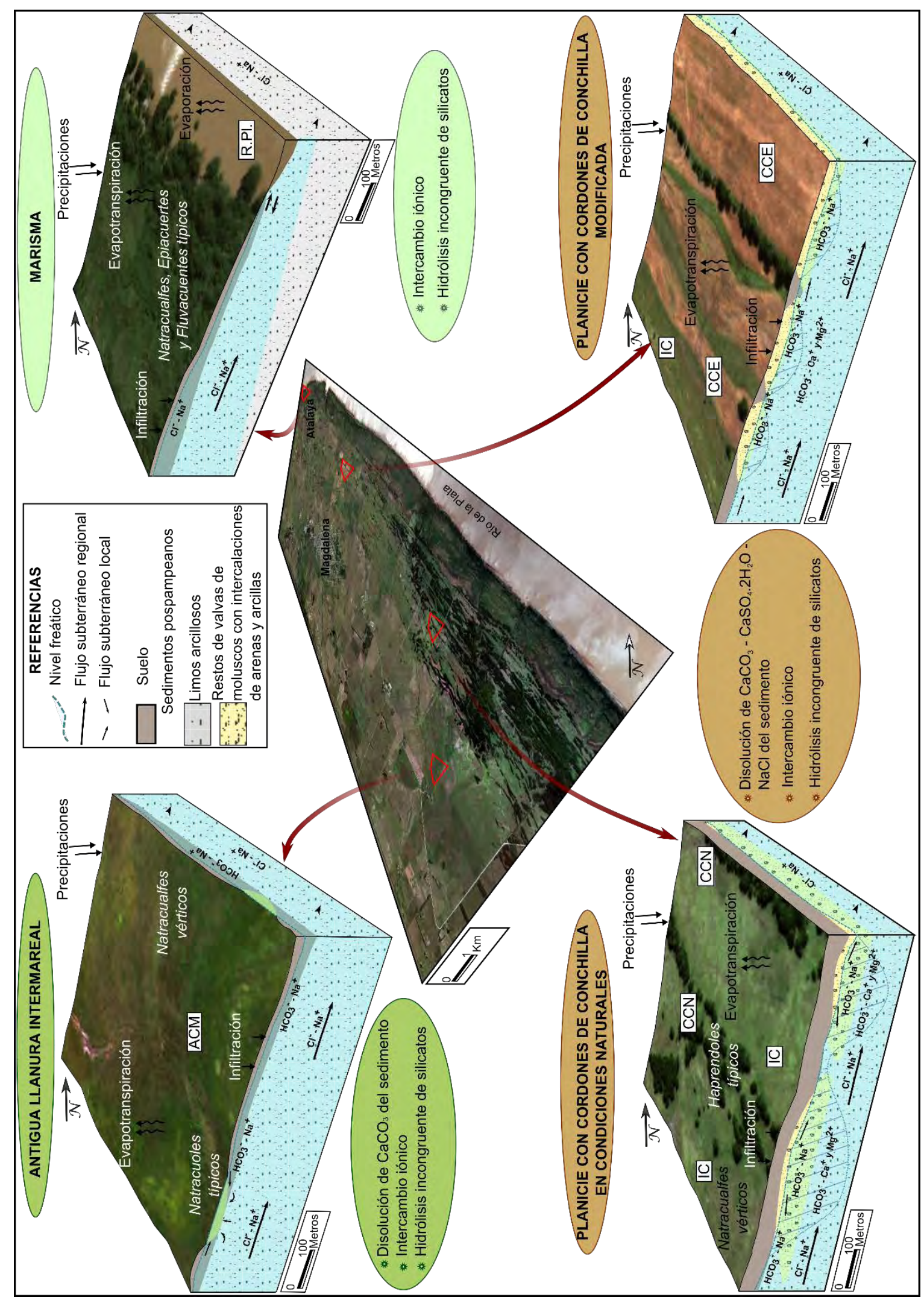

Figura 7.2. Funcionamiento geohidrológico de los subambientes que componen la planicie costera del Río de la Plata medio. En la figura se indican las principales componentes del ciclo hidrológico y los procesos geoquímicos que se reconocen en cada subambiente. La facies hidroquímica representativa de cada subambiente se indica a partir de la fórmula química de los iones dominantes (p. ej. $\mathrm{HCO}_{3}{ }^{-}-\mathrm{Na}^{+}$indica una facies bicarbonatada sódica). 
El reconocimiento de las facies a distintas profundidades y en distintos lugares evidencia variaciones verticales y laterales en las características hidroquímicas del acuífero freático en la planicie con cordones de conchilla. A partir de esto, se puede interpretar que el acuífero freático presenta una zona superficial de tipo bicarbonatada sódica, de al menos 2 metros de espesor y distribuida en todo el subambiente (Fig. 7.2). La composición química de esta zona estaría regulada por la composición original del agua meteórica y los procesos geoquímicos que fueron mencionados para esta facies en la antigua llanura intermareal. Además, y particularmente asociado a los cordones de conchilla, se puede interpretar que existe en el acuífero una zona por debajo del agua bicarbonatada sódica de característica bicarbonatada cálcica y magnésica (Fig. 7.2). Este cambio de facies podría estar relacionado a la disolución de las conchillas carbonáticas de los cordones. Respecto a la facies clorurada sódica, ésta representa la facies de mayor salinidad, ubicándose por debajo de las facies bicarbonatada cálcica, magnésica y sódica en los cordones de conchilla e intercordones (Fig. 7.2). La química de la facies clorurada sódica respondería a los procesos citados anteriormente para la antigua llanura intermareal, la cual en profundidad también presenta facies de este tipo. Por otro lado, la facies clorurada sódica de los pozos someros de la transecta 2 podría estar asociada a pleamares extraordinarias, ya que esta zona está muy próxima al Río de la Plata y podría haber sido inundada en alguno de estos eventos. De esta forma, se podría haber acumulado el agua del flujo mareal en superficie, debido a la baja permeabilidad de los sedimentos superficiales de los intercordones, y luego por evaporación dar lugar a la formación de precipitados salinos de tipo yeso y halita que después habrían sido disueltos con las precipitaciones (Carol et al., 2009). Estos procesos de disolución quedan reflejados en las signaturas isotópicas y en la relación de las mismas con los iones sulfato y cloruro (Figs. 6.17, 6.18 y 6.19).

La disposición de las facies se correspondería con el desarrollo de lentes de agua dulce asociadas a los cordones de conchilla, y limitadas por agua subterránea más salina. Estos reservorios de agua dulce son comunes en geoformas equivalentes a lo largo de la planicie costera del Río de la Plata (Carol et al., 2015; Tanjal et al., 2017; Cellone et al., 2018). Estas lentes se extienden hasta cerca de 10 - 12 metros de profundidad lo que determina que se alojen también en los sedimentos loessicos subyacentes. La profundización de las lentes a igual tasa de recarga depende de la topografía del cordón, la posición del nivel freático y la permeabilidad de los sedimentos (Ghyben, 1888; Herzberg, 1901; Fetter, 1972), desarrollándose lentes de mayor espesor cuando la topografía y nivel freático es más elevada y mayor sea la permeabilidad. Esto permite interpretar que, en condiciones naturales, como las estudiadas en la Reserva Natural y Cultural El Saladero (transecta 4; Fig. 6.7) las lentes sean de mayor espesor que aquellas de la Estancia Villa Villabona (transecta 3; Fig. 6.5) donde los cordones de conchilla fueron explotados provocando una disminución en la topografía y permeabilidad (se extrae la conchilla y se rellenan con material arenoso menos permeable). Así, la explotación de los cordones de conchilla ocasiona un detrimento en las reservas de agua dulce dentro de la planicie costera (Carol et al., 2015; Tanjal et al., 2017a). Particularmente, la salinización de los pozos de 
abastecimiento de la localidad de Atalaya (ver muestras de facies clorurada sódica de esta localidad; Fig. 4.22) podría estar asociada a la explotación de los cordones de conchilla sobre los que se asienta este pueblo, aunque la sobreexplotación del acuífero freático también podría producir o incrementar este proceso. Estos problemas de salinización fueron remediados a través de la construcción de un acueducto que transporta agua desde la localidad de Magdalena proveniente de la explotación del acuífero semiconfinado de la llanura loessica.

\subsubsection{Marisma}

En la marisma la dinámica y química del agua subterránea está fuertemente condicionada por los flujos mareales que la inundan periódicamente durante las pleamares. Esta inundación ocasiona que el agua del Río de la Plata sea una fuente de recarga del agua subterránea somera producto de su infiltración y propagación a través de los sedimentos. El ingreso del agua del Río de la Plata hacia el agua subterránea ocasiona el ascenso del nivel freático y cambios en la salinidad del agua (Fig. 5.10). De esta manera la química del agua subterránea refleja la influencia del estuario por la presencia de facies levemente clorurada sódica y contenidos isotópicos también similares a los registrados en el Río de la Plata (Pera Ibarguren, 2004; Dapeña, 2008; Santucci et al., 2017a; Fig. 6.7). Dado que el régimen mareal en el estuario es semidiurno, los constantes intercambios de flujo que ocurren entre la marisma y el Río de la Plata hacen que dentro de la planicie costera la marisma sea el subambiente que presenta la mayor variabilidad en el tiempo. Cabe destacar que la recarga a partir de la infiltración del agua de la lluvia es un proceso que no se descarta, sólo ocurre que éste resulta ser de menor relevancia si se compara con la recarga que ocurre por infiltración del flujo mareal.

\subsection{COMPARACIÓN DEL FUNCIONAMIENTO GEOHIDROLÓgICO DEL LITORAL DEL PARTIDO DE MAGDALENA EN EL CONTEXTO DE LA PLANICIE COSTERA DEL RÍO DE LA PLATA}

La gran extensión que presenta la planicie costera del Río de la Plata y las variaciones geomorfológicas a lo largo de ésta determinan que existan sectores con distintos comportamientos geohidrológicos. Los modelos conceptuales generados para el litoral del estuario medio en el partido de Magdalena permiten comprender el comportamiento geohidrológico en este sector de la planicie costera y compararlo con otros sectores ya estudiados.

En el litoral del estuario interior y medio (Fig. 7.3), las actividades antrópicas alteraron fuertemente la dinámica y química del agua de la planicie costera. En estos sectores el desarrollo urbano principalmente de barrios cerrados (Melo et al., 2012), la instalación de puertos y polo petroquímicos (Santucci et al., 2016, 
2017a, b), las zonas destinadas a la disposición de residuos sólidos urbanos (D’ambrosio et al., 2017), la ampliación del puerto de La Plata (Represa, 2014) y la agricultura (Hurrel et al., 2011) modificaron su funcionamiento natural. Estas modificaciones provocaron cambios en la interacción entre los flujos mareales y subterráneos y la química del agua que en sectores presenta graves problemas de contaminación. Esta situación es comparable con los cambios en la química y dinámica del agua superficial de la planicie costera de Magdalena producida por las industrias que se desarrollan en el área (ver Apartado 4.3; Fig. 4.17).

Dentro del litoral del estuario medio, en el partido de Punta indio (Fig. 7.3), la planicie costera presenta subambientes equivalentes y con un comportamiento geohidrológico similar al estudiado en esta Tesis (Cellone et al., 2016). Sin embargo, en este sector no existen cuencas hidrográficas definidas, ya que los cordones de conchilla presentan mayor expresión y limitan al drenaje superficial hacia el Río de la Plata. Los cordones de conchilla están mejor preservados que en el partido de Magdalena, permitiendo la formación de lentes de agua dulce que sustentan, a partir de perforaciones domiciliarias, a los habitantes de la localidad de Punta Indio (Cellone et al., 2018). Si bien aquí las reservas no son tan limitadas como en Atalaya no dejan de ser fuentes de abastecimiento vulnerables que requieren de una explotación sustentable.

En el estuario exterior, litoral de la Bahía Samborombón (Fig. 7.3), los subambientes siguen siendo similares, no así el agua del estuario en donde la salinidad se incrementa debido a la influencia mareal. En este sector el estuario es de cuña salina y su salinidad es cercana a $2 \mathrm{~g} / \mathrm{L}$ en el sector norte de la bahía y cercana a $20 \mathrm{~g} / \mathrm{L}$ en el sector sur (Balay, 1961). La marisma tiende a ensancharse alcanzando un máximo cercano a los 25 Kilómetros en el partido de General Lavalle incrementándose también la salinidad del agua subterránea en este subambiente (Carol et al., 2012a, 2013b, 2016). Los cordones de conchilla tienden a desaparecer hacia el sector central de la bahía y en esta zona constituyen la única fuente de agua dulce utilizada para abastecimiento. La actividad minera, al igual que en el litoral de Magdalena, deterioró gran parte de los recursos hídricos de agua dulce alojados en los cordones (Tejada et al., 2011; Carol et al., 2015). En el extremo sur de la planicie costera pequeños mantos arenosos acumulan lentes de agua dulce, aunque no constituyen fuentes explotables para abastecimiento (Carol et al., 2009). El abastecimiento en la localidad de General Lavalle, que es el principal centro poblado del extremo sur de la planicie costera, se realiza a partir de la toma de agua superficial desde el canal 2, el cual presenta en ocasiones también problemas de salinización producto del flujo mareal (Melo et al., 2015). 


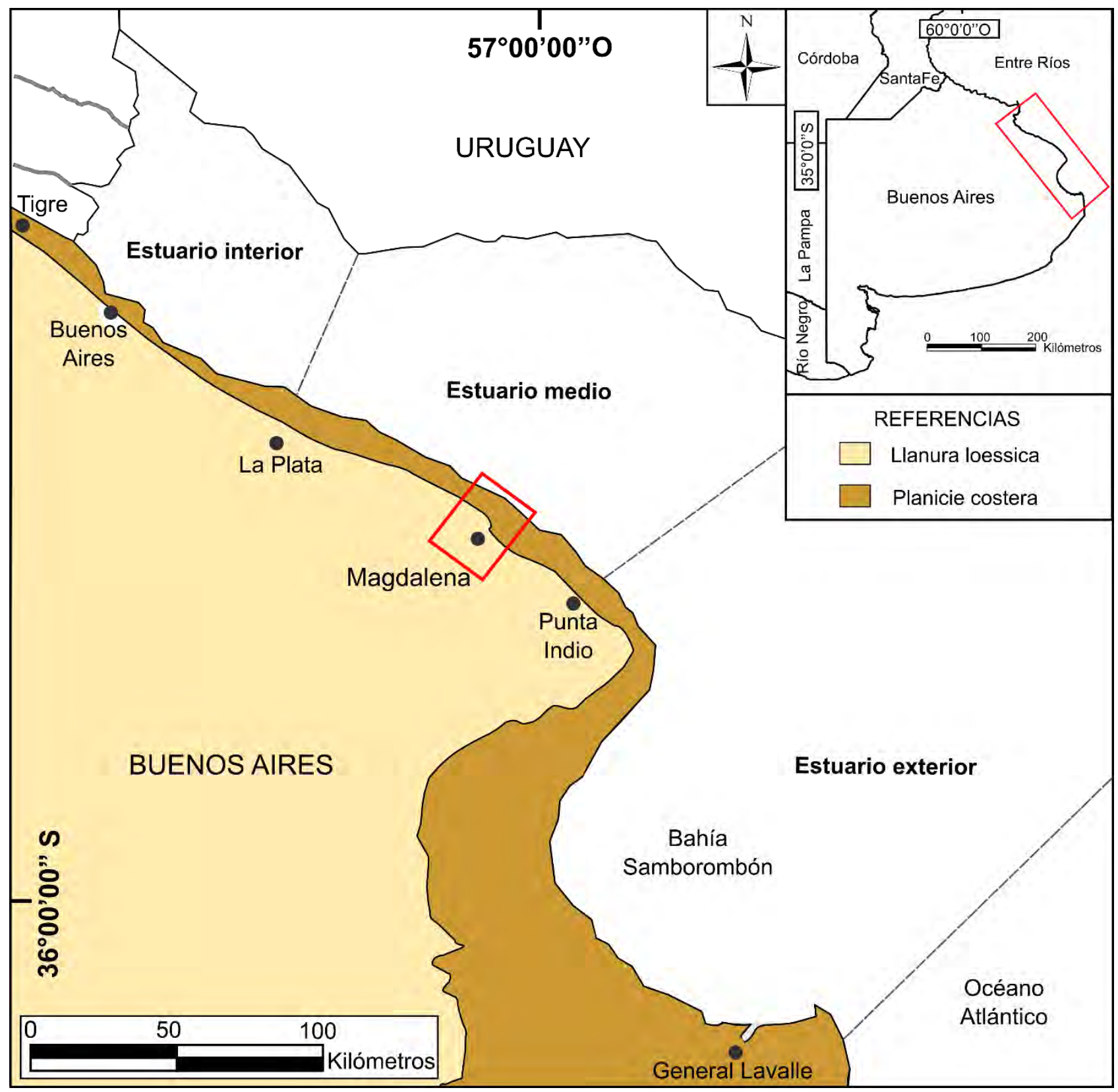

Figura 7.3. Ubicación del litoral del partido de Magdalena en el contexto de la planicie costera del Río de la Plata. 


\section{Capítulo 8. CONCLUSIONES}

El estudio a nivel regional de las características geohidrológicas del noreste de la provincia de Buenos Aires y, a escala local, de las cuencas hidrográficas de los arroyos Buñirigo y Juan Blanco y de los subambientes de la planicie costera junto al análisis integral del Capítulo 7, permiten arribar a las siguientes conclusiones sobre el comportamiento geohidrológico de la planicie costera del Rio de la Plata medio en el litoral del partido de Magdalena.

La planicie costera del Río de la Plata medio constituye una unidad geomorfológica en la cual se identifican tres subambientes asociados: la antigua llanura intermareal, la planicie con cordones de conchilla y la marisma. Esta unidad limita hacia el suroeste con la llanura loessica.

Las cuencas hidrográficas de los arroyos Buñirigo y Juan Blanco se desarrollan sobre estas unidades geomorfológicas. Los arroyos son de carácter efluente y reciben, además, el aporte del escurrimiento superficial durante las precipitaciones. La descarga subterránea en los arroyos adquiere relevancia en la llanura loessica, mientras que en la planicie costera la baja permeabilidad de los sedimentos dominantes hace que el flujo de descarga sea bajo. La hidrodinámica e hidroquímica de la cuenca del arroyo Juan Blanco puede considerarse como representativa de un ambiente prístino. Por su parte, en la cuenca media y baja del arroyo Buñirigo la actividad antrópica, principalmente el vertido de efluentes de la actividad industrial, modificó tanto la dinámica como la calidad del agua del arroyo.

En un marco geohidrológico regional la planicie costera constituye principalmente un ámbito de circulación del agua subterránea que proviene de la llanura loessica (zona de recarga). De esta forma se advierte un flujo subterráneo regional en sentido sudoeste a noreste que descarga en el Río de la Plata. En referencia a la composición hidroquímica de este flujo, en la llanura loessica el agua es de baja salinidad y de tipo bicarbonatada sódica, mientras que en la planicie costera hay un aumento de salinidad y se reconocen distintas facies vinculadas a los subambientes descriptos en esta unidad geomorfológica.

Pese a las diferencias litológicas de los distintos subambientes, el agua de la precipitación infiltra con poca evaporación y recarga localmente al agua subterránea somera. Asimismo, escurre superficialmente hacia las zonas deprimidas y se evapotranspira. En relación al funcionamiento geohidrológico se reconocen dentro del agua subterránea somera variaciones en la dinámica y química asociadas a las características propias de los subambientes identificados, las que pudieron ser simplificadas en modelos conceptuales, que 
si bien no representan la complejidad propia de cada ambiente, muestran las principales variables y procesos que ocurren en cada subambiente.

En la antigua llanura intermareal la escasa pendiente del terreno favorece la infiltración del agua de las precipitaciones por sobre el escurrimiento superficial. El nivel freático se localiza, por lo general, a menos de un metro de profundidad y aflora en las depresiones sinuosas que forman los antiguos canales de marea. La composición del agua subterránea somera es de tipo bicarbonatada sódica. Esta composición química estaría controlada por la composición original del agua meteórica, la disolución de $\mathrm{CO}_{2}$ (g) y de minerales carbonáticos, el intercambio iónico y la disolución incongruente de plagioclasas. En profundidad el agua tiende a aumentar la salinidad y pasar a facies clorurada sódica a causa posiblemente de un mayor tiempo de interacción agua-sedimento ocasionado, en gran medida, por la velocidad muy lenta del flujo subterráneo por el escaso gradiente hídrico.

En la planicie con cordones de conchilla la infiltración del agua de lluvia ocurre de manera preferencial en la zona de cordones. La composición del agua subterránea en este subambiente evidencia variaciones verticales y laterales en las características hidroquímicas del acuífero freático. En la zona superficial del mismo y, de al menos 2 metros de espesor, el agua es de tipo bicarbonatada sódica y estaría regulada por la composición original del agua meteórica y los procesos geoquímicos que fueron mencionados para esta facies en la antigua llanura intermareal. Asociado a los cordones de conchilla, se puede interpretar que existe en el acuífero una zona por debajo del agua bicarbonatada sódica de característica bicarbonatada cálcica y magnésica, de aproximadamente 10 a 12 metros de profundidad, relacionada posiblemente a la disolución de las conchillas carbonáticas de los cordones. Por debajo de las facies bicarbonatada cálcica, magnésica y sódica en todo el subambiente se reconoce la facies clorurada sódica que respondería a los procesos mencionados para el agua subterránea profunda en la antigua llanura intermareal.

La disposición de las facies en el subambiente de planicie con cordones de conchilla se correspondería con el desarrollo de lentes de agua dulce asociadas a los cordones de conchilla, y limitadas por agua subterránea más salina. En condiciones naturales las lentes son de mayor espesor que aquellas originadas donde los cordones de conchilla fueron explotados por la antropización, provocando una disminución en la topografía y permeabilidad de los mismos. La explotación de los cordones de conchilla ocasiona un detrimento en las reservas de agua dulce dentro de la planicie costera.

En la marisma, la dinámica y química del agua subterránea está fuertemente condicionada por los flujos mareales que la inundan periódicamente durante las pleamares. Esta inundación ocasiona que el agua del Río de la Plata sea una fuente de recarga del agua subterránea somera producto de su infiltración y propagación a través de los sedimentos. El ingreso del agua del Río de la Plata hacia el agua subterránea 
ocasiona el ascenso de los niveles freáticos y los cambios en la salinidad del agua subterránea la cual presenta facies levemente clorurada sódica y contenidos isotópicos similares a los del río.

Las características hidrogeomorfológicas de la llanura loessica y los subambientes que constituyen la planicie costera condicionan de manera directa el ingreso de nitrato al agua subterránea somera. Del análisis en conjunto de estas características y el contenido de nitrato y microorganismos se concluye que las zonas de recarga (llanura loessica y cordones de conchilla) constituyen las áreas más vulnerables al ingreso de contaminantes desde la superficie debido a la rápida infiltración que presentan los sedimentos que las conforman. En estas zonas, se identificaron posibles fuentes de contaminación puntual asociadas a la cría intensiva de ganado o a los pozos sépticos de los cascos de estancia pero en todos los casos las concentraciones de nitrato están dentro de los parámetros aceptados por el Código Alimentario Argentino para consumo humano.

Los resultados obtenidos en esta Tesis no sólo aportan datos de base para un sector de la planicie costera poco estudiado sino que, además, contribuyen a un mejor entendimiento del funcionamiento geohidrológico de esta extensa unidad geomorfológica. No obstante, los modelos generados en esta tesis presentan aún incertidumbres en el funcionamiento geohidrológico que plantean la necesidad de desarrollar a futuro mediciones de variables hidrológicas a largo plazo y estudios más detallados. En la planicie costera el estudio geohidrológico, en condiciones naturales y bajo la modificación antrópica, resulta de vital importancia tanto en la gestión del agua utilizada para abastecimiento humano como para la preservación de los ambientes de reserva natural que se encuentran en esta unidad. 


\section{BIBLIOGRAFÍA}

Alcalá, F.J. y Custodio, E., 2008. Using the $\mathrm{Cl} / \mathrm{Br}$ ratio as a tracer to identify the origin of salinity in aquifers in Spain and Portugal. Journal of Hydrology, 359, 189-207. https://doi.org/10.1016/j.jhydrol.2008.06.028

Allen R.G., Smith M., Pereira L.S., y Perrier, A., 1994. An update for the calculation of reference evapotranspiration. ICID Bulletin, 43, 2, 129.

Allen, R.G., Raes, D., Pereira, L.S. y Smith, M., 2006. Evapotranspiración del cultivo. Guías para la determinación de los requerimientos de agua de los cultivos. Estudio FAO Riego y Drenaje, №56.

Ameghino, F., 1889. Contribución al conocimiento de los mamíferos fósiles de la República Argentina. Actas de la Academia Nacional de Ciencias, Córdoba, Tomo VI, 1-1027.

American Public Health Association (A.P.H.A.), 1998. Standard methods for the examination of water y wastewater. Washington, 20th Edition.

Appelo, C.A.J. y Postma, D., 2005. Geochemistry, groundwater and pollution. A.A. Balkema Publishers, Rotterdam, Netherlands. 2nd. Edition, 649.

Arenas Granados, P.J., 2010. Manejo costero integrado y sustentabilidad: un análisis propositivo de políticas públicas en las dos caras atlánticas (España-Portugal-Colombia-Panamá). Tesis doctoral, Universidad de Cádiz, Puerto Real, 414.

Arturi, M.F. y Goya, J.F., 2004. Estructura, dinámica y manejo de los talares del NE de Buenos Aires. Ecología y manejo de los bosques de Argentina. Laboratorio de Investigación de Sistemas Ecológicos y Ambientales, Facultad de Ciencias Agrarias y Forestales, Universidad Nacional de La Plata, 23.

Auge, M.P., Hernández, M.A. y Hernández, L., 2002. Actualización del conocimiento del acuífero semiconfinado Puelche en la provincia de Buenos Aires, Argentina. En: Bocanegra, E., Martínez, D., Massone, H. (Eds.), Groundwater and human development, $32^{\circ}$ International Congress of IAH and $6^{\circ}$ Congress of ALHSUD, Mar del Plata, 624-633.

Balay, M.A., 1961. El Río de la Plata entre la atmósfera y el mar. Publicación H-621, Servicio de Hidrografia Naval, Buenos Aires, 153.

Bracaccini, O.I., 1972. Cuenca del Salado. En: Leanza, A.F. (Ed.), Geología Regional Argentina. Academia Nacional de Ciencias, Córdoba, 407-418.

Cagnoni, M., Faggi, A.M. y Ribichich, A., 1996. La vegetación de la Reserva El Destino (Partido de Magdalena, Provincia de Buenos Aires). Parodiana, 9, 25-44.

Carol, E., Kruse, E. y Mas-Pla, J., 2009. Hydrochemical and isotopical evidence of ground water salinization processes on the coastal plain of Samborombón Bay, Argentina. Journal of Hydrology, 365, 335-345. https://doi.org/10.1016/j.jhydrol.2008.11.041

Carol, E., Kruse, E. y Pousa, J.L., 2011. Influence of the geologic and geomorphologic characteristics and of crab burrows on the interrelation between surface water and groundwater in an estuarine coastal wetland. Journal of Hydrology, 403, 234-241. https://doi.org/10.1016/j.jhydrol.2011.04.007

Carol, E. y Kruse, E., 2012. Hydrochemical characterization of the water resources in the coastal environments of the outer Río de la Plata estuary, Argentina. Journal of South American Earth Sciences, 37, 113121. http://doi.org/10.1016/i.jsames.2012.02.009

Carol, E., Dragani, W.C., Kruse, E. y Pousa, J.L., 2012a. Surface water and groundwater characteristics in the wetlands of the Ajó River (Argentina). Continental Shelf Research, 49, 25-33. https://doi.org/10.1016/j.csr.2012.09.009 
Carol, E., Kruse, E., Laurencena, P.C., Rojo, A. y Deluchi, M.H., 2012b. Ionic exchange in groundwater hydrochemical evolution. Study case: the drainage basin of El Pescado creek (Buenos Aires province, Argentina). Environmental Earth Sciences, 65, 421-428.

Carol, E., Kruse, E., Mancuso, M. y Melo, M., 2013a. Local and regional water flow quantification in groundwater-dependent wetlands. Water Resources Management, 27, 807-817. https://doi.org/10.1007/s11269-012-0216-9

Carol, E., Kruse, E. y Tejada, M., 2013b. Surface water and groundwater response to the tide in coastal wetlands: Assessment of a marsh in the outer Río de la Plata estuary, Argentina. Journal of Coastal Research, 65, 1098-1103.

Carol, E., Mas-Pla, J. y Kruse, E., 2013bc. Interaction between continental y estuarine waters in the wetlands of the northern coastal plain of Samborombón Bay, Argentina. Applied Geochemistry 34, 152-163. http://doi.org/10.1016/i.apgeochem.2013.03.006

Carol, E., 2015. Procesos geohidrológicos y geoquímicos que condicionan la composición del agua subterránea en el humedal de Bahía Samborombón. Anales de la Academia Nacional de Ciencias Exactas, Físicas y Naturales, 67, 26-40.

Carol, E., García, L. y Borzi, G., 2015. Hydrogeochemistry and sustainability of freshwater lenses in the Samborombón Bay wetland, Argentina. Journal of South American Earth Sciences, 60, 21-30.

Carol, E., Alvarez, M.P. y Borzi, G.E., 2016. Assessment of factors enabling halite formation in a marsh in a humid temperate climate (Ajó Marsh, Argentina). Marine Pollution Bulletin 106, 323-328. https://doi.org/10.1016/j.marpolbul.2016.03.031

Carol, E. y Kruse, E., 2016. Hydrochemical variability associated with rainfall regime: a case study in the coastal wetland of the outer Río de la Plata Estuary, Argentina. Environmental Earth Sciences, 75, 907.

Carol, E., Braga, F., Donnici, S., Kruse, E. y Tosi, L., 2017. The hydrologic landscape of the Ajó coastal plain, Argentina: An assessment of human-induced changes. Anthropocene, 18, 1-14. https://doi.org/10.1016/j.ancene.2017.05.001

Cavallotto, J.L., 1995. Evolución geomorfológica de la llanura costera ubicada en el margen sur del Río de la Plata. Tesis doctoral, Facultad de Ciencias Naturales y Museo, Universidad Nacional de La Plata, 237.

Cavallotto, J.L., 2002. Evolución holocena de la llanura costera del margen sur del Río de la Plata. Revista de la Asociación Geológica Argentina, 57, 376-388.

Cavallotto, J.L., Violante, R.A. y Colombo, F., 2005. Evolución y cambios ambientales de la llanura costera de la cabecera del río de la Plata. Revista de la Asociación Geológica Argentina, 60, 353-367.

Cellone, F., Deluchi, M.H., Melo, M. y Carol, E., 2014a. Interacción entre los usos de la tierra y los recursos hídricos en la cuenca del arroyo Buñirigo, Argentina. En: 2do Congreso Internacional de Hidrología de Llanuras, Santa Fe.

Cellone, F., Melo, M., Carol, E., 2014b. Geohidrología del extremo noreste de la provincia de Buenos Aires (Argentina). En: Encuentro del "International Center of Earth Sciencies" E-ICES 10, Buenos Aires, Resumen impreso, 21.

Cellone, F., Elizalde, N., Tosi, L. y Carol, E., 2016. Identificación y delimitación de lentes de agua subterránea dulce en la planicie costera del Río de la Plata, Punta Indio, Buenos Aires, Argentina. En: I Jornadas Internacionales de Ambiente y III Jornadas Nacionales de Ambiente, Tandil. 
Cellone, F., Tosi, L. y Carol, E., 2018. Estimating the freshwater-lens reserve in the coastal plain of the middle Río de la Plata Estuary (Argentina). Science of The Total Environment, 630, 357-366. https://doi.org/10.1016/j.scitotenv.2018.02.236

Clark, I., 2015. Groundwater geochemistry and isotopes. CRC Press, Boca Raton, Florida, 437.

Coleman, M.L., Shepherd, T.J., Durham, J.J., Rouse, J.E. y Moore, G.R., 1982. Reduction of water with zinc for hydrogen isotope analysis. Analytical Chemistry, 54, 993-995.

Craig, H. y Gordon, L.I., 1965. Deuterium and oxygen 18 variations in the ocean and the marine atmosphere. Stable Isotopes in Oceanic Studies and Paleotemperatures.

Dalla Salda, L., 1981. El basamento de la isla Martín García, Río de la Plata. Revista de la Asociación Geológica Argentina, 26, 29-43.

Da Lio, C., Tosi, L., Zambon, G., Vianello, A., Baldin, G., Lorenzetti, G., Manfè, G. y Teatini, P., 2013. Long-term groundwater dynamics in the coastal confined aquifers of Venice (Italy). Estuarine, Coastal and Shelf Science, 135, 248-259. https://doi.org/10.1016/j.ecss.2013.10.021

D’ambrosio, M., Elordi, M.L., Buffone, B., Balbi, K., Porta, A., Andrinolo, D. y Cano, L., 2017. Evaluación de la calidad del agua de la laguna de Los Patos, Ensenada, mediante índices de calidad y de contaminación. En: VI Congreso Bianual PROIMCA, IV Congreso Bianual PRODECA, Bahía Banca.

Dapeña, C. y Panarello, H.O., 2004. Composición isotópica de la lluvia de Buenos Aires. Su importancia para el estudio de los sistemas hidrológicos pampeanos. Revista Latino-Americana de Hidrogeología, 4, $17-25$.

Dapeña, C., 2008. Isótopos Ambientales Livianos: su aplicación en hidrología e hidrogeología. Tesis doctoral, Departamento de Ciencias Geológicas, Facultad de Ciencias Exactas y Naturales, Universidad de Buenos Aires, 442.

De Franco, R., Biella, G., Tosi, L., Teatini, P., Lozej, A., Chiozzotto, B., Giada, M., Rizzetto, F., Claude, C. y Mayer, A., 2009. Monitoring the saltwater intrusion by time lapse electrical resistivity tomography: The Chioggia test site (Venice Lagoon, Italy). Journal of Applied Geophysics 69, 117-130.

Devia, G.K., Ganasri, B.P., Dwarakish, G.S., 2015. A review on hydrological models. Aquatic Procedia, 4, 1001-1007.

D'Onofrio, E.E., Fiore, M.M.E. y Romero, S.I., 1999. Return periods of extreme water levels estimated for some vulnerable areas of Buenos Aires. Continental Shelf Research, 19, 1681-1693.

Fetter, W.C., 1972. Position of the saline water interface beneath oceanic islands. Water Resources Research, 8, 1307-1315.

Fidalgo, F., De Francesco, F.O. y Colado, U., 1973a. Geología superficial de las hojas Castelli, J.M. Cobo y Monasterio (provincia de Buenos Aires). En: 5o Congreso Geológico Argentino, 27-39.

Fidalgo, F., Colado, U.R. y De Francesco, F.O., 1973b. Sobre ingresiones marinas cuaternarias en los partidos de Castelli, Chascomús y Magdalena (Provincia de Buenos Aires). En: $5^{\circ}$ Congreso Geológico Argentino, 225-240.

Fidalgo, F., De Francesco, F.O. y Pascual, R., 1975. Geología superficial de la Llanura Bonaerense. Geología de la provincia de Buenos Aires, $6^{\circ}$ Congreso Geológico Argentino, Bahía Blanca, Relatrio, 103-138.

Fidalgo, F. y Martínez, O., 1983. Algunas características geomorfológicas dentro del partido de La Plata, provincia de Buenos Aires. Revista de la Asociación Geológica Argentina, 38, 263-279.

Frenguelli, J., 1950. Rasgos generales de la morfología y la geología de la provincia de Buenos Aires. LEMIT, 2, 3-72. 
Frenguelli, J., 1957. Geografía de la República Argentina. Neozoico. GAEA, Sociedad Argentina de Estudios Geográficos, 1-113.

Fucks, E.E. y Deschamps, C.M., 2008. Depósitos continentales cuaternarios en el noroeste de la provincia de Buenos Aires. Revista de la Asociación Geológica Argentina, 63, 326-343.

Fucks, E.E., Schnack, E.J. y Aguirre, M.L., 2010. Nuevo ordenamiento estratigráfico de las secuencias marinas del sector continental de la Bahía Samborombón, provincia de Buenos Aires. Revista de la Asociación Geológica Argentina, 67, 27-39.

Ghyben, B.W., 1888. Nota in verband met de voorgenomen putboring nabij, Amsterdam (Notes on planned well drilling near Amsterdam). The Hague. Tijdschrift van het Koninklijk Instituut van Ingenieurs, 21, 8-22.

Gonfiantini, R., 1978. Standards for stable isotope measurements in natural compounds. Nature, 271, 534.

Gonfiantini, R., 1986. Environmental isotopes in lake studies. Hybook of Environmental Isotope Geochemistry, The Terrestrial Environment, 113-168.

González Bonorino, F., 1965. Mineralogia de las fracciones arcilla y limo del Pampeano en el área de la Ciudad de Buenos Aires y su significado estratigráfico y sedimentológico. Revista de la Asociación Geológica Argentina, 20, 67-148.

González, N., 2005. Los ambientes hidrogeológicos de la provincia de Buenos Aires. En: de Barrio, R.E., Etcheverry, R.O., Caballé, M.F. y Llambías, E. (Eds.), Geología y Recursos Minerales de la Provincia de Buenos Aires, $16^{\circ}$ Congreso Geológico Argentino, La Plata, Relatorio, 359-374.

Groeber, P., 1945. Las aguas surgentes y semisurgentes del norte de la Provincia de Buenos Aires. Revista La Ingeniería, 49, 371-387.

Guarracino, L., Carrera, J., Vázquez-Suñé, E., 2012. Analytical study of hydraulic and mechanical effects on tide-induced head fluctuation in a coastal aquifer system that extends under the sea. Journal of Hydrology 450, 150-158.

Herzberg, A., 1901. Die Wasserversorgung einiger Nordseeber (The water supply of parts of the North Sea coast in Germany): Z. Gasbeleucht Wasserversorg, 44, 815-844.

Hurrell, J.A., Costantino, F.B., Puentes, J.P., Ulibarri, E.A. y Pochettino, M.L., 2011. Huertos familiares periurbanos de las costas de Ensenada - Berisso y de la Isla Martín García (Buenos Aires, Argentina). Bonplandia, 213-229.

Hurtado, M.A., Moscatelli, G.N. y Godagnone, R.E., 2005. Los suelos de la provincia de Buenos Aires. En: de Barrio, R.E., Etcheverry, R.O., Caballé, M.F., Llambías, E. (Eds.), Geología y Recursos Minerales de la Provincia de Buenos Aires, $16^{\circ}$ Congreso Geológico Argentino, La Plata, Relatorio, 201-218.

Hurtado, M.A., Giménez, J.E., Cabral, M.G., da Silva, M., Martinez, O.R., Camilión, M.C., Sánchez, C.A., Muntz, D., Gebhard, J.A. y Forte, L.M., 2006. Análisis ambiental del partido de La Plata. Consejo Nacional de Inversiones - Municipalidad de La Plata, 129.

Imbellone, P.A. y Giménez, J.E., 1997. Micromorphology of soils in quaternary littoral sequences. Northeastern Buenos Aires Province, Argentina. Soil Micromorphology: studies on soil diversity, diagnostic and dynamics, Moscú-Wageningen, 93-105.

Imbellone, P.A., Giménez, J.E. y Cuberes, M.G., 2012. Suelos loéssicos influenciados por depósitos de conchilla pleistocenos de la Formación Pascua, Noreste de la provincia de Buenos Aires, Argentina. Latin American Journal of Sedimentology and Basin Analysis, 19, 67-88.

Instituto Nacional De Estadística y Censos (I.N.D.E.C.), 2010. Censo Nacional de Población, Hogares y Viviendas. 
INTA (Instituto Nacional de Tecnología Agropecuaria), 2011. Cartas de suelos de la República Argentina. Magdalena 3557-20-2, Vieytes 3557-20-4, Magdalena Este 3557-21-1 y Álvarez Jonte 3557-21-3. http://anterior.inta.gov.ar/suelos/cartas/

Introcaso, A. y Ramos, V.A., 1984. La Cuenca del Salado: un modelo de evolución aulacogénica. En: 9o Congreso Geológico Argentino, Actas, 3, 27-46.

Kortatsi, B.K., 2006. Hydrochemical characterization of groundwater in the Accra plains of Ghana. Environmental Geology, 50, 299-311.

Kruse, E., Varela, L.B., Laurencena, P.C., Deluchi, M.H., Rojo, A. y Carol, E.S., 2003. Modificaciones del ciclo hidrológico en un área del Noreste de la Provincia de Buenos Aires, Argentina. Simposio El Agua y la Ciudad Sostenible: Hidrogeología Urbana, Instituto Geológico y Minero de España (Ed.), Barcelona.

Kruse E, Carol E, Mancuso M, Laurencena P, Deluchi M, Rojo A. 2013. Recharge assessment in an urban area: a case study of La Plata, Argentina. Hydrogeology Journal, 21, 1091-1100.

Ladouche, B. y Weng, P., 2005. Hydrochemical assessment of the Rochefort marsh: Role of surface y groundwater in the hydrological functioning of the wetland. Journal of Hydrology, 314, 22-42.

Laurencena, P.C., Deluchi, M.H., Rojo, A. y Kruse, E., 2010. Influencia de la explotación de aguas subterráneas en un sector del área periurbana de La Plata. Revista de la Asociación Geológica Argentina, 66, 484489.

Lis, G., Wassenaar, L.I. y Hendry, M.J., 2008. High-precision laser spectroscopy D/H y ${ }^{18} \mathrm{O} /{ }^{16} \mathrm{O}$ measurements of microliter natural water samples. Analytical chemistry, 80, 287-293.

López, R.A., Marcomini, S.C. y Kalesnik, F., 2013. Artificial lakes management in the estuarine plain of the Río de la Plata, Buenos Aires, Argentina. Ocean \& Coastal Management, 77, 66-72. https://doi.org/10.1016/i.ocecoaman.2012.03.002

Marchese, H.G. y Di Paola, E., 1975. Miogeosinclinal Tandil. Revista de la Asociación Geológica Argentina, 30, 161-179.

Martínez, O., Hurtado, M.A. y Jiménez, J., 2006. Caracterización ambiental de los humedales costeros del Río de la Plata, provincia de Buenos Aires, Argentina. Revista de Geociencias, 5, 55-64.

Melo, M., Carol, E. y Kruse, E., 2012. Cambios geomorfológicos en la Planicie Costera del Río de la Plata: Implicancias en la relación agua superficial-agua subterránea. En: Congreso Argentino de Cuaternario y Geomorfología, Río Cuarto, Actas, 187-194.

Melo, M., Santucci, L. y Carol, E., 2015. Pautas de manejo del recurso hídrico tendientes a solucionar los problemas de salinización que afectan el abastecimiento de agua en General Lavalle. En: 2das Jornadas de Geociencias para la Ingeniería, Instituto de Geodesia y Geofísica Aplicadas, Departamento de Agrimensura, Museo de Ciencia y Técnica, Universidad de Buenos Aires.

Montalto, F.A., Steenhuis, T.S. y Parlange, J.Y., 2006. The hydrology of Piermont Marsh, a reference for tidal marsh restoration in the Hudson river estuary, New York. Journal of Hydrology, 316, 108-128.

Moussa, A.B., Zouari, K. y Marc, V., 2011. Hydrochemical and isotope evidence of groundwater salinization processes on the coastal plain of Hammamet-Nabeul, north-eastern Tunisia. Physics and Chemistry of the Earth, Parts A/B/C, 36, 167-178. https://doi.org/10.1016/j.pce.2010.03.039

Odum, E.P., 1979. The value of wetlands: a hierarchical approach. Wetland Functions y Values: The State of Our Understying. P.E. Greeson, J.R. Clark y J.E. Clark (Eds.). American Water Resources Association, Bethesda, Maryly, 1 - 25. 
Pousa, J., Tosi, L., Kruse, E., Guaraglia, D., Bonardi, M., Mazzoldi, A., Rizzetto, F. y Schnack, E., 2007. Coastal processes and environmental hazards: the Buenos Aires (Argentina) y Venetian (Italy) littorals. Environmental Geology, 51, 1307-1316.

Panarello, H.O. y Parica, C.A., 1984. Isótopos del oxígeno en hidrogeología e hidrología. Primeros valores en aguas de lluvia de Buenos Aires. Revista de la Asociación Geológica Argentina, 39, 3-11.

Parkhurst, D.L. y Appelo, C.A.J., 1999. User's guide to PHREEQC (Version 2): A computer program for speciation, batch-reaction, one-dimensional transport, and inverse geochemical calculations.

Pascale, A.J. y Damario, E.A., 1997. El balance hidrológico seriado y su utilización en estudios agroclimáticos. Revista de la Facultad de Agronomía de La Plata. LIII (1-2): 15-34.

Pera Ibarguren, S., 2004. Surface water-groundwater interactions in transmition enviroments: the Rio de la Plata coastal plain, Argentina. Tesi di dottorato, Facoltà di Scienze matematiche fisiche e naturali, Università Ca' Foscari Venezia.

Ramos, V.A., 1999. Las provincias geológicas del territorio argentino. En: Caminos, R. (Ed.), Geología Argentina. Instituto de Geología y Recursos Minerales - SEGEMAR, Buenos Aires, 41-96.

Represa, S., 2014. Ampliación del puerto La Plata. Lectura desde la perspectiva del conflicto ambiental. En: I Congreso Latinoamericano sobre Conflictos Ambientales, Universidad Nacional de General Sarmiento.

Russo, A., Ferello, R. y Chebli, G., 1979. Llanura Chaco Pampeana. Segundo Simposio de Geología Regional Argentina. Academia Nacional de Ciencias de Córdoba, 139-183.

Sala, J.M., 1972. Contribución al estudio geohidrológico del Noreste de la Provincia de Buenos Aires. Comité de Estudios de Aguas Subterráneas del Noreste de la provincia de Buenos Aires (E.A.S.N.E.) - Consejo Federal de Inversiones (C.F.I.), Buenos Aires, 144.

Salazar Lea Plaza, J.C. y Moscatelli, G.N., 1989. Mapa de suelos de la provincia de Buenos Aires. SAGyP-INTA, Buenos Aires, 525.

Santa Cruz, J.N., 1972. Estudio sedimentológico de la Formación Puelches en la provincia de Buenos Aires. Revista de la Asociación Geológica Argentina, 27, 5-62.

Santucci, L., Tanjal, C. y Carol, E., 2016. Análisis de cambios de uso de suelo en relación al crecimiento industrial y la expansión urbana. Estudio de caso en un sector de la planicie costera del Río de la Plata. En: $1^{\text {as }}$ Jornadas de Hábitat y Ambiente, IHAM-FAUD-UNMdP, Mar del Plata.

Santucci, L., Carol, E., Borzi, G. y García, M.G., 2017a. Hydrogeochemical and isotopic signature of surface and groundwater in a highly industrialized sector of the Rio de la Plata coastal plain (Argentina). Marine Pollution Bulletin, 120, 387-395. https://doi.org/10.1016/j.marpolbul.2017.05.007

Santucci, L., Tanjal, C., Borzi, G., y Carol, E., 2017b. Pasivos ambientales como fuente de contaminación del agua en un sector de la planicie costera del Río de la Plata. En: VI Congreso Bianual PROIMCA y IV Congreso Bianual PRODECA, Bahía Blanca.

Simler, R., 2009. Diagrammes. Avignon, Laboratoire d'Hydrogéologie d'Avignon. http://www.Iha.univavignon.fr/LHA-Logiciels.htm

Sorooshian, S., Hsu, K., Coppola, E., Tomassetti, B., Verdecchia, M., Visconti, G., 2008. Hydrological modelling and the water cycle: coupling the atmospheric and hydrological models. Springer Science and Business Media.

Stiff, H.A., 1951. The interpretation of chemical water analysis by means of patterns. Journal of Petroleum Technology, 192, 376-379. 
Tanjal, C., Carol, E.S., Richiano, S. y Santucci, L., 2017a. Freshwater lenses as ecological and population sustenance, case study in the coastal wetland of Samborombón Bay (Argentina). Marine Pollution Bulletin, 122, 426-431. https://doi.org/10.1016/j.marpolbul.2017.05.050

Tanjal, C., Santucci, L., Carol, E.S. y Richiano, S., 2017b. Recursos hídricos vs explotación minera: monitoreo de la calidad del agua como base de la gestión de lentes de agua dulce. En: VI Congreso Bianual PROIMCA y IV Congreso Bianual PRODECA, Bahía Blanca.

Tavella, G.F., 2005. Cuenca del Salado. En: de Barrio, R.E., Etcheverry, R.O., Caballé, M.F. y Llambías, E. (Eds.), Geología y Recursos Minerales de la Provincia de Buenos Aires, $16^{\circ}$ Congreso Geológico Argentino, La Plata, Relatorio, 459-472.

Teatini, P., Tosi, L. y Strozzi, T., 2011. Quantitative evidence that compaction of Holocene sediments drives the presently subsidence of the Po Delta, Italy. Journal of Geophysical Research: Solid Earth, 116.

Tejada, M., Carol, E. y Kruse, E., 2011. Límites y potencialidades de las reservas de agua dulce en el humedal de la Bahía de Samborombón, Argentina. Revista de Geología Aplicada a la Ingeniería y al Ambiente, 27, 57-61.

Thornthwaite, C.W. y Mather, J.R., 1957. Instructions and tables for computing potential evapotranspiration and the water balance. Publication in Climatology, 10, 185-311.

Tofalo, O.R., Etchichury, M.C., Fresina, M., 2005. Características texturales y petrofacies de depósitos neógenos, Bancalari, provincia de Buenos Aires. Revista de la Asociación Geológica Argentina, 60, 316-326.

Tosi, L., Rizzetto, F., Zecchin, M., Brancolini, G. y Baradello, L., 2009. Morphostratigraphic framework of the Venice Lagoon (Italy) by very shallow water VHRS surveys: Evidence of radical changes triggered by human-induced river diversions. Geophysical Research Letters, 36.

Tosi, L., Teatini, P. y Strozzi, T., 2013. Natural versus anthropogenic subsidence of Venice. Scientific reports, 3. $10.1038 /$ srep02710

Tóth, J., 1999. Groundwater as a geologic agent: an overview of the causes, processes, and manifestations. Hydrogeology Journal, 7, 1-14.

Violante, R.A. y Parker, G., 2000. El Holoceno en las regiones marinas y costeras del nordeste de la provincia de Buenos Aires. Revista de la Asociación Geológica Argentina, 55, 337-351.

Yrigoyen, M.R., 1975. Geología del subsuelo y plataforma continental. En: Geología de la provincia de Buenos Aires, $6^{\circ}$ Congreso Geológico Argentino, Bahía Blanca, Relatorio, 139-168.

Yrigoyen, M.R., 1999. Los depósitos cretácicos y terciarios de las cuencas del Salado y del Colorado. En: Caminos, R. (Ed.), Geología Argentina. Instituto de Geología y Recursos Minerales - SEGEMAR, Buenos Aires, 645-650.

Zampella, R.A., Bunnell, J.F., Laidig, K.J. y Procopio, N.A., 2010. Aquatic degradation in shallow coastal plain lakes: Gradients or thresholds? Ecological Indicators, 10, 303-310. https://doi.org/10.1016/j.ecolind.2009.06.001 


\section{Muestras de agua analizadas}




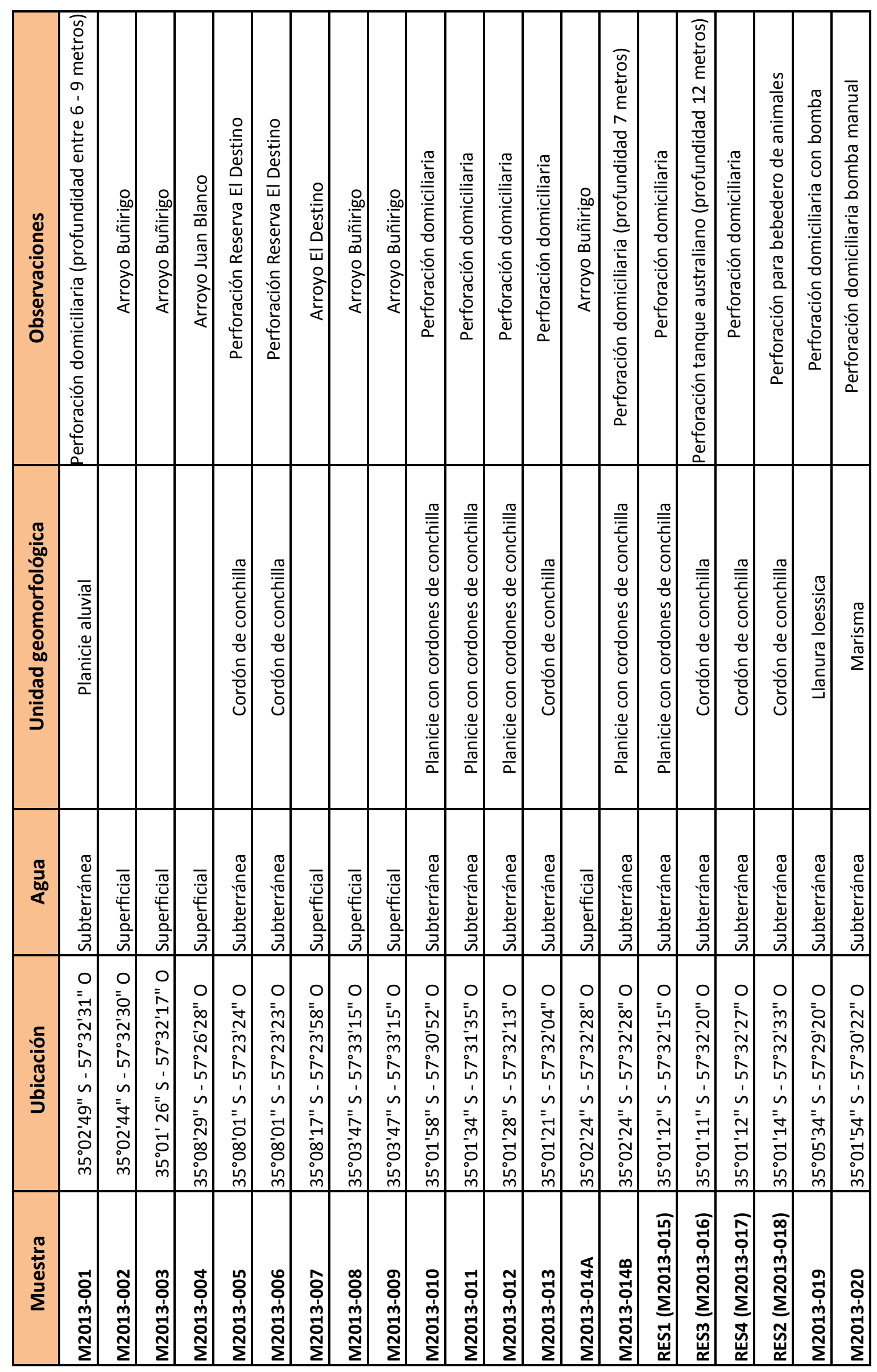



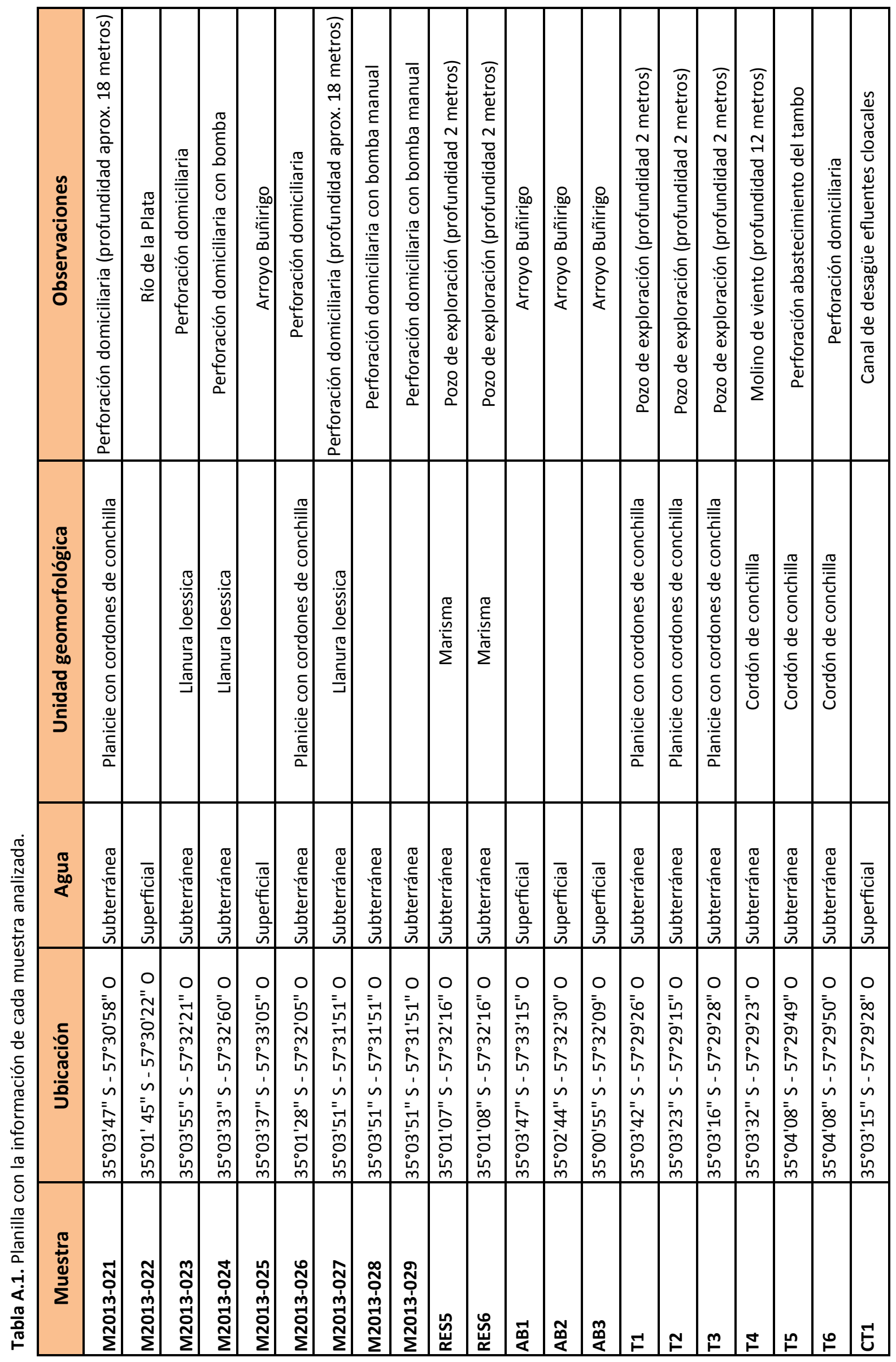


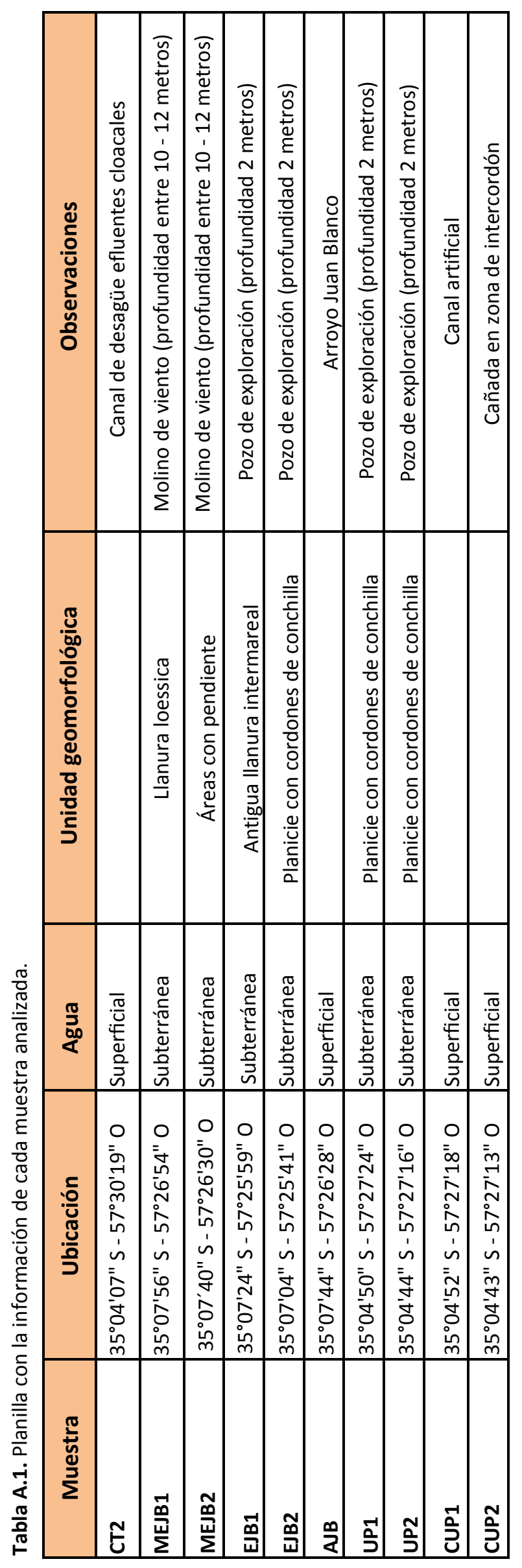




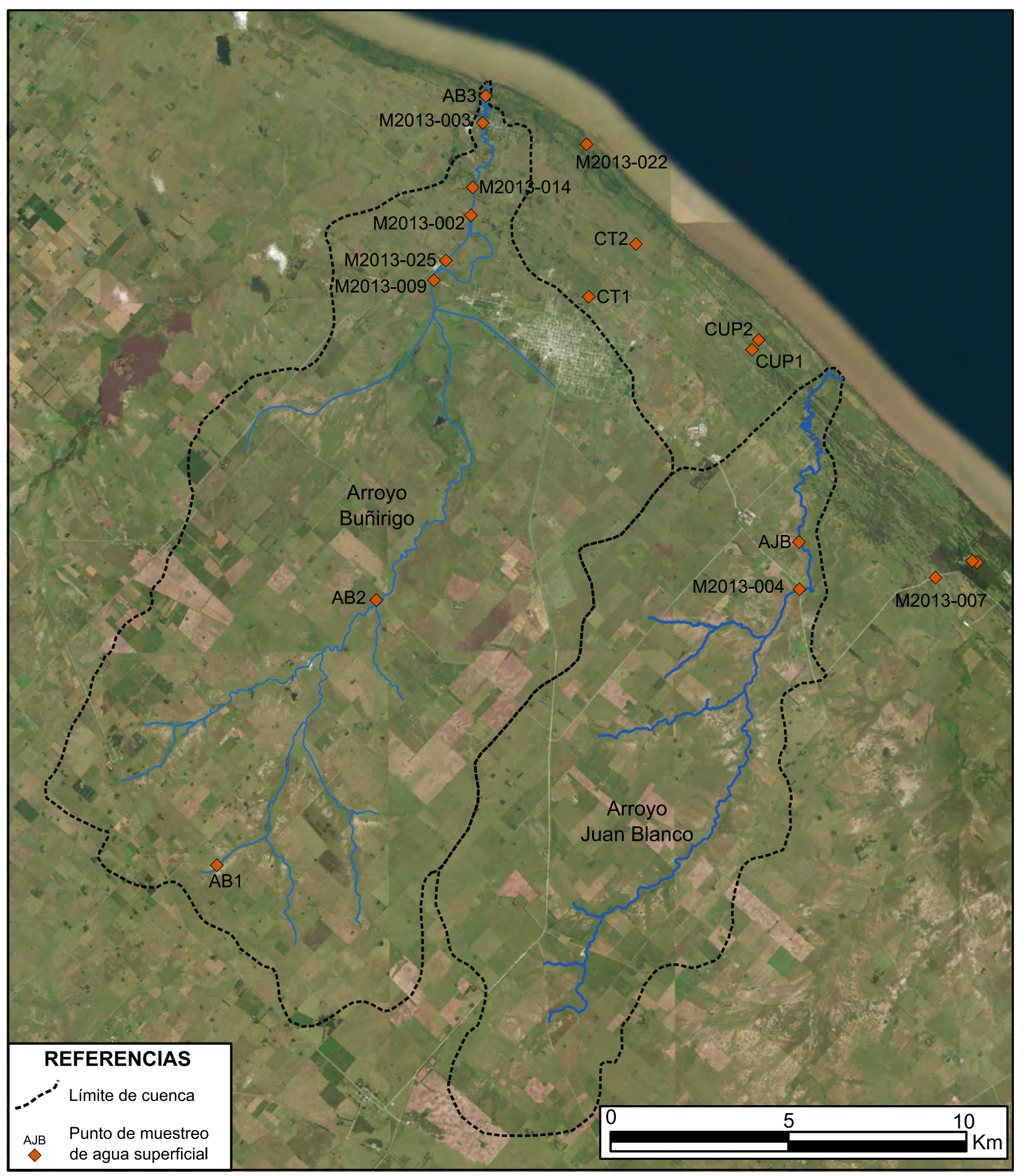

Figura A.1a. Ubicación en el área de estudio de las muestras correspondientes a agua superficial. 


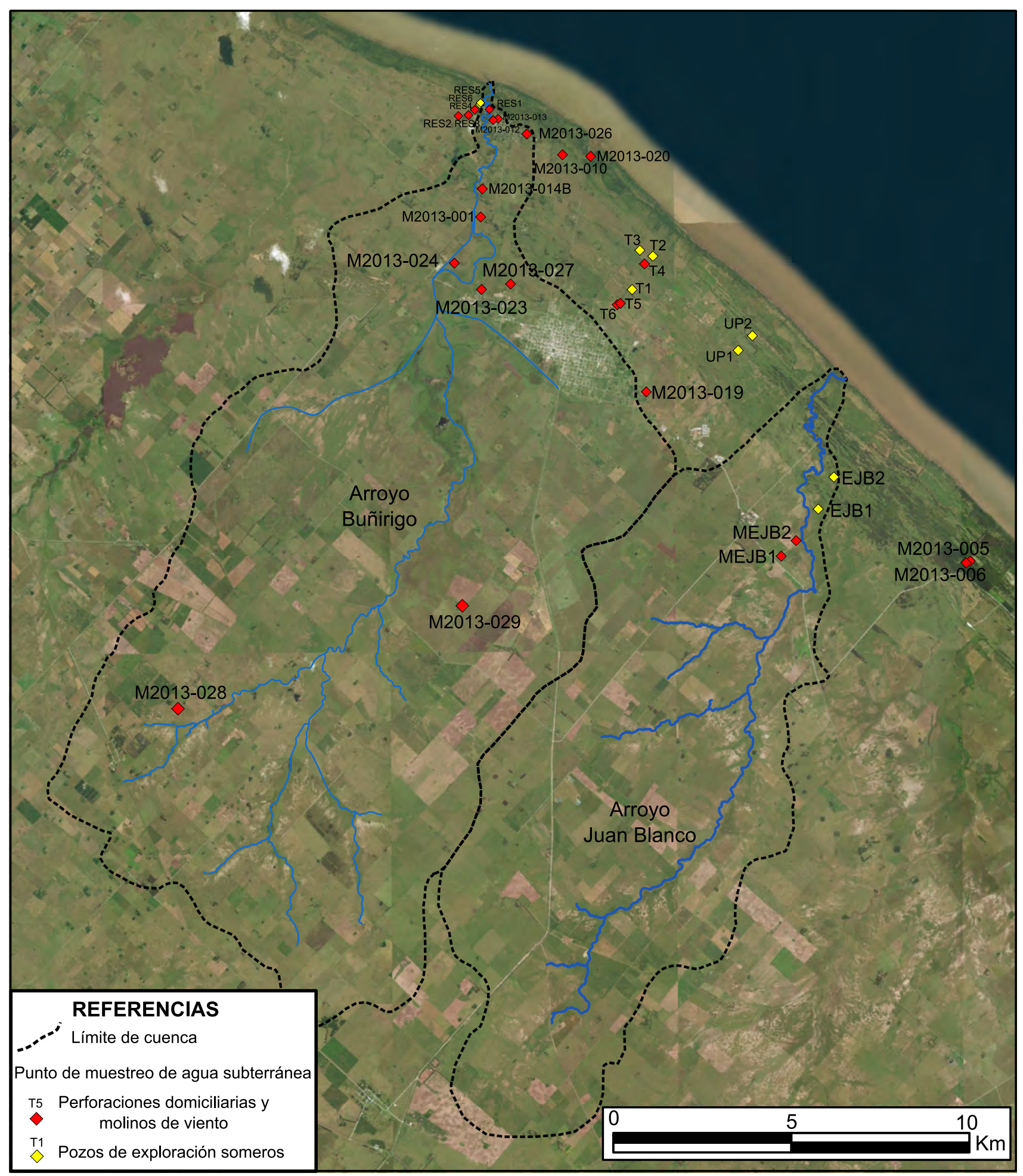

Figura A.1b. Ubicación en el área de estudio de las muestras correspondientes a agua subterránea. 
Tabla A.2a. Valores de la medición in situ de la conductividad eléctrica y temperatura del agua para las muestras recolectadas en el campo en la campaña de marzo de 2013.

\begin{tabular}{|c|c|c|c|c|}
\hline Muestra & Fecha & Hora & Conductividad $(\mu \mathrm{s} / \mathrm{cm})$ & Temperatura $\left({ }^{\circ} \mathrm{C}\right)$ \\
\hline M2013-001 & $22 / 03 / 2013$ & 9:00 & 2300 & 18,4 \\
\hline M2013-002 & $22 / 03 / 2013$ & 9:20 & 6704 & 19,3 \\
\hline M2013-003 & $22 / 03 / 2013$ & 9:35 & 1698 & 19,6 \\
\hline M2013-004 & $22 / 03 / 2013$ & $10: 20$ & 676 & 19,2 \\
\hline M2013-005 & $22 / 03 / 2013$ & $10: 50$ & 440 & 18,8 \\
\hline M2013-006 & $22 / 03 / 2013$ & $11: 00$ & 515 & 18,4 \\
\hline M2013-007 & $22 / 03 / 2013$ & $11: 30$ & 1060 & 19,7 \\
\hline M2013-008 & $22 / 03 / 2013$ & $13: 00$ & 2800 & 19,9 \\
\hline M2013-009 & $28 / 03 / 2013$ & $8: 30$ & 2915 & 18,5 \\
\hline M2013-010 & $28 / 03 / 2013$ & 9:00 & 4240 & 19,5 \\
\hline M2013-011 & $28 / 03 / 2013$ & 9:20 & 3930 & 19,8 \\
\hline M2013-012 & $28 / 03 / 2013$ & $9: 35$ & 1827 & 19,9 \\
\hline M2013-013 & $28 / 03 / 2013$ & 9:50 & 1333 & 19,6 \\
\hline M2013-014A & $28 / 03 / 2013$ & $10: 30$ & 6170 & 21,1 \\
\hline M2013-014B & $28 / 03 / 2013$ & $10: 35$ & 1932 & 19,7 \\
\hline RES1 & $28 / 03 / 2013$ & $11: 30$ & 1292 & 21,1 \\
\hline RES2 & $28 / 03 / 2013$ & $11: 40$ & 1717 & 22,4 \\
\hline RES3 & $28 / 03 / 2013$ & $12: 00$ & 674 & 21,4 \\
\hline RES4 & $28 / 03 / 2013$ & $12: 20$ & 1139 & 20,0 \\
\hline M2013-019 & $28 / 03 / 2013$ & $13: 30$ & 633 & 18,3 \\
\hline M2013-020 & $28 / 03 / 2013$ & $13: 45$ & 2105 & 19,4 \\
\hline M2013-021 & $28 / 03 / 2013$ & $14: 00$ & 7540 & 19,2 \\
\hline M2013-022 & $28 / 03 / 2013$ & $14: 15$ & 599 & 27,7 \\
\hline M2013-023 & $28 / 03 / 2013$ & $14: 40$ & 1161 & 19,3 \\
\hline M2013-024 & $28 / 03 / 2013$ & $15: 00$ & 1905 & 18,3 \\
\hline M2013-025 & $28 / 03 / 2013$ & $15: 20$ & 29300 & 24,3 \\
\hline M2013-026 & $18 / 04 / 2013$ & $10: 30$ & No se pudo medir & No se pudo medir \\
\hline M2013-027 & $18 / 04 / 2013$ & $11: 00$ & 1613 & 19,0 \\
\hline
\end{tabular}




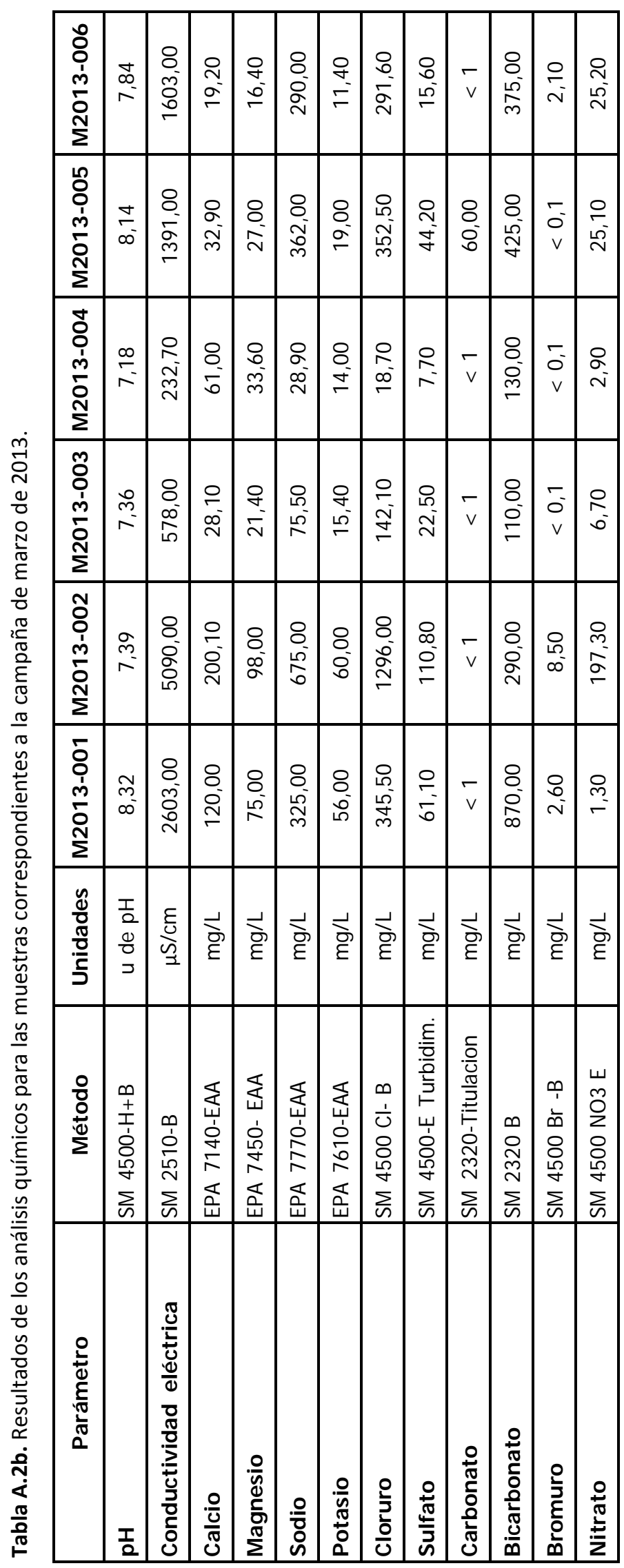




\begin{tabular}{|c|c|c|c|c|c|c|c|c|c|c|c|c|}
\hline 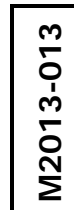 & 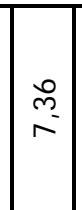 & $\underset{\sim}{\stackrel{g}{q}}$ & $\mid \begin{array}{l}0 \\
0 \\
0 \\
0\end{array}$ & $\mid \begin{array}{c}0 \\
i \\
\infty\end{array}$ & $\mid \begin{array}{l}\tilde{n} \\
\tilde{m}\end{array}$ & in & $\left|\begin{array}{l}0 \\
\stackrel{0}{0} \\
-1\end{array}\right|$ & $\begin{array}{l}-1 \\
m \\
m\end{array}$ & $\vec{v}$ & $\begin{array}{l}: \\
0 \\
0\end{array}$ & $\begin{array}{l}-1 \\
0 \\
v\end{array}$ & $\vec{i}$ \\
\hline 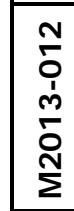 & $\mid \begin{array}{l}0 \\
\stackrel{0}{\wedge}\end{array}$ & $\begin{array}{l}m \\
\stackrel{M}{G}\end{array}$ & 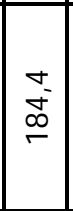 & $\begin{array}{l}0 \\
\infty \\
\infty\end{array}$ & $\mid \begin{array}{l}0 \\
0 \\
i\end{array}$ & in & $\left|\begin{array}{l}0 \\
\infty \\
\\
\text { N }\end{array}\right|$ & $\mid \begin{array}{c}\sim \\
\infty \\
\infty\end{array}$ & $\vec{v}$ & 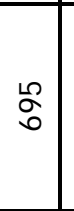 & $\begin{array}{l}- \\
0 \\
0 \\
v\end{array}$ & $\stackrel{m}{i}$ \\
\hline 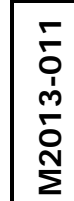 & $\stackrel{\sim}{\sim}$ & 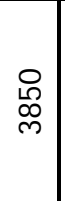 & $\mid \begin{array}{l}\mathbb{d} \\
\underset{\sim}{d}\end{array}$ & 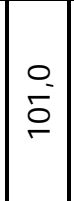 & $\mid \begin{array}{l}0 \\
\hat{g} \\
\forall\end{array}$ & $\approx$ & $\begin{array}{l}0 \\
i \\
i\end{array}$ & $\mid \begin{array}{l}0 \\
\stackrel{0}{\sim} \\
\tilde{N}\end{array}$ & $\vec{v}$ & 8 & $\stackrel{\infty}{\sim}$ & $\stackrel{+}{\underset{*}{*}}$ \\
\hline 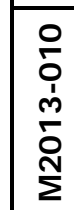 & $\stackrel{\widetilde{N}}{\stackrel{2}{n}}$ & $\frac{q}{7}$ & $\left|\begin{array}{c}m \\
\mathcal{N} \\
\end{array}\right|$ & $\hat{g}$ & $\left|\begin{array}{c}0 \\
\tilde{N} \\
\infty \\
\infty\end{array}\right|$ & $\mid \begin{array}{l}0 \\
\dot{0}\end{array}$ & $\begin{array}{l}0 \\
\stackrel{\sim}{\sim} \\
\exists\end{array}$ & $\mid \begin{array}{c}m \\
\tilde{p}_{m} \\
m\end{array}$ & $\vec{v}$ & $\begin{array}{l}\stackrel{\infty}{\infty} \\
\infty\end{array}$ & $\begin{array}{l}0 \\
\text { in }\end{array}$ & \begin{tabular}{l}
$\stackrel{\Perp}{f}$ \\
\multirow{f}{*}{}
\end{tabular} \\
\hline 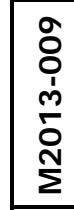 & 员 & 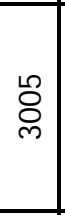 & $\mid \begin{array}{c}v \\
\tilde{Z} \\
\vec{F}\end{array}$ & $\mid \begin{array}{c}0 \\
\tilde{y} \\
\infty\end{array}$ & 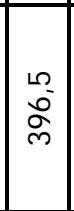 & $\begin{array}{l}0 \\
\text { 定 }\end{array}$ & $\left|\begin{array}{c}0 \\
0 \\
0 \\
\wedge\end{array}\right|$ & 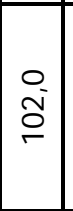 & $\vec{v}$ & 吕 & $\stackrel{\mathscr{f}}{+}$ & $\mid \begin{array}{c}m \\
\tilde{m}\end{array}$ \\
\hline 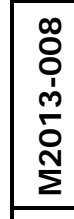 & $\stackrel{\substack{m \\
\sim}}{=}$ & \begin{tabular}{l}
0 \\
\multirow{N}{*}{}
\end{tabular} & 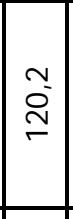 & $\begin{array}{l}\circ \\
\stackrel{9}{1}\end{array}$ & $\left|\begin{array}{c}\hat{a} \\
\hat{n} \\
\stackrel{n}{n}\end{array}\right|$ & $\mid \begin{array}{l}0 \\
\text { 㟔 }\end{array}$ & $\begin{array}{l}0 \\
0 \\
n \\
n\end{array} \mid$ & $\left|\begin{array}{c}0 \\
\overrightarrow{1} \\
\infty\end{array}\right|$ & $\vec{v}$ & 品 & $\stackrel{0}{\dot{m}_{i}}$ & 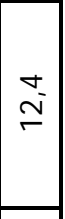 \\
\hline $\begin{array}{l}\frac{y}{0} \\
\frac{\pi}{0} \\
\frac{0}{5} \\
5\end{array}$ & $\begin{array}{l}\frac{T}{0} \\
\frac{D}{0} \\
J\end{array}$ & $\begin{array}{l}\underline{\Xi} \\
\text { जิ }\end{array}$ & ज्ञ & छे & जे & छे & ज़ & जे & ज्ञा & जे & ही & ज्ञ \\
\hline $\begin{array}{l}\frac{0}{8} \\
\frac{\pi}{2} \\
\end{array}$ & 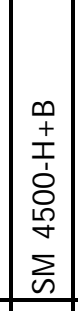 & 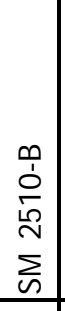 & 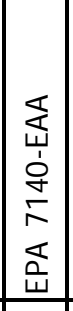 & 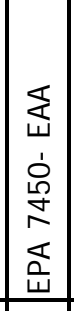 & 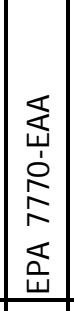 & 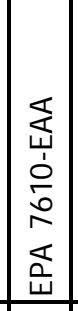 & 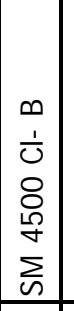 & 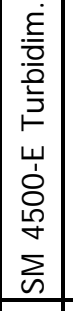 & 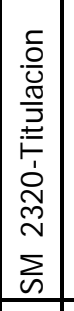 & $\begin{array}{l} \\
\infty \\
0 \\
\tilde{N} \\
N \\
\sum_{n} \\
\end{array}$ & 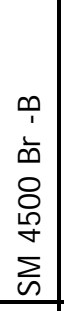 & 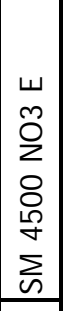 \\
\hline 0 & $\frac{1}{2}$ & 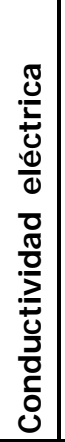 & $\begin{array}{l}\frac{0}{\mathrm{U}} \\
\frac{\mathrm{U}}{\mathrm{U}}\end{array}$ & 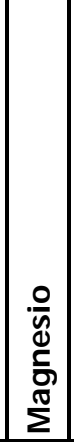 & $\mid \begin{array}{l}0 \\
\frac{0}{8} \\
0\end{array}$ & 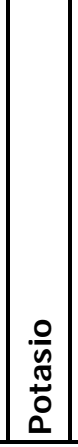 & $\begin{array}{l}0 \\
\frac{0}{2} \\
\frac{0}{U}\end{array} \mid$ & $\left|\begin{array}{c}0 \\
\frac{2}{0} \\
\bar{v} \\
\bar{n}\end{array}\right|$ & 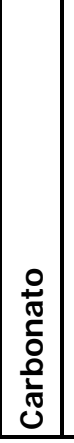 & $\begin{array}{l}\frac{8}{0} \\
\frac{0}{0} \\
\frac{8}{0} \\
\frac{0}{0} \\
\frac{0}{0}\end{array}$ & & $\begin{array}{l}0 \\
\stackrel{0}{0} \\
\frac{\mathbf{z}}{\mathbf{z}}\end{array}$ \\
\hline
\end{tabular}




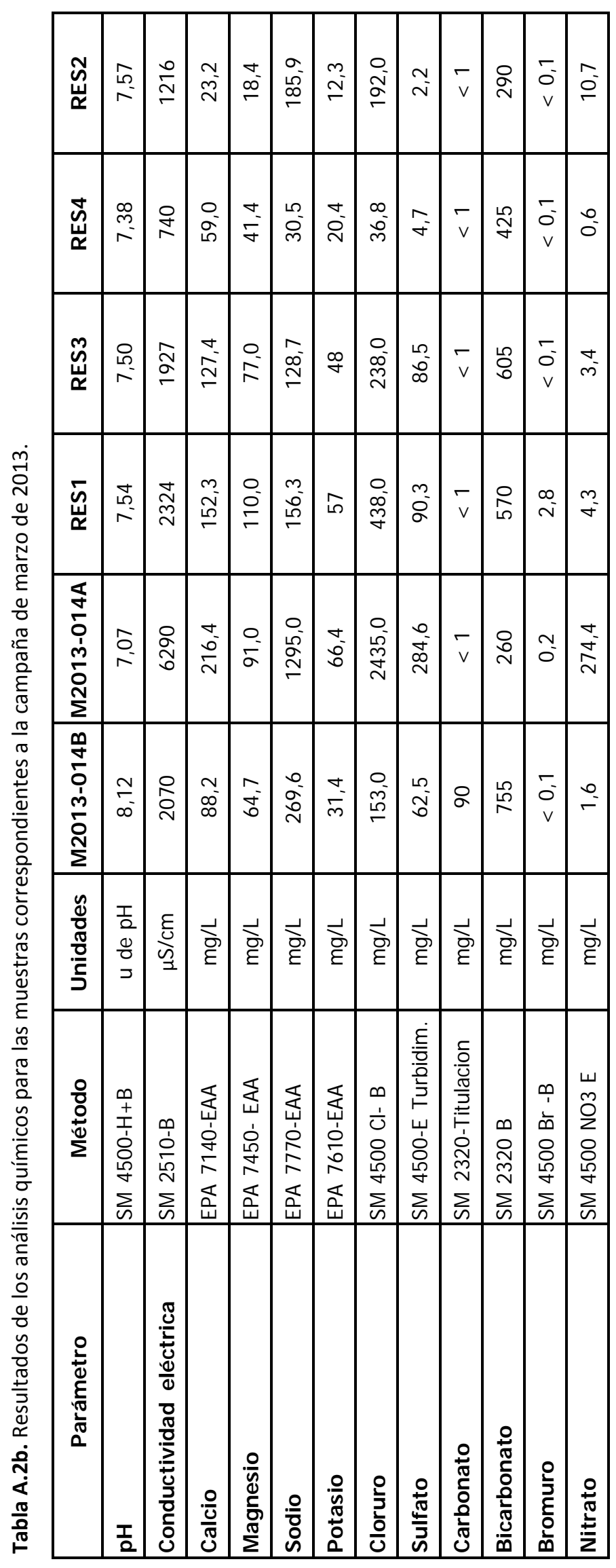




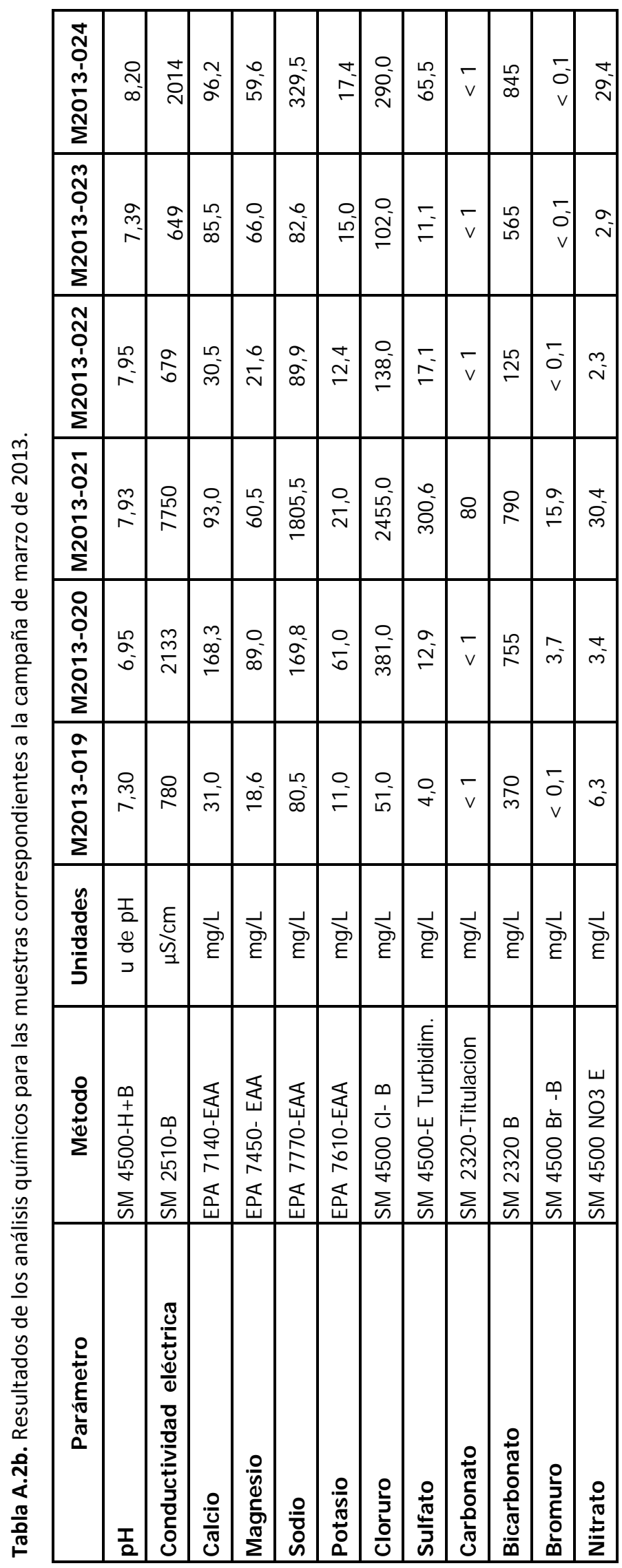




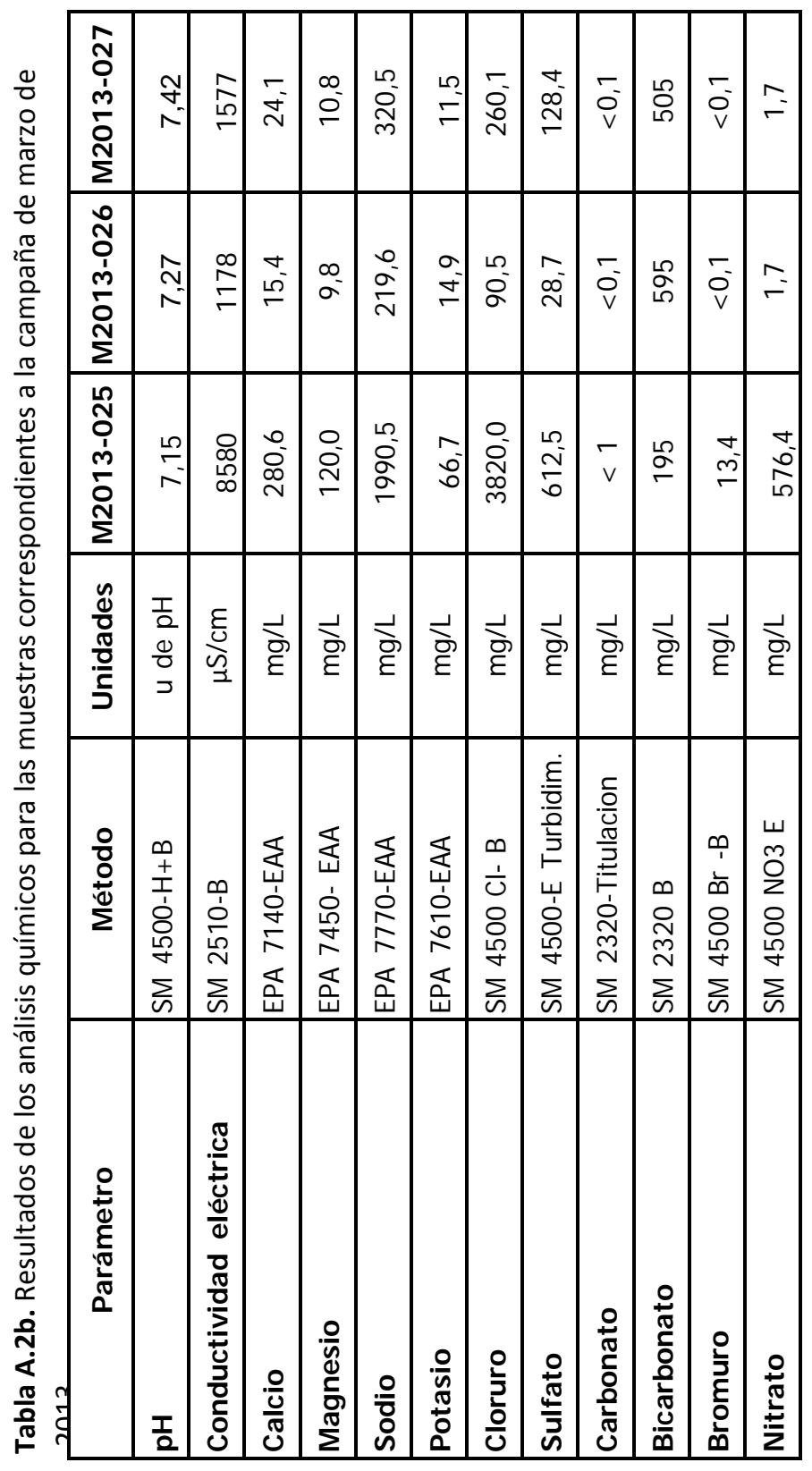




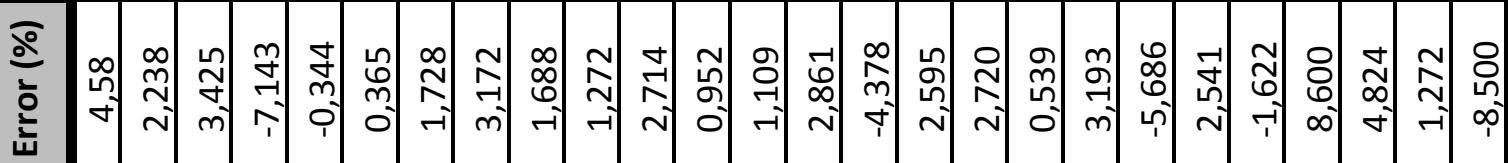

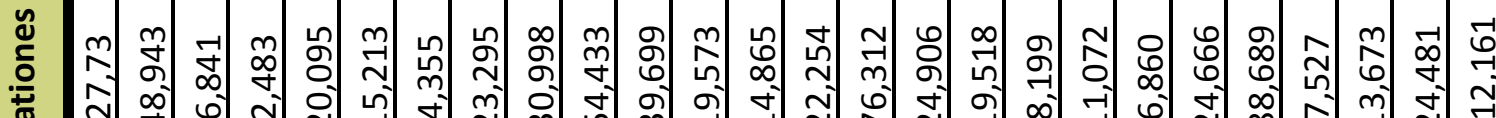

తั

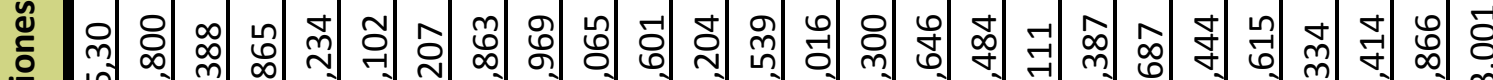
ஸे

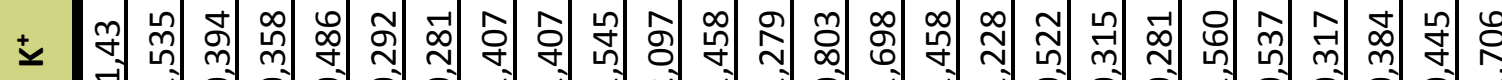

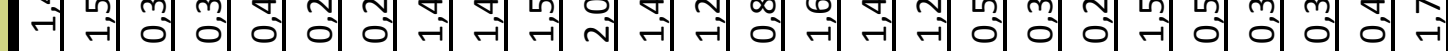

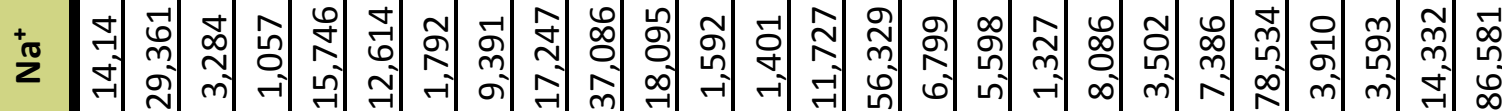

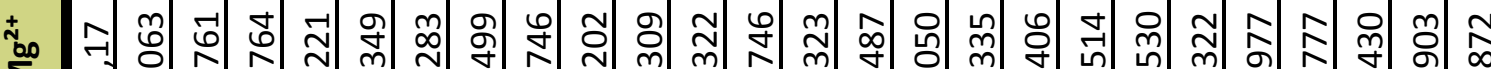

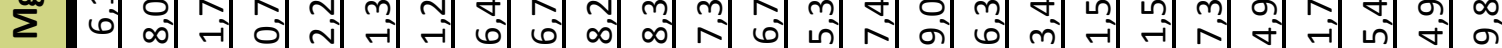

స ন

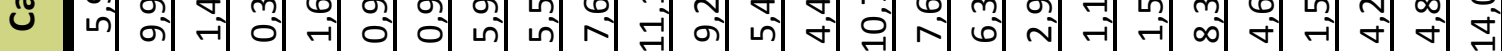

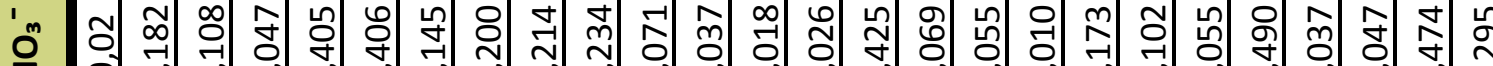

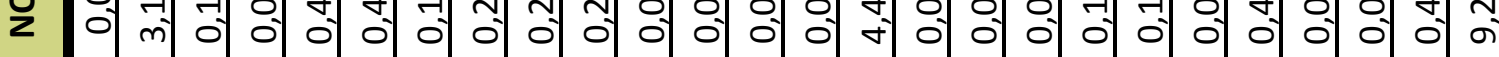

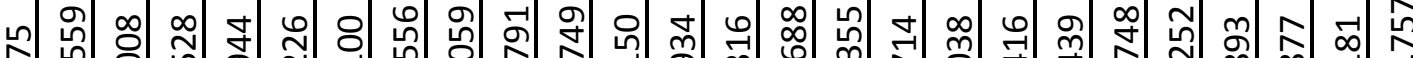

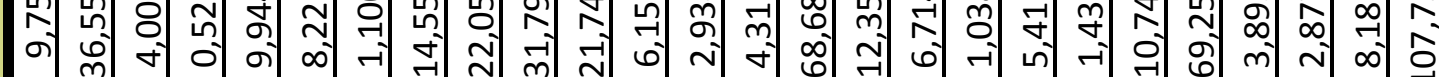

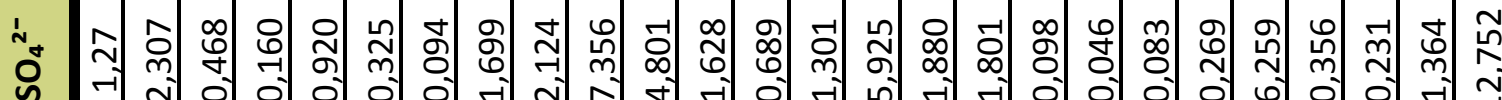

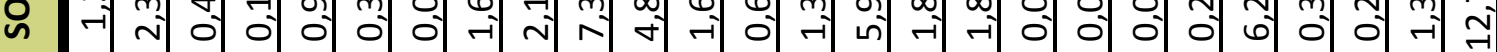

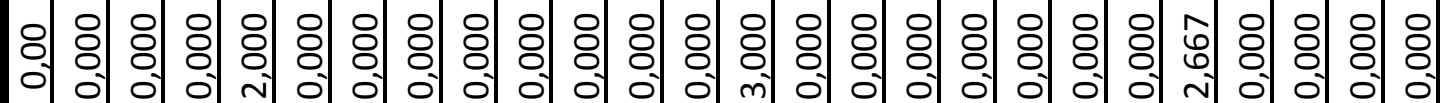

'́m

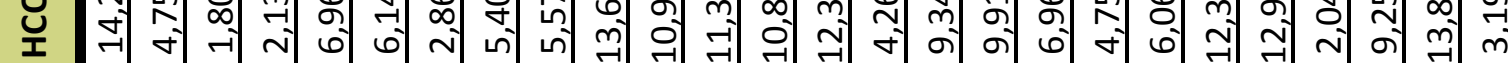




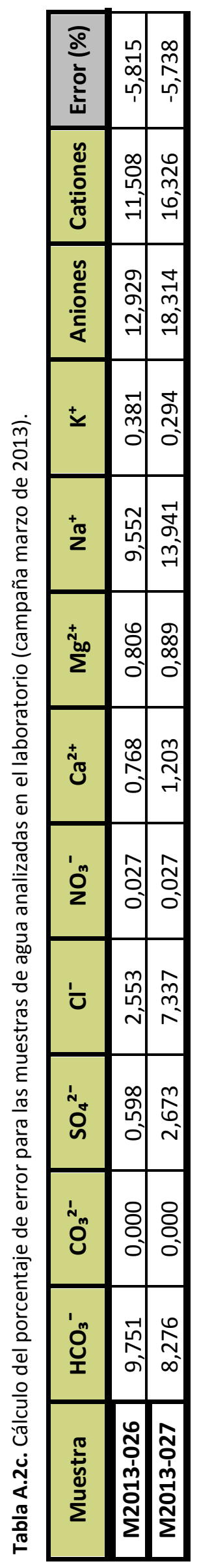




\section{ANEXO III}

\section{Muestras de agua campaña 2014}


Tabla A.3a. Valores de la medición in situ de la conductividad eléctrica y temperatura de agua para las muestras recolectadas en el campo en la campaña de abril de 2014.

\begin{tabular}{|c|c|c|c|c|}
\hline Muestra & Fecha & Hora & Conductividad $(\mu \mathrm{s} / \mathrm{cm})$ & Temperatura $\left({ }^{\circ} \mathrm{C}\right)$ \\
\hline$\overline{\mathrm{T} 1}$ & $04 / 04 / 2014$ & $8: 30$ & 1420 & 19,1 \\
\hline$\overline{T 2}$ & $04 / 04 / 2014$ & 9:40 & 2925 & 19,3 \\
\hline T3 & $04 / 04 / 2014$ & $11: 00$ & 1360 & 19,7 \\
\hline T4 & $14 / 04 / 2014$ & $10: 49$ & 2067 & 18,8 \\
\hline T5 & $14 / 04 / 2014$ & $11: 30$ & 2669 & 18,6 \\
\hline T6 & $14 / 04 / 2014$ & $11: 40$ & 1974 & 18,4 \\
\hline CT1 & $04 / 04 / 2014$ & $11: 30$ & 1216 & 19,9 \\
\hline CT2 & $14 / 04 / 2014$ & $12: 15$ & 1002 & 19,6 \\
\hline MEJB1 & $14 / 04 / 2014$ & $13: 00$ & 1164 & 18,3 \\
\hline MEJB2 & $14 / 04 / 2014$ & $13: 25$ & 4240 & 19,5 \\
\hline AJB & $14 / 04 / 2014$ & $13: 45$ & 175 & 15,0 \\
\hline EJB1 & $14 / 04 / 2014$ & $14: 00$ & 1976 & 19,2 \\
\hline EJB2 & $14 / 04 / 2014$ & $14: 15$ & 1747 & 18,9 \\
\hline AB1 & $15 / 04 / 2014$ & 8:05 & 433 & 13,6 \\
\hline AB2 & $15 / 04 / 2014$ & $8: 28$ & 700 & 13,9 \\
\hline AB3 & $15 / 04 / 2014$ & $8: 45$ & 730 & 15,1 \\
\hline UP1 & $15 / 04 / 2014$ & $10: 30$ & 6045 & 19,7 \\
\hline UP2 & $15 / 04 / 2014$ & $12: 50$ & 6730 & 19,3 \\
\hline CUP1 & $15 / 04 / 2014$ & $11: 30$ & 776 & 15,1 \\
\hline CUP2 & $15 / 04 / 2014$ & $13: 00$ & 1000 & 21,9 \\
\hline RES3 & $15 / 04 / 2014$ & $13: 45$ & 1070 & 20,3 \\
\hline RES5 & $15 / 04 / 2014$ & $14: 00$ & 654 & 19,1 \\
\hline RES6 & $15 / 04 / 2014$ & $14: 15$ & 890 & 19,4 \\
\hline RES4 & $15 / 04 / 2014$ & $14: 30$ & 880 & 19,2 \\
\hline
\end{tabular}




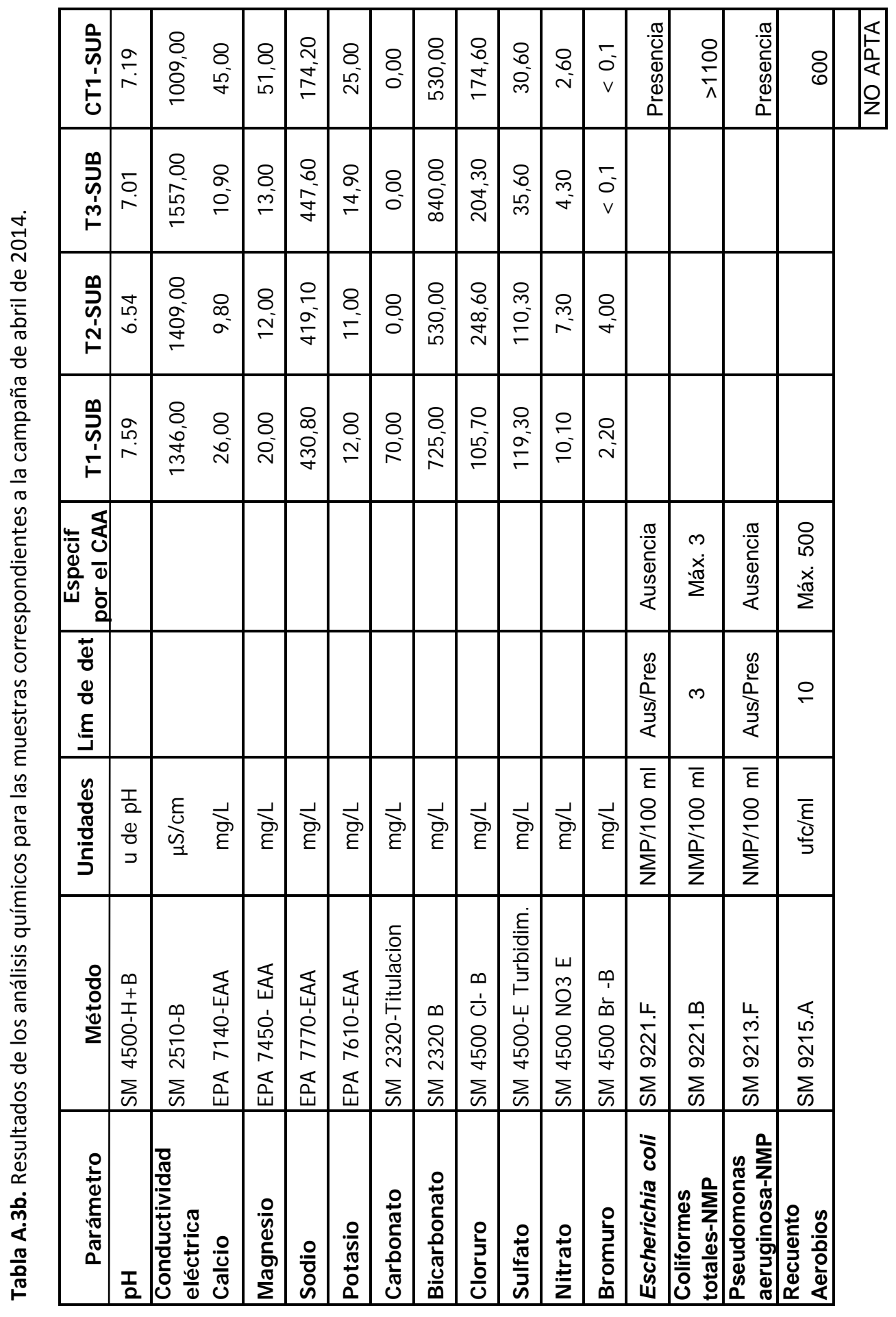




\begin{tabular}{|c|c|c|c|c|c|c|c|c|c|c|c|c|c|c|c|c|c|}
\hline 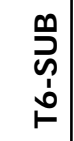 & $\begin{array}{l}-7 \\
-1 \\
\infty\end{array}$ & $\begin{array}{l}\text { \& } \\
\text { ì } \\
\text { ì }\end{array}$ & $\begin{array}{l}8 \\
\text { Nं } \\
\text { N }\end{array}$ & $\begin{array}{l}8 \\
0 \\
0\end{array}$ & $\begin{array}{l}\stackrel{\Upsilon}{N} \\
\tilde{N} \\
\end{array}$ & $\begin{array}{l}8 \\
\infty^{0} \\
-1\end{array}$ & $\begin{array}{l}8 \\
8 \\
\infty\end{array}$ & $\begin{array}{l}8 \\
\text { ñ } \\
\text { กn }\end{array}$ & $\begin{array}{l}8 \\
\\
\\
\end{array}$ & 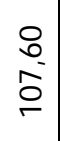 & \begin{tabular}{l}
$\infty$ \\
$⿱ 亠 䒑$ \\
\cline { 1 - 1 }
\end{tabular} & $\begin{array}{l}\stackrel{0}{1} \\
\text { o }\end{array}$ & & & & & \\
\hline 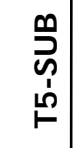 & $\stackrel{\stackrel{n}{\sim}}{r}$ & $\begin{array}{l}8 \\
\infty 0 \\
00 \\
0 \\
\text { O }\end{array}$ & $\begin{array}{l}8 \\
\dot{0} \\
\text { v }\end{array}$ & 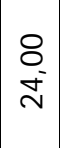 & 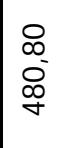 & $\begin{array}{l}8 \\
\infty 0^{-}\end{array}$ & $\begin{array}{l}8 \\
0\end{array}$ & $\begin{array}{l}8 \\
\text { ñ }\end{array}$ & 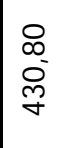 & 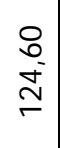 & \begin{tabular}{l}
8 \\
\hdashline \\
$\dot{9}$
\end{tabular} & $\begin{array}{l}\stackrel{?}{1} \\
\text { o }\end{array}$ & 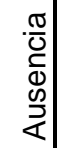 & $\tilde{v}$ & 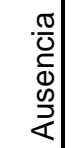 & 이 & $\mid \begin{array}{l}\mathbb{E} \\
\frac{Q}{\alpha}\end{array}$ \\
\hline 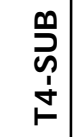 & $\stackrel{\vec{m}}{r}$ & $\begin{array}{l}8 \\
80 \\
8 \\
0\end{array}$ & $\begin{array}{l}8 \\
0 \\
i\end{array}$ & $\begin{array}{l}8 \\
\text { ஸి }\end{array}$ & $\begin{array}{l}8 \\
\mathbb{8} \\
\stackrel{\mathbb{N}}{N}\end{array}$ & $\begin{array}{l}8 \\
i \\
-i\end{array}$ & $\begin{array}{l}8 \\
0 \\
0\end{array}$ & $\begin{array}{l}8 \\
\text { ஸn } \\
\text { กn }\end{array}$ & $\begin{array}{l}8 \\
\text { 志 } \\
\text { }\end{array}$ & $\begin{array}{l}\mathbb{8} \\
\stackrel{+}{+} \\
-\end{array}$ & $\begin{array}{l}8 \\
\text { in }\end{array}$ & $\begin{array}{l}8 \\
8\end{array}$ & & & & & \\
\hline $\begin{array}{l}\stackrel{0}{\vec{n}} \\
\stackrel{u}{\dot{n}} \\
\tilde{\mathrm{c}}\end{array}$ & $\underset{i}{\stackrel{0}{r}}$ & $\begin{array}{l}8 \\
\text { Oे } \\
\text { o } \\
\text { Oे }\end{array}$ & $\begin{array}{l}8 \\
\varphi^{-} \\
\end{array}$ & $\begin{array}{l}8 \\
0 \\
\text { ட }\end{array}$ & $\mid \begin{array}{l}0 \\
-1 \\
0 \\
0 \\
-1\end{array}$ & $\begin{array}{l}8 \\
\text { ஸे }\end{array}$ & $\begin{array}{l}8 \\
0\end{array}$ & $\begin{array}{l}8 \\
\text { ஸ் } \\
\text { o }\end{array}$ & 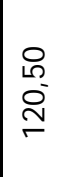 & $\begin{array}{l}8 \\
8 \\
\text { m }\end{array}$ & $\begin{array}{l}\stackrel{\sim}{N} \\
\stackrel{1}{*}\end{array}$ & $\begin{array}{l}\tilde{1} \\
0 \\
\mathrm{v}\end{array}$ & 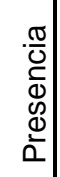 & $\begin{array}{l}8 \\
\stackrel{-}{-1} \\
\stackrel{1}{\wedge}\end{array}$ & 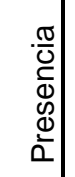 & 요 & $\mid \begin{array}{l}\varangle \\
\frac{E}{2} \\
\frac{\alpha}{\alpha} \\
0 \\
z\end{array}$ \\
\hline 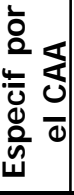 & & & & & & & & & & & & & 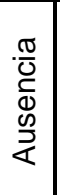 & $\begin{array}{l}m \\
\dot{x} \\
\stackrel{\times}{\Sigma}\end{array}$ & $\begin{array}{l}\frac{\pi}{0} \\
\frac{\pi}{0} \\
\frac{\omega}{2}\end{array}$ & 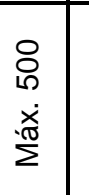 & \\
\hline 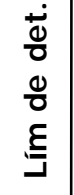 & & & & & & & & & & & & & 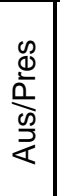 & $m$ & 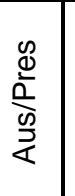 & 위 & \\
\hline $\begin{array}{l}y \\
\frac{y}{0} \\
\frac{\pi}{0} \\
\frac{0}{5} \\
5\end{array}$ & $\begin{array}{l}\frac{T}{\partial} \\
0 \\
0 \\
\end{array}$ & $\frac{\xi}{\tilde{v}}$ & के & $\overrightarrow{\mathrm{g}}$ & हे & ఫे & ठे & छे & के & ఫे & के & के & 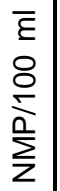 & $\begin{array}{l}\bar{\varepsilon} \\
8 \\
\stackrel{-1}{\alpha} \\
\sum_{z}\end{array}$ & 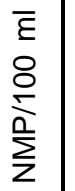 & $\begin{array}{l}\bar{\xi} \\
\frac{0}{J}\end{array}$ & \\
\hline $\begin{array}{l}0 \\
8 \\
8 \\
\Sigma \\
\Sigma\end{array}$ & 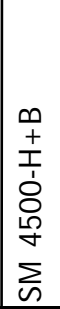 & $\begin{array}{l}\infty \\
\text { ○े } \\
\text { ஸ્1 } \\
\stackrel{N}{N} \\
\sum_{n}\end{array}$ & 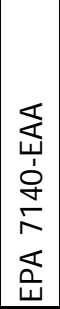 & 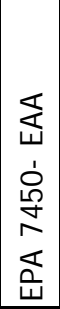 & 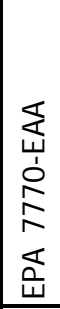 & 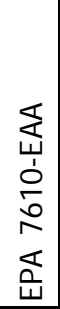 & 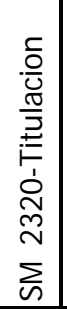 & $\begin{array}{l}\infty \\
\stackrel{\infty}{N} \\
\underset{N}{N} \\
\sum_{n}\end{array}$ & 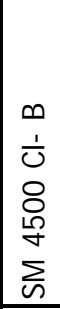 & 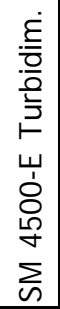 & 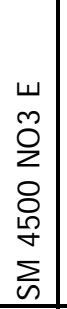 & 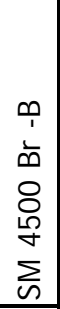 & $\begin{array}{l}\stackrel{L}{-} \\
\stackrel{-}{N} \\
\delta \\
\sum_{\infty}\end{array}$ & $\begin{array}{l}\infty \\
\stackrel{n}{N} \\
\sum_{\omega}\end{array}$ & $\begin{array}{l}\stackrel{\sqcup}{M} \\
\stackrel{N}{N} \\
\sum_{\omega}\end{array}$ & 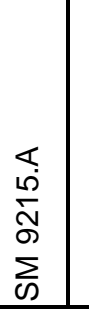 & \\
\hline 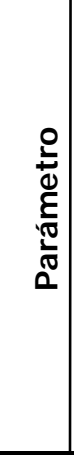 & $\frac{I}{2}$ & 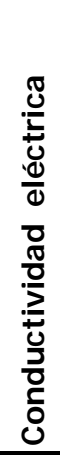 & $\frac{\frac{0}{U}}{\frac{U}{U}}$ & $\begin{array}{l}\frac{o}{y} \\
\frac{5}{5} \\
\frac{\pi}{\Sigma} \\
\sum\end{array}$ & 응 & $\begin{array}{l}0 \\
\frac{0}{5} \\
\text { ¿ँ } \\
0\end{array}$ & 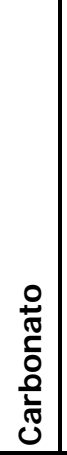 & 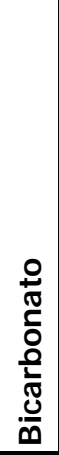 & $\begin{array}{l}\frac{o}{2} \\
\frac{1}{0} \\
\text { v }\end{array}$ & $\begin{array}{l}\frac{8}{0} \\
\frac{c}{5} \\
\hat{n}\end{array}$ & $\begin{array}{l}8 \\
\frac{8}{5} \\
\frac{5}{z}\end{array}$ & 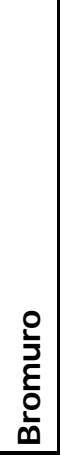 & 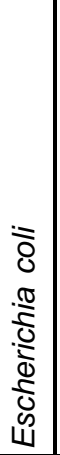 & 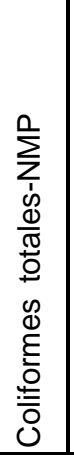 & 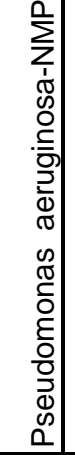 & 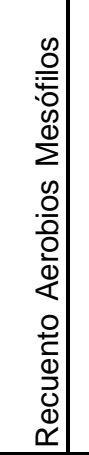 & \\
\hline
\end{tabular}




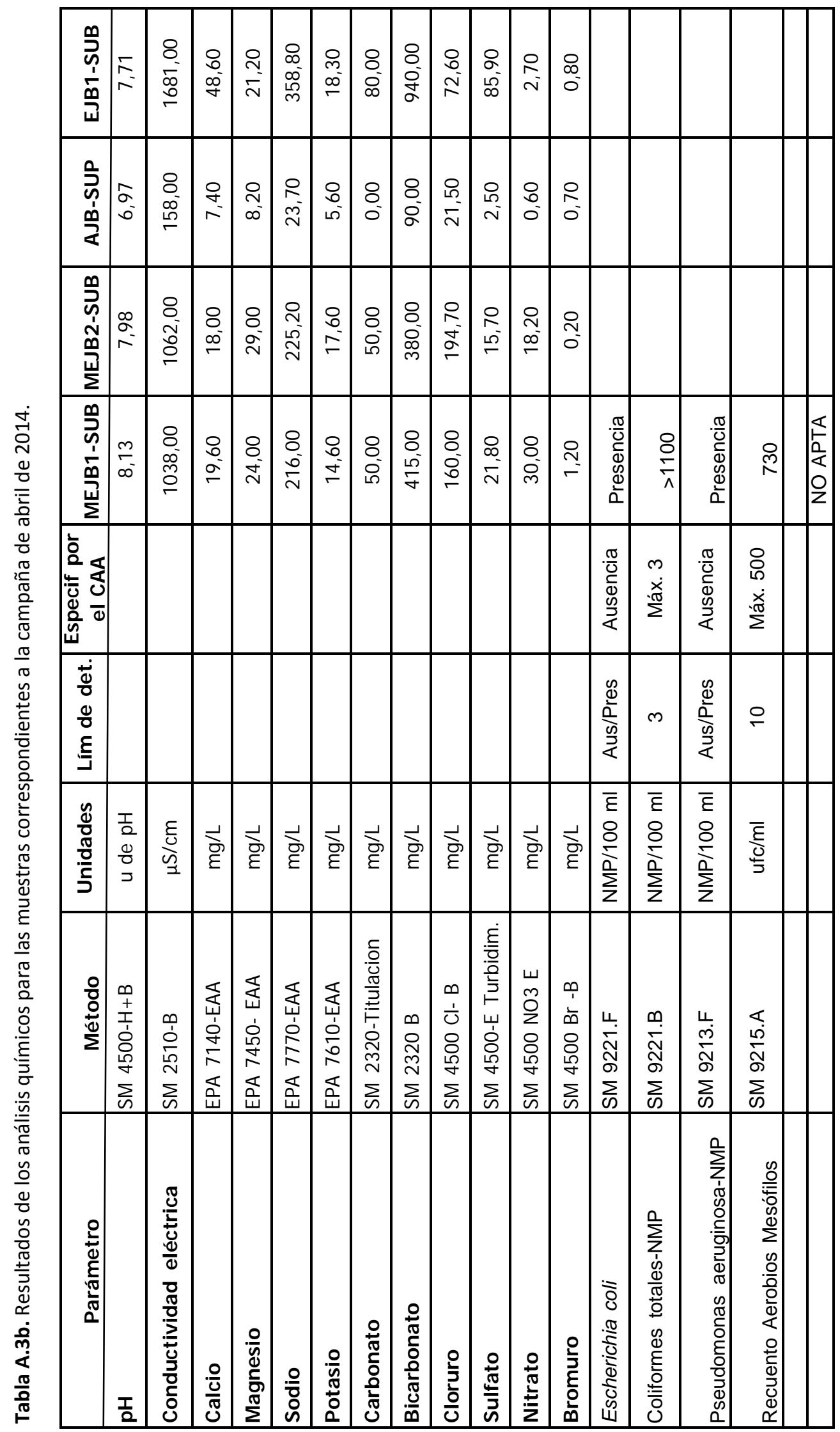




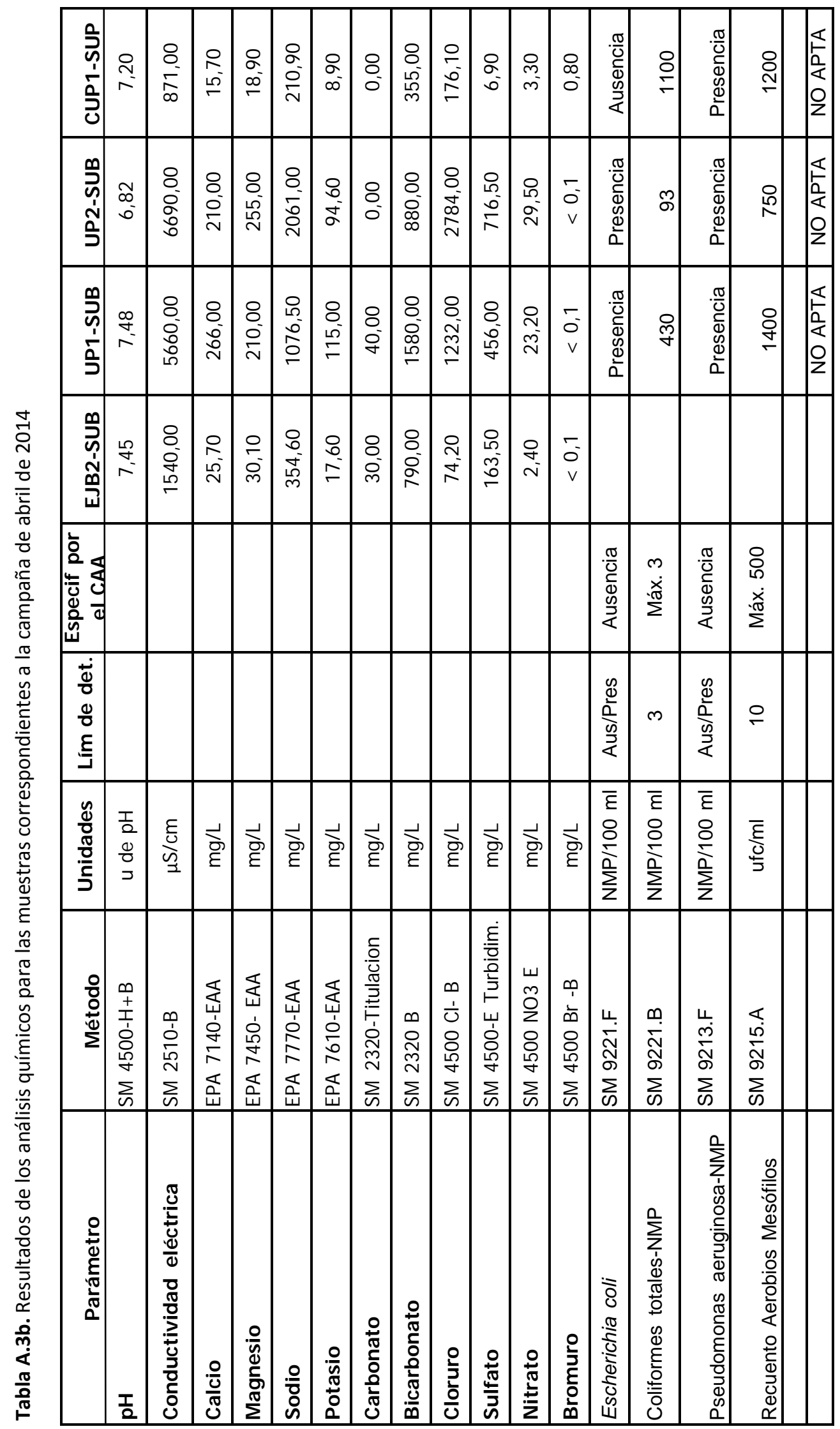




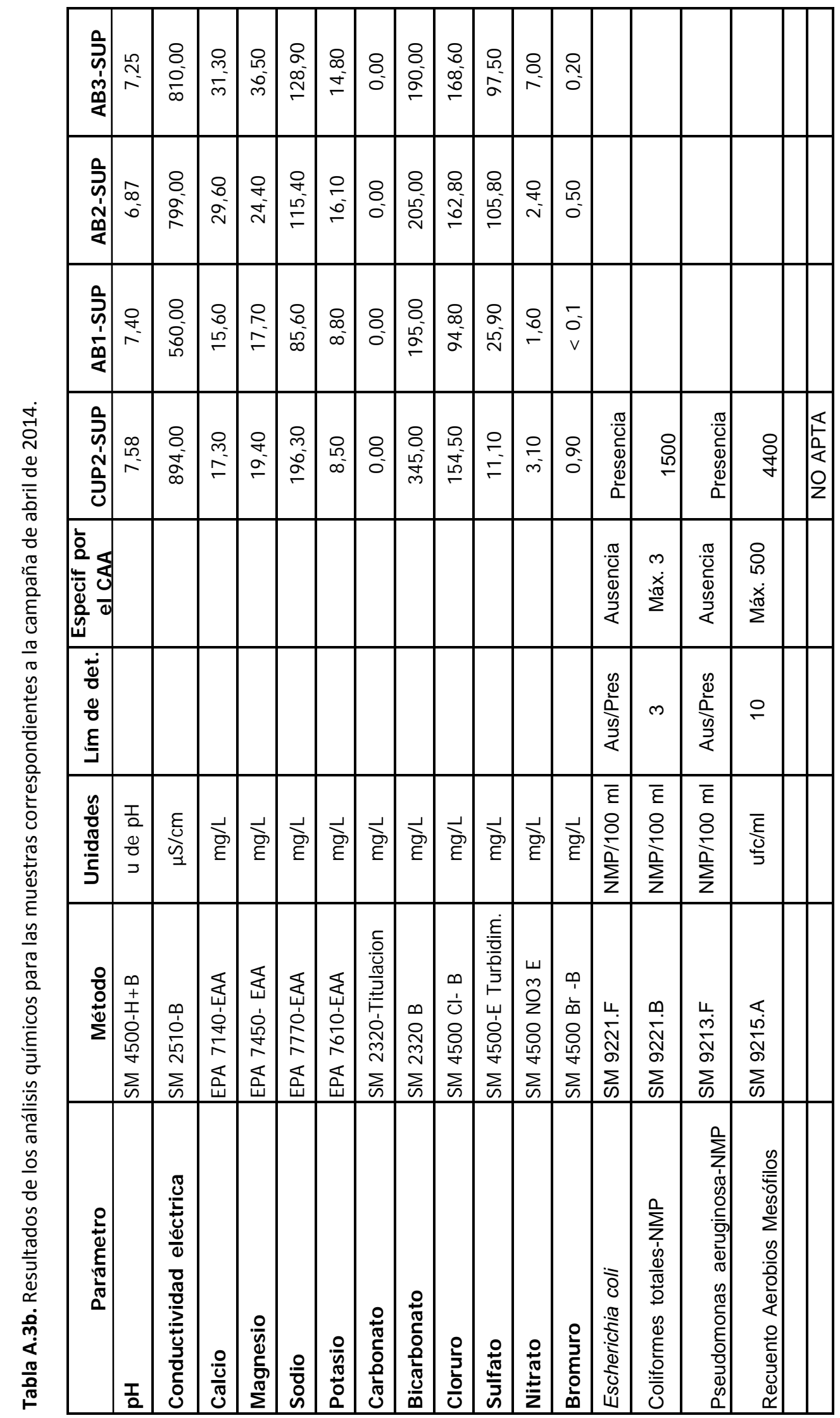




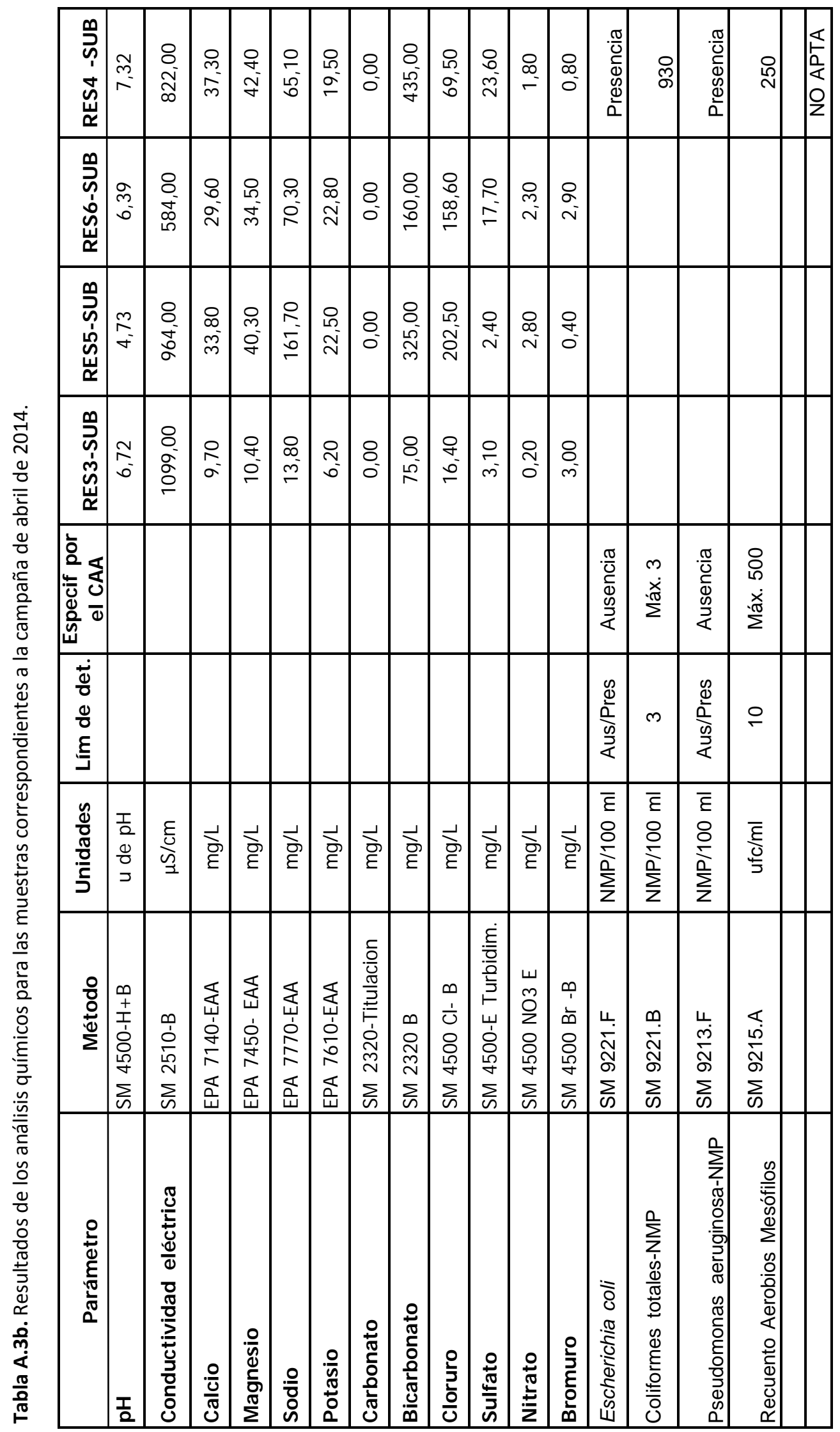




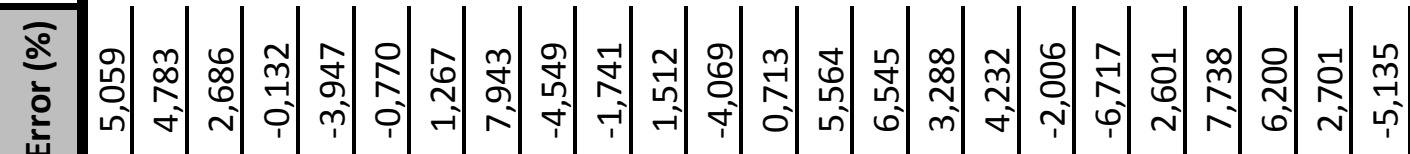

峁

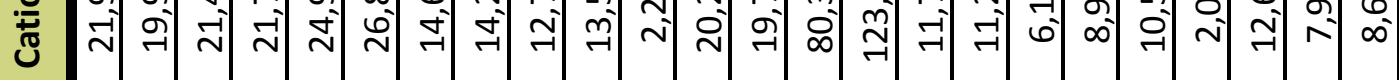

总

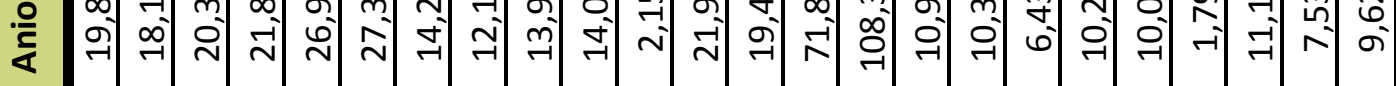

'心

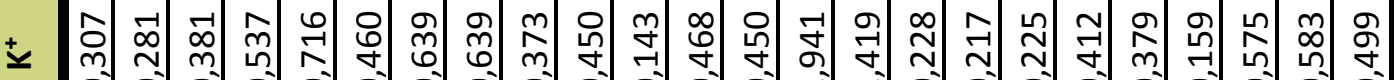

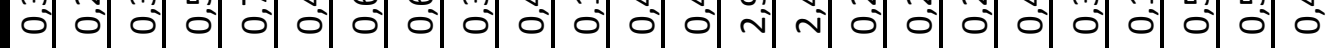

+

z

ڤ

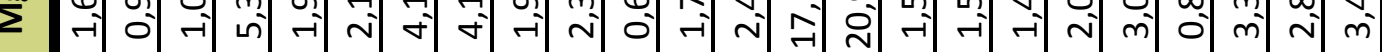

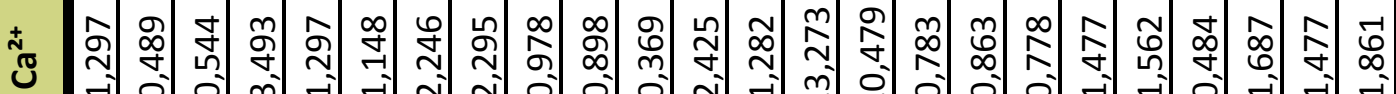

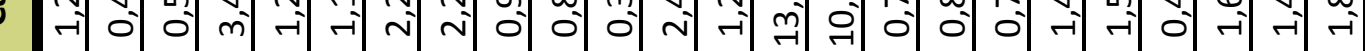

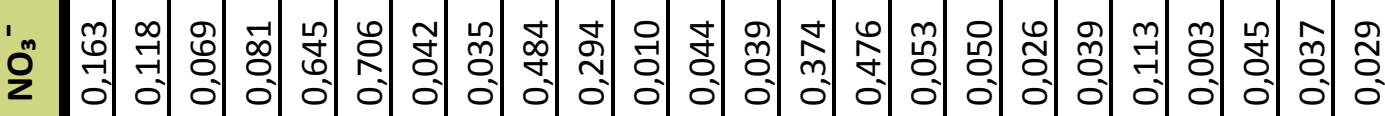

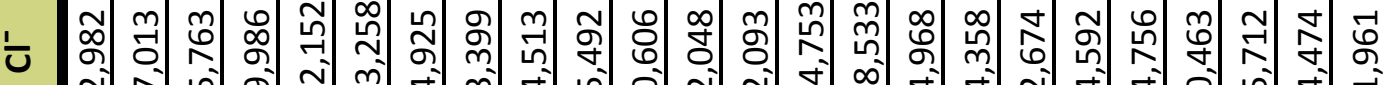

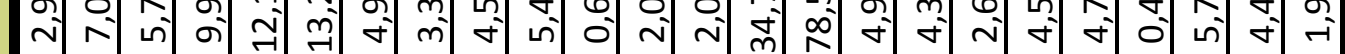

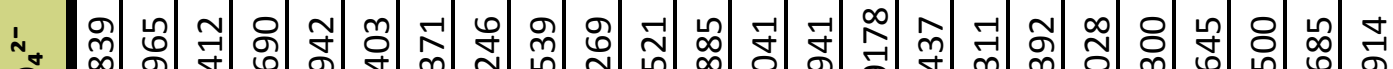

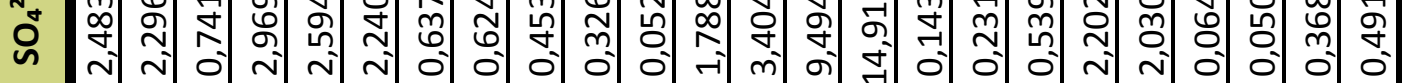

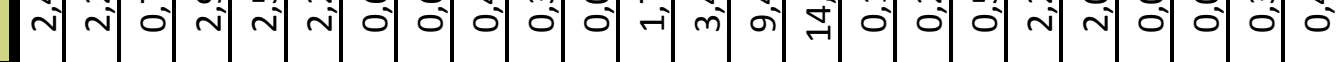

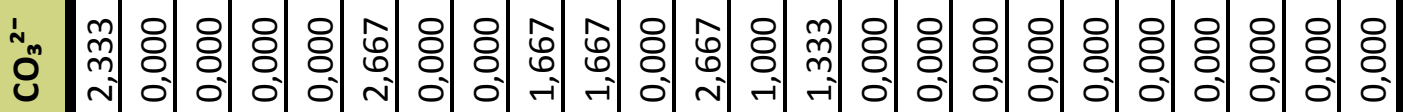

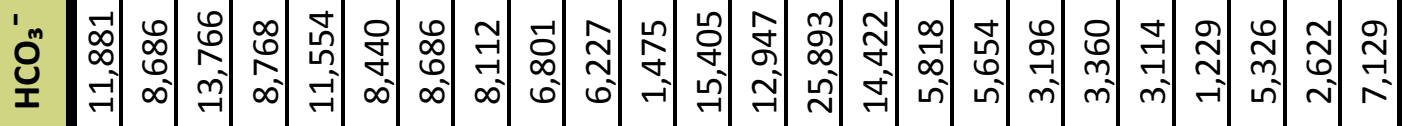

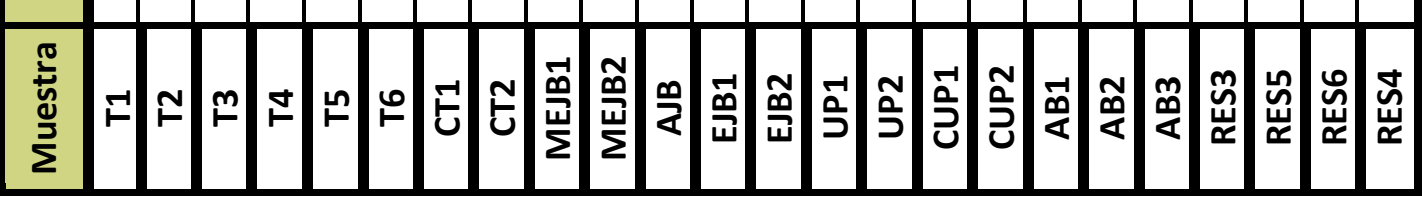

